\title{
ALISSON GOMES DE MORAES
}

Entropia máxima na modelação do fator de atrito $(f)$ de escoamento forçado.

Tese apresentada à Escola Politécnica da Universidade de São Paulo para obtenção do título de Doutor em Engenharia.

São Paulo 


\section{ALISSON GOMES DE MORAES}

Entropia máxima na modelação do fator de atrito $(f)$ de escoamento forçado.

Tese apresentada à Escola Politécnica da Universidade de São Paulo para obtenção do título de Doutor em Engenharia.

Área de Concentração:

Engenharia Hidráulica

Orientador:

Prof. Dr. Podalyro Amaral de Souza

São Paulo 
Este exemplar foi revisado e alterado em relação à versão original, sob responsabilidade única do autor e com a anuência de seu orientador.

São Paulo, 06 de janeiro de 2010.

Assinatura do autor

Assinatura do orientador

FICHA CATALOGRÁFICA

Moraes, Alisson Gomes de

Entropia máxima na modelação do fator de atrito (f) de escoamento forçado / A.G. de Moraes. -- ed.rev. -- São Paulo, 2010.

$151 \mathrm{p}$.

Tese (Doutorado) - Escola Politécnica da Universidade de São Paulo. Departamento de Engenharia Hidráulica e Sanitária.

1. Mecânica dos fluídos 2. Perda de carga 3. Escoamento 4. Turbulência 5. Entropia (Matemática aplicada) I. Universidade de São Paulo. Escola Politécnica. Departamento de Engenharia Hidráulica e Sanitária II. t. 


\section{AGRADECIMENTOS}

Este trabalho apenas foi possível devido à colaboração recebida pelo autor vinda de diversas pessoas. A seguir são apresentadas algumas pessoas fundamentais para a elaboração deste trabalho.

Agradecimentos ao Professor Doutor Podalyro Amaral de Souza, da Escola Politécnica, orientador deste trabalho. Pelas dicas, sugestões e empenho para que este trabalho se tornasse realidade.

À Universidade de Princeton nos Estados Unidos, em especial ao Professor Doutor Alexander Smits. O qual orientou e forneceu os dados necessários para os ajustes necessários dos modelos desenvolvidos no capítulo 4.

Também da Escola Politécnica, agradecimentos ao Professor Doutor Milton Tomoyki Tsutyia (em memória). O qual inspirou a elaboração do trabalho apresentado no capítulo 5, também participou discretamente do desenvolvimento deste doutorado.

Tendo participado em muitos momentos da vida do autor, este deve muitos agradecimentos à Escola Politécnica da Universidade de São Paulo. Em especial a todos integrantes do Departamento de Hidráulica e Saneamento (PHD).

Outras instituições como: a Companhia de Saneamento Básico do Estado de São Paulo (SABESP), a Universidade Estadual Paulista Julio de Mesquita Filho (UNESP) através de sua Faculdade de Tecnologia de São Paulo (FATEC-SP) e ao Centro Tecnológico de Hidráulica (CTH). Estas também foram importantes para o desenvolvimento deste trabalho.

O autor pede perdão caso tenha esquecido de alguém. Porém, a todos, é deixado os mais sinceros agradecimentos. 
"Se eu vi mais longe, foi por estar de pé sobre ombros de gigantes "(Isaac Newton) 


\section{RESUMO}

MORAES, Alisson Gomes de. Entropia máxima na modelação do fator de atrito ( $f$ ) de escoamento forçado. 2009. 142 f. Tese (Doutorado) - Escola Politécnica da Universidade de São Paulo, São Paulo, 2009.

Esta tese apresenta um desenvolvimento do fator de atrito $(f)$ para escoamentos incompressíveis. O desenvolvimento é baseado no modelo clássico de Colebrook-White e no recente modelo da Entropia Máxima. Este desenvolvimento pode ser considerado como um modelo conceitual, porém não completamente, por causa do relacionamento entre o número de Reynolds ( $\operatorname{Re}$ ) e o parâmetro de entropia $(M)$ determinado através de ajustes numéricos realizados com bons dados experimentais.

Quatro algoritmos de cálculo foram criados para simplificar a aplicação do modelo, evidenciando sua eficácia e a eficiência.

Palavras chave: Mecânica dos fluidos, perda de carga, escoamento, turbulência, entropia (Matemática aplicada) 


\section{ABSTRACT}

MORAES, Alisson Gomes de. Maximum entropy for modeling friction factor $(f)$ from forced flow. 2009. 142 f. Thesis (Doctor) - Escola Politécnica da Universidade de São Paulo, São Paulo, 2009.

This thesis presents a development of friction factor $(f)$ for incompressible pipe flow calculation. The development is based on the classical Colebrook-White model and on the recent maximum entropy model. The development cam be considered as a conceptual one, but not completely, because the relationship that links the Reynolds number ( Re ) to the entropy parameter $(M)$ was determined by numerical fitting on accurate but experimental data.

Four calculation algorithms were produced to simplify the model applications, evidencing efficiency and effectiveness.

Keywords: Friction Factor, lose energy, flow, Maximum entropy, Universal low 


\section{LISTA DE ILUSTRAÇÕES}

Figura 1. Desenho esquemático de ensaio realizado. Fonte BERnOUlLi (1738).......6

Figura 2. RePresentaÇÃo da CAMAdA LIMITE. Fonte: PRANDTL E TIETJENS (1934)_....7

Figura 3. Distribuição laminar de Velocidade Próximo a uma Entrada. Fonte: PRANDTL E TIETJENS (1934). 7

Figura 4. Distribuição turbulenta de velocidade. Fonte: PRANDTL e TIETJENS (1934).

Figura 5. GeraÇÃo da distribuição de VElocidades turbulenta APÓS A REGião de ENTRADA. Testes FeITOS POR NiKuRAdSE. Fonte: PRANDTL E TIETJENS (1934). 9

Figura 6. Subcamada Viscosa Junto À PAREDE do tUbo EM UM ESCOAMENTO TURBULENTO ATRAVÉS DO MESMO. FONTE: PRANDTL E TIETJENS (1934). ...... 11

Figura 7. Resultados obtidos nos ensaios em todas SituaÇões de EnSAio. Fonte: COLEBROOK E WHITE (1937).

Figura 8. Diagrama de Moody. Fonte: MOODY (1944) ................................................... 15

Figura 9. Diagrama de Rouse. Fonte: ROUSE (1946)................................................. 18

Figura 10.Diagrama De Li. Fonte: SIMON (1976). 22

Figura 11.Diagrama do escoamento em tubulações de Asthana. Fonte: SIMON (1976). 22

Figura 12. Diagrama de ComparaÇÃo entre a diVisão da PUlSaÇÃo de VElOCIDAde Pelo QUADRADO DA VELOCIDADE DE ATRITO E A POSIÇÃO RELATIVA NA TUBULAÇÃO EM FUNÇÃO DO RAIO. FONTE FOX ET AL. (1983) 25

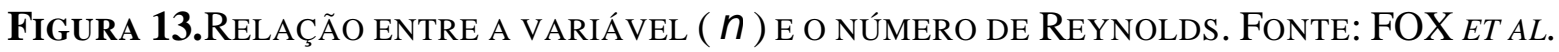
(1983). 
Figura 14. VARIAÇÃo dos PERFIS DE VElocidade DE ACORdo COM O PARÂMETRO N DA EQUAÇÃO (14). FONTE: FOX ET AL. (1983). 28

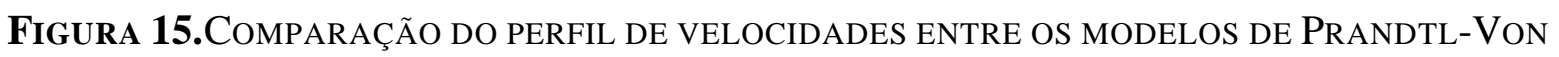
KÁRMÁn E CHIU. Fonte CHIU (1987). 32

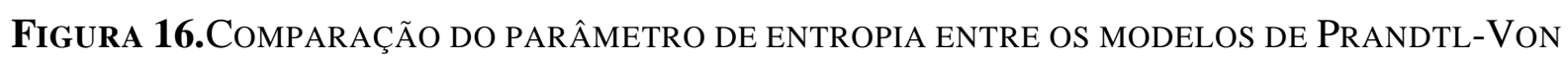
KÁRMÁn E CHIU. FonTE CHIU (1987). 32

Figura 17.COMPARAÇÃo DO PERFIL DE VELOCIDADE NAS PROXIMIDADES DO FUNDO DO CANAL entre os modelos de Prandtl-Von Kármán e CHIU. Fonte CHIU (1987). .. 33

Figura 18. ComparaÇão do PARÂMETRO DE ENTROPIA COM O PERFIL DE VELOCIDADES. FONTE: CHIU (1988) 35

Figura 19.GRÁficos de DistribuiçÃo do PERFIL DE VELOCIDADES ADMENSIONALIZADOS PARA UM PLANO FÍSICO EM FUNÇÃO DO PARÂMETRO DE ENTROPIA. FONTE: CHIU ET AL. (1993) 37

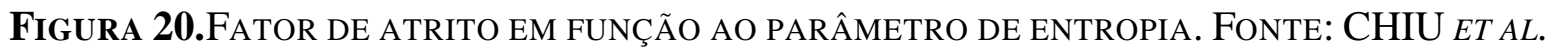
(1993). 39

Figura 21.Número de ReynOldS EM FUnÇão Ao PARÂMETRo DE ENTROPIA. Fonte: CHIU ET AL. (1993) 39

Figura 22. Comparação ENTRE os MOdelos DE PERFIL DE VElOCIDAdES DE ENTROPIA MÁXima e de NikURAdSE (1932). FonTE CHIU ET AL. (1993). 40

Figura 23. ComparaÇão ENTRE GRADIENTES dOS MODELOS DE PERFIL DE VELOCIDADES DE ENTROPIA MÁXIMA E FóRMUla Universal. Fonte: CHIU ET AL. (1993).

Figura 24.COMPARAÇão ENTRE MODELOS BASEAdOS NO PRINCÍPIO DA ENTROPIA MÁXIMA. FONTE BARBÉ ET AL. (1991). 43

Figura 25.Diagrama de SoluÇão de PRoblema da VAZ̃̃o (Q). Fonte: SouZa ET al. (1991) 
Figura 26. Diagrama de solução de problema Perda de CARga $(\Delta H)$. Fonte: Souza $E T$ AL. (1991) 46

Figura 27. Diagrama de soluÇão de problema do diâmetro ( $D$ ). Fonte: Souza $E T$ a 4 . (1991)

Figura 28. Diagrama de solução de problema do diâmetro ( $D$ ). Fonte: Souza $E t ~ a L$. (1991) 48

Figura 29. COMPARAÇ̃̃o ENTRE VALORES MEDIDOS E CALCULAdOS COM BASE NA FORMULAÇÃO LOGARITMA. FONTE ARAÚJO E CHAUDHRY (1998) .50

Figura 30.COMPARAÇão ENTRE VALORES MEDIDOS E CALCULADOS COM BASE NA FORMULAÇ̃̃o BASEADA NA ENTROPIA MÁXIMA. FONTE ARAÚJO E CHAUDHRY (1998)...... 50

Figura 31.GrÁfico do FAtor de Atrito ( $f$ ) EM FUnÇão do nÚMERo de Reynolds (Re), COMPARANDO OS DADOS OBTIDOS PELAS UNIVERSIDADES DE OREGON E PRINCETON. 55

Figura 32. Gráfico do fator de Atrito ( $f$ ) EM FunÇão do número de Reynolds (Re), 59

Figura 33. COMPARAÇÃO DOS DADOS EXPERIMENTAIS (ASTERISCOS) COM DADOS CALCULADOS (LINHA) EM GRÁFICO DE VELOCIDADE MÉDIA RELATIVA VERSUS O RAIO RELATIVO PARA O ESCOAMENTO DE ÁGUA EM TUBULAÇÃO COM RE $=4.000$ E DIÂMETRO NOMINAL DE 10 MM. FONTE KARPELSON (2008). .63

Figura 34. Fluxograma do algoritmo desenVolvido por Karpelson (2008). 64

Figura 35.Gráfico de ajuste para obtenção da CONSTANTE " $C$ ”. 82

Figura 36. Fluxograma de cÁlculo do parÂmetro de entropia (M) .84

Figura 37. Algoritmo de cÁlculo do parâmetro de ENTRopia (M) ESCRito EM Visual Basic Application (VBA). .85

Figura 38.GrÁfico de AJUSte ENTRE O NÚMERo de REYNOLdS E O PARÂMETRO dE ENTROPIA. 
Figura 39.Gráfico de AJUSTE ENTRE o NÚMERo de REYNOLdS E A FUnÇão EXPONENCIAL do PARÂMETRO DE ENTROPIA. 87

Figura 40.Gráfico de AJuste ENTRE O NúMERo de REynOLdS E O EXPONENCIAL do PARÂMETRO DE ENTROPIA MULTIPLICADO PELO PARÂMETRO DE ENTROPIA. 88

Figura 41. ComparaÇão ENTRE o GRÁFico da Figura (21) E A EQUAÇão (58). 90

Figura 42. Gráfico do adimensional de Prandtl $\left(C_{p}\right)$ EM FunÇão do Parâmetro de ENTROPIA (M) 94

Figura 43. Gráfico de COMPARAÇão ENTRE A EQUAÇÃo (71) E FIGURA (20) COM A EQUAÇão $(60)$ 96

Figura 44. RELACIONAMENTO ENTRE O PRODUTO DO NÚMERO DE REYNOLDS E A RAIZ DO FATOR DE ATRITO $(\operatorname{Re} \sqrt{f})$ E O NÚMERO DE REYNOLDS (RE). 101

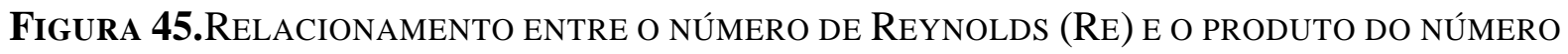
DE REYNOLDS E A RAIZ DO FATOR DE ATRITO $(\operatorname{Re} \sqrt{f})$. 101

Figura 46. Relacionamento ENTRE A DiVisÃo do NúmERo DE REYNOLDS E A RAIZ QUiNTA DO FATOR DE ATRito ( $\operatorname{Re} / \sqrt[5]{f})$ E O NÚMERO DE REYNOLDS (RE). 102

Figura 47.Relacionamento EntRe a RAIZ QUADRADA DA RAZÃo DO NÚMERO DE REYNOLDS E O FATOR DE ATRITO $(\sqrt{\operatorname{Re} / f})$ PELO NÚMERO DE REYNOLDS (RE) 102

Figura 48.GrÁfico RESUmo dos RELACIONAMENTOS ENTRE O NÚMERO DE REYNOLDS (Re ) E AS COMBINAÇÕES ENTRE O NÚMERO DE REYNOLDS ( Re ) E O FATOR DE ATRITO ( $f$ ). 103

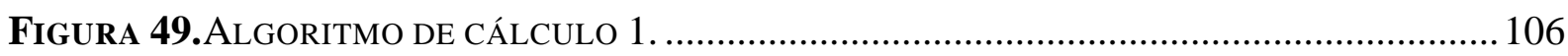

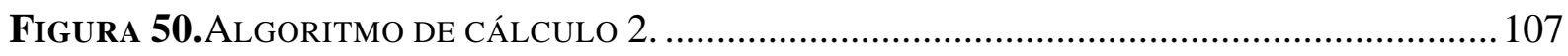

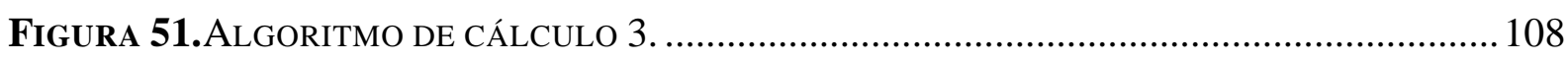

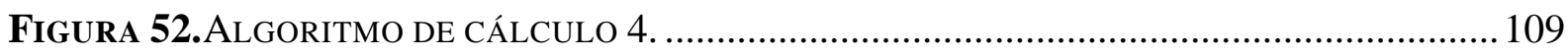

Figura 53.ComparaÇÃo ENTRE CÁlCULOS DE FATORES DE ATRITO.................................... 116 
Figura 54.HARPA de COMPARAÇÃo ENTRE MÉTOdos DE DETERMinAÇão do FATOR DE ATRITO

(F) PARA OS REGIMES TURBULENTO MISTO E TURBULENTO RUGOSO.

Figura 55. GráFICO dE COMPARAÇÃo ENTRE DADOS DE ENSAIOS E DADOS CALCULADOS ATRAVÉS DO ALGORITMO 1 126

Figura 56. Gráfico de COMPARAÇÃo ENTRE DAdOS DE ENSAIOS E DADOS CALCULADOS ATRAVÉS DO ALGORITMO 2.

Figura 57.CAMINHAMENTO DA ADUTORA. 130

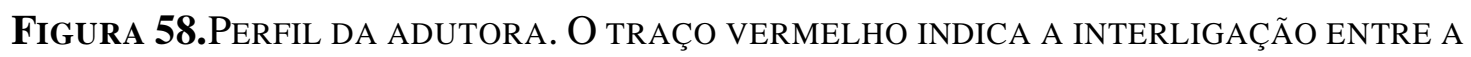
ADUTORA EXISTENTE E A PROJETADA. 130

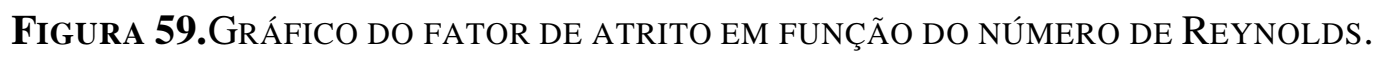
143

Figura 60.GrÁFICO do FATOR DE ATRITO EM FUnÇÃo PARÂMETRO DE ENTROPIA. 144 


\section{LISTA DE TABELAS}

Tabela 1. Tabela com as Quatro formulações eXPlicitas de CÁlculo. Fonte: SOUZA ET AL. (1991). 44

Tabela 2. CÁlculo da Função de Viscosidade Turbulenta ou Aparente - Dados:

LANGELANKDSVIK ET AL. (2008) 80

Tabela 3. Cálculo do ParÂmetro de Entropia (M) 86

TAbela 4. TABela de COMPARAÇÃo ENTRE os VAlORES do PARÂMETRo DE ENTROPIA (M). 89

Tabela 5. Cálculo do valor do adimensional de Prandtl $\left(\underline{C_{p}}\right)$ 93

TABela 6. TABela de Calculo do fator DE ATRito ( $\underline{f})$. 95

TABela 7. Relacionamentos A PARTIR do nÚMERo de REynOlds (RE) E O FATOR DE ATRITO (F) 100

TABela 8. COMPARAÇÃo ENTRE MOdElos MATEMÁticos PARA O FATOR DE ATRITO ESCOAMENTO LISO. 116

Tabela 9. Comparação entre Métodos - Escoamentos turbulento misto e TURBULENTO RUGOSO. 118

TABEla 10.TABElA DE VALIDAÇÃo DO ALGORITMO 1. COMPARAÇão ENTRE VAZÃO DE ENSAiO E CALCULADA. 122

TABela 11.TABela de VAlidaÇão DO ALGORITMo 2. CoMPARAÇÃo ENTRE PERDA DE CARGA DE ENSAIO E CALCULADA. 123

TABela 12.TABEla de VALIDAÇÃO DO ALGORITMO 3. COMPARAÇÃO ENTRE DiÂMETRO DE ENSAIO E CALCULADO.

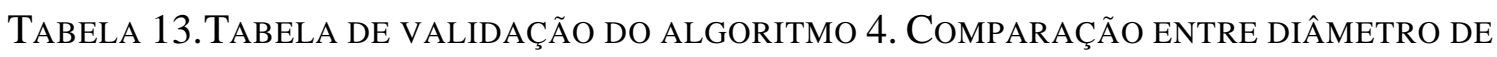
ENSAIO E CALCULADO.

TABEla 14.DAdos DE ENTRADA PARA O CÁLCULO DO DIÂMETRO DO TRECHO 1. 132

TABElA 15.CÁlCULO DO DiÂMETRO PARA O TRECHO 1 DA ADUTORA 
TABELA 16.DAdos DE ENTRADA PARA O CÁLCULO DA PERDA DE CARGA NO TRECHO 1.......... 133

TABELA 17.CÁlCULO DA PERDA DE CARGA PARA O TRECHO 1 DA ADUTORA ............................ 133

TABELA 18.DAdos DE ENTRADA PARA o CÁLCULO DO DiÂMETRO DO TRECHO 2. .................... 134

TABELA 19.CÁlCULO do DiÂMETRo PARA O TRECHO 2 DA ADUTORA..................................... 134

TABela 20.DAdos de ENTRADA PARA o CÁlCUlO DA PERDA DE CARGA NO TRECHO 2.......... 135

TABELA 21.CÁlCUlo dA PERdA DE CARGA PARA O TRECHO 2 DA ADUTORA ........................... 135

TABELA 22.DAdos DE ENTRADA PARA o CÁLCULO DA PERDA DA VAZ̃̃o................................ 135

TABELA 23.CÁlCULO DA PERDA DA VAZÃo EM AMBos os TRECHOS DA ADUTORA................... 136

TABELA 24.CÁLCULO ITERATIVO DA VAZÃo MÁXIMA DA ADUTORA ........................................ 136

TABELA 25.COMPARAÇÃO DE RESULTADOS ENTRE MODELOS DE CÁLCULO PARA

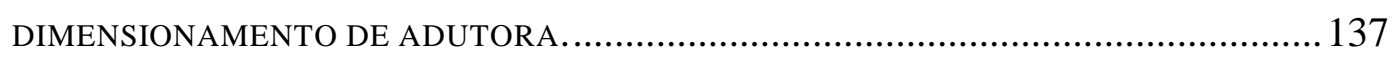




\section{LISTA DE SÍMBOLOS}

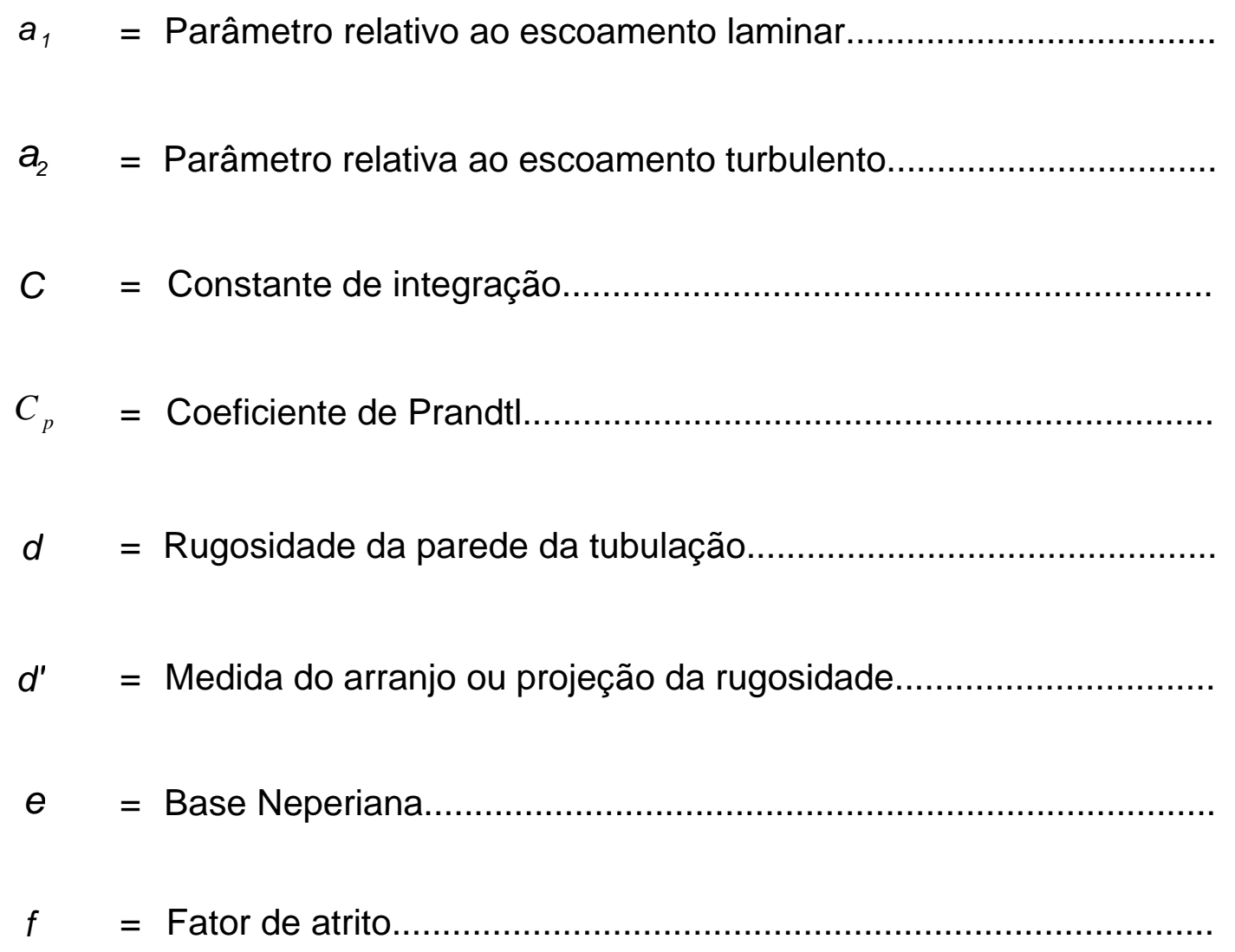

$(m)$

$(m)$

$g \quad=$ Aceleração gravitacional $\left(\frac{m}{s^{2}}\right)$

$h \quad=$ Altura do escoamento em um canal.

$H(u)=$ Entropia da velocidade.

$H(X)=$ Entropia termodinâmica.

$K=$ Constante de Von Kármán.

$k=$ Coeficiente de perda de carga localizada

$L \quad=$ Comprimento do tubo. 


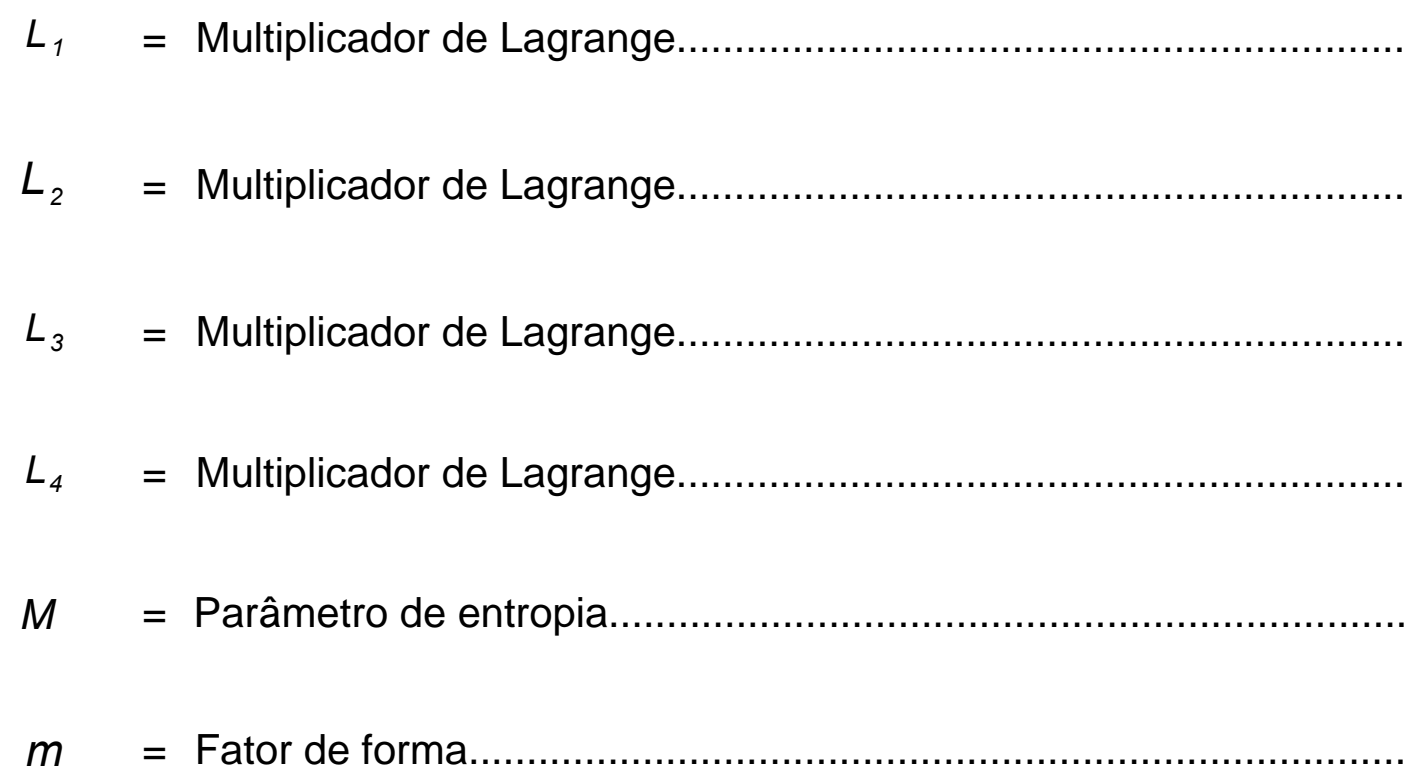

$n \quad$ = Parâmetro exponencial empírico de correção.

$n_{1}=$ Parâmetro dependente da condição do escoamento laminar.

$n_{2} \quad=$ Parâmetro dependente da condição do escoamento turbulento.....

$P \quad=$ Pressão

$p=$ Probabilidade acumulada de um sistema estar do estado $(\mathrm{X})$........

$p(u)=$ Probabilidade da variável velocidade

$p(X)=$ Probabilidade sem o dado simples

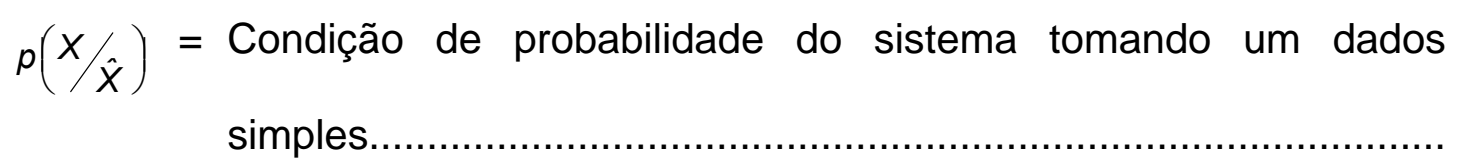

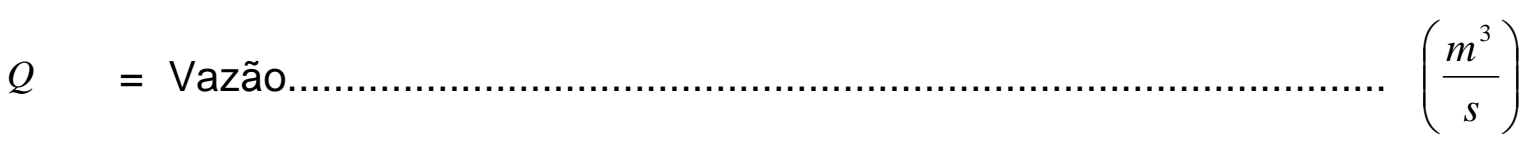


$R \quad=$ Raio do tubo

$\operatorname{Re}=$ Número de Reynolds.

$\operatorname{Re}_{a}=$ Número de Reynolds aparente

$r \quad$ = Distância do centro do tubo.

$(m)$

$t=$ Tempo.

$U \quad=$ Velocidade do escoamento na borda da camada limite................. $\left(\frac{m}{s}\right)$

$u \quad=$ Velocidade pontual $\left(\frac{m}{s}\right)$

$u \quad=$ Velocidade média do escoamento $\left(\frac{m}{s}\right)$

$u_{d} \quad=$ Parâmetro relacionado com $(M)$ e com a velocidade média

$u_{i}=$ Componente velocidade $\left(\frac{m}{s}\right)$

$u_{k}=$ Componente velocidade $\left(\frac{m}{s}\right)$

$u_{\max }=$ Velocidade máxima do escoamento. $\left(\frac{m}{s}\right)$

$u_{*} \quad=$ Velocidade de atrito do escoamento $\left(\frac{m}{s}\right)$ 
$u_{x}{ }^{\prime} \quad=$ Velocidade de pulsação do escoamento no eixo x....................... $\left(\frac{m}{s}\right)$

$u_{y}{ }^{\prime}=$ Velocidade de pulsação do escoamento no eixo y...................... $\left(\frac{m}{s}\right)$

$X \quad=$ Condição do sistema.

$\hat{X} \quad=$ Erro atribuído à condição do sistema

$x_{i} \quad=$ Vetor unitário do plano horizontal.

$(m)$

$x \quad=$ Distância no plano horizontal a partir de um ponto de referência... $(m)$

$y=$ Distância da parede do tubo.

$(m)$

$y_{h}=$ Profundidade do canal.

$(m)$

$z \quad=$ Eixo vertical

$(m)$

$W_{\mu}=$ Dissipação viscosa local.

$\Delta p \quad=$ Diferença entre pressões.

$\delta=$ Espessura da camada limite

$\varepsilon \quad=$ Coordenada adimensional.

$\varepsilon_{0}=$ Coordenada inicial adimensional.

$\varepsilon_{\max }=$ Coordenada máxima adimensional. 
$\mu \quad=$ Viscosidade dinâmica do fluido............................................... $\left(\frac{m^{2}}{s}\right)$

$\rho \quad=$ Massa específica do fluido...................................................... $\left(\frac{\mathrm{kg}}{\mathrm{m}^{3}}\right)$

$\tau_{0} \quad=$ Tensão de cisalhamento do escoamento............................. $(\mathrm{Pa})$ 


\section{SUMÁRIO}

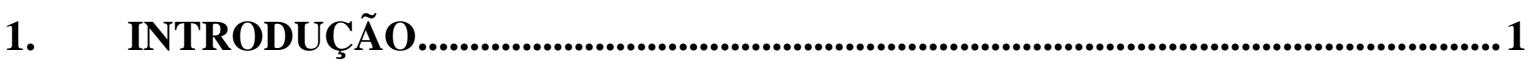

2. OBJETIVOS

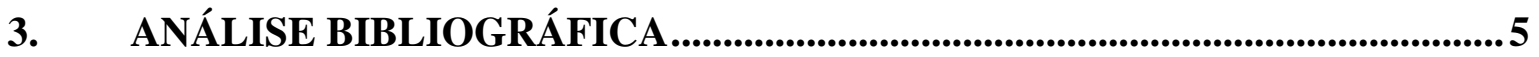

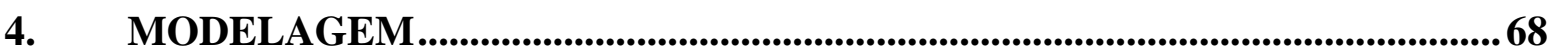

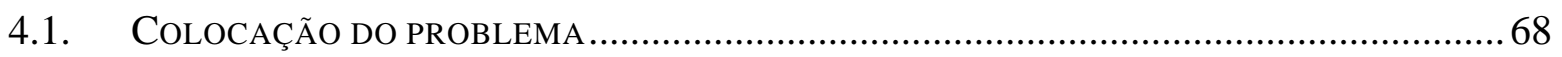

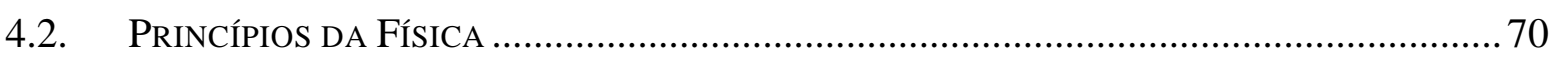

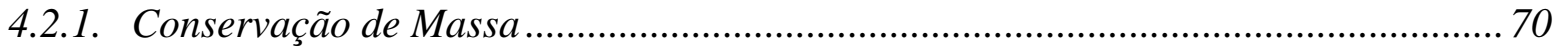

4.2.2. Primeira Lei da Termodinâmica …………………............................................ 71

4.3. IDENTIFICAÇão DaS LEIS PARTICULARES................................................................ 72

4.3.1. Fórmula Universal de perda de carga distribuída ................................................. 72

4.3.2. Equacionamento do fator de atrito elaborado por Colebrook................................... 73

4.3.3. Equacionamento do fator de atrito baseado na Entropia Máxima ……………….... 73

4.3.4. Equacionamento do fator de atrito desenvolvido por McKEON et al. (2004).......... 73

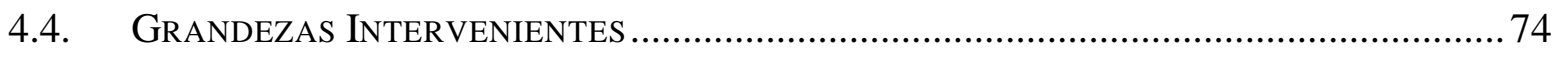

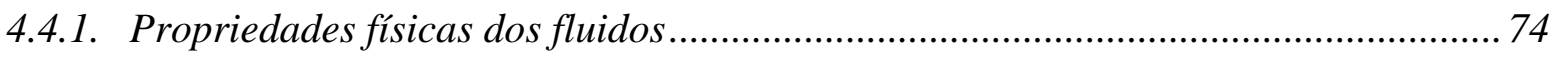

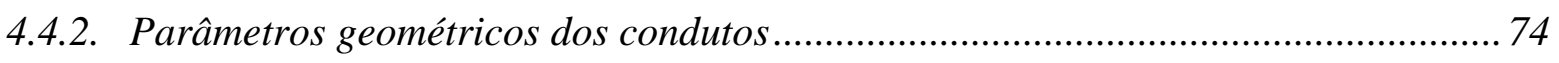

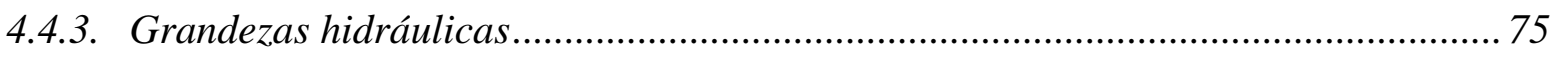

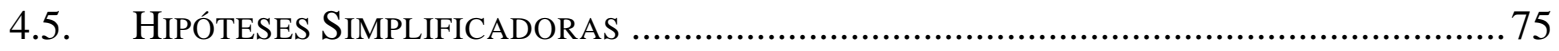

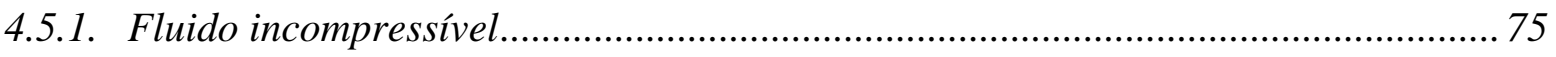

4.5.1. Velocidade máxima no eixo do tubo ........................................................................ 75

4.5.2. Gradiente de velocidade nulo no eixo do tubo....................................................... 76

4.5.1. Princípio da aderência ......................................................................................... 76

4.5.2. Gradiente de velocidade diferente de zero junto às paredes do tubo......................... 76 
4.5.3. Dados fornecidos por McKEON et al. (2004) e LANGELANKDSVIK et al. (2008) são paradigmas 76

4.6. DESENVOLVIMENTO DO MODELO MATEMÁtICO .77

4.6.1. Análise do Mecanismo da Turbulência .77

4.6.2. Ajuste do parâmetro de Entropia .83

4.6.3. Conjectura de Prandtl 91

4.6.4. Algoritmo de cálculo. 96

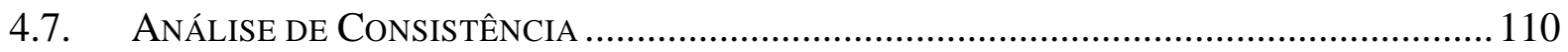

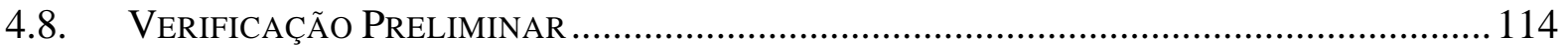

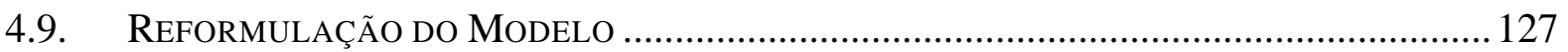

5. EXEMPO DE APLICAÇÃO DO MODELO .................................................... 128

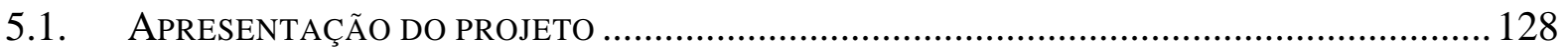

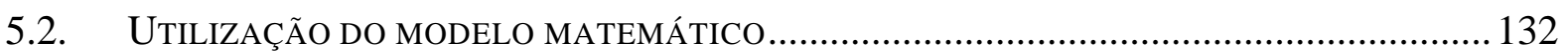

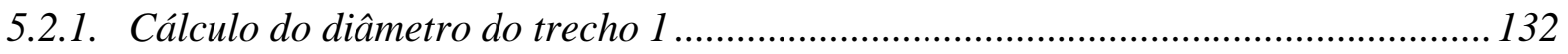

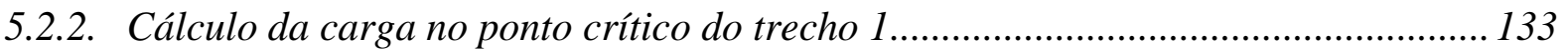

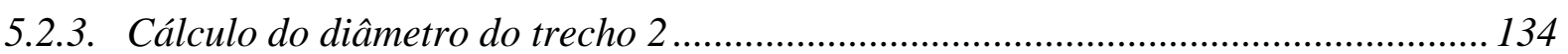

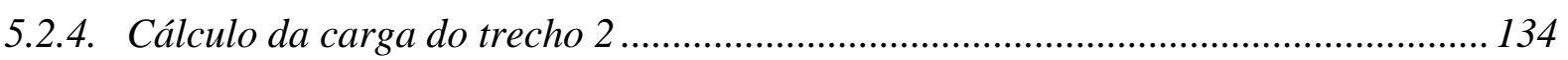

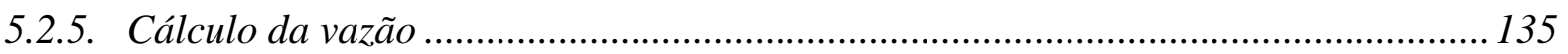

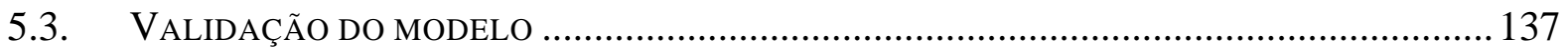

6. DISCUSSÃ

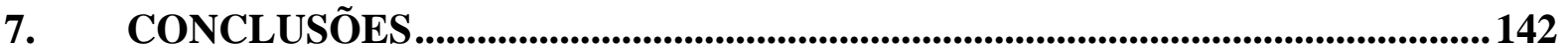

8. RECOMENDAÇÕES PARA FUTUROS TRABALHOS ...............................147

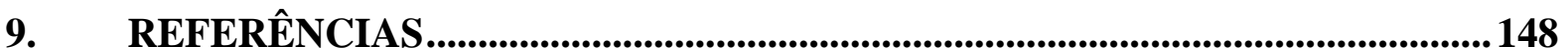




\section{INTRODUÇÃO}

A água é um composto vital para a sobrevivência de todo e qualquer ser sobre a terra. Sua disposição sobre a superfície terrestre é muito distinta, sendo que grande parte está nos mares, onde se encontra nela diluído considerável percentual de cloreto de sódio (sal), o que a torna imprópria para o consumo da maioria das espécies existente sobre a terra, inclusive o homem.

A água existente sobre os continentes é de quantidade muito limitada e cíclica, variando em função das épocas do ano e de fenômenos climáticos como o El Niño. Fica logo evidente a necessidade de se buscar água em mananciais onde há sua disponibilidade, os quais ficam cada vez mais distantes dos grandes centros urbanos. Com esse objetivo foram criados, ainda na era antiga, sistemas de abastecimento público e de irrigação, os quais deram origem às barragens, aquedutos e adutoras. O crescimento populacional ocorrido após a Idade Moderna demandou uma necessidade maior de água e energia, tornando um desafio para o transporte de grande quantidade de água a distâncias cada vez mais longínquas. Estas estruturas foram sendo construídas em tamanhos cada vez maiores, demandando maior quantidade de energia para a sua operação.

A necessidade de transporte de outros fluidos, além da água, tornou-se importante, principalmente após o advento da Revolução Industrial na Idade Moderna. Para tanto, muitas vezes a energia potencial não tinha condições de suprir a demanda de energia do escoamento e, em alguns casos, o escoamento necessitava de energia para vencer a mesma. 
A correta determinação dos esforços a serem aplicados ao fluido para que este pudesse escoar por dentro de uma tubulação ou canal tornou-se um ponto crucial aos sistemas de transporte de fluidos. Dentre as várias forças existentes atuantes sobre o escoamento as forças tangenciais de resistência ao escoamento junto à tubulação têm destaque especial. Essas são forças reativas à força aplicada ao escoamento, de acordo com a Segunda Lei de Newton, as quais são dissipadas na forma de calor, segundo a Primeira Lei da Termodinâmica.

Durante muito tempo foram desenvolvidos métodos empíricos para a determinação de tais forças, porém, os mesmos apenas podiam ser aplicados em casos específicos, nem sempre muito úteis em função dos erros gerados pelos mesmos. Apenas na segunda metade do século XIX os pesquisadores Darcy e Weisbach desenvolveram uma formulação com fundamentos conceituais, a qual, em virtude de sua ampla utilidade ficou conhecida como Fórmula Universal. Em tal fórmula, além dos parâmetros básicos do escoamento até então amplamente conhecidos, surgiu um elemento conhecido como fator de atrito $(f)$.

Tal fator surge em função das condições de escoamento, sempre sendo associado ao número de Reynolds do mesmo. Apesar do grande desenvolvimento ocorrido nas ultimas décadas, ainda não se tem notícia do desenvolvimento de uma formulação que atenda simultaneamente: princípio da aderência, velocidade máxima no centro do tubo, gradiente de velocidade nulo no eixo do tubo e gradiente de velocidade diferente de zero junto à parede do tubo.

Assim como no desenvolvimento da Fórmula Universal, o desenvolvimento de uma formulação conceitual para o fator de atrito torna-se importante, pois há um ganho de precisão em seu resultado e possibilidade de sua generalização. Portanto, 
será possível elaborar projeto de sistemas, onde os conceitos de Mecânica dos Fluidos sejam aplicados, com mais eficiência e com menor consumo de energia. Em época de escassez de recursos naturais, crescente demanda por energia para as atividades humanas, a melhoria de eficiência dos sistemas associados à Mecânica dos Fluidos torna-se de importância extremamente relevante. 


\section{OBJETIVOS}

Esta proposta tem como objetivos primários:

- Fazer levantamento do estado da arte.

O levantamento do estado da arte baseia-se em uma análise bibliográfica abrangente sobre o tema deste trabalho através de consulta a livros, periódicos e Internet. Serão analisados os trabalhos precursores, que levantaram a relevância do tema; os trabalhos clássicos, os quais deram as maiores contribuições no desenvolvimento da determinação do fator de atrito; e os trabalhos mais recentes encontrados sobre o tema.

- Propor método de cálculo conceitual.

A proposta de método de cálculo conceitual tem como objetivo apresentar um modelo desenvolvido a partir dos princípios da física, aplicando hipóteses simplificadoras, a fim de eliminar os termos cujas influências não são significantes no resultado.

- Fazer crítica ao método de cálculo conceitual proposto.

Após a elaboração do modelo conceitual, faz-se necessário comprovar sua veracidade através de testes de consistência dos resultados obtidos e comparação do resultado do mesmo com protótipos e ensaios laboratoriais, cujos dados encontram-se na literatura existente sobre o tema objeto deste trabalho. 


\section{ANÁLISE BIBLIOGRÁFICA}

A presente análise bibliográfica será desenvolvida com enfoque cronológico nos trabalhos precursores, clássicos e recentes. Inicialmente serão analisados os trabalhos precursores, os quais foram as bases para o desenvolvimento atual do equacionamento do fator de atrito para cálculo da perda de carga. Em seguida serão analisados os trabalhos clássicos, que são trabalhos mais avançados, os quais tratam o tema com riqueza de detalhes, tornando-se referência aos demais trabalhos existentes desde então. Ao final, serão apresentadas as bibliografias recentes, as quais dão uma noção da produção científica atual sobre este tema. No fechamento, serão discutidos os principais trabalhos analisados.

O problema da determinação do mecanismo da perda de carga em tubulações é tão antigo quanto à própria Hidráulica. Até a edição de BERNOULLI (1732) não existiam equacionamentos do escoamento de base conceitual.

BERNOULLI (1732) apresentou os princípios do equacionamento hidráulico conceitual da energia. Esse equacionamento relacionou a energia potencial do escoamento, energia cinética e perda de carga. $O$ equacionamento da perda de carga desde então, passou a ser a principal incógnita a ser pesquisada para o cálculo de um escoamento.

Tomando-se como base o equacionamento desenvolvido por BERNOULLI (1732), BERNOULLI (1738) relacionou-o com ensaios experimentais. Segundo este, o escoamento poderia ser representado a partir de linhas de direção perpendicular às linhas de fluxo do fluido, formando um perfil de velocidades. O comportamento do 
perfil de velocidades comporta-se de maneira similar em condutos geometricamente semelhantes, independente de suas dimensões.

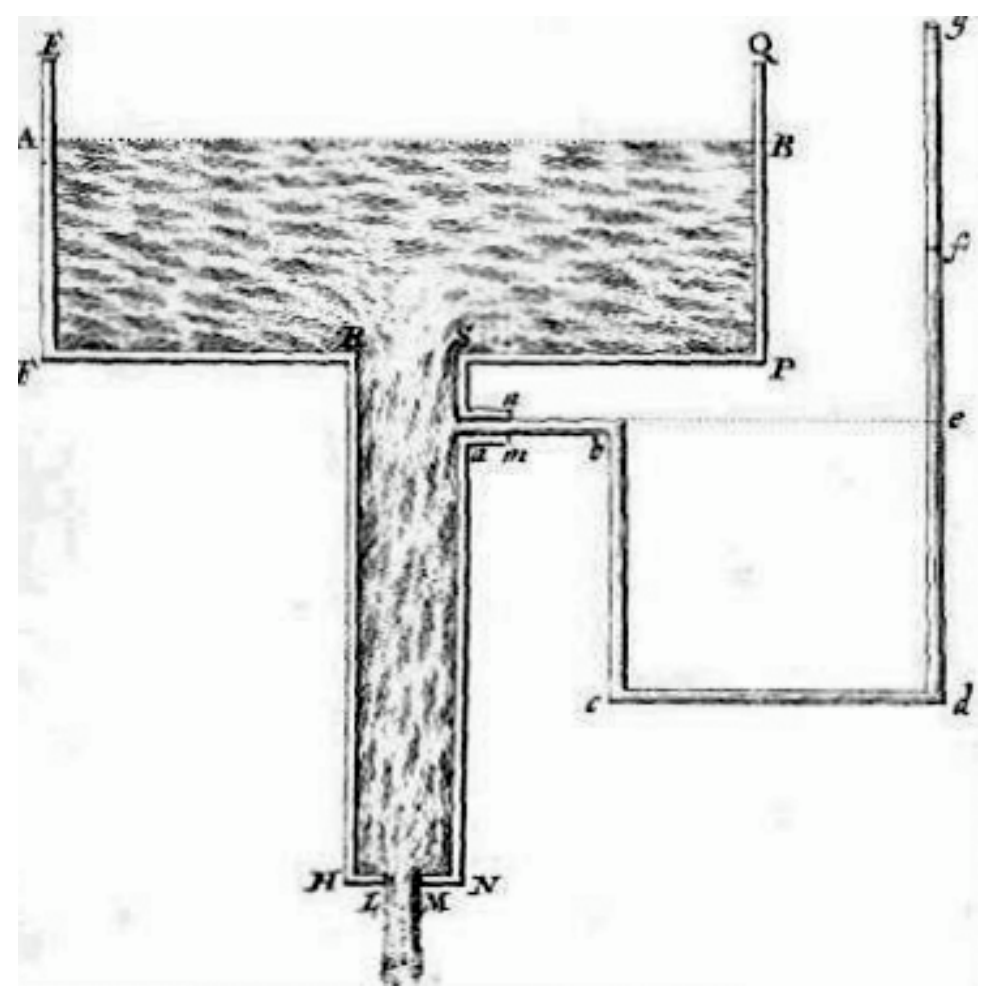

Figura 1. Desenho esquemático de ensaio realizado. Fonte BERNOULLI (1738).

BERNOULLI (1738) descreveu a existência de movimentos caóticos entre as partículas de fluido de um escoamento turbulento. Esses movimentos caóticos causam choques entre essas partículas. Tais choques provocam dissipação de energia.

PRANDTL e TIETJENS (1934) focaram o trabalho no tratamento matemático do escoamento de um fluido em um meio qualquer. Esse trabalho apresentou a modelação da camada limite e sua influência sobre o perfil de velocidades. Também foram apresentadas a conjectura de Prandtl e o modelo do perfil de velocidades de Von Kármán. 
Esses autores descreveram experiências realizadas em fluidos de pequena viscosidade ao redor de um corpo imerso. Quando em movimento em relação ao fluido, esse corpo criava um gradiente de velocidades no fluido existente na vizinhança. A transição da velocidade zero para a velocidade observada próximo ao corpo, foi denominada como camada limite.

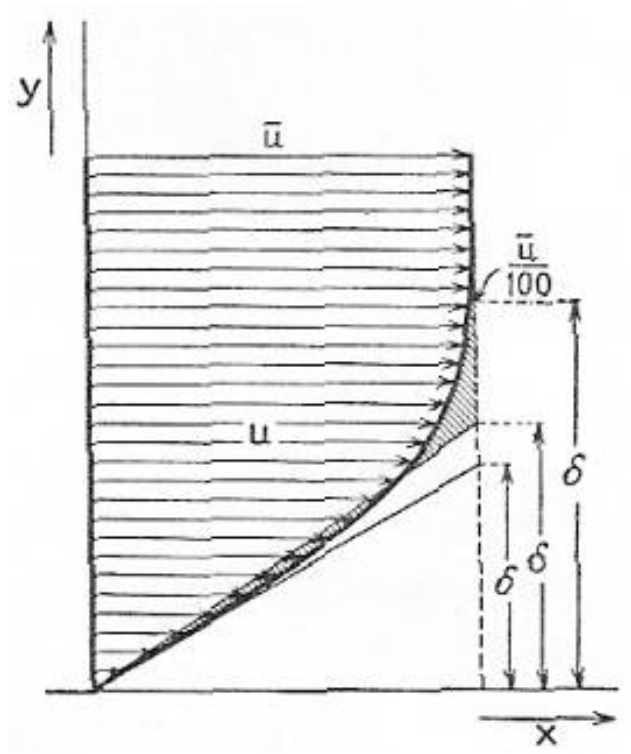

Figura 2. Representação da camada limite. Fonte: PRANDTL e TIETJENS (1934).

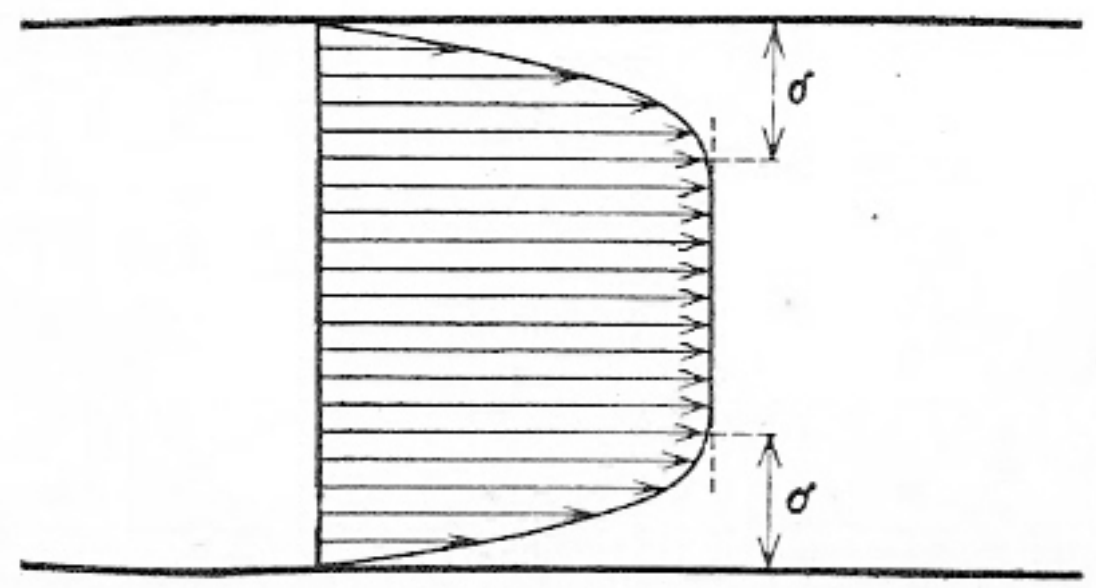

Figura 3. Distribuição laminar de velocidade próximo a uma entrada. Fonte: PRANDTL e TIETJENS (1934). 
Ao entrar em um tubo qualquer, o escoamento percorre uma determinada distância até que se desenvolva completamente. Segundo PRANDTL e TIETJENS (1934), o ponto o qual o escoamento completou seu desenvolvimento é o local de encontro da camada limite da parede da tubulação.

A figura (3) apresenta um perfil de velocidades não totalmente estabelecido de um escoamento em um tubo. Nessa é possível verificar a presença, segundo PRANDTL e TIETJENS (1934), de uma camada limite junto às paredes da tubulação. No centro da tubulação, o deslocamento do fluido não sofre a influência da parede do tubo.

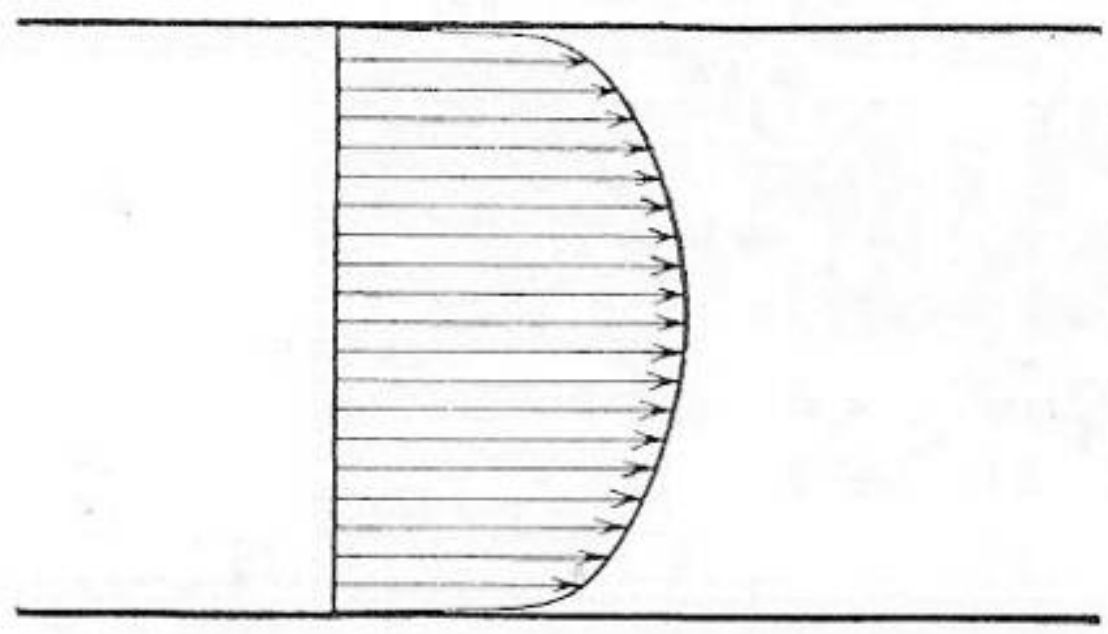

Figura 4. Distribuição turbulenta de velocidade. Fonte: PRANDTL e TIETJENS (1934).

Um escoamento totalmente formado apresenta um perfil similar ao mostrado na figura (4). Segundo PRANDTL e TIETJENS (1934) o perfil de velocidades apresenta o gradiente de velocidades igual a zero no centro do tubo. Junto às paredes da tubulação a velocidade do escoamento é zero.

STANTON e PANNELL (1914) apud PRANDTL e TIETJENS (1934) estudaram o perfil de velocidades em função do raio da tubulação. A figura (5) 
apresenta quatro perfis de velocidades para um escoamento de número de Reynolds de 42.000. Estes são em função da distância relativa entre a entrada do escoamento no tubo e seu diâmetro interno.

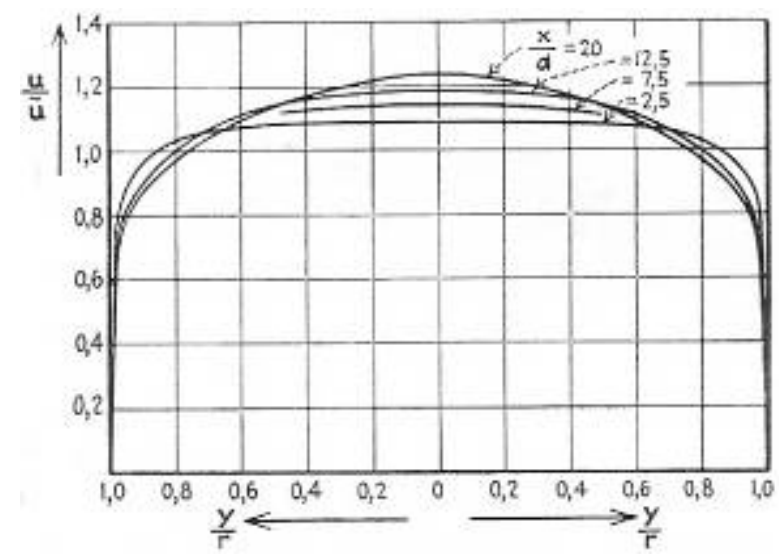

Figura 5. Geração da distribuição de velocidades turbulenta após a região de entrada. Testes feitos por Nikuradse. Fonte: PRANDTL e TIETJENS (1934).

PRANDTL e TIETJENS (1934) relataram que o perfil de distribuição de velocidades de um tubo com escoamento completamente formado depende do número de Reynolds. Independente do diâmetro da tubulação, esse perfil varia conforme a variação do número de Reynolds do escoamento.

A rugosidade da parede do tubo influencia no perfil de velocidades de um escoamento turbulento. PRANDTL e TIETJENS (1934) descreveram o efeito produzido pela rugosidade em tubulações. Em um tubo liso, esta influência é observada apenas na formação de uma subcamada viscosa junto à parede da tubulação, sendo praticamente desprezível. Já em um tubo rugoso, esta provoca um incremento na turbulência do escoamento.

PRANDTL e TIETJENS (1934) apresentaram dois modelos de perfil de velocidades. O primeiro foi a "Lei da potência um sétimo". Em seguida foi apresentado o perfil desenvolvido por Von Kármán. 
A "Lei da potência um sétimo" foi proposta por Blasius a partir de dados experimentais. Esta lei descreve um perfil de velocidades de um escoamento turbulento. Esta lei foi representada matematicamente através da equação (1).

$$
u=u_{\max }\left(\frac{y}{R}\right)^{1 / 7}
$$

Onde:

$$
\begin{aligned}
u & =\text { Velocidade pontual; } \\
u_{\max } & =\text { Velocidade máxima do escoamento; } \\
y & =\text { Distância da parede do tubo; } \\
R & =\text { Raio do tubo. }
\end{aligned}
$$

PRANDTL e TIETJENS (1934) fizeram crítica quanto à validade da "Lei da potência um sétimo". A faixa onde esta lei apresenta resultados aceitáveis inicia-se com o escoamento turbulento e vai até números de Reynolds aproximadamente 50.000. Acima de tal número esta lei vai se transformando quando o número de Reynolds chega próximo a 200.000 numa lei de variação de potência um oitavo.

VON KÁRMAN (1930) apud PRANDTL e TIETJENS (1934) apresentou uma modelação do perfil de velocidades para um escoamento turbulento totalmente formado. Esta modelação dividiu o escoamento em duas partes.

Localizada junto à tubulação, a primeira parte do escoamento seria uma subcamada viscosa. Essa subcamada é apresentada como uma reta na figura (6). Essa subcamada não está em função do diâmetro da tubulação. Ao final da subcamada viscosa inicia-se o escoamento turbulento existente na tubulação. 
O escoamento do centro da tubulação foi descrito por VON KÁRMAN (1930) apud PRANDTL e TIETJENS (1934) em função do raio da tubulação. Esta se inicia ao final da subcamada viscosa e se estende até o centro da tubulação, conforme apresentado na figura (5).

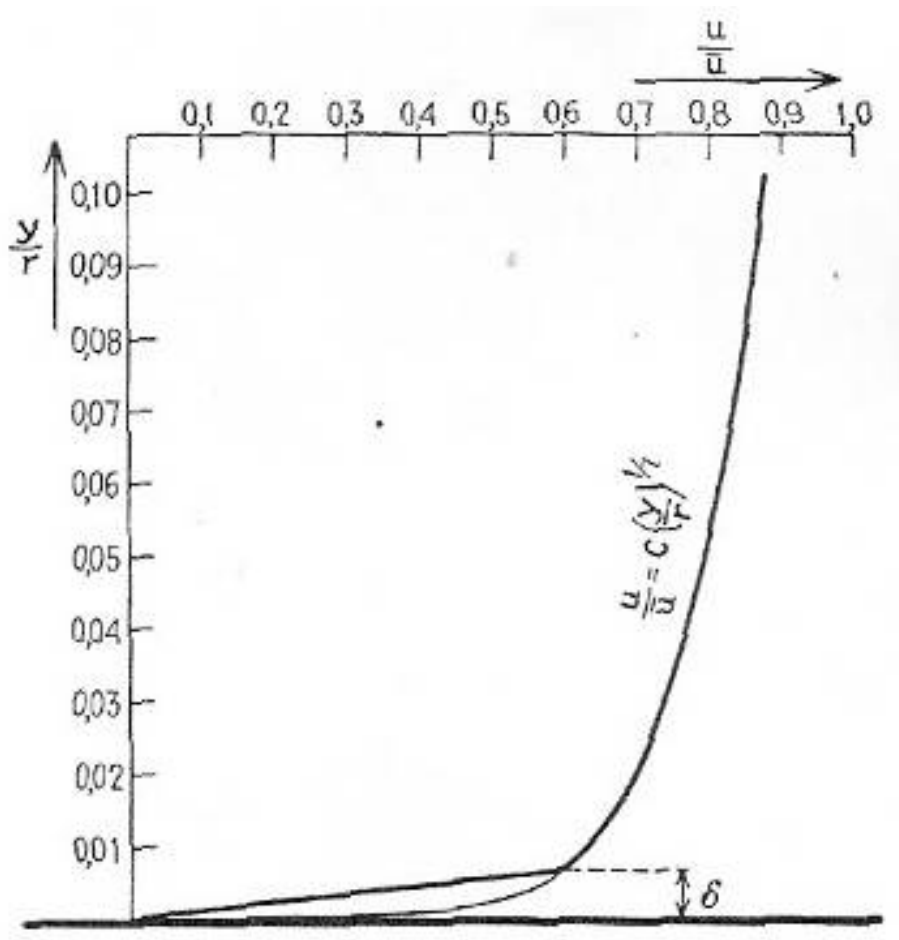

Figura 6. Subcamada viscosa junto à parede do tubo em um escoamento turbulento através do mesmo. Fonte: PRANDTL e TIETJENS (1934).

E equacionamento matemático do perfil de Von Kármán teve como base a "Conjectura de Prandtl". Esta conjectura, segundo PRANDTL e TIETJENS (1934), relata que a relação entre a velocidade média, máxima e de atrito de um escoamento é um coeficiente, conforme descrito na equação (2).

PRANDTL e TIETJENS (1934) preconizam que este coeficiente seria uma constante. Esta constante seria válida para escoamento turbulento, determinando o perfil de velocidades do mesmo. 
Baseando-se nesta conjectura, VON KÁRMAN (1930) apud PRANDTL e TIETJENS (1934) desenvolveu o equacionamento do perfil de velocidades apresentado na equação (3). Este modelo do perfil é uma função da posição da velocidade no escoamento e de uma constante, denominada de constante de Von Kármán.

$$
\begin{gathered}
\frac{u_{\max }-u}{u_{*}}=C_{p} \\
\frac{u_{\max }-u}{u_{*}}=\frac{1}{K}\left[\log \frac{2 R}{y}-1\right]
\end{gathered}
$$

Onde:

$C_{p}=$ Coeficiente de Prandtl;

$K=$ Constante de Von Kármán;

$u=$ Velocidade pontual;

$u_{\max }=$ Velocidade máxima do escoamento;

$u_{*} \quad=$ Velocidade de atrito do escoamento;

$R \quad=$ Raio do tubo;

$y=$ Distância da parede do tubo.

PRANDTL e TIETJENS (1934) relataram que os resultados obtidos a partir das equações (3) e (4) são bons. A constante de Von Kármán $(K)$ é de aproximadamente 0,36 .

A velocidade no meio da tubulação, segundo PRANDTL e TIETJENS (1934), tem variação, devido à turbulência. Esta tem flutuação de aproximadamente $5 \%$. Esta flutuação diminui rapidamente quanto mais próximo se está da parede do tubo. 
Segundo COLEBROOK e WHITE (1937) em escoamento em tubos rugosos, a rugosidade da parede do tubo exerce influência considerável no perfil do escoamento.

COLEBROOK e WHITE (1937) estudaram o efeito da rugosidade para o regime turbulento misto. Nesta determinação foram utilizados dados de ensaios experimentais por eles realizados.

Os ensaios foram realizados em uma bancada de ensaios composta por tubos artificialmente rugosos. Esta rugosidade foi obtida ao se colar grãos de areia à parede interna do tubo. Os ensaios foram classificados dependendo da granulometria dos grãos utilizados nos tubos.

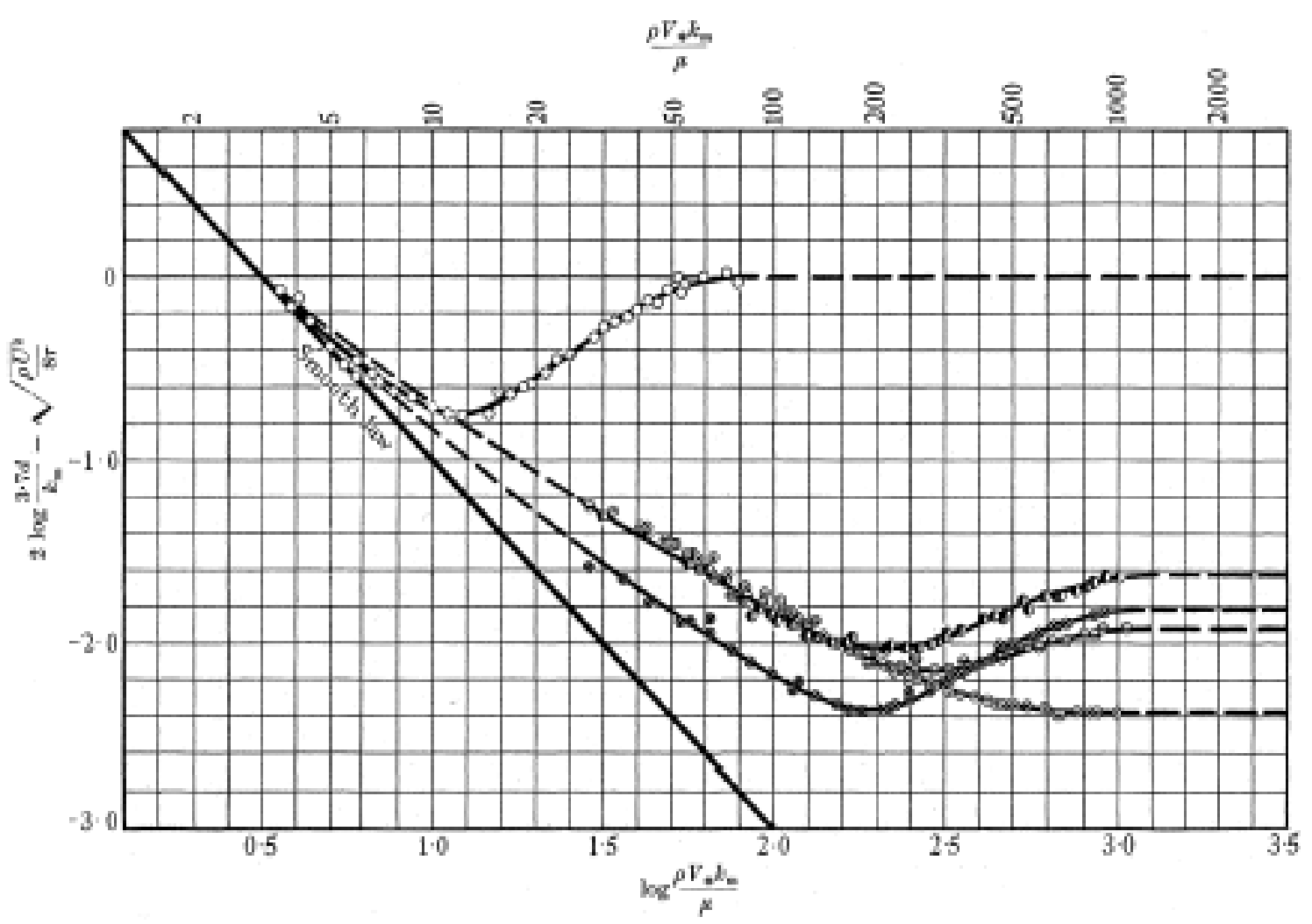

Figura 7. Resultados obtidos nos ensaios em todas situações de ensaio. Fonte: COLEBROOK e WHITE (1937). 
COLEBROOK e WHITE (1937) apresentaram como resultado de seu estudo do regime turbulento misto em diferentes níveis de rugosidade da parede do tubo. Os resultados são apresentados na figura (7).

A figura (7) apresentou os resultados de ensaio de COLEBROOK e WHITE (1937) em função do logaritmo do número de Reynolds. É possível notar uma depressão na transição do escoamento turbulento misto e turbulento para todas as rugosidades. Essa depressão ocorreu devido aos ensaios terem sido realizados com rugosidades artificiais uniformes.

COLEBROOK e WHITE (1937) abriram caminho para o trabalho realizado por Colebrook em 1939, o qual formulou equacionamento do fator de atrito para tubos comerciais. Até o término da edição desta tese não foi possível a obtenção de uma cópia deste trabalho.

COLEBROOK (1939) apud MOODY (1944) equacionou o escoamento turbulento misto. Este equacionamento foi baseado no modelo de Prandtl ajustado a dados experimentais. A equação resultante, equação (4), apresentou resultados de qualidade, sendo até os dias atuais a mais empregada para determinação do fator de atrito $(f)$.

$$
\frac{1}{\sqrt{f}}=-2 \log \left(\frac{k}{3,71 D}+\frac{2,51}{\operatorname{Re} \sqrt{f}}\right)
$$

Onde:

$D$ = Diâmetro interno do tubo;

$k$ = Rugosidade equivalente hidráulica da parede do tubo; 
Re = Número de Reynolds molecular;

$f \quad=$ Fator de atrito.

MOODY (1944) apresentou o diagrama da figura (8), baseado na equação (4). Este foi elaborado visando facilitar o cálculo de escoamento em tubulações comerciais. Tal diagrama é atualmente conhecido como "Diagrama de Moody".

Este diagrama relaciona o fator de atrito $(f)$ ao número de Reynolds. Pode ser dividido em quatro partes: Regime laminar, zona crítica, regime turbulento misto e regime turbulento rugoso.

O regime laminar abrange uma faixa de número de Reynolds entre 0 e aproximadamente 3500 . Foi representado como uma reta descendente. É importante lembrar que as escalas utilizadas no diagrama da figura (8) são logarítmicas.

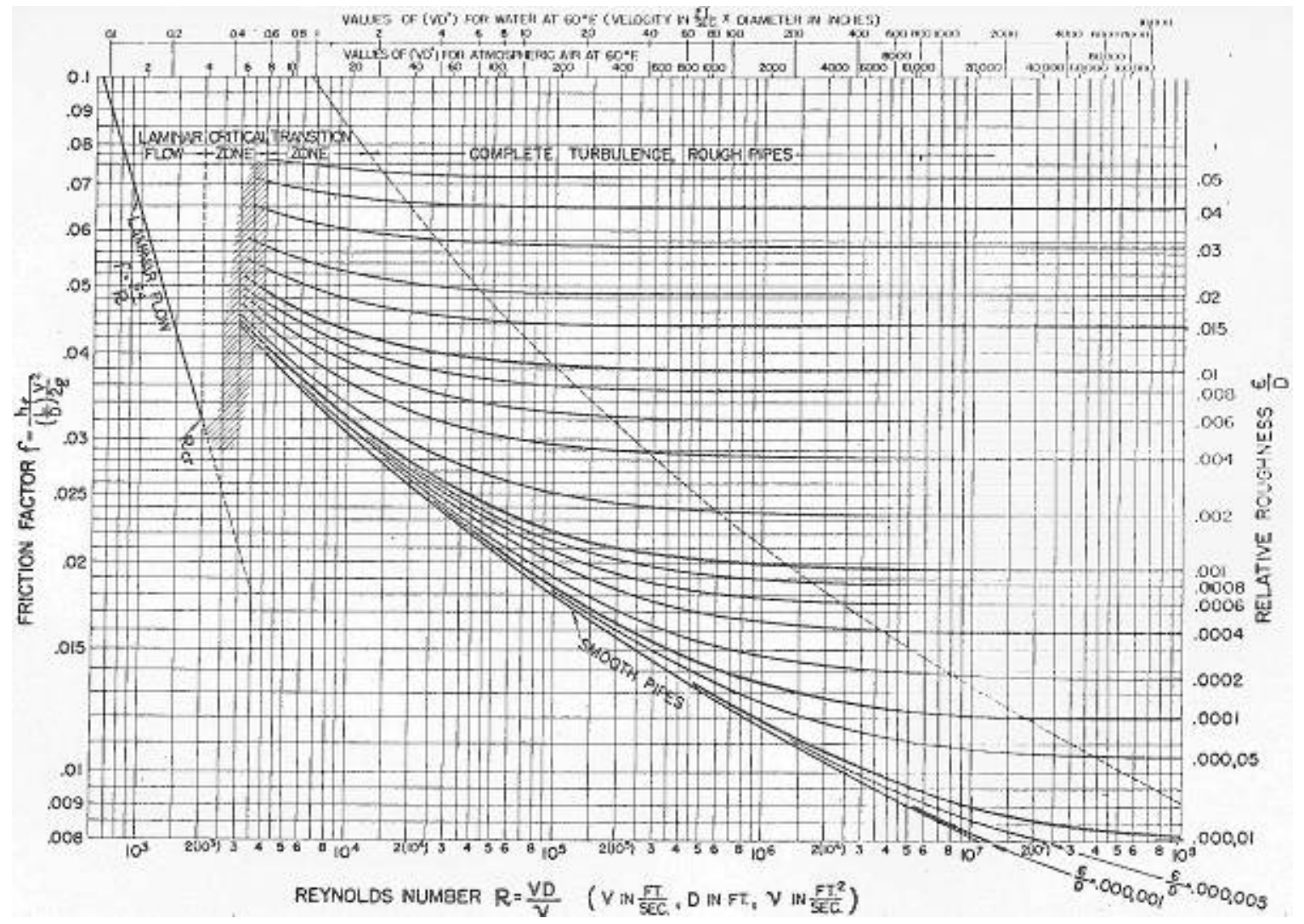

Figura 8. Diagrama de Moody. Fonte: MOODY (1944) 
A zona crítica é uma faixa de descontinuidade entre o regime laminar e turbulento. Esta zona é representada no diagrama da figura (8) como uma hachura. Esta hachura está na faixa de valores de número de Reynolds aproximadamente entre 3000 e 4500.

Descrito no diagrama da figura (8) como zona de transição está o regime turbulento misto. Este regime abrange a faixa entre os números de Reynolds de 3000 ao infinito. Faz parte deste regime o escoamento turbulento em tubos lisos.

Segundo MOODY (1944) a separação entre o regime turbulento misto e rugoso é uma linha descrita na equação (5).

$$
\frac{\operatorname{Re} \sqrt{f}}{D / k}=200
$$

Onde:

$D=$ Diâmetro da tubulação;

$f \quad=\quad$ Fator de atrito;

$k=$ Rugosidade hidraulicamente equivalente;

$\operatorname{Re}=$ Número de Reynolds.

Tanto nos regimes turbulentos misto e rugoso, a relação entre o número de Reynolds $(\operatorname{Re})$ e o fator de atrito $(f)$ é dividida em diferentes linhas. Estas linhas representam a rugosidade relativa da tubulação.

ROUSE (1946) apresentou tratativas quanto ao cálculo da perda de carga no escoamento. A primeira versou sobre a influência da subcamada viscosa na perda de carga do escoamento. Na segunda foi apresentado um diagrama que relacionava 
graficamente o número de Reynolds, o fator de atrito e a rugosidade relativa da tubulação.

Segundo ROUSE (1946), em escoamentos no regime turbulento liso, existe uma subcamada viscosa junto da parede do tubo. Em tubos lisos, o aumento do número de Reynolds do escoamento propicia a redução da subcamada viscosa. Em tubos rugosos a influência da subcamada rugosa vai até o ponto em que a rugosidade passa ter dimensão maior que esta, gerando acréscimo de turbulência no escoamento.

ROUSE (1946) fez crítica acerca dos ensaios desenvolvidos por Nikuradse. É destacado que os mesmos, apesar do grande valor científico, não apresentam resultados aplicáveis às tubulações comerciais. Tal fato, segundo ROUSE (1946), deve-se à utilização de areia uniforme para artificialmente simular a rugosidade da tubulação.

ROUSE (1946) apresentou o diagrama da figura (9) o qual relaciona o fator de atrito $(f)$ e o número de Reynolds para tubulações comerciais. Este diagrama é muito similar ao diagrama apresentado por MOODY (1944).

A diferença entre o diagrama da figura (9) e o da figura (8) é a introdução do adimensional chamado número de Rouse. Este adimensional é obtido pela multiplicação do número de Reynolds pela raiz do fator de atrito $(\operatorname{Re} \sqrt{f})$. A escala também foi anamorfoseada para que fosse possível entrar com os quatro adimensionais apresentados na figura (9). 


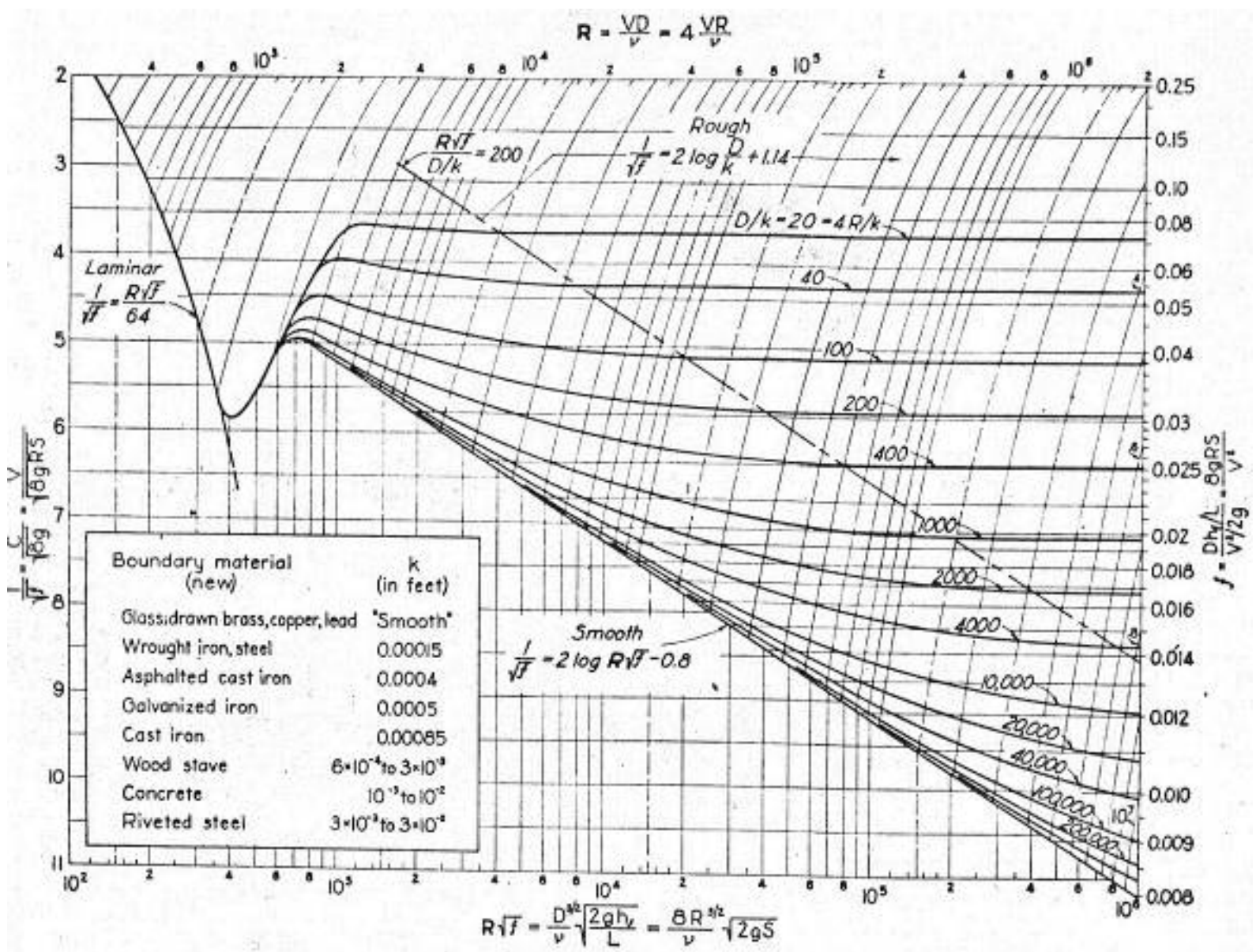

Figura 9. Diagrama de Rouse. Fonte: ROUSE (1946).

OTTONI NETTO (1950) fez um levantamento do estado da arte até então existente. $\mathrm{O}$ autor reuniu em uma única obra os estudos que fundamentavam o tratamento matemático do escoamento em tubulações.

Em meados do século XIX, Hagen e Poiseuille, segundo OTTONI NETTO (1950), realizaram os primeiros experimentos. Em 1883 Osborne Reynolds publicou trabalho baseado em sua experiência clássica de escoamento de um filete de água colorida no centro de um escoamento de água sem corante. A partir dos resultados obtidos foi desenvolvido o adimensional que leva seu nome. Em 1904 Ludwig Prandtl publicou um estudo realizado com placas delgadas lisas resultando na definição da existência da camada limite. 
Segundo OTTONI NETTO (1950) o escoamento em tubos cilíndricos, pode ser inicialmente caracterizado através do desenvolvimento de uma camada limite ocorrendo em uma placa lisa com seção em revolução, onde depois de percorrida uma distância longitudinal as camadas limites se encontram no centro do tubo. $\mathrm{O}$ encontro das camadas limites forma o escoamento conhecido como plenamente desenvolvido a partir de onde as teorias tradicionais de perda de carga em tubulações passam a valer.

OTTONI NETTO (1950) descreve que a perda de carga em um escoamento plenamente desenvolvido ocorre devido à interação do escoamento com o tubo, obedecendo a Segunda Lei de Newton, surgindo uma tensão de cisalhamento no sentido contrário ao mesmo. A fórmula universal da perda de carga foi desenvolvida a partir da estimativa dessa tensão tangencial, onde foi introduzido um termo conhecido como fator de atrito $(f)$. Esse autor descreve algumas tentativas de se obter uma formulação para tal fator, porém todas de maneira empírica, limitadas às condições de ensaio das mesmas.

Através da Teoria de Von Kármán, a qual descreve aproximadamente de perfil de velocidades no interior de uma tubulação, OTTONI NETTO (1950) reproduziu a demonstração, a base utilizada para a equação generalizada da perda de carga (6). Tal equação é de origem semi-empírica e ajustada com os dados provindos do experimento de Nikuradse para escoamento em tubos rugosos.

$$
\frac{1}{\sqrt{f}}=2 \log \left(\frac{R}{k}\right)+1,74
$$

Onde: 
$f=$ Fator de atrito;

$R \quad=$ Raio do tubo;

$k=$ Rugosidade equivalente hidráulica da tubulação;

O petróleo produzido em poços submarinos geralmente é transportado para o continente através de oleodutos. Durante tal transporte, em virtude da diferença de temperatura ambiente, a viscosidade de fluido modifica-se durante o percurso. Tal fato torna a modelagem matemática do escoamento de petróleo nestas tubulações, utilizado o equacionamento implícito de Colebrook, muito trabalhosa. A partir dessa linha de pesquisa, SWAMEE e JAIN (1976) desenvolveram um equacionamento explicito para o fator de atrito objetivando a otimização dos estudos em tubulações.

A equação (7), proposta por SWAMEE e JAIN (1976), sintetizou em uma única equação o cálculo explícito do fator de atrito para os regimes turbulento e turbulento misto. Tal equação apresentou maior simplicidade de cálculo pelo fato de não necessitar a identificação do regime de escoamento (laminar, ou as três alternativas de turbulento).

$$
f=\left\{\left(\frac{64}{\operatorname{Re}}\right)^{8}+9,5\left[\ln \left(\frac{k}{3,71 D}+\frac{5,74}{\operatorname{Re}^{0,9}}\right)-\left(\frac{2500}{\operatorname{Re}}\right)^{6}\right]^{-16}\right\}^{1 / 8}
$$

Onde:

$D$ = Diâmetro do tubo;

$f=$ Fator de atrito;

$R e=$ Número de Reynolds;

$k=$ Rugosidade da parede interna da tubulação. 
SWAMEE e JAIN (1976) concluíram que a formulação por eles proposta superou os métodos de determinação do fator de atrito do escoamento $(f)$ em relação às formulações até então existentes. Segundo os autores, a utilização desta formulação simplifica o cálculo para determinação do fator de atrito.

Visando simplificar o cálculo do escoamento, SIMON (1976) apresentou dois métodos não iterativos para calculo de dados do escoamento. Ambos os métodos são métodos gráficos.

Desenvolvido por LI (1974) apud SIMON (1976), o primeiro método foi desenvolvido tendo como base o diagrama de Moody. Os valores do fator de atrito (f), do número de Reynolds $(R e)$ e da rugosidade relativa deste diagrama foram substituídos.

Estes adimensionais foram desenvolvidos por considerações dimensionais. Esta tratativa utilizou como base a equação universal da perda de carga e o equacionamento do número de Reynolds $(R e)$ em função da vazão. O gráfico da figura (10) apresenta o diagrama de Li.

O segundo método apresentado por SIMON (1976) foi o método desenvolvido por um pesquisador Etíope chamado Asthana. Este pesquisador criou um novo gráfico. Este gráfico, assim como no caso anterior, baseia-se em adimensionais para o cálculo direto. A figura (11) apresenta o diagrama de Asthana. 


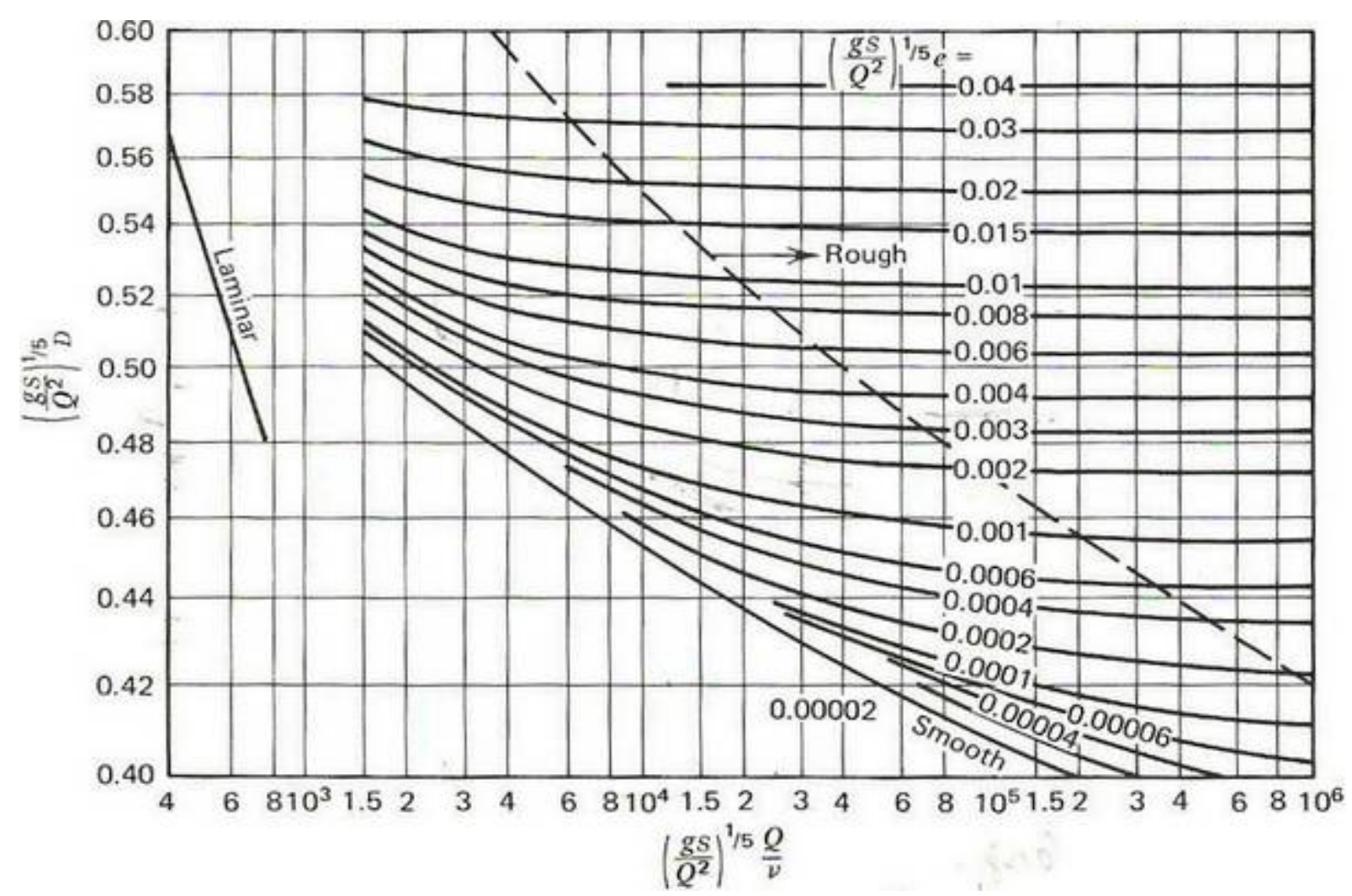

Figura 10. Diagrama de Li. Fonte: SIMON (1976).

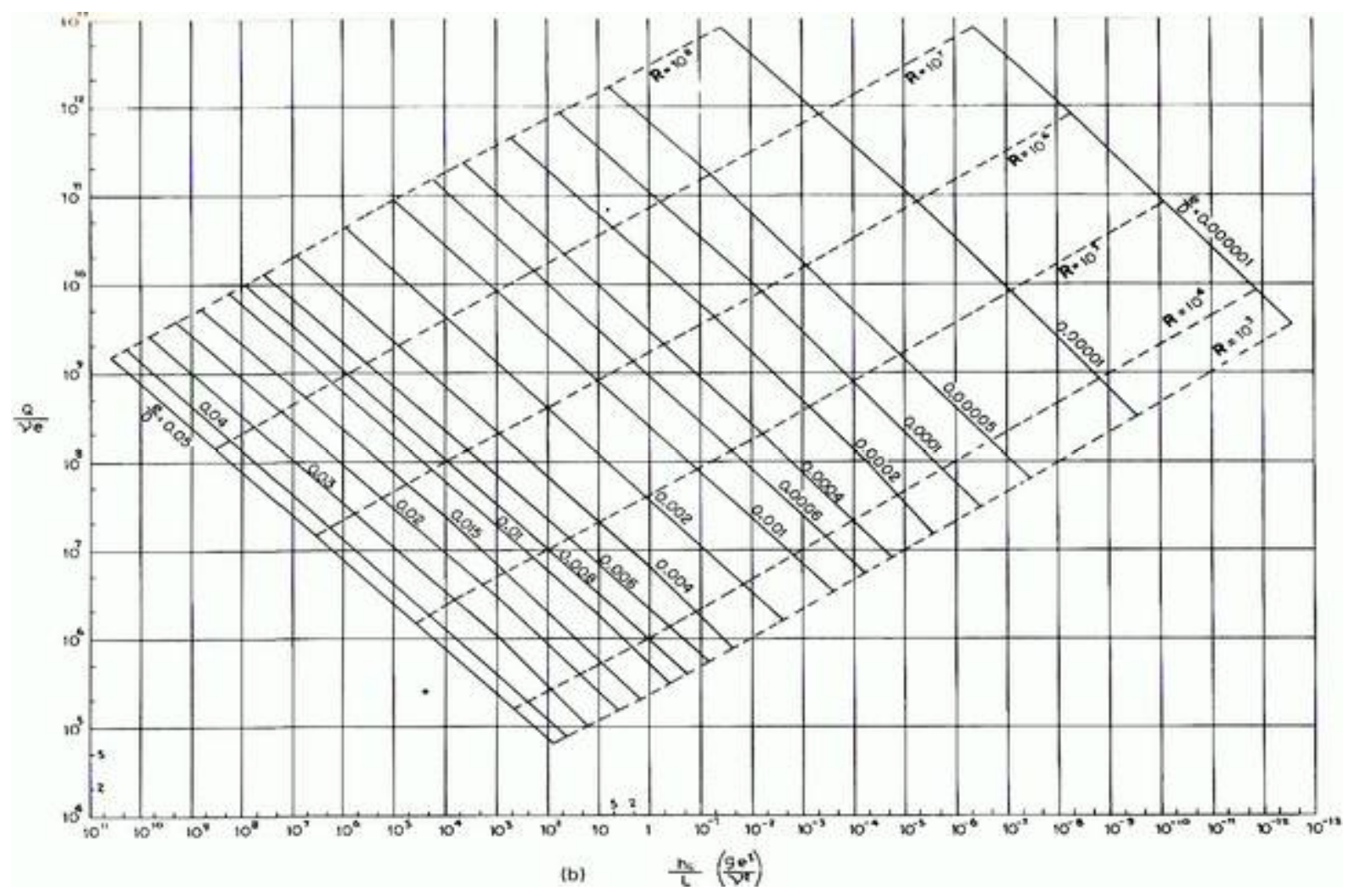

Figura 11. Diagrama do escoamento em tubulações de Asthana. Fonte: SIMON (1976). 
Ambos os métodos apresentados por SIMON (1976) podem ser utilizados para o cálculo do escoamento em tubulações, evitando-se entrar em cálculos iterativos. Porém, são métodos gráficos, não podendo ser empregados em sistemas computacionais.

STREETER e WYLIE (1982) relatam que os ensaios de perda de carga em tubos rugosos elaborados por Nikuradse não são válidos para tubos comerciais. Tal fato deve-se aos ensaios terem sido realizados com areia com diâmetro uniforme. Em função deste fato, STREETER e WYLIE (1982) recomendam a utilização da formulação desenvolvida por Colebrook.

Ainda segundo estes autores o fator de atrito $(f)$ de um escoamento turbulento liso é função das variáveis descritas na equação (8). Já quando o escoamento é o turbulento rugoso, as dimensões relacionadas com a rugosidade das paredes internas da tubulação exercem influência no cálculo do fator de atrito $(f)$, conforme equação (9).

$$
\begin{gathered}
f=f(\bar{u}, D, \rho, \mu,) \\
f=f\left(\bar{u}, D, \rho, \mu, e, e^{\prime}, m\right)
\end{gathered}
$$

Onde:

$D$ = Diâmetro da tubulação;

$e=$ Rugosidade da parede interna da tubulação;

$e^{\prime} \quad=$ Medida do arranjo ou projeção da rugosidade;

$f=$ Fator de atrito;

$m=$ Fator de forma; 
$\bar{u} \quad=\quad$ Velocidade média do escoamento;

$\mu \quad=$ Viscosidade dinâmica do fluido;

$\rho=$ Massa específica do fluído.

Segundo STREETER e WYLIE (1982) rugosidades relativas da tubulação (e/D) menores que 0,001 se aproximam da curva para os tubos hidraulicamente lisos.

STREETER e WYLIE (1982) relatam que no escoamento turbulento misto, subcamada viscosa suficientemente espessa para deixar apenas as imperfeições mais protuberantes causem um acréscimo da turbulência no escoamento. Já no escoamento turbulento rugoso, esta faz com que a subcamada viscosa tenha seu efeito muito reduzido.

A relação entre a tensão de cisalhamento e a velocidade média em um escoamento turbulento, segundo FOX et al. (1983), é muito complexa. Isto se deve à existência de flutuações nas velocidades entre as camadas do escoamento, criando uma tensão adicional se comparado ao escoamento laminar. $O$ escoamento turbulento totalmente apresentado por Reynolds apud FOX et al. (1983) pode ser descrito pela equação (10).

$$
\tau_{0}=\mu \frac{d \bar{u}}{d y}-\rho \bar{u}_{x}^{\prime} \bar{u}_{y}{ }^{\prime}
$$

Onde:

$\bar{u}=$ Velocidade média do escoamento;

$\bar{u}_{x}{ }^{\prime}=$ Pulsação de velocidade do escoamento na direção $\mathrm{x}$; 


$$
\begin{aligned}
\bar{u}_{y}{ }^{\prime} & =\text { Pulsação de velocidade do escoamento na direção y; } \\
y & =\text { Distância da parede do tubo; } \\
\mu & =\text { Viscosidade do fluido; } \\
\tau_{0} & =\text { Tensão de atrito do escoamento. }
\end{aligned}
$$

Segundo FOX et al. (1983) o produto das pulsações de velocidade, quando dividido pelo quadrado da velocidade de atrito do escoamento, é próximo de 1 . Ao aproximar-se do centro da tubulação, o valor desta divisão vai paulatinamente tendendo a zero, alcançando este valor no centro da tubulação. Isto demonstra a predominância da turbulência nas proximidades do centro da tubulação.

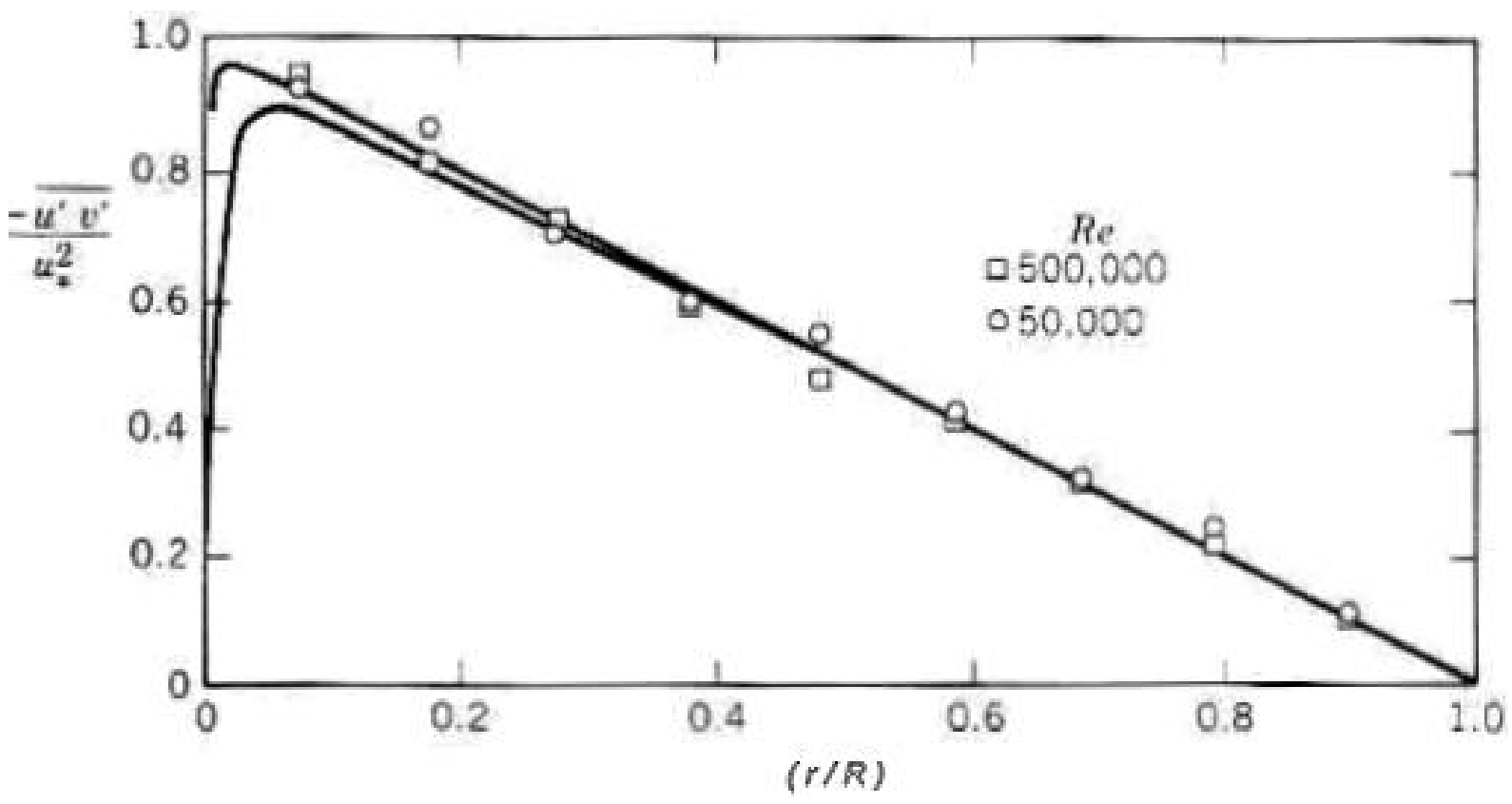

Figura 12. Diagrama de comparação entre a divisão da pulsação de velocidade pelo quadrado da velocidade de atrito e a posição relativa na tubulação em função do raio. Fonte FOX et al. (1983).

FOX et al. (1983) apresentaram na figura (12) um relacionamento entre as pulsações de velocidade e sua posição relativa na tubulação.Neste gráfico é possível verificar que nas proximidades do centro e junto às paredes do tubo as pulsações tendem a zero. O ponto de máximo das pulsações está nas proximidades 
do centro do tubo. Neste ponto o produto das pulsações de velocidades é aproximadamente igual ao quadrado da velocidade de atrito do escoamento.

Von Kármán apud FOX et al. (1983) desenvolveu um modelo de escoamento turbulento, dividindo este em duas partes, de acordo com a teria da camada limite de Prandtl. A primeira a subcamada viscosa, junto à parede da tubulação. No centro da tubulação, este relata a existência de um escoamento turbulento.

A subcamada laminar pode ser representada pela equação (11). Nesta o efeito viscoso é dominante para a perda de carga do escoamento.

A faixa turbulenta de um escoamento turbulento liso pode ser representada pela equação (12). Já o escoamento turbulento rugoso pode ser representado pela equação (13). Nesta faixa de escoamento a dissipação turbulenta é o fator predominante para a perda de carga do escoamento.

$$
\begin{gathered}
\frac{\bar{u}}{u_{*}}=\frac{y u_{*}}{v} \\
\frac{\bar{u}}{u_{*}}=2,5 \ln \frac{y u_{*}}{\mu}+5,0 \\
\frac{u_{\max }-\bar{u}}{u_{*}}=2,5 \ln \frac{R}{y}
\end{gathered}
$$

Onde:

$$
\begin{aligned}
& R=\text { Raio do tubo; } \\
& u_{\max }=\text { Velocidade máxima do escoamento; } \\
& \bar{u} \quad=\text { Velocidade média do escoamento; }
\end{aligned}
$$




$$
\begin{aligned}
& u_{*} \quad=\text { Velocidade de atrito do escoamento; } \\
& y \quad=\text { Distância da parede do tubo; } \\
& \mu \quad=\text { Viscosidade do fluido. }
\end{aligned}
$$

FOX et al. (1983) reproduziu a equação de energia (14) para escoamentos com regime turbulento liso, para determinação do perfil de velocidades.

$$
\frac{\bar{u}}{u_{*}}=\left(1-\frac{r}{R}\right)^{1 / n}
$$

Onde:

$$
\begin{aligned}
& n=\text { Parâmetro empírico; } \\
& R \quad=\text { Raio do tubo; } \\
& r \quad=\text { Distância do centro do tubo; } \\
& \bar{u} \quad=\text { Velocidade média temporal do escoamento; } \\
& u_{*} \quad=\text { Velocidade de atrito do escoamento. }
\end{aligned}
$$

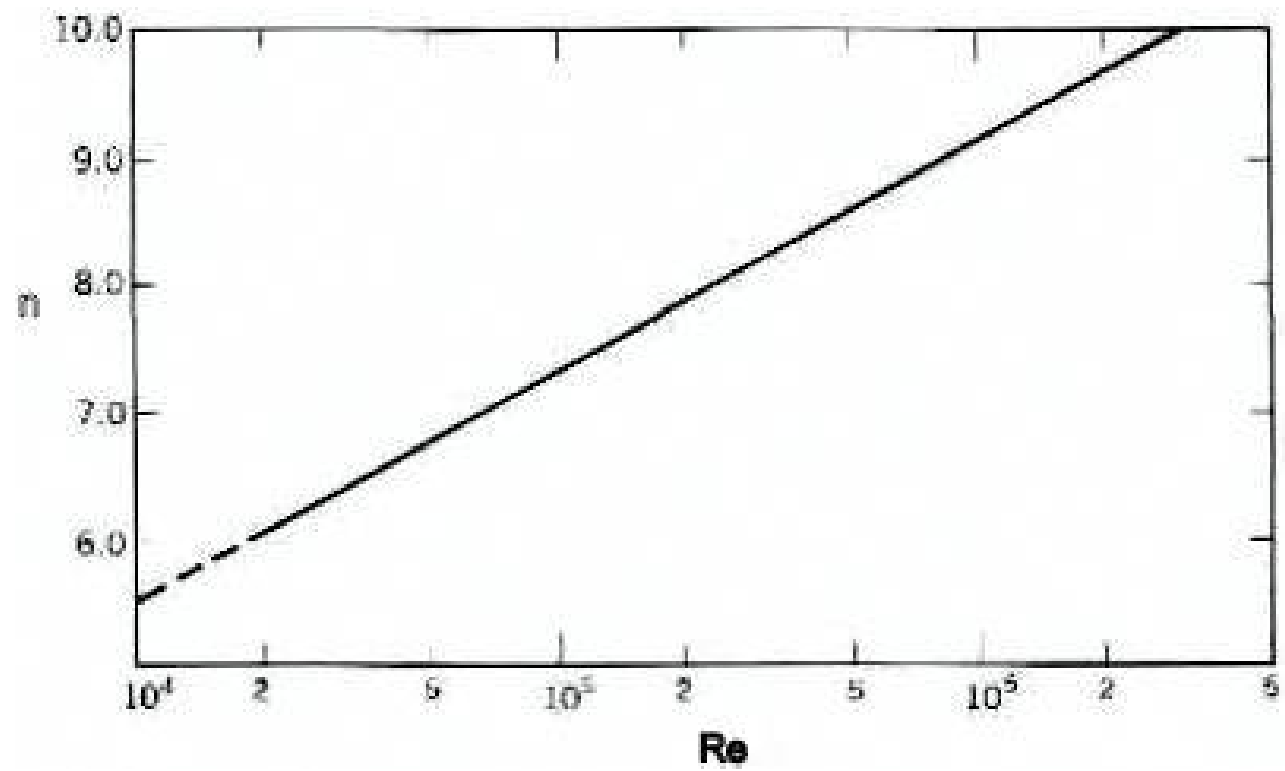

Figura 13. Relação entre a variável ( $n$ ) e o número de Reynolds. Fonte: FOX et al. (1983). 
O parâmetro $(n)$, segundo o mesmo, é dependente do número de Reynolds, conforme apresentado na figura (13). Cada valor deste parâmetro refere-se à um determinado perfil de velocidades, conforme apresentado na figura (14).

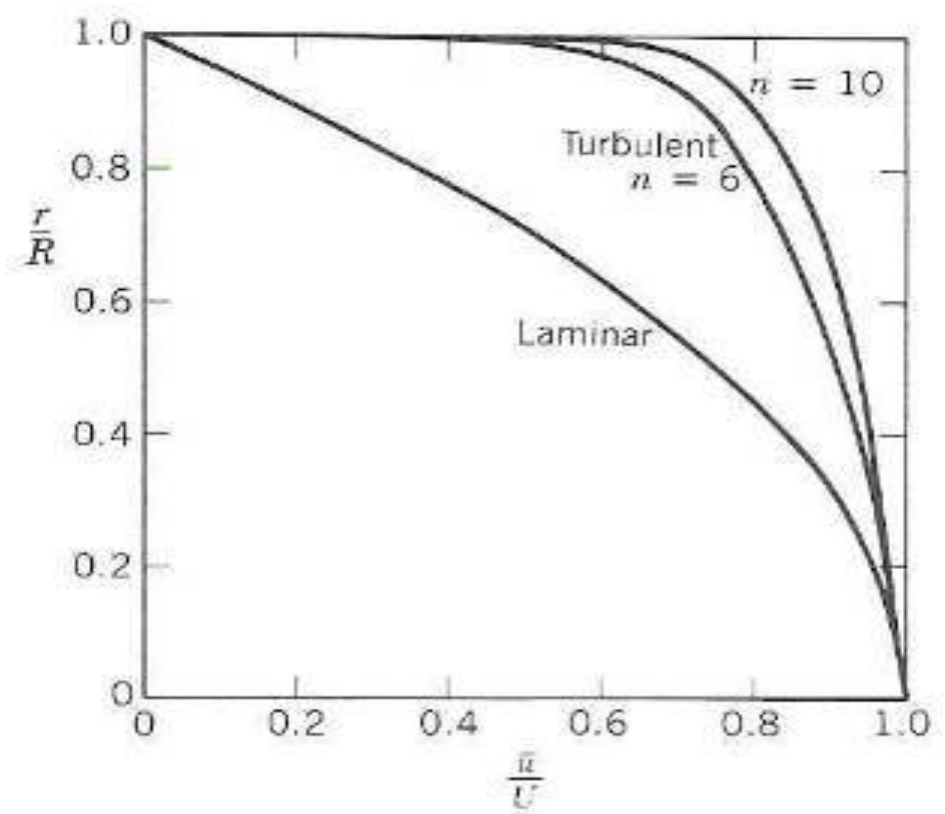

Figura 14. Variação dos perfis de velocidade de acordo com o parâmetro $n$ da equação (14). Fonte: FOX et al. (1983).

CHIU (1987) desenvolveu um modelo diferente para o perfil de velocidades. Este utilizou como ferramenta os conceitos de entropia e teoria da comunicação.

Segundo CHIU (1987) o conceito da entropia foi utilizado para fundamentar a ligação entre o mundo determinístico e o probabilístico, sendo esse último pouco familiar para os engenheiros hidráulicos, segundo esse autor.

A teoria da comunicação quantifica matematicamente a recepção de uma informação sobre a ocorrência de um evento. A medida desta é feita dividindo-se dois termos relacionados com a probabilidade de um evento, depois e antes da chegada de uma determinada mensagem, conforme equação (15). Quando a transmissão é feita "sem ruído", a probabilidade de chegada da mensagem é igual a 
1. Esta função de probabilidade é descrita por uma função logarítmica, tornando-a negativa quando a probabilidade de chegada da mensagem é igual a 1.

$$
\ln \frac{p(X / \hat{X})}{p(X)}
$$

Onde:

$$
\begin{aligned}
& p(X)=\text { Probabilidade sem o dado simples; } \\
& X \quad=\text { Condição do sistema anterior a transmissão de uma informação; } \\
& \hat{X} \quad=\text { Erro atribuído à condição do sistema. }
\end{aligned}
$$

A entropia é a função de probabilidades acumuladas que mede a informação gerada e transmitida por um evento, através da somatória ponderada pela probabilidade de quantas vezes um evento ocorreu, conforme descrito nas equações (16) e (17). A primeira equação é a definição discreta, já a segunda aplica-se para os casos de problemas com variação contínua.

$$
\begin{aligned}
& H(X)=-\sum_{j} p\left(X_{j}\right) \ln p\left(X_{j}\right) \\
& H(X)=-\int p(X) \ln p(X) d x
\end{aligned}
$$

Onde:

$$
\begin{aligned}
& p \quad=\text { Probabilidade (função de probabilidades acumuladas); } \\
& X \quad=\text { Condição do sistema anterior a transmissão de uma informação; } \\
& H(X)=\text { Entropia. }
\end{aligned}
$$


De acordo com o princípio da entropia, segundo CHIU (1987), no estado de equilíbrio um sistema tende a maximizar a entropia sobre a previamente contida. Ao maximizar a entropia, estima-se que o evento de maior probabilidade é o que ocorrerá. Este princípio pode ser utilizado para modelar a distribuição mais provável dos estados de um sistema.

A partir dos conceitos de entropia e teoria da informação, CHIU (1987) desenvolveu equacionamentos de forma conceitual para perfil de distribuição de velocidade, distribuição da tensão de cisalhamento e distribuição da concentração de sedimentos. Esse autor utilizou o método de elencar a hipótese de maior probabilidade de ocorrência, ou seja, foi utilizado o método de maximização do funcional de entropia para o desenvolvimento destes equacionamentos.

Tendo em vista o perfil de distribuição de velocidades, o qual é objeto da presente tese, CHIU (1987), considerando que a probabilidade a ser encontrada seria associada ao perfil de velocidades, reescreveu a equação do mesmo para que a probabilidade fosse em função do mesmo, equação (18). Após tal consideração, foi possível reescrever a equação da entropia para que a mesma se tornasse em função da velocidade, integrando-a na equação (18) no intervalo de zero à velocidade máxima na equação (19).

$$
\begin{gathered}
p(u)=\left(D_{h} \frac{d u}{d z}\right)^{-1} \\
H(u)=-\int_{0}^{u_{\max }} p(u) \ln p(u) d u
\end{gathered}
$$

Onde: 


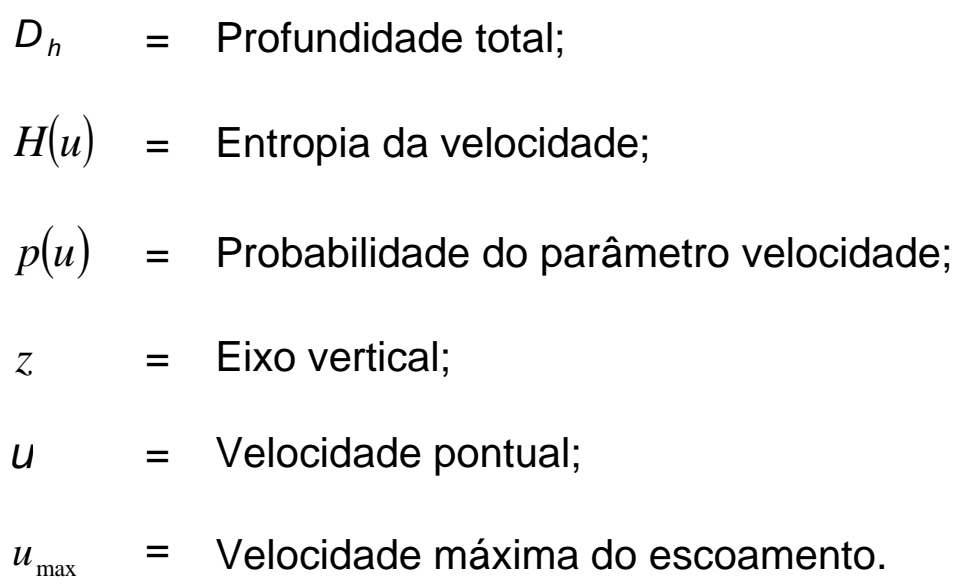

CHIU (1987) obteve a equação (20) para o caso de escoamento em um canal, com velocidade máxima $\left(u_{d}\right)$ na superfície. Esse equacionamento tem do perfil de velocidades cunho totalmente conceitual. Esse autor comparou a equação (20) com a formulação do perfil de velocidades de Prandtl-Von Kármán e com resultados obtidos através de medições.

A formulação proposta por CHIU (1987) apresentou resultados muito próximos aos dados experimentais. Também apresentou maior precisão em relação ao perfil de velocidades de Prandtl-Von Kármán, principalmente nas regiões próximas às paredes de um canal, onde esta ultima não representa a realidade com fidelidade.

$$
u=\frac{u_{*}}{M} \ln \left[1+\left(e^{M u_{d} / u_{*}}-1\right) \frac{y}{D_{h}}\right]
$$

Onde:

$$
\begin{aligned}
D_{h} & =\text { Profundidade total; } \\
e & =\text { Base neperiana; } \\
M & =\text { Parâmetro de entropia; }
\end{aligned}
$$




$$
\begin{array}{ll}
y & =\text { Profundidade pontual; } \\
u & =\text { Velocidade pontual; } \\
u_{d} & =\text { Velocidade máxima na superfície livre; } \\
u_{*} & =\text { Velocidade de atrito do escoamento. }
\end{array}
$$

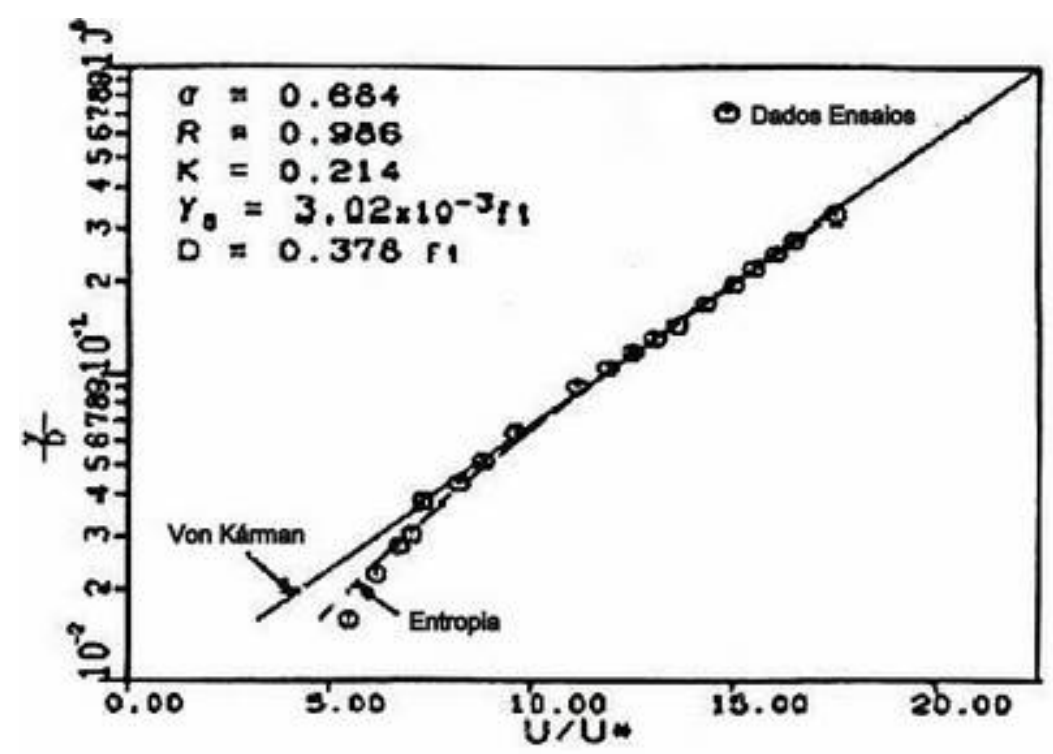

Figura 15. Comparação do perfil de velocidades entre os modelos de Prandtl-Von Kármán e CHIU. Fonte CHIU (1987).

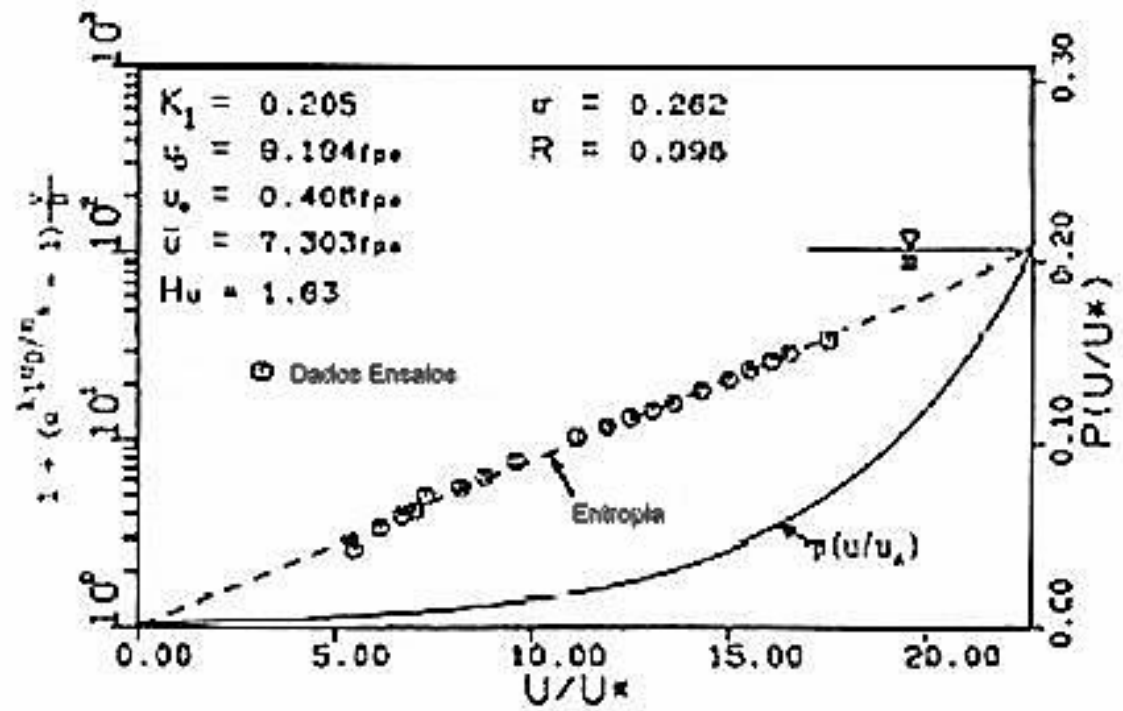

Figura 16. Comparação do parâmetro de entropia entre os modelos de Prandtl-Von Kármán e CHIU. Fonte CHIU (1987). 


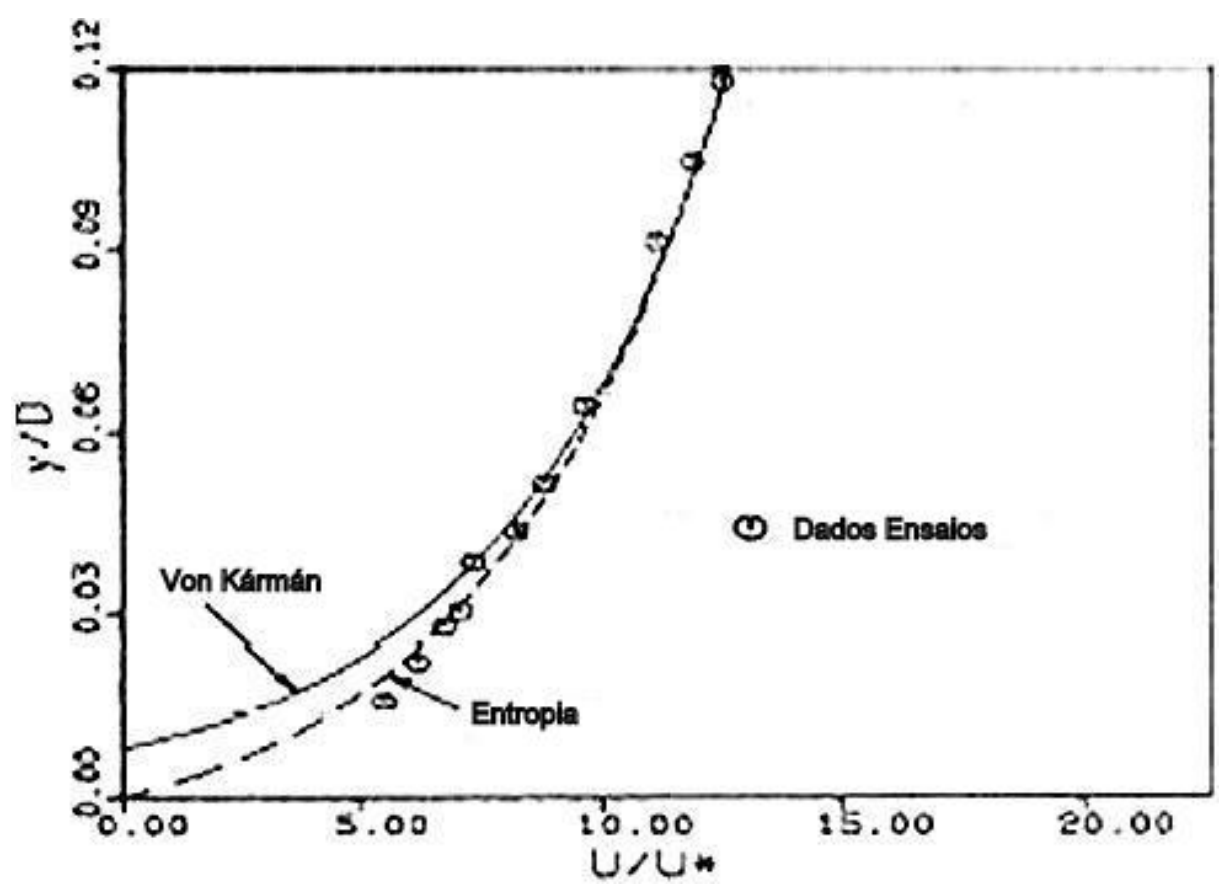

Figura 17. Comparação do perfil de velocidade nas proximidades do fundo do canal entre os modelos de Prandtl-Von Kármán e CHIU. Fonte CHIU (1987).

Fazendo uso do modelo da entropia máxima CHIU (1988) estudou a utilização deste com a finalidade de estimar o perfil de velocidades em uma seção de um canal aberto. A partir de desenvolvimento da equação (21), a qual apresenta um sistema de coordenadas isovelozes.

$$
\begin{aligned}
\frac{u}{u_{\max }}= & \frac{1}{M} \ln \left[1+\left(e^{M}-1\right) \frac{\varepsilon-\varepsilon_{0}}{\varepsilon_{\max }-\varepsilon_{0}}\right] \\
& \frac{\varepsilon-\varepsilon_{0}}{\varepsilon_{\max }-\varepsilon_{0}}=\int_{0}^{u} p\left(u_{\varepsilon}\right) d u
\end{aligned}
$$

Onde:

$e \quad=\quad$ Base neperiana;

$M \quad=\quad$ Parâmetro de entropia; 


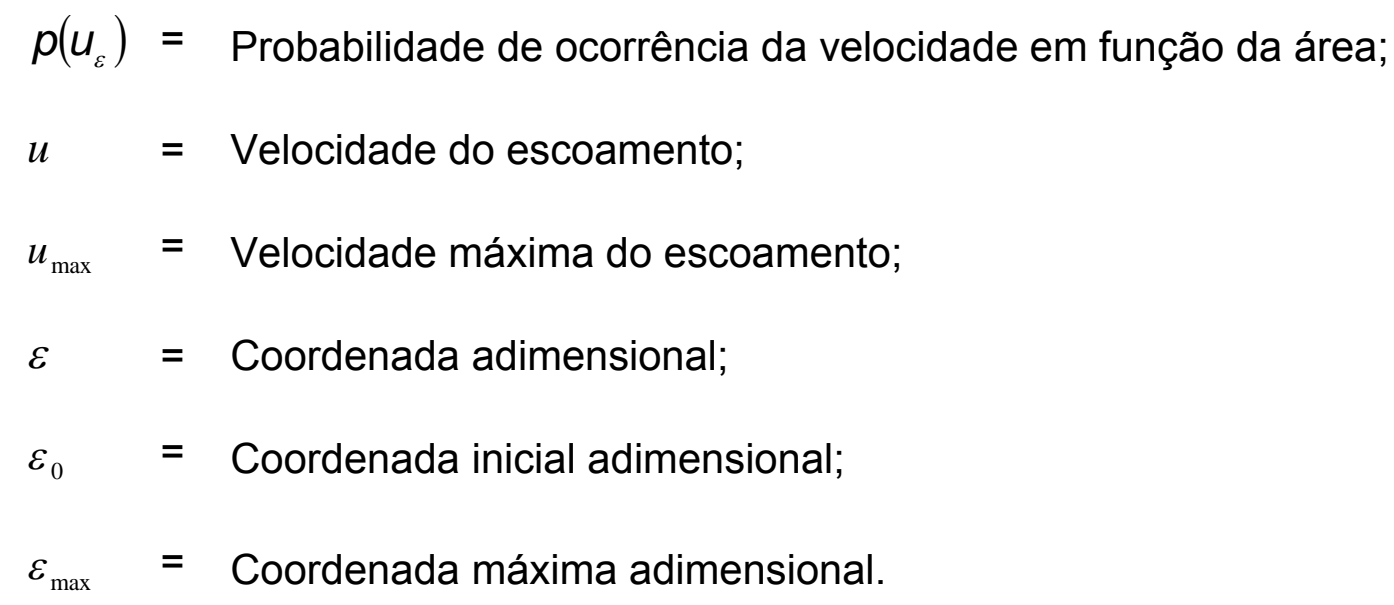

CHIU (1988) também apresentou uma relação entre o parâmetro de entropia ( $M$ ) e o perfil de um escoamento qualquer. Na figura (18) é possível notar o comportamento do perfil para alguns valores do parâmetro de entropia. Dentre estes valores constam os valores teóricos limites: zero, o qual representa a entropia elevada ao máximo, e infinito $(\infty)$ o qual representaria um escoamento livre de viscosidade.

Segundo CHIU (1988) a partir deste equacionamento é possível obter os parâmetros referentes ao atrito de diversas fórmulas como universal, Chezy ou Manning. Este equacionamento, segundo o mesmo, também vale para qualquer condição de escoamento, tanto laminar quanto turbulento. CHIU (1988) concluiu "a definição e a demonstração de utilidade do parâmetro $(M)$ como um novo parâmetro hidráulico que mostra a importância e o valor da informação dada pela localização e magnitude da velocidade máxima $\left(u_{\max }\right)$ na seção de um canal”.

Segundo EINSTEIN e CHIEN (1965) apud CHIU (1989) "é bem conhecido que o modelo baseado na lei logarítmica de Prandtl-Von Kármán tem desempenho pobre nas proximidades do fundo, especialmente no escoamento com sedimentos". 
Isto posto, CHIU (1989) propôs a utilização do modelo baseado no conceito da entropia máxima para transporte de sedimentos.

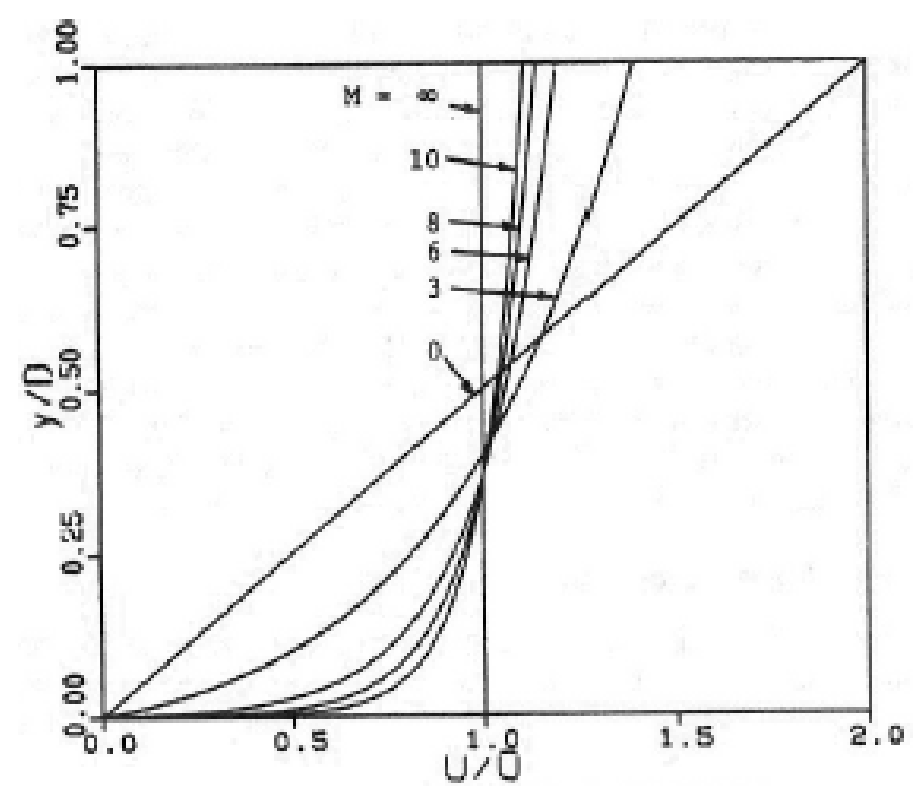

Figura 18. Comparação do parâmetro de entropia com o perfil de velocidades. Fonte: CHIU (1988)

Foram desenvolvidos por CHIU (1989) três modelos para estimar o transporte de sedimentos. Tais modelos apresentaram resultados satisfatórios, sendo recomendados o seu uso por CHIU (1989).

CHIU et al. (1993) foi um trabalho focado em escoamento em pressão. Este teve como objetivo aplicar os conceitos desenvolvidos em CHIU (1987) e CHIU (1988) para o escoamento em conduto forçado. Visou também apresentar uma alternativa às formulações para determinação do fator de atrito $(f)$ de origem empíricas.

CHIU $(1988,1989)$ apud CHIU et al. (1993), a partir da aplicação do conceito de entropia máxima foi possível modelar o perfil de velocidade para tubulações. Para tanto, foi substituída a integração das probabilidades apresentado na equação (19) por um sistema de coordenadas adimensionais radiais para uma tubulação de 
formato circular. A partir desta substituição, foi possível reescrever a equação (21) generalizada apenas para tubos de seção circular, na equação (23).

$$
\frac{u}{u_{\max }}=\frac{1}{M} \ln \left[1+\left(e^{M}-1\right)\left(1-\frac{r^{2}}{R^{2}}\right)\right]
$$

Onde:

$$
\begin{array}{ll}
e & =\text { Base neperiana; } \\
M & =\text { Parâmetro de entropia; } \\
r & =\text { Posição radial; } \\
R & =\text { Raio do tubo; } \\
u & =\text { Velocidade do escoamento; } \\
u_{\max } & =\text { Velocidade máxima do escoamento. }
\end{array}
$$

A vazão do escoamento em um tubo pode ser obtida pela integração do perfil de velocidade dado pela equação (23). A divisão da vazão pela área da seção transversal do tubo fornece uma expressão para a velocidade média $(\bar{u})$ na seção, que depende apenas do parâmetro de entropia $(M)$ e da velocidade máxima $\left(u_{\max }\right)$, equação (24).

$$
\frac{\bar{u}}{u_{\max }}=\frac{e^{M}}{e^{M}-1}-\frac{1}{M}
$$

Onde:

$$
\begin{array}{ll}
e & =\text { Base neperiana; } \\
M & =\text { Parâmetro de entropia; } \\
u & =\text { Velocidade do escoamento; }
\end{array}
$$


$u_{\max }=$ Velocidade máxima do escoamento.

Apesar da simplicidade de tal formulação, o parâmetro de entropia $(M)$ transformou-se num instrumento vital para o equacionamento da mesma, porém sem que possuísse um valor definido em termos de grandezas macroscópicas. Era óbvio que tal parâmetro fosse dependente das variáveis do escoamento, as quais, quando aplicadas com correção apresentavam perfis de velocidades muito próximos a perfis medidos em modelos físicos.

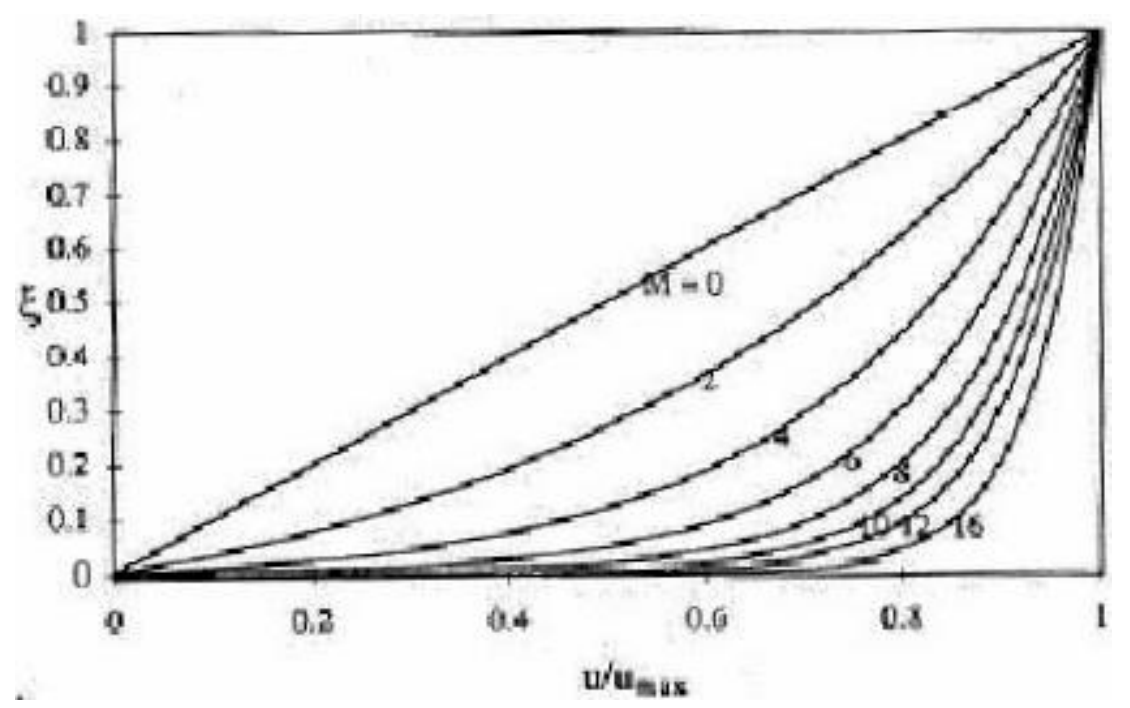

Figura 19. Gráficos de distribuição do perfil de velocidades admensionalizados para um plano físico em função do parâmetro de entropia. Fonte: CHIU et al. (1993)

Através de dedução algébrica, tendo como base a tensão de cisalhamento do escoamento, da equação do perfil de velocidades do escoamento (23) e da fórmula universal, CHIU et al. (1993) desenvolveu o equacionamento da perda de carga (25). A partir de tal formulação é possível isolar a equação (26) referente ao fator de atrito da fórmula universal, a qual pode ser reescrita através da equação (27). 


$$
\begin{gathered}
h_{f}=32 \frac{\left(e^{M}-1\right)}{M}\left(\frac{\bar{u}}{u_{\max }}\right)^{-1}\left(\frac{D \bar{u}}{\mu}\right)^{-1}\left(\frac{\mu_{T}}{\mu}\right) \frac{L}{D} \frac{\bar{u}^{2}}{2 g} \\
f=32 \frac{\left(e^{M}-1\right)}{M}\left(\frac{\bar{u}}{u_{\max }}\right)^{-1}\left(\frac{D \bar{u}}{\mu}\right)^{-1}\left(\frac{\mu_{T}}{\mu}\right) \\
f=\frac{32}{\operatorname{Re}_{a}}\left(\frac{\left(e^{M}-1\right)^{2}}{M e^{M}-e^{M}+1}\right)
\end{gathered}
$$

Onde:

$$
\begin{array}{ll}
D & =\text { Diâmetro da tubulação; } \\
e & =\text { Base neperiana; } \\
f & =\text { Fator de atrito; } \\
L & =\text { Comprimento da tubulação; } \\
M & =\text { Parâmetro de entropia; } \\
\operatorname{Re}_{a} & =\text { Número de Reynolds aparente; } \\
\bar{u} & =\text { Velocidade média do escoamento; } \\
u_{\max } & =\text { Velocidade máxima do escoamento; } \\
\mu & =\text { Viscosidade dinâmica do fluido; } \\
\mu_{T} & =\text { "Viscosidade" turbulenta (aparente). }
\end{array}
$$




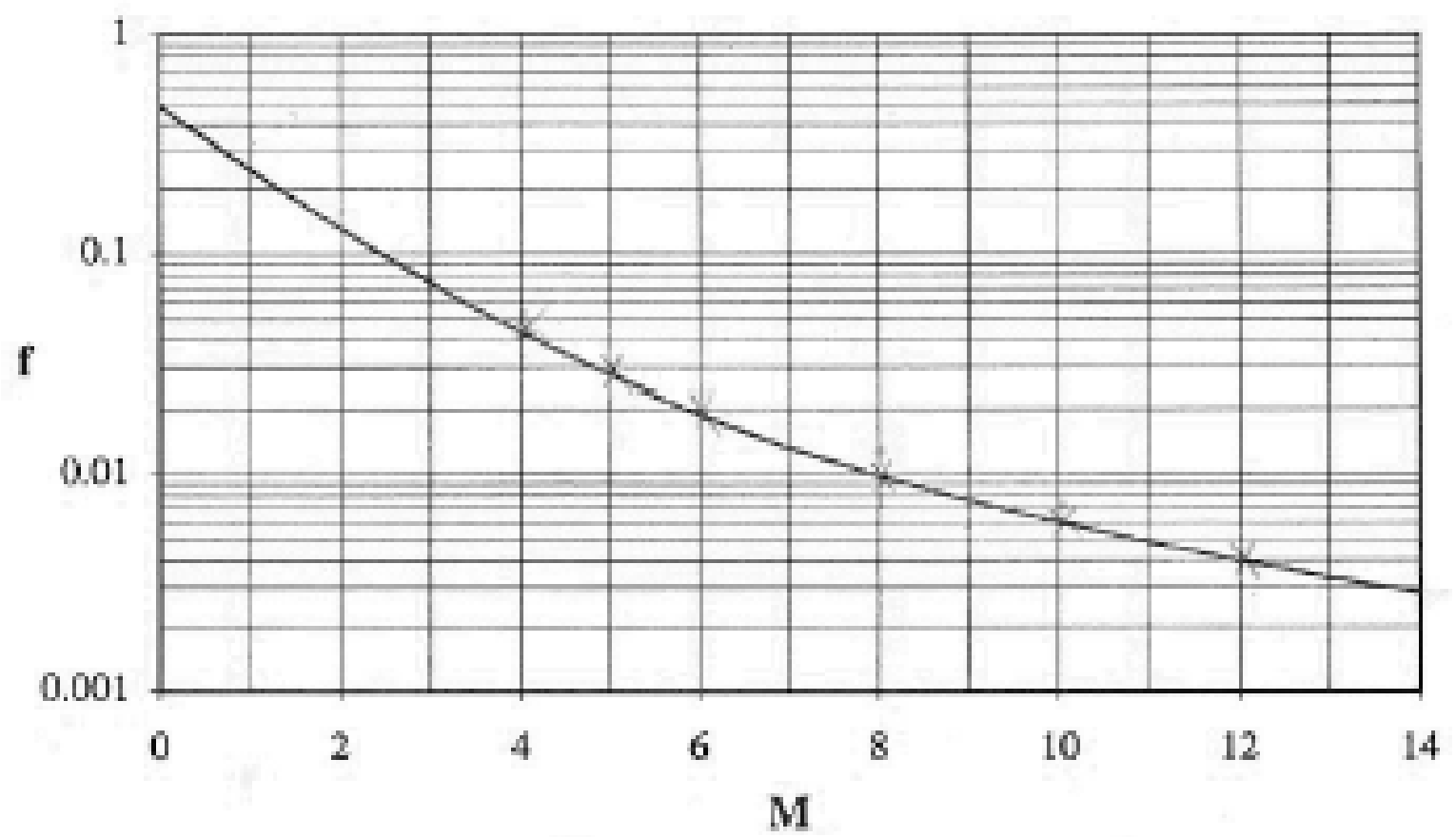

Figura 20. Fator de atrito em função ao parâmetro de entropia. Fonte: CHIU et al. (1993).

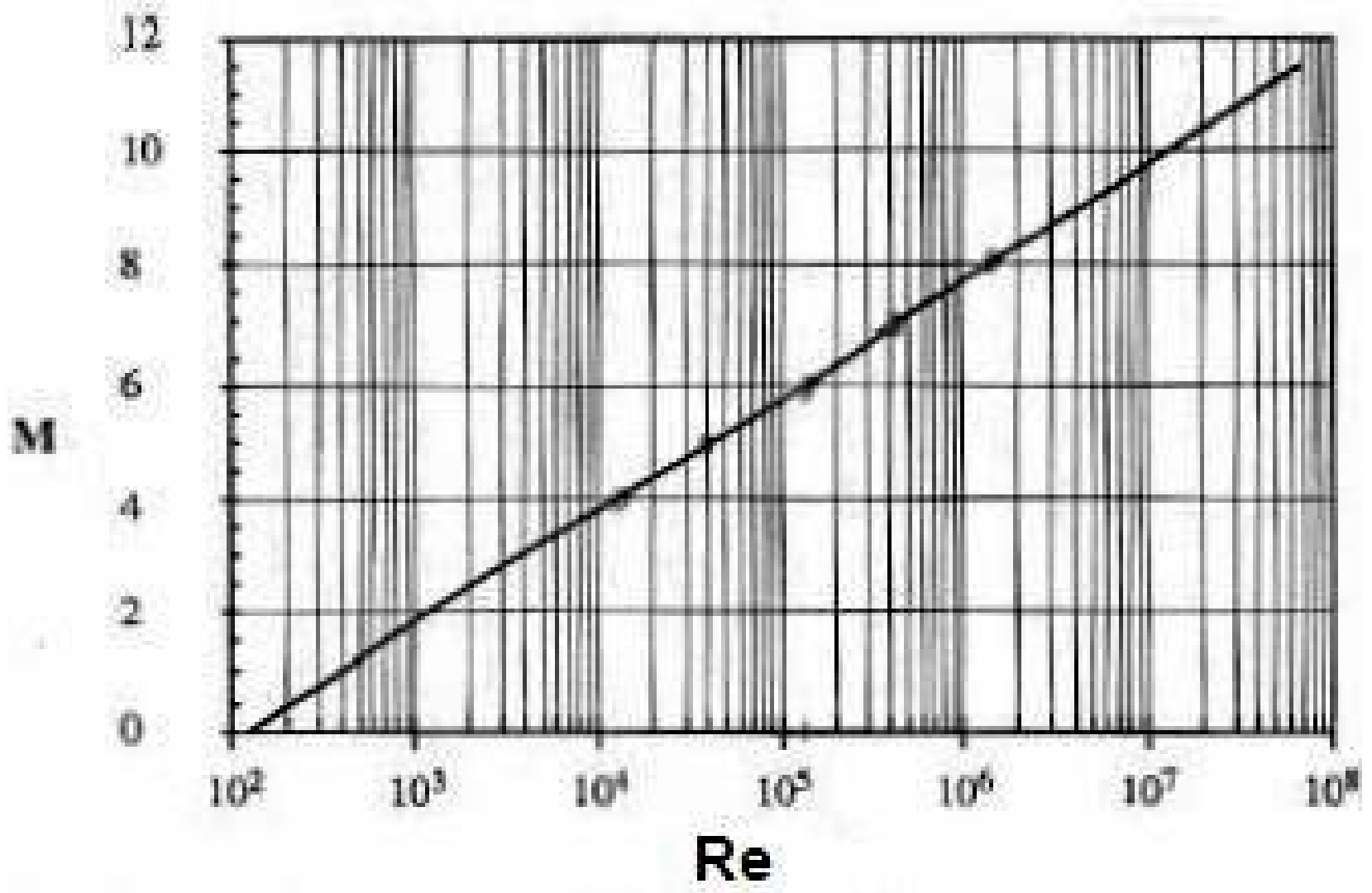

Figura 21. Número de Reynolds em função ao parâmetro de entropia. Fonte: CHIU et al. (1993). 


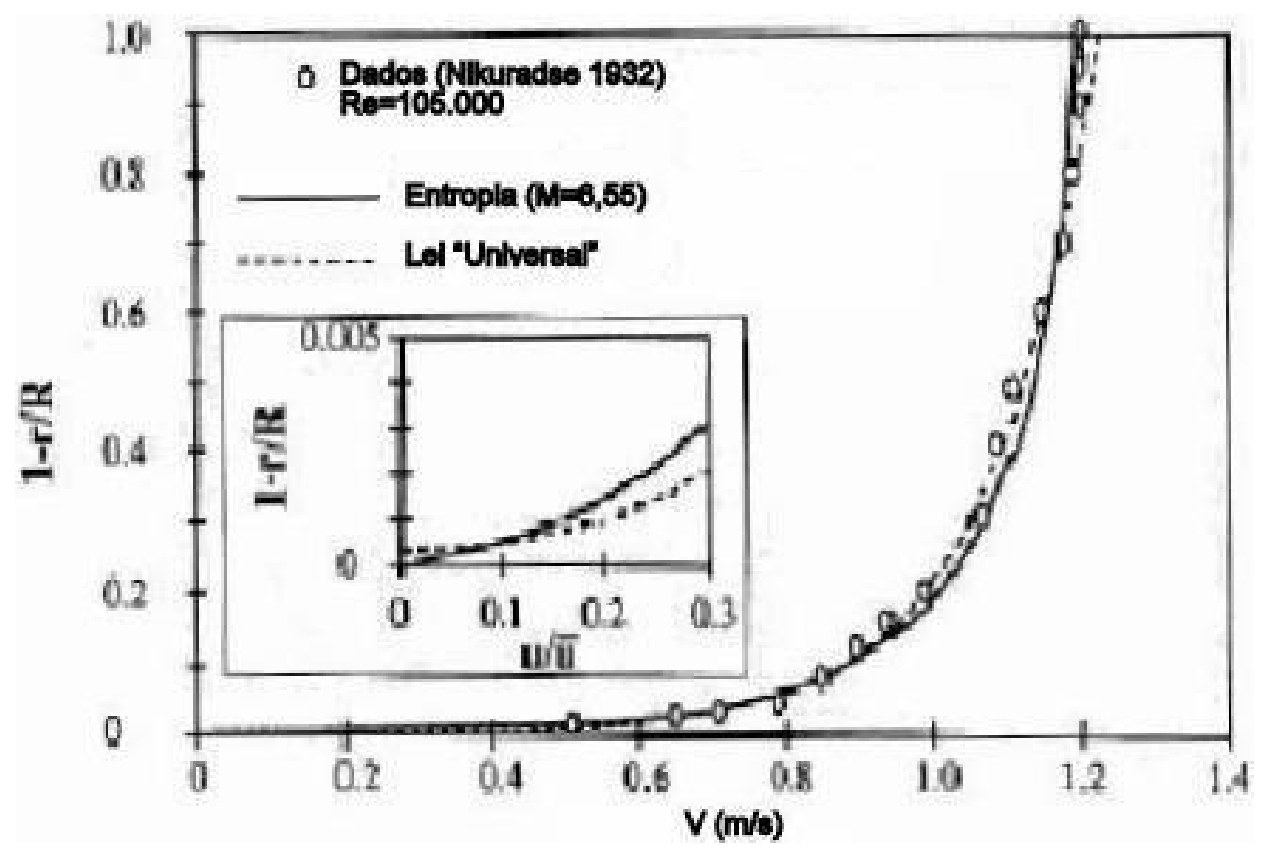

Figura 22. Comparação entre os modelos de perfil de velocidades de entropia máxima e de Nikuradse (1932). Fonte CHIU et al. (1993).

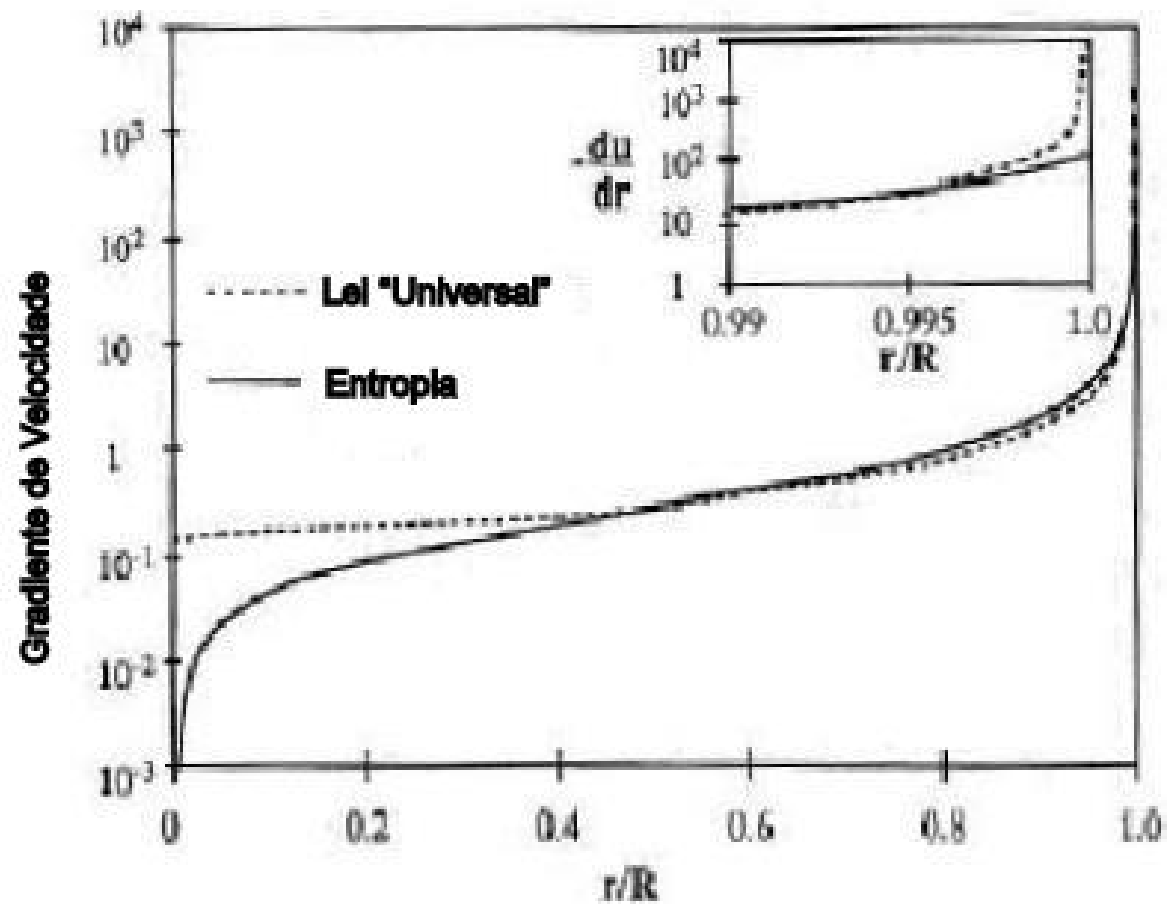

Figura 23. Comparação entre gradientes dos modelos de perfil de velocidades de entropia máxima e Fórmula Universal. Fonte: CHIU et al. (1993). 
A equação (27) apresenta o relacionamento entre fator de atrito, o número de Reynolds aparente do escoamento e o parâmetro de entropia. A partir deste equacionamento, CHIU et al. (1993) utilizou-se de medições experimentais de autores por ele citados para determinar a relação entre o parâmetro de entropia $(M)$ e o número de Reynolds ( $\mathrm{Re}$ ), para escoamento turbulento hidraulicamente liso $\left(\operatorname{Re}_{a}=\operatorname{Re}\right)$.

O modelo apresentado por CHIU et al. (1993) satisfaz as premissas que se esperaram de um escoamento: Junto às paredes a velocidade é zero, no centro do tubo apresenta o gradiente nulo de velocidade, o equacionamento pode ser utilizado para qualquer condição de escoamento.

CHIU et al. (1995) propuseram a utilização do modelo baseado na entropia máxima para obtenção das velocidades média e máxima do escoamento. Esses concluíram que o parâmetro $(M)$ atribuído a uma seção é um valor que reflete as condições de descarga de um determinado canal estável ou conduto forçado. Ainda segundo CHIU et al. (1995), o parâmetro de entropia faz-se tão importante para a determinação das condições de escoamento em uma determinada seção quanto às velocidades máxima e média do mesmo.

BARBÉ et al. (1991) sugeriram uma modificação no desenvolvimento elaborado por CHIU (1987). Estes sugeriram não mais desprezar uma terceira condição de contorno, a qual é representada pelo multiplicador de Lagrange $\left(L_{3}\right)$.

No desenvolvimento da formulação do perfil de velocidade de CHIU (1987), na equação (20), foram apresentados dois multiplicadores de Lagrange $\left(L_{1}\right)$ e $\left(L_{2}\right)$, um dos quais é convertido em passo posterior no parâmetro de entropia $(M)$. Os 
termos $\left(L_{3}\right)$ e $\left(L_{4}\right)$ representam respectivamente o coeficiente de Boussinesq e o coeficiente de Coriolis, os quais são considerados não significativos.

$$
\int e^{\left(L_{1}+L_{2} u+L_{3} u^{2}+L_{4} u^{3}\right)} d u=\frac{y_{h}}{h}+C
$$

Onde:

$C=$ Constante de integração;

$e=$ Base neperiana;

$h=$ Altura do escoamento em um canal;

$L_{1} \quad=$ Multiplicador de Lagrange;

$L_{2}=$ Multiplicador de Lagrange;

$L_{3}=$ Multiplicador de Lagrange;

$L_{4}=$ Multiplicador de Lagrange;

$u=$ Velocidade pontual;

$y_{h}=$ Profundidade do canal;

BARBÉ et al. (1991) propuseram um método para utilização do $\left(L_{3}\right)$. Segundo o mesmo, o desenvolvimento baseou-se em uma série de MacLaurin, obtida a partir da expansão daquele valor. Foi obtida a equação (29) para o perfil de velocidades. A resolução dos multiplicadores de Lagrange é indicada por BARBÉ et al. (1991) através de um intrincado sistema de equações.

$$
e^{\left(L_{1}-1\right)}\left\{e^{\left(L_{2} u\right)}+L_{3}\left[e^{\left(L_{2} u\right)}\left(u^{2}-\frac{2 u}{L_{2}}+\frac{2}{L_{2}^{2}}\right)\right]\right\}=\left[\frac{y_{h}}{h}+e^{\left(L_{1}-1\right)}\left(\frac{1}{L_{1}}+\frac{2 L_{3}}{L_{2}^{3}}\right)\right] L_{2}
$$

Onde: 


$$
\begin{aligned}
& e=\text { Base neperiana; } \\
& h \quad=\text { Altura do escoamento em um canal; } \\
& L_{1}=\text { Multiplicador de Lagrange; } \\
& L_{2}=\text { Multiplicador de Lagrange; } \\
& L_{3}=\text { Multiplicador de Lagrange; } \\
& L_{4}=\text { Multiplicador de Lagrange; } \\
& u=\text { Velocidade do escoamento; } \\
& y_{h}=\text { Profundidade; }
\end{aligned}
$$

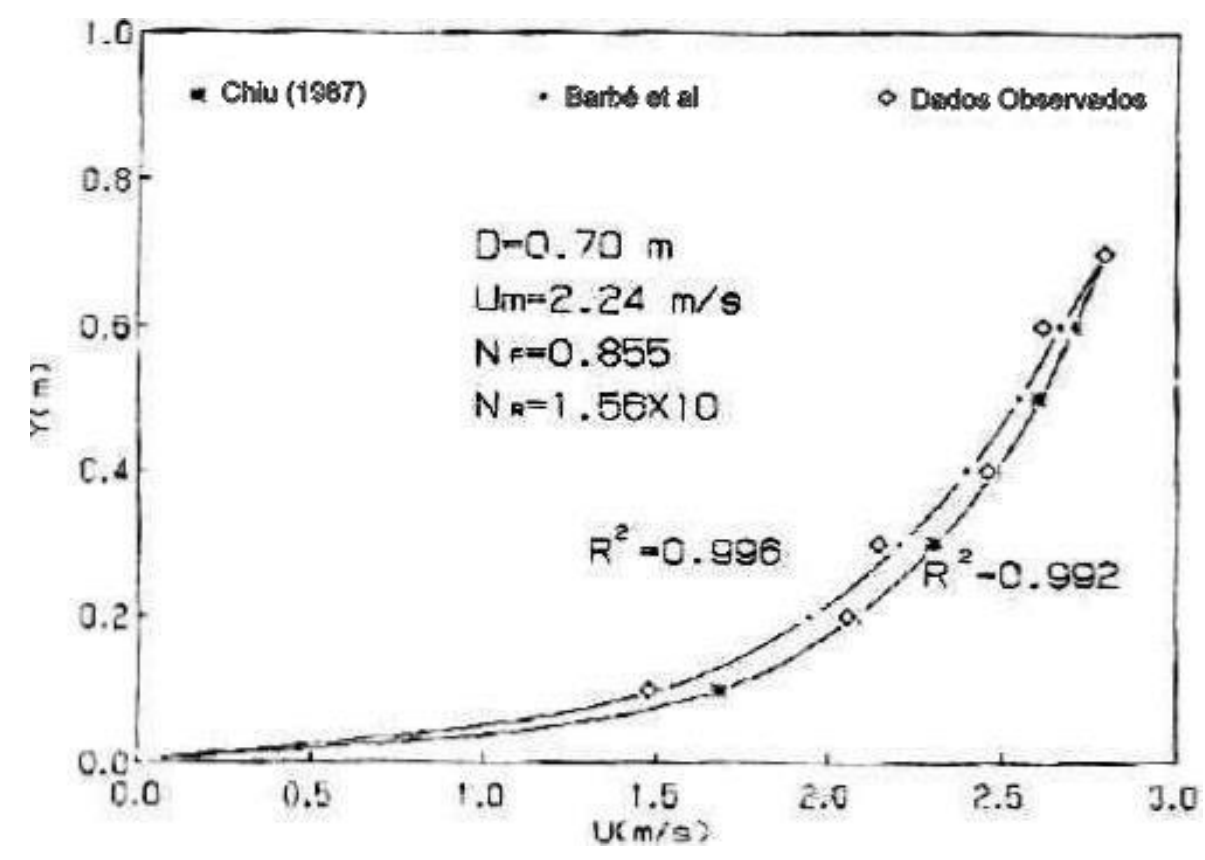

Figura 24. Comparação entre modelos baseados no princípio da entropia máxima. Fonte BARBÉ et al. (1991).

Segundo BARBÉ et al. (1991) foram obtidos resultados muito superiores quando comparado ao equacionamento logarítmico do perfil de velocidades. Porém os resultados não foram significativamente superiores ao modelo apresentado por CHIU (1987), apesar de sua complexidade de uso. A figura (24) apresenta a comparação entre os modelos baseados no princípio da entropia máxima 
apresentados por CHIU (1987), BARBÉ et al. (1991) e dados obtidos experimentalmente.

SOUZA et al. (1991) desenvolveram quatro algoritmos de cálculo para utilização em tarefas computacionais. Foram feitas deduções, de modo a tornar explícita a fórmula do fator de atrito $(f)$, tanto para regimes laminar quanto turbulento misto.

Tabela 1. Tabela com as quatro formulações explicitas de cálculo. Fonte: SOUZA et al. (1991).

\begin{tabular}{|c|c|c|c|c|}
\hline $\begin{array}{c}\text { Tip } \\
\text { o }\end{array}$ & Adimensionais & Laminar & \multicolumn{2}{|r|}{ Turbulento Misto } \\
\hline$F_{1}$ & $f=F_{1}\left(R e, \frac{k}{D}\right)$ & $f=\frac{64}{R e}$ & $\frac{1}{\sqrt{f}}=-$ & $2 \log \left(\frac{k}{3,71 D}+\frac{5,62}{R e^{0,9}}\right)$ \\
\hline$F_{2}$ & $f=F_{2}\left(\operatorname{Re} \sqrt{f}, \frac{k}{D}\right)$ & $f=\left(\frac{64}{R e \sqrt{f}}\right)^{2}$ & $\frac{1}{\sqrt{f}}=-$ & $-2 \log \left(\frac{k}{3,71 D}+\frac{2,51}{\operatorname{Re} \sqrt{f}}\right)$ \\
\hline$F_{3}$ & $f=F_{3}\left(\operatorname{Re} f^{1 / 5}, \frac{4 Q}{k \pi v}\right.$ & $f=\frac{181}{\left(\frac{4 Q}{k \pi v}\right)^{5 / 4}}$ & $\frac{1}{\sqrt{f}}=-2 \log$ & $\frac{0,38\left(\frac{4 Q}{k \pi v}\right)^{1,042}}{\operatorname{Re} f^{1 / 5}}+\frac{4,15}{\left(\frac{4 Q}{k \pi v}\right)^{0,937}}$ \\
\hline$F_{4}$ & $f=F_{3}\left(\left(\frac{R e}{f}\right)^{1 / 2}, \frac{V k}{v}\right)$ & $f=\frac{8}{\left(\frac{R e}{f}\right)^{1 / 2}}$ & $\frac{1}{\sqrt{f}}=-2 \log$ & $\frac{1,03\left(\frac{V k}{v}\right)}{\left(\left(\frac{R e}{f}\right)^{1 / 2}\right)^{5 / 3}}+\frac{18,83}{\left(\left(\frac{R e}{f}\right)^{1 / 2}\right)^{3 / 2}}$ \\
\hline
\end{tabular}




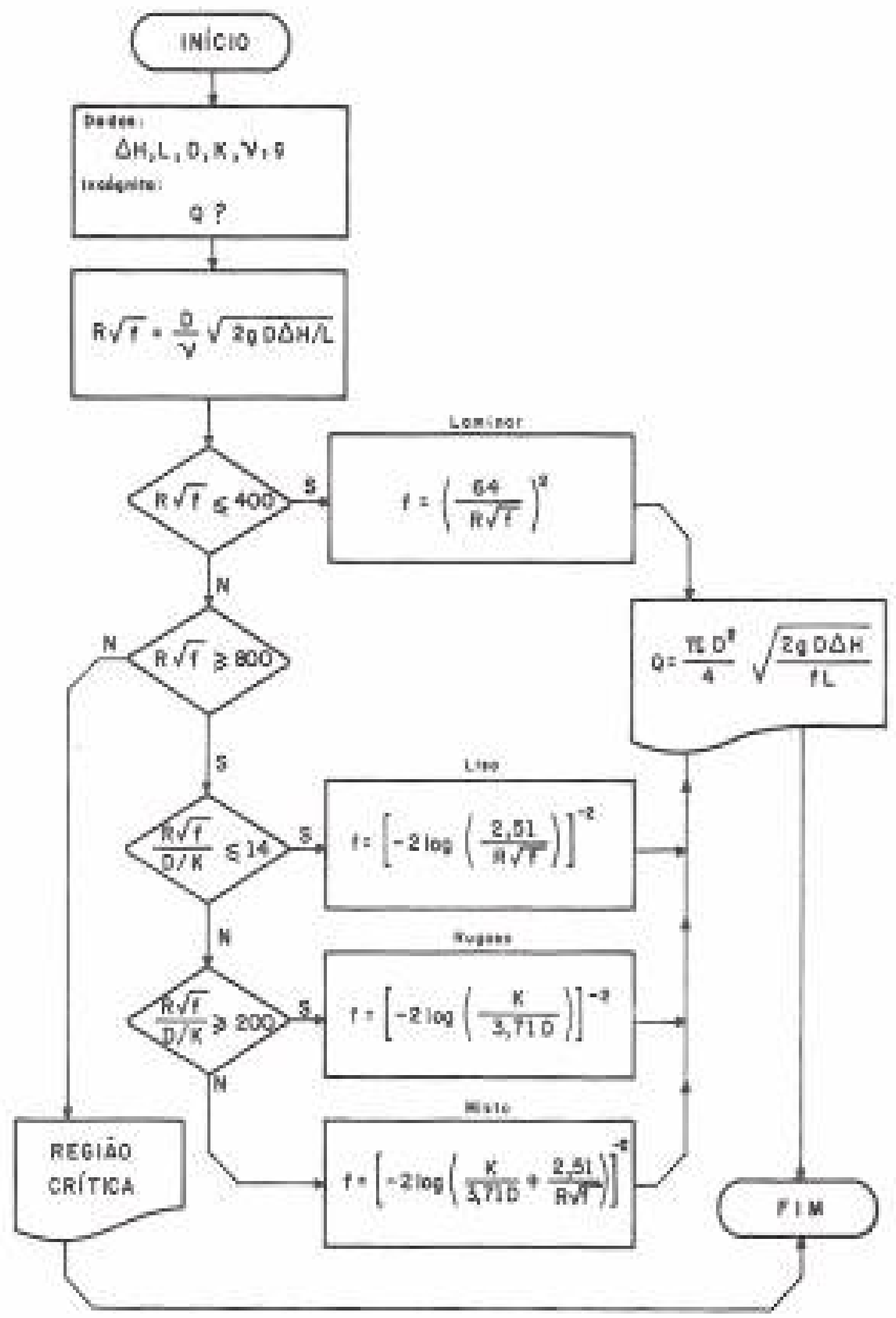

Figura 25. Diagrama de solução de problema da vazão (Q). Fonte: Souza et al. (1991) 


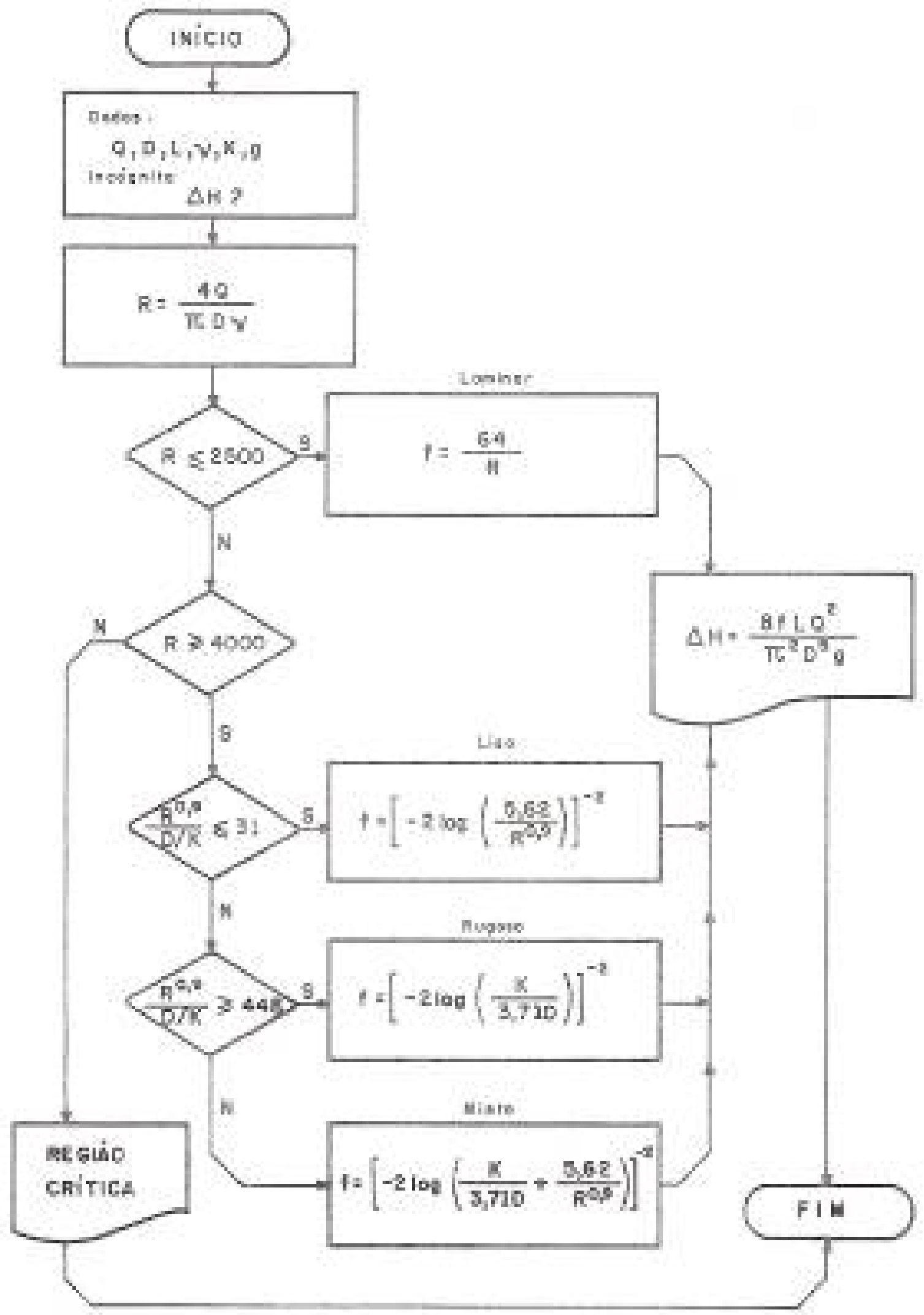

Figura 26. Diagrama de solução de problema perda de carga ( $\Delta H$ ). Fonte: Souza et al. (1991) 


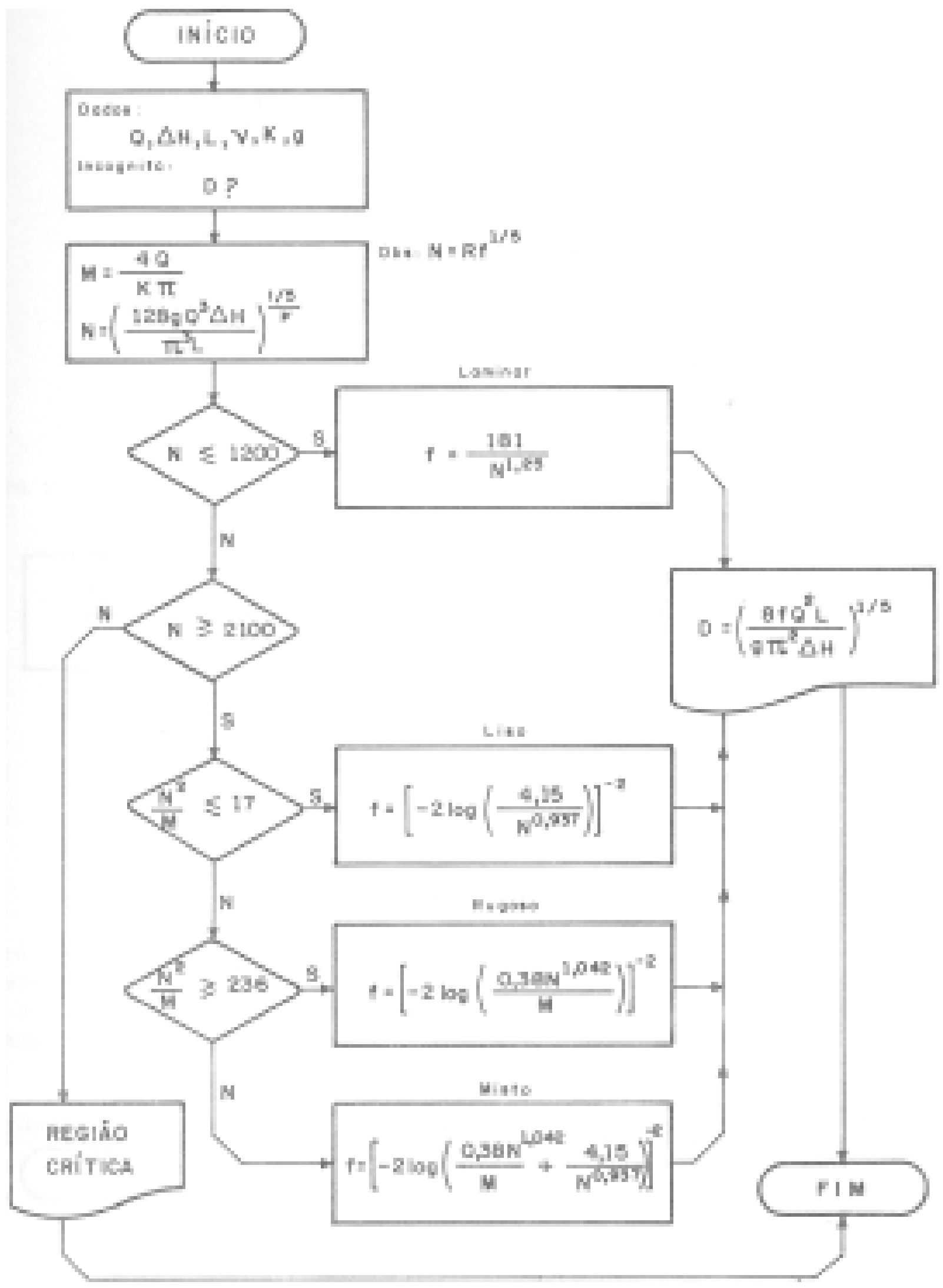

Figura 27. Diagrama de solução de problema do diâmetro ( $D$ ). Fonte: Souza et al. (1991). 


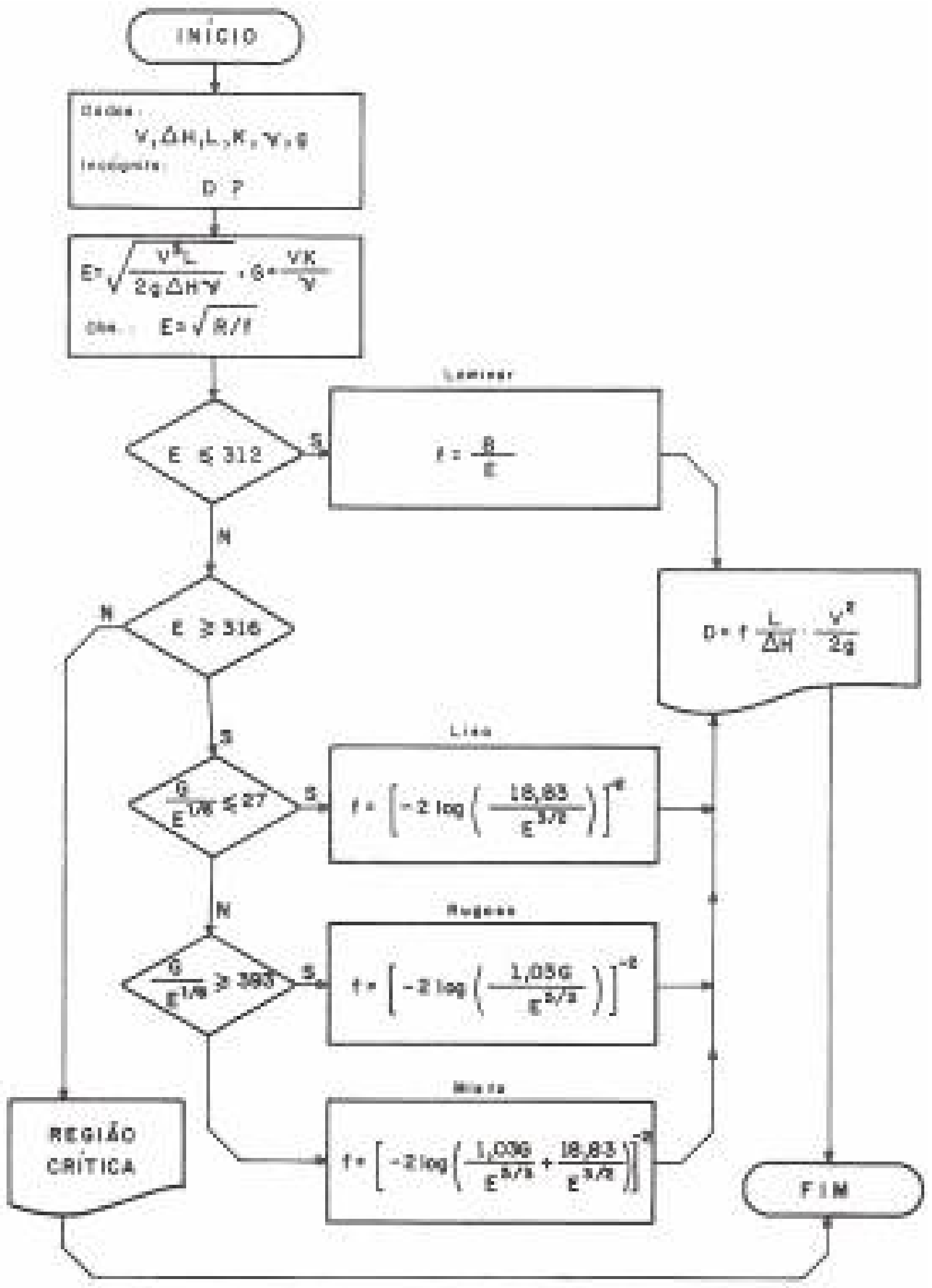

Figura 28. Diagrama de solução de problema do diâmetro ( $D$ ). Fonte: Souza et al. (1991). 
As quatro formulações contidas na tabela (1), apresentadas por SOUZA et al. (1991), foram desenvolvidas visando à determinação de uma incógnita específica para cada equacionamento. O primeiro equacionamento visa a determinação da vazão, o segundo visa a determinação da perda de carga, o terceiro e o quarto a determinação do diâmetro da tubulação. Entre a terceira e a quarta formulações varia o dado de entrada, sendo na terceira a vazão e na quarta a velocidade.

A partir das formulações apresentas na tabela (1) SOUZA et al. (1991) elaboraram os algoritmos de cálculo apresentados nas figuras (25), (26), (27) e (28). Nestes algoritmos SOUZA et al. (1991) advertem quanto ao problema referente ao cálculo de valores na transição entre os regimes laminar e turbulento.

ARAÚJO e CHAUDHRY (1998) compararam dois modelos para perfil de distribuição de velocidades bidimensional. Um modelo logarítmico foi comparado com o modelo da entropia máxima e dados obtidos através de ensaios. Tal comparação objetivou encontrar o método de maior precisão para determinação do perfil de velocidades.

O primeiro modelo, CHIU e CHIOU (1986) apud ARAÚJO e CHAUDHRY (1998) utilizou a equação logarítmica similar à de Von Kármán, porém propondo um método de cálculo. O segundo modelo foi proposto por CHIU (1988), através da equação (27).

Os resultados obtidos por ARAÚJO e CHAUDHRY (1998) foram comparados através de gráficos contidos nas figuras (29) e (30). Nestes é possível notar que existe maior convergência aos dados de ensaio quando utilizado o modelo baseadose na entropia máxima. É válido ressaltar que os dados obtidos por experimentos necessariamente apresentam uma margem de erro, mesmo quando obtidos com os 
mais sofisticados equipamentos existentes. Portanto, é possível que os erros apresentados nas figuras (29) e (30) sejam, em grande parte, atribuídos ao erro intrínseco dos ensaios laboratoriais. Os erros instrumentais são maiores quando as grandezas medidas são menores em termos relativos.

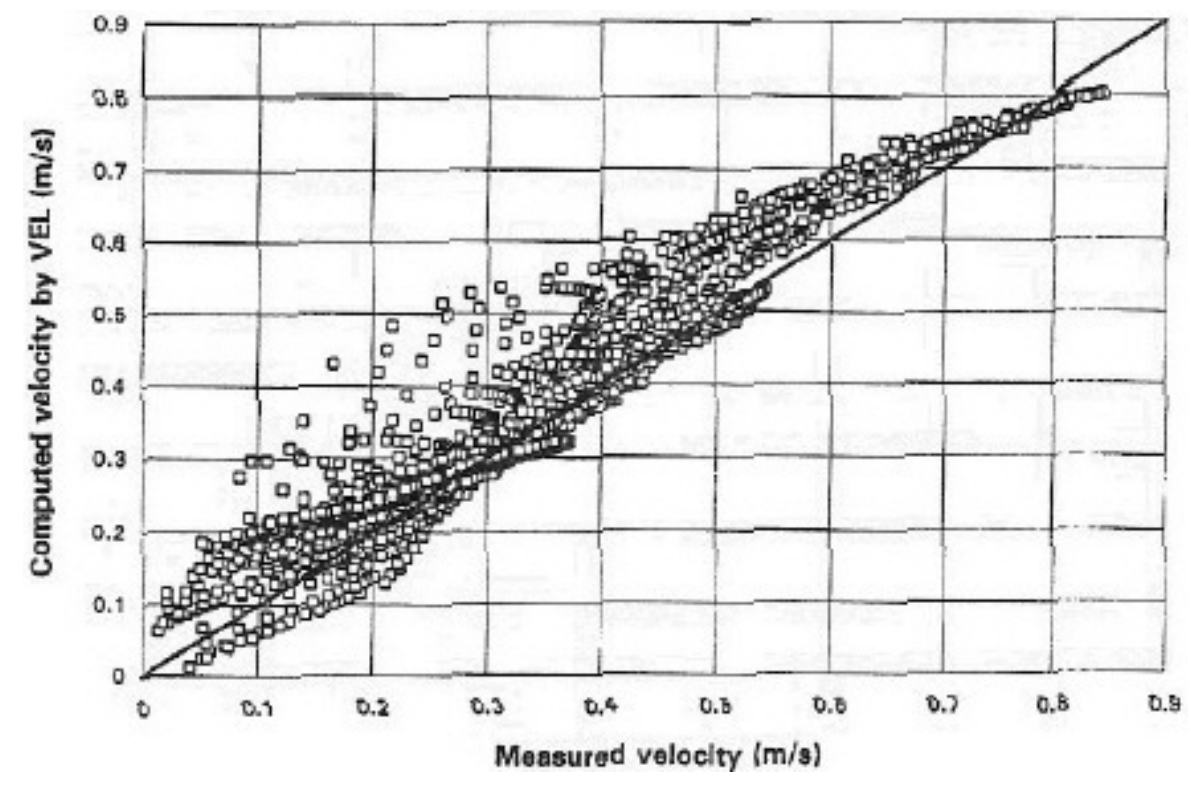

Figura 29. Comparação entre valores medidos e calculados com base na formulação logaritma. Fonte ARAÚJO e CHAUDHRY (1998).

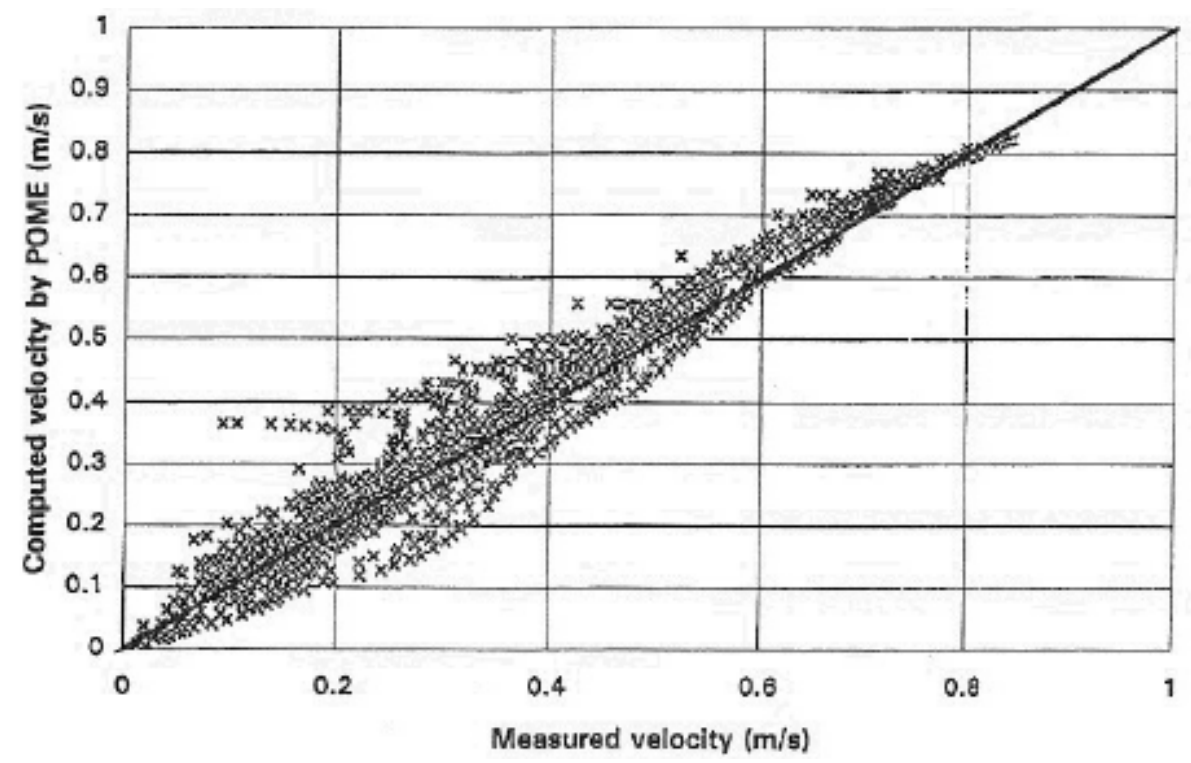

Figura 30. Comparação entre valores medidos e calculados com base na formulação baseada na entropia máxima. Fonte ARAÚJO e CHAUDHRY (1998). 
ARAÚJO e CHAUDHRY (1998) concluíram que o modelo baseado na entropia máxima apresentou melhores resultados quando comparado ao perfil logarítmico de velocidades. Segundo estes autores, o estudo realizado atestou a validade do princípio da entropia máxima aplicado à Hidráulica.

LI et al. (1999) buscaram desenvolver um critério simplificado para modelagem matemática do perfil de velocidades dentro de uma tubulação qualquer. Para tanto, tais autores utilizaram uma sistemática de cálculo variacional, criando um funcional incorporando tanto a potência dissipada por unidade de volume, quanto a potência total dissipada por unidade de volume.

Um funcional, segundo ELSGOLTZ (1977), é uma relação matemática, análoga a uma função, que operando a partir de uma função de entrada produz um valor real. A aplicação do princípio do cálculo variacional visa encontrar os valores de máximo e mínimo dos funcionais, encontrando assim a função que descreve, no caso, o perfil de velocidades do escoamento.

O funcional criado por LI et al. (1999) resumiu-se a uma soma de dois termos. O primeiro referente à fase laminar do escoamento. Já o segundo resume-se à parte turbulenta do escoamento.

LI et al. (1999) criaram a função adotando o raio da tubulação $(R)$ como constante, e parâmetros a serem determinados. Estes parâmetros são encontrados utilizando-se o princípio do cálculo variacional. Encontrando os valores limites para os mesmos, além de fatores de correção, resultando na equação (30).

$$
u=a_{1}\left[1-\left(\frac{r}{R}\right)^{n_{1}}\right]+a_{2}\left[1-\frac{r}{R}\right]^{\frac{1}{n_{2}}}
$$


Onde:

$$
\begin{aligned}
& a_{1}=\text { Parâmetro relativo ao escoamento laminar; } \\
& a_{2} \quad=\text { Parâmetro relativo ao escoamento turbulento; } \\
& n_{1} \quad=\text { Parâmetro dependente da condição de escoamento laminar; } \\
& n_{2}=\text { Parâmetro dependente da condição de escoamento turbulento; } \\
& r \quad=\text { Distância do centro do tubo; } \\
& R \quad=\text { Raio do tubo; } \\
& u \quad=\text { Velocidade pontual. }
\end{aligned}
$$

Tais constantes dependem das condições de escoamento para cada tipo de escoamento. Para determinação destes parâmetros, LI et al. (1999) integraram a fórmula da dissipação viscosa local unitária (31) no raio da tubulação para determinar a variação total da mesma.

$$
W_{\mu}(r)=\mu\left[\frac{d u}{d r}\right]^{2}
$$

Onde:

$$
\begin{aligned}
& r=\text { Distância perpendicular ao tubo ao pondo do escoamento } \\
& \quad \text { considerado; } \\
& u \quad=\quad \text { Velocidade local no pondo considerado do raio da tubulação; } \\
& W_{\mu}=\text { Função dissipação viscosa local; } \\
& \mu \quad=\quad \text { Viscosidade dinâmica do fluido. }
\end{aligned}
$$


A partir desta integração e da integração da velocidade no raio da seção da tubulação foram encontrados os parâmetros da equação (30). Segundo LI et al. (1999) os resultados deste equacionamento foram satisfatórios.

LI et al. (1999) concluíram que o perfil de velocidades do escoamento pode ser resumido através de um único equacionamento. Este equacionamento é composto por um termo laminar e outro turbulento.

A obtenção de um método mais eficiente para a determinação da vazão de um rio, através de apenas poucos pontos de medição, foi o objetivo de MINEI (1999). Como ferramenta para tal desenvolvimento foi utilizado o conceito de entropia máxima.

Com base na formulação desenvolvida por CHIU (1987), MINEI (1999) propôs um modelo de medição vazão em rios. Neste modelo a medição de velocidade é feita em apenas três pontos em uma mesma vertical.

Através de um método interativo descrito MINEI (1999), é possível obter o perfil de velocidades verticais da seção escolhida do rio. Reduzindo-se expressivamente a quantidade de pontos necessários para a medição da vazão no perfil de velocidades.

Com o objetivo de elaborar um método para a determinação de transições de seções otimizadas, onde ocorresse a mínima perda de carga, CARVALHO (2001), utilizou como ferramenta o conceito da entropia máxima. Tendo como ponto de partida o equacionamento do perfil de velocidades, equação (27) descrita por CHIU, esta autora elaborou um algoritmo para dimensionamento otimizado de tomadas d'água. 
CARVALHO (2001) estudou a otimização nas tomadas d'água de hidroelétricas. Foram utilizados dados experimentais de modelos físicos reduzidos de 5 barragens diferentes realizados no Centro Tecnológico de Hidráulica (Convênio entre o Departamento de Águas e Energia Elétrica e a Universidade de São Paulo).

CARVALHO (2001) propôs um algoritmo em forma de fluxograma e em linguagem de programação Turbo Pascal. Os dados de entradas são apenas os parâmetros básicos do escoamento para aquele tipo de tubulação forçada: comprimento, vazão, número de seções, área máxima e área mínima. Os parâmetros de precisão podem ser adotados: distância entre seções e número de repetições.

WALSKI et al. (2001) têm seu foco na modelação computacional de redes de distribuição de água. Este recomenda a utilização do equacionamento desenvolvido por SWAMEE e JAIN (1976) para determinação do fator de atrito $(f)$ apesar de atestar como mais preciso o equacionamento de Colebrook. Segundo os mesmos autores, esta formulação tem sua faixa de precisão no intervalo entre $10^{-6} \leq \varepsilon / D \leq 10^{-2}$, quando $4 \times 10^{3} \leq R e \leq 10^{8}$.

Foram realizados experimentos, utilizando-se de sistemas de precisão de medição, pelas universidades de Princeton e Oregon, os quais são relatados por McKEON et al. (2004). Tais experimentos utilizaram-se de diferentes técnicas gerando resultados com grande precisão, os quais podem ser avaliados através de sua sobreposição, na figura (31). 


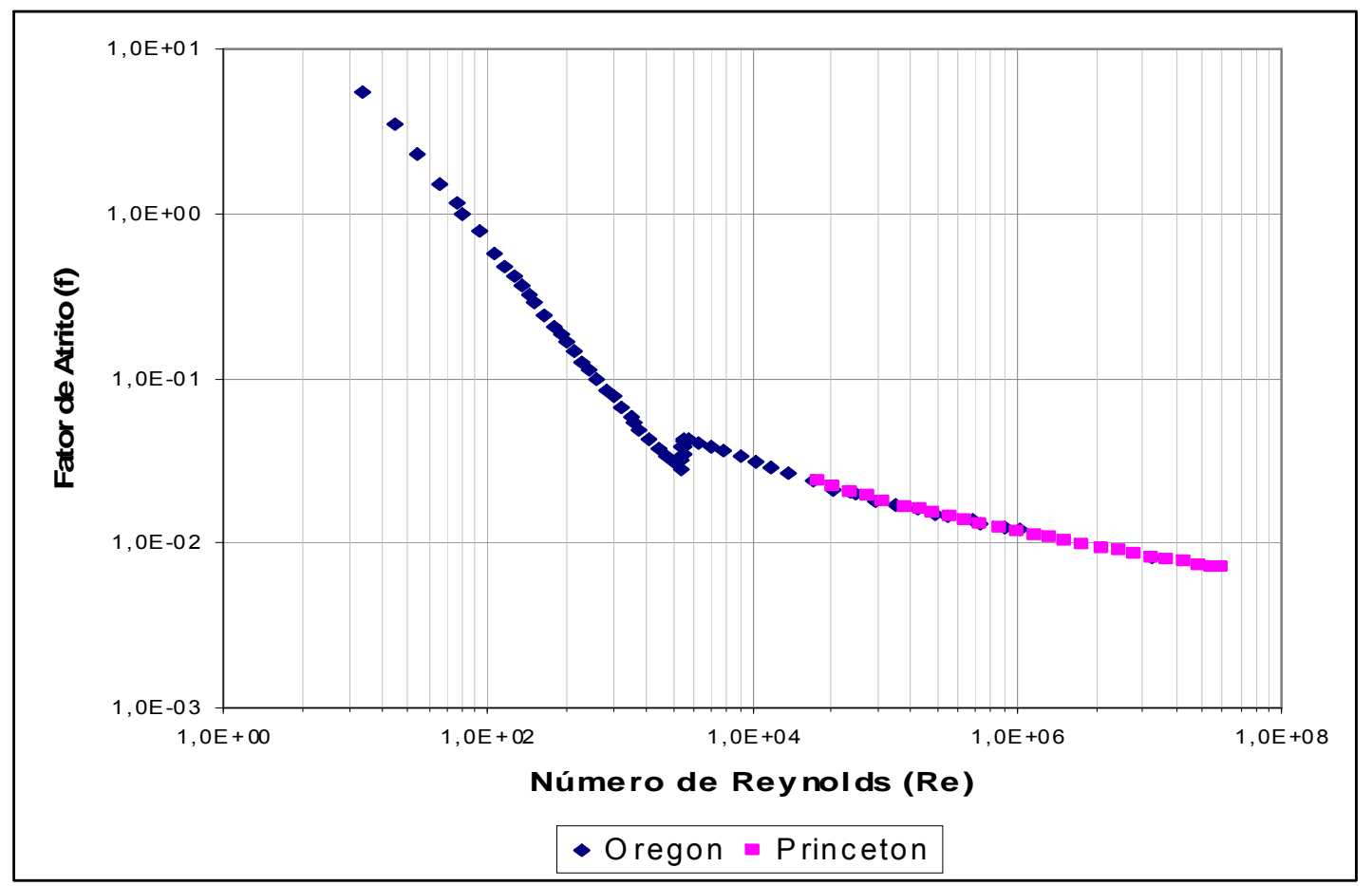

Figura 31. Gráfico do fator de atrito $(f)$ em função do número de Reynolds $(\operatorname{Re})$, comparando os dados obtidos pelas Universidades de Oregon e Princeton.

Os dados obtidos pela Universidade de Oregon, segundo SWANSON et al. (2002) apud McKEON et al. (2004), foram obtidos a partir de ensaio realizado em uma bancada de pequena dimensão, com peso de aproximadamente 0,0283 kgf (1 onça). Nos ensaios, para pequenos números de Reynolds, foram utilizados como fluidos diversos gases à temperatura ambiente: hélio, oxigênio, nitrogênio, dióxido de carbono, sulfuro hexafloureto de enxofre. Para números de Reynolds maiores, utilizou-se hélio líquido.

Os ensaios realizados na Universidade de Princeton, segundo McKEON et al. (2004), utilizaram-se de um "super tubo" de grande diâmetro e com peso de aproximadamente 25.000 kgf. Para a realização do ensaio foi utilizado ar comprimido como fluido. 
Das dimensões de ambas bancadas de ensaio McKEON et al. (2004) apresentou apenas os dados reativos à suas massas. Tal informação não tem significado prático para estudos hidráulicos. A validade dos dados de ensaios informadas por esse autor se dá por terem sidos ensaios criteriosos e com a utilização de instrumentação de tecnologia contemporânea. A coincidência dos dados de ambas universidades, contidos na figura (31) demonstra tal qualidade.

Segundo estes autores, apesar da grande diferença de escala entre os estudos supracitados, os resultados foram muito semelhantes, dando grande credibilidade aos mesmos. Com isto, através de ajuste numérico no intervalo de dados do número de Reynolds acima de 3.000, McKEON et al. (2004) propuseram a formulação (32) para o fator de atrito, em função do número de Reynolds.

$$
\frac{1}{\sqrt{f}}=1,930 \log (\operatorname{Re} \sqrt{f})-0,537
$$

Onde:

$$
\begin{aligned}
& f=\text { Fator de atrito; } \\
& R e=\text { Número de Reynolds } .
\end{aligned}
$$

A análise da equação (32), obtida por McKEON et al. (2004), indicou um índice de correlação de aproximadamente 0,999. Os dados obtidos nesses ensaios serão, nesta tese, considerados como paradigma para os estudos nos próximos capítulos.

Baseando-se em dados obtidos em ensaios no super tubo da Universidade de Princeton, MCKEON et al. (2005) estudaram a precisão da fórmula do fator de atrito de Prandtl para altos números de Reynolds para regime turbulento hidraulicamente 
liso. Segundo McKEON et al. (2005), para grandes números de Reynolds a constante de Von Kármán sofre distorção.

McKEON et al. (2005) realizaram uma série de análises estatísticas comparativas entre modelo e protótipo. A partir destas análises concluíram que a fórmula de Prandtl apresenta erro aproximado de 1,7\% quando o número de Reynolds ultrapassa $10^{6}$. Este eleva-se à medida que o número de Reynolds aumenta, chegando a um erro de $3,2 \%$ a um número de Reynolds superior a $10^{8}$.

Tal estudo mostrou-se válido do ponto de vista da atualização de uma formulação empírica já consagrada. Apesar da grande precisão apresentada pelos dados obtidos, MCKEON et al. (2005) poderiam ter desenvolvido tais estudos baseando-se em modelos teóricos, os quais, quando bem elaborados, representam melhor os fenômenos físicos, em relação aos modelos empíricos.

PORTO (2004) apresentou conceitos básicos de hidráulica, contendo além das bases teóricas, formulações de cunho prático. Dentre estas formulações destacam-se a lei de potência $1 / 7$ apresentado por Prandtl e equacionamento logarítmico do fator de atrito de Colebrook e SWAMEE e JAIN (1976).

Dentre os diversos equacionamentos apresentados para determinação do fator de atrito, PORTO (2004) recomendou o uso das formulações apresentadas por SWAMEE e JAIN (1976). Segundo o mesmo, apesar desta formulação apresentar um erro em relação à de Colebrook, principalmente nos valores mais baixos do número de Reynolds, é recomendável seu uso. Na comparação entre as duas formulações SWAMEE e JAIN (1976) apresenta um erro inferior a $2 \%$, o que segundo PORTO (2004) é irrelevante. 
Segundo PORTO (2004) "as rugosidades absolutas equivalentes dos diversos materiais utilizados na prática de condução de água são de difícil especificação, devido aos processos industriais e grau de acabamento da superfície, idade das tubulações, etc. A literatura apresenta tabelas de valores da rugosidade para diversos materiais com variações em faixas largas, além de diferente, para o mesmo material, em diferentes fontes de dados". Tal afirmação implica que a determinação da rugosidade de cálculo para tubos comerciais é imprecisa.

PORTO (2004) apresenta, em forma de tabelas, grande quantidade de dados de fator de atrito $(f)$ em função do número de Reynolds. Tais tabelas estão organizadas em função dos diâmetros por elas apresentadas, informando ainda a vazão, perda de carga e rugosidade relativa.

Utilizando-se o equacionamento da entropia máxima como ferramenta, LIMA (2006) pesquisou a variação do fator de atrito $(f)$ durante um transitório hidráulico. Segundo FOX (1984) apud LIMA (2006) o fator de atrito $(f)$ utilizado para o regime permanente, quando submetido ao regime transitório não pode ser utilizado, pois este altera-se.

LIMA (2006) elaborou a modelação matemática da tensão de cisalhamento para obtenção do fator de atrito $(f)$ em transitório hidráulicos. Segundo o autor a modelação não foi suficientemente satisfatória, apesar da melhora nos resultados teóricos em relação aos modelos existentes, o modelo proposto por LIMA (2006) é de difícil utilização.

LAGELANDSVIK et al. (2007) realizaram ensaios para a determinação do fator de atrito em tubos comerciais. Tais ensaios foram realizados na Universidade de Princeton. 
Tais ensaios utilizaram a mesma bancada descrita por McKEON et al. (2004). Inclusive foram utilizados a mesma instrumentação de medição. Isto posto, os dados fornecidos por LAGELANDSVIK et al. (2007) oferecem a mesma qualidade em relação aos dados fornecidos por McKEON et al. (2004).

$\mathrm{Na}$ figura (32), os dados para escoamento liso foram fornecidos por McKEON et al. (2004). Já os dados para escoamento turbulento misto foram fornecidos por LAGELANDSVIK et al. (2007).

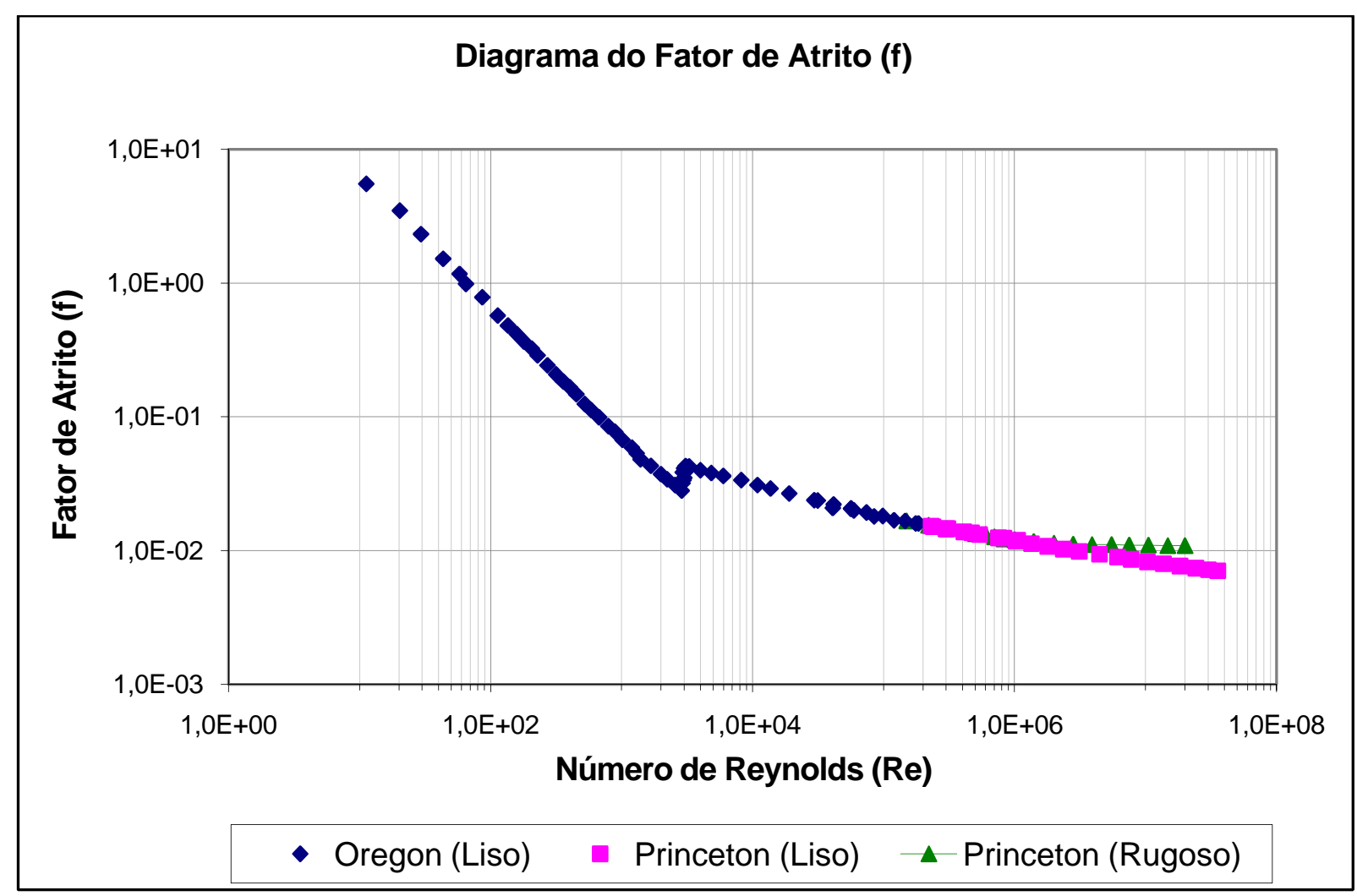

Figura 32. Gráfico do fator de atrito $(f)$ em função do número de Reynolds $(R e)$,

Os dados para escoamento turbulento misto fornecido por LAGELANDSVIK et al. (2007) apresentam sua coerência na figura (32). Para os dados com números de Reynolds mais baixos, a curva de tendência apresenta concordância com o 
alinhamento da curva do escoamento turbulento liso. Nos números de Reynolds maiores, a linha de tendência assume comportamento típico do regime turbulento misto.

A busca por uma equação que descrevesse o escoamento em um tubo de diâmetro desconhecido foi o foco de SWAMEE e SWAMEE (2007). Estes autores avaliaram as equações até então existentes para o fator de atrito, as quais varrem todos os valores do número de Reynolds e consideraram-nas de uso trabalhoso. Segundo os mesmos, buscou-se simplificar as formulações através da adimensionalização do diâmetro, fator de atrito e viscosidade. Com isto foi possível elaborar formulação do diâmetro (D) e da vazão $(\mathrm{Q})$ para ambos os regimes de escoamento, utilizando-se de dedução algébrica e introduzido-se um fator de correção experimental.

São apresentadas as equações (33) e (34) em SWAMEE e SWAMEE (2007). Os autores relataram que a equação (33) fornece resultados com maior precisão que a equação (34).

$$
\begin{gathered}
D=0,66\left[\left(214,75 \frac{v L Q}{g h_{f}}\right)^{6,25}+d^{1,25}\left(\frac{L Q^{2}}{g h_{f}}\right)^{4,75}+v Q^{9,4}\left(\frac{L}{g h_{f}}\right)^{5,2}\right]^{0,04} \\
Q=D^{2} \sqrt{\frac{g D h_{f}}{L}}\left\{\left(\frac{128 v}{\pi D \sqrt{\frac{g D h_{f}}{L}}}\right)^{4}+1,153\left[\left(\frac{415 v}{D \sqrt{\frac{g D h_{f}}{L}}}\right)^{8}-\ln \left(\frac{d}{3,7 D}+\frac{1,775 v}{D \sqrt{\frac{g D h_{f}}{L}}}\right)\right]^{-4}\right\}^{-0,25}
\end{gathered}
$$

Onde:

$D=$ Diâmetro da tubulação; 
$g \quad=$ Aceleração gravitacional;

$h_{f} \quad=$ Perda de carga distribuída;

$L=$ Comprimento do tubo;

$Q \quad=$ Vazão;

$d=$ Rugosidade da parede interna da tubulação;

$v \quad=\quad$ Viscosidade cinemática do fluído.

Analisando-se o artigo SWAMEE e SWAMEE (2007), nota-se que a partir da viscosidade cinemática e da perda de carga é possível a determinação de qualquer condição de escoamento viscoso, seja laminar ou turbulento.

Portanto, é possível fazer um equacionamento único para o fator de atrito em função do número de Reynolds. Este deve considerar o efeito turbulento provocado pela parede do tubo associado a uma viscosidade aparente.

Estudos descritos por KARPELSON (2008) relatam que aquele autor buscou elaborar um algoritmo que pudesse descrever o perfil de velocidades dentro de uma tubulação e procurou desenvolver um equacionamento com base conceitual.

Foram criticadas as equações de Navier-Stokes para tal fim, considerando-as de uso demasiadamente complexo. Porém segundo KARPELSON (2008), as formulações clássicas para determinação do perfil de velocidades, especialmente a proposta por Von Kármán, não o descrevem satisfatoriamente.

A partir da equação de Navier-Stokes (35), KARPELSON (2008) desenvolveu um algoritmo para a determinação do perfil de velocidades, tanto para canais quanto para tubulações. Este considera a turbulência existente no escoamento, adicionando uma componente de flutuação para a componente velocidade. 
Com o rearranjo da equação de Navier-Stokes (35), considerando a flutuação de velocidades e a adoção da hipótese de velocidade igual a zero junto à parede da tubulação. Para a utilização deste algoritmo foram deduzidas as fórmulas (36), (37) e (38), as quais são utilizadas na seqüência informada através da figura (34), onde este algoritmo está apresentado na forma de fluxograma para facilitar sua compreensão.

$$
\begin{gathered}
\frac{\partial u_{i}}{\partial t}+V_{k} \frac{\partial u_{i}}{\partial x}=-\frac{1}{\rho} \frac{\partial P}{\partial x_{i}}+v \frac{\partial^{2} u_{i}}{\partial x^{2}} \\
C=\frac{1}{\rho} \frac{\partial P}{\partial z} \\
C+v \frac{d^{2}\left(u_{z}\right)}{d r^{2}}+v \frac{1}{r} \frac{d\left(u_{z}\right)}{d r}=2 A\left(u_{z}\right) \frac{d\left(u_{z}\right)}{d r}-3 B\left(u_{z}\right)^{2} \frac{d\left(u_{z}\right)}{d r}+\left(B u^{2}-A u\right) \frac{d\left(u_{z}\right)}{d r} \\
\bar{u}=\frac{R_{e} v}{2 R}
\end{gathered}
$$

Onde:

$$
\begin{array}{ll}
P \quad & \text { Pressão; } \\
t \quad & =\text { Tempo; } \\
\bar{u} & =\text { Velocidade média do escoamento; } \\
u_{i} & =\text { Componente velocidade; } \\
u_{k} \quad=\text { Componente velocidade; } & \text { Vetor unitário do plano horizontal; } \\
x_{i} \quad=\quad \text { Distância no planto horizontal a partir de um ponto de referência; } &
\end{array}
$$


$\rho=$ Massa específica do fluido;

$v=$ Viscosidade cinemática do fluido.

KARPELSON (2008) comparou dados obtidos experimentalmente com os resultados obtidos através do uso do algoritmo por ele elaborado. Tal comparação demonstrou grande semelhança entre os dados, conforme demonstrado no gráfico comparativo (33).

Apesar de existirem pequenas diferenças entre os dados experimentais e calculados. É possível considerar os dados calculados como corretos, levando-se em conta que os experimentais carecem, por melhor medidos que sejam, de precisão quando estas medições aproximam-se das faixas de precisão impostas pelos equipamentos utilizados.

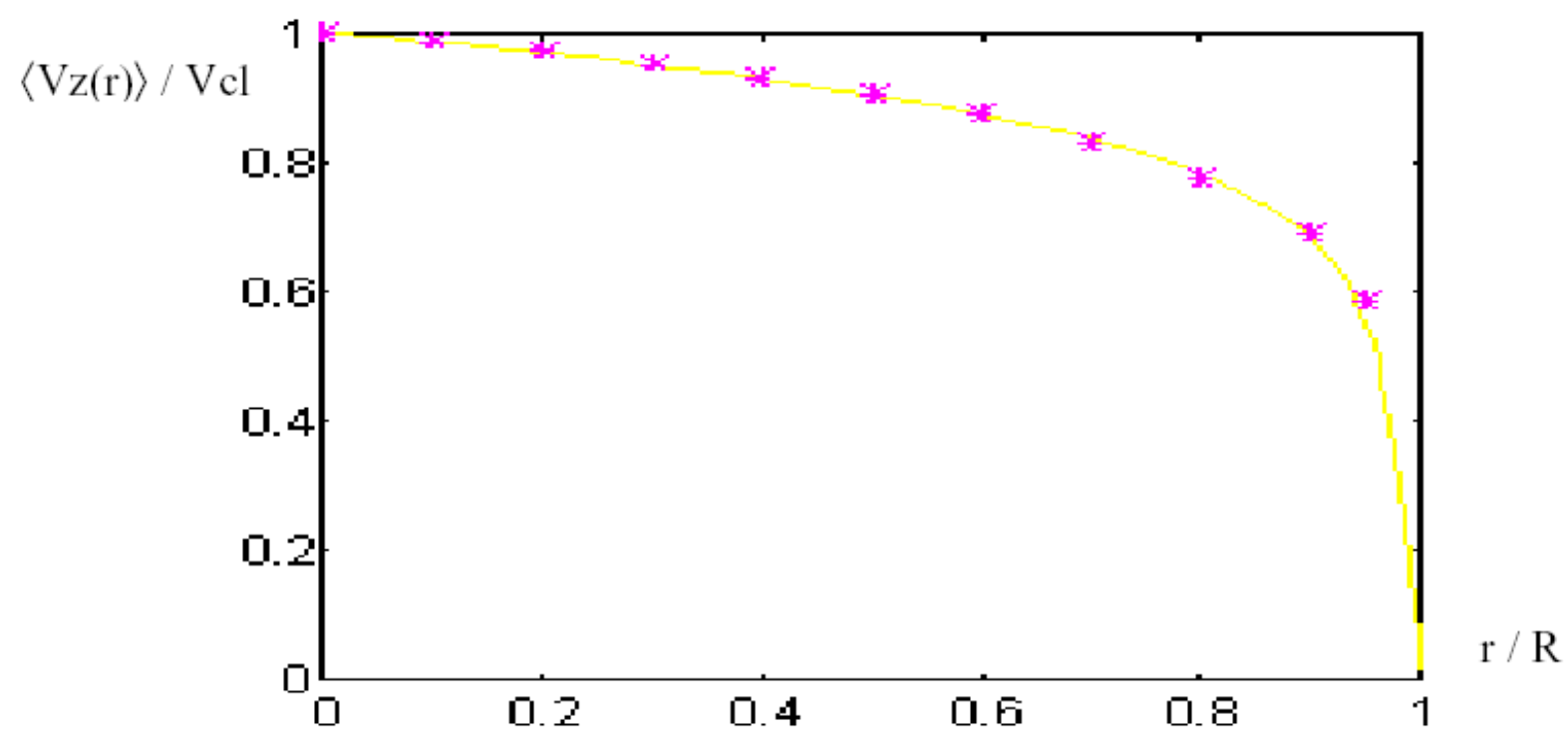

Figura 33. Comparação dos dados experimentais (asteriscos) com dados calculados (linha) em gráfico de velocidade média relativa versus o raio relativo para o escoamento de água em tubulação com $R e=4.000$ e diâmetro nominal de 10 mm. Fonte Karpelson (2008). 


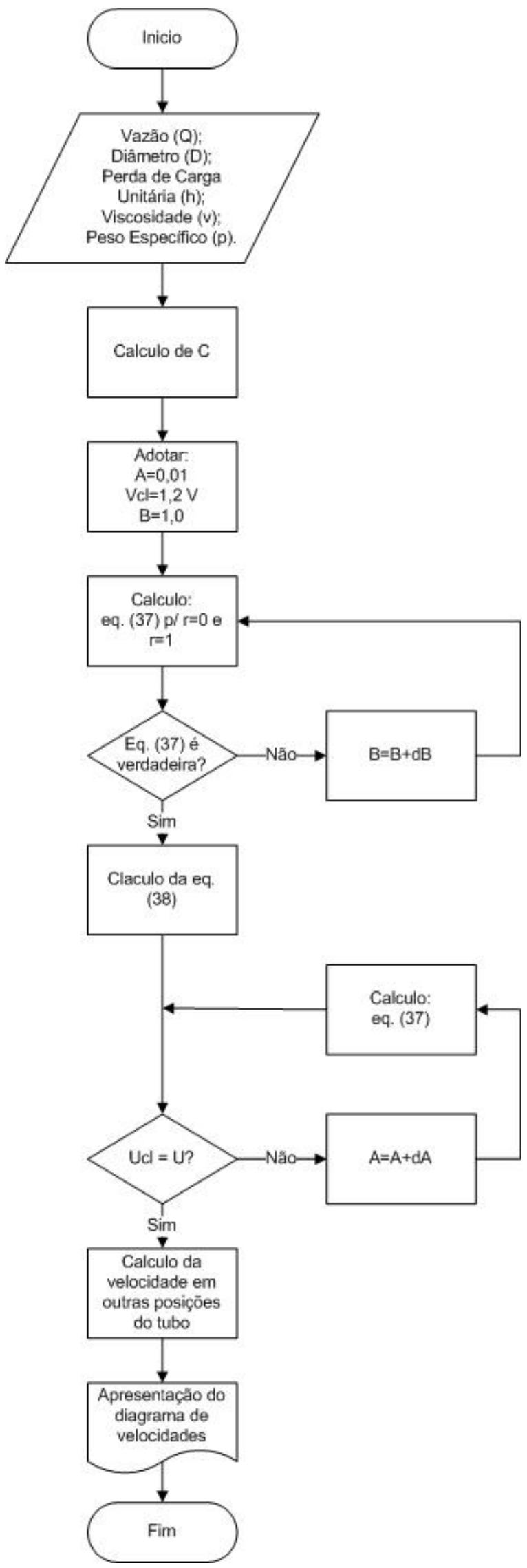

Figura 34. Fluxograma do algoritmo desenvolvido por Karpelson (2008). 
Com base nesta revisão bibliográfica ficou evidente a preocupação, por parte dos pesquisadores citados, em criar modelos mais realísticos, os quais atendam as hipóteses físicas atribuídas ao escoamento em condutos fechados. Tal preocupação chega até os dias atuais, onde são propostos modelos cada vez mais simples e precisos. Para tanto, os trabalho atuais baseiam-se cada vez menos em modelos empíricos migrando para modelos semi-conceituais ou conceituais.

Os trabalhos precursores, destacando-se neste trabalho BERNOULLI (1732) e BERNOULLI (1738), criaram a base para o desenvolvimento da Hidráulica. Tais trabalhos são reconhecidamente clássicos da Física, os quais sintetizaram as leis da termodinâmica de Newton juntamente com a conservação de massa e quantidade de movimento.

Com o desenvolvimento da fórmula universal da perda de carga foi introduzido o fator de atrito $(f)$. Este adimensional desde então tem recebido a atenção de muitos autores.

O perfil de velocidades do escoamento foi foco de VON KÁRMÁN (1930) e PRANDTL e TIETJENS (1934). COLEBROOK e WHITE (1937), MOODY (1944) e ROOSE (1946) contribuíram para o equacionamento do fator de atrito $(f)$ amplamente utilizado nos dias atuais. O estudo destes trabalhos tem importante papel para o conhecimento dos mecanismos físicos relacionados com o fator de atrito do escoamento $(f)$.

Trabalhos realizados a partir da segunda metade do século XX visaram essencialmente a determinação de uma forma mais prática e precisa do fator de atrito $(f)$. Dentre os trabalhos clássicos destacam-se SWAMEE e JAIN (1976) e CHIU (1987). O primeiro sintetizou as fórmulas para os vários regimes de 
escoamento em uma única fórmula, porém limitada em termos de número de Reynolds, mas abrangendo a maioria das utilizações. O segundo elaborou uma formulação totalmente conceitual e simples para determinação do atrito $(f)$, desenvolvido a partir da teoria da comunicação, onde se destaca o parâmetro $(M)$. Tais trabalhos deram uma contribuição notória para o desenvolvimento da formulação do atrito $(f)$.

Os trabalhos mais recentes dividiram-se basicamente em duas linhas de pesquisa. A primeira, representada neste trabalho por McKEON et al. (2004), aproveitou-se do desenvolvimento tecnológico da instrumentação para a obtenção de dados experimentais de grande precisão. Já a segunda linha de pesquisa, seguiu o desenvolvimento dos trabalhos dos anos 70 e 80 , cujos principais expoentes citados neste trabalho são ARAÚJO e CHAUDHRY (1998), LI et al. (1999), CARVALHO (2001),. SWAMEE, Nimisha e SWAMEE, Probhata K. (2007) e KARPELSON (2008). Tais linhas tentaram obter formulações precisas e de fácil utilização para a determinação do fator de atrito $(f)$.

A teoria da entropia máxima, apresentada em CHIU (1987), tem grande destaque neste trabalho. O estudo do parâmetro de entropia $(M)$ representa uma grande evolução para a determinação do atrito $(f)$. Este fator representa os parâmetros intervenientes do escoamento representados pelo número de Reynolds aparente $\left(\operatorname{Re}_{a}\right)$.

O fator de atrito para escoamentos lisos, segundo o equacionamento desenvolvido por CHIU (1987), é função do parâmetro $(M)$ e do número de Reynolds aparente. Porém, o parâmetro que varia entre o escoamento turbulento 
rugoso e o liso é o número de Reynolds aparente $\left(\operatorname{Re}_{a}\right)$, em função da viscosidade turbulenta. Portanto, há de se concluir que a curva do fator de atrito para escoamentos lisos é a mesma para o escoamento turbulento misto, quando se leva em conta a viscosidade turbulenta do escoamento.

A partir do uso do Reynolds aparente, o gráfico de Moody perderia sua harpa, ou seja, se igualaria ao gráfico apresentado por McKEON et al. (2004). Além disto, a criação de uma única curva, a qual tem formato contínuo quando considerado o equacionamento desenvolvido por CHIU (1987). Tal fato simplifica o equacionamento do fator de atrito, utilizando apenas uma equação para todos os tipos de escoamento.

A partir das informações obtidas nesta revisão bibliográfica, foi possível delimitar o foco desta pesquisa e obter informações necessárias para o tratamento científico deste desenvolvimento. Nos próximos capítulos serão feitos os tratamentos necessários e apresentado o modelo objetivo deste trabalho. 


\section{MODELAGEM}

\subsection{Colocação do problema}

Conforme descrito no capítulo 3, para o cálculo do fator de atrito dentro de uma tubulação com escoamento plenamente desenvolvido, existe o predomínio de formulações implícitas e empíricas para a determinação do fator de atrito $(f)$. Estas formulações tiveram como base o modelo desenvolvido por Nikuradse. Este modelo apresenta falhas conceituais.

Os ajustes numéricos feitos utilizando tal formulação conseguiram minimizar estas falhas conceituais. Geralmente estes equacionamentos apresentam resultados próximos à realidade. Porém estas formulações são implícitas, necessitando de métodos numéricos iterativos nas aplicações.

Nas últimas décadas houve o surgimento de equacionamentos explícitos para o fator de atrito, o que facilitara o seu cálculo. Tais equacionamentos, de caráter empírico, apenas operavam em faixas de valores do número de Reynolds limitadas. Esta limitação compromete o resultado destas equações para os extremos da faixa de validade, não sendo possível sua generalização.

Foi proposto por CHIU et al. (1993) um equacionamento para modelar matematicamente o escoamento dentro de um conduto circular fechado. Utilizou-se como base o Princípio da Entropia Máxima, o que lhe garante uma base conceitual mais realística. Este equacionamento, proposto por CHIU et al. (1993), é generalizado, ou seja, pode ser aplicado para todos os regimes descritos pelo número de Reynolds. Este modelo apresenta resultados precisos, e descreve os regimes laminar e turbulento. 
Existem várias referências bibliográficas, apresentadas no capítulo 3, indicando que, de algum modo, que as curvas dos regimes turbulento misto e turbulento rugoso convergiriam para a curva do regime turbulento liso. CHIU et al. (1993) afirmaram que o modelo de entropia pode descrever qualquer regime de escoamento.

Sem que se tenha dado a devida atenção Colebrook propôs um equacionamento relativo ao acréscimo da turbulência provocada pelo interação do escoamento com a parede da tubulação. A partir desta proposta, Colebrook transformou o equacionamento desenvolvido por Nikuradse para regime turbulento liso, para uma relação que descreve os regimes turbulento misto e rugoso. Em decorrência, existe uma relação unívoca entre o fator de atrito, o número de

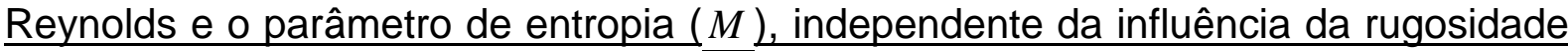
da parede da tubulação.

O equacionamento baseado na entropia, apesar de genérico e apresentar resultados realísticos, o parâmetro de entropia $(M)$ que nele está presente é pouco estudado, não existindo nenhuma relação determinada entre este e o número de Reynolds. Já os equacionamentos empíricos sofrem por serem equações que necessitam ter sua utilização bem analisada, devida suas faixas de validade.

A formulação de uma equação explícita, genérica e conceitualmente realista teria um caráter benéfico, diminuindo os passos de cálculo para determinação do fator de atrito. Tal equacionamento, por descrever melhor o fenômeno físico, pode ser utilizado para uma maior variedade de aplicações, as quais os modelos atuais têm utilizações limitadas. 
Uma outra face do equacionamento existente é a conjectura proposta por Prandtl. Esta conjectura descreve a existência de um coeficiente de cálculo, que segundo Prandtl é uma constante. Esta afirmação vem ao encontro do modelo proposto por Nikuradse. Porém, até os dias atuais, existe a necessidade de comprovação desta afirmação de Prandtl.

\subsection{Princípios da Física}

A Mecânica dos Fluidos (e por extensão a Hidráulica) pode ser estruturada com base em quatro princípios da Física:

Conservação de Massa;

Quantidade de Movimento;

Primeira Lei da Termodinâmica;

Segunda Lei da Termodinâmica.

$\mathrm{Na}$ modelação do método aqui proposto serão apenas utilizados o princípio da Conservação de Massa e a Primeira Lei da Termodinâmica.

\subsubsection{Conservação de Massa}

O modelo aqui sugerido considera que não há perda e nem ganho de massa dentro de um sistema. Em sua forma mais geral expressa-se, com apoio do teorema de Reynolds, como a seguinte equação integral (39).

$$
\frac{\partial}{\partial t} \int_{V_{c}} \rho d V+\int_{S_{c}} \rho \vec{v} \cdot d \vec{A}=0
$$

Onde: 


$$
\begin{aligned}
A & =\text { Área; } \\
S_{c} & =\text { Superfície de controle; } \\
t \quad & =\text { Tempo; } \\
\vec{v} & =\text { Vetor velocidade; } \\
V & =\text { Volume; } \\
V_{c} & =\text { Volume de controle; } \\
\rho & =\text { Massa específica do fluido. }
\end{aligned}
$$

\subsubsection{Primeira Lei da Termodinâmica}

A Primeira Lei da Termodinâmica trata do balanço de energia, trabalho e calor para um sistema. Este princípio da Física pode ser descrito matematicamente pela equação (40).

$$
\frac{\delta Q}{d t}+\frac{\delta W}{d t}=\frac{\partial}{\partial t} \int_{V_{c}} e d V+\int_{S_{c}} \rho e \vec{v} \cdot d \vec{A}
$$

$$
e=\left(g z+\frac{1}{2} v^{2}+u\right)
$$

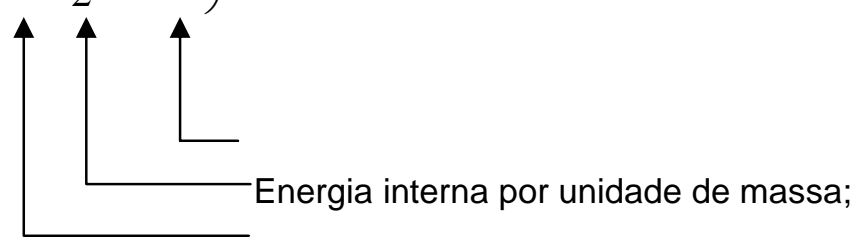

Energia cinética por unidade de massa;

Energia potencial por unidade de massa. 


\subsection{Identificação das leis particulares}

Outras leis particulares também podem ser requeridas para 0 desenvolvimento dos modelos matemáticos:

Fórmula Universal da perda de carga distribuída;

Equacionamento do fator de atrito elaborado por Colebrook;

Equacionamento do fator de atrito baseado na Entropia Máxima desenvolvido por CHIU et al. (1993);

Equacionamento do fator de atrito desenvolvido por McKEON et al. (2004).

\subsubsection{Fórmula Universal de perda de carga distribuída}

Dentre as várias equações existentes, foi escolhido o equacionamento proposto por Darcy-Weisbach, equação (42), devido ao fato de a mesma ser uma formulação de origem conceitual.

$$
\Delta H=f \frac{L}{D} \frac{V^{2}}{2 g}
$$

Onde:

$D$ = Diâmetro da tubulação de adução;

$f=$ Fator de atrito da tubulação;

$g \quad=$ Aceleração gravitacional;

$L$ = Comprimento da tubulação;

$V \quad=\quad$ Velocidade média do escoamento;

$\Delta H=$ Perda de carga distribuída. 


\subsubsection{Equacionamento do fator de atrito elaborado por Colebrook}

O equacionamento proposto por Colebrook em 1939. Tal equacionamento é apresentado no capítulo 3, equação (4).

$$
\frac{1}{\sqrt{f}}=-2 \log \left(\frac{k}{3,71 D}+\frac{2,51}{\operatorname{Re} \sqrt{f}}\right)
$$

Onde:

$D=$ Diâmetro interno do tubo;

$k=$ Rugosidade equivalente hidráulica da parede do tubo;

$\operatorname{Re}=$ Número de Reynolds molecular;

$f \quad=$ Fator de atrito.

\subsubsection{Equacionamento do fator de atrito baseado na Entropia Máxima}

O equacionamento do fator de atrito baseado na Entropia máxima foi apresentado por CHIU et al. (1993). Este equacionamento introduz no cálculo do fator de atrito o parâmetro de entropia $(M)$. Tal parâmetro tem relação unívoca com o número de Reynolds.

Este equacionamento foi apresentado no capítulo 3, equação (27).

4.3.4. Equacionamento do fator de atrito desenvolvido por McKEON et al. (2004)

Ajustando o fator de atrito em função do número de Reynolds (Re), McKEON et al. (2008) pospuseram um equacionamento para o fator de atrito $(f)$. Porém este 
ajuste utilizou como base o modelo desenvolvido por Nikuradse, o qual apresenta imperfeições.

Assim como os equacionamentos dos itens 4.3 .2 e 4.3.3, os detalhes deste equacionamento foram apresentados no capítulo 3, equação (32).

\subsection{Grandezas Intervenientes}

As grandezas intervenientes são aquelas que são necessárias como dados de entrada para a utilização do modelo. Tais dados podem ser divididos em propriedades físicas dos fluidos, parâmetros geométricos dos condutos e grandezas hidráulicas.

\subsubsection{Propriedades físicas dos fluidos}

O modelo proposto tem validade para qualquer fluido Newtoniano. Para tanto é necessário obter os valores da viscosidade molecular e da massa específica do fluido que está escoando dentro do tubo.

$\rho=$ Massa específica do fluido;

$v \quad=$ Viscosidade molecular do fluido.

\subsubsection{Parâmetros geométricos dos condutos}

A tubulação exerce influência sobre o escoamento do fluido. $O$ diâmetro interno do tubo, rugosidade da parede interna da tubulação e o comprimento são dados de entrada fundamentais para o modelo proposto.

$D=$ Diâmetro interno do tubo;

$k=$ Rugosidade equivalente hidráulica da parede do tubo; 
$L=$ Comprimento da tubulação.

\subsubsection{Grandezas hidráulicas}

Estas grandezas, ao contrário das demais grandezas, não são fixas. $\mathrm{Na}$ ausência de escoamento, estas grandezas são iguais a zero.

$$
\begin{aligned}
& Q \quad=\text { Vazão; } \\
& \bar{u}=\text { Velocidade média; } \\
& u_{*}=\text { Velocidade de atrito; } \\
& \Delta H=\text { Perda de carga distribuída; } \\
& \tau_{0}=\text { Tensão de cisalhamento. }
\end{aligned}
$$

\subsection{Hipóteses Simplificadoras}

\subsubsection{Fluido incompressível}

A consideração da incompressibilidade do fluido, não causa diferenças significativas no resultado. Este desenvolvimento não considera eventos, como ondas de choque. $O$ efeito da compressibilidade apenas tem influência sobre o resultado quando o número de Mach é superior a 0,3, segundo FOX et al. (2008).

\subsubsection{Velocidade máxima no eixo do tubo}

Em escoamento através de um tubo o ponto de velocidade máxima deste escoamento coincide com o eixo do tubo. Tal afirmação pode ser observada nas figuras (4) e (5). 


\subsubsection{Gradiente de velocidade nulo no eixo do tubo.}

O ponto de inflexão do perfil de velocidades do escoamento coincide com a velocidade máxima do mesmo no eixo do tubo. Ou seja, a derivada do perfil de velocidade do escoamento igualada a zero é coincidente com o eixo da tubulação.

\subsubsection{Princípio da aderência}

O princípio da aderência relata que o escoamento adere à parede do tubo, ou seja, em sua interface a velocidade do escoamento é igual à da parede do tubo.

\subsubsection{Gradiente de velocidade diferente de zero junto às paredes do tubo}

Apesar do escoamento aderir à parede do tubo, seu gradiente no mesmo ponto não é zero. Isto ocorre porque ao se distanciar da parede do tubo as partículas tende a ter maior velocidade em relação à tubulação.

\subsubsection{Dados fornecidos por McKEON et al. (2004) e LANGELANKDSVIK et al. (2008) são paradigmas}

Conforme descrito no capítulo 3, os ensaios descritos em McKEON et al. (2004) e LANGELANKDSVIK et al. (2008) foram considerados paradigmas por este trabalho. Isto se deve à qualidade dos ensaios realizados pelas universidades de Princeton e Oregon, descritos por tais autores. 


\subsection{Desenvolvimento do modelo matemático}

Este desenvolvimento foi dividido em quatro partes para facilitar a compreensão. Os primeiros três desenvolvimentos serão utilizados como base para o desenvolvimento dos algoritmos de cálculo.

\subsubsection{Análise do Mecanismo da Turbulência}

Esta análise visa determinar o mecanismo descrito no equacionamento do fator de atrito $(f)$ para o regime turbulento misto, desenvolvido por Colebrook em 1939, equação (4). Esse equacionamento baseia-se na modelagem elaborada por Nikuradse para o escoamento turbulento liso, porém inserindo um termo que relaciona o fator de atrito $(f)$ às condições de contato do escoamento com a parede do tubo.

Para isolar o termo de turbulência, inicialmente foi colocado o termo que descreve o escoamento liso em evidência.

$$
\frac{1}{\sqrt{f}}=-2 \log \left[\frac{2,51}{\operatorname{Re} \sqrt{f}}\left(1+\frac{k \operatorname{Re} \sqrt{f}}{3,71 D \times 2,51}\right)\right]
$$

Como resultado, foi possível isolar na equação (43), entre parênteses, o termo referente à turbulência gerada pela parede do tubo. Este termo carrega consigo a influência das condições da rugosidade da parede do tubo associada às condições de escoamento.

A apresentação do equacionamento pode ser melhorada isolando-se os termos dependentes do tubo e do escoamento. 


$$
\frac{1}{\sqrt{f}}=-2 \log \left\{\frac{2,51}{\operatorname{Re} \sqrt{f}}\left[1+\frac{1}{3,71 \times 2,51} \operatorname{Re} \sqrt{f}\left(\frac{k}{D}\right)\right]\right\}
$$

$\mathrm{Na}$ apresentação da equação (44) é possível notar uma constante multiplicando os termos referentes ao escoamento e ao tubo. Visando facilitar rearranjos subseqüentes, esta constante foi divida pela raiz de oito.

$$
\frac{C}{\sqrt{8}}=\frac{1}{2,51 \times 3,71} \Rightarrow C=0,304
$$

Com a introdução desta constante "C" na equação (44) obtém-se a equação (46).

$$
\frac{1}{\sqrt{f}}=-2 \log \left\{\frac{2,51}{\operatorname{Re} \sqrt{f}}\left[1+\frac{0,304}{\sqrt{8}} \operatorname{Re} \sqrt{f}\left(\frac{k}{D}\right)\right]\right\}
$$

A expressão descrita entre os colchetes da equação (46) representa a influência das paredes do tubo. Essa influência se apresenta na forma de um acréscimo da turbulência extrínseca ao regime turbulento liso. Esse acréscimo de turbulência no escoamento influi diretamente no fator de atrito.

Na equação (46) o fator de atrito $(f)$ pode ser substituído pela sua definição clássica dada pela equação (47). Também na equação pode-se introduzir a definição do número de Reynolds, equação (48). Estas duas substituições transformam a equação (46) na equação (49), que após simplificações produz a equação (50)

$$
\frac{\bar{u}}{u_{*}}=\sqrt{\frac{8}{f}} \Rightarrow \sqrt{f}=\sqrt{8} \frac{u_{*}}{\bar{u}}
$$




$$
\begin{gathered}
\operatorname{Re}=\frac{\bar{u} D}{v} \\
\frac{1}{\sqrt{f}}=-2 \log \left\{\frac{2,51}{\operatorname{Re} \sqrt{f}}\left[1+\frac{0,304}{\sqrt{8}}\left(\frac{\bar{u} D}{v}\right)\left(\sqrt{8} \frac{u_{*}}{\bar{u}}\right)\left(\frac{k}{D}\right)\right]\right\} \\
\frac{1}{\sqrt{f}}=-2 \log \left[\frac{2,51}{\operatorname{Re} \sqrt{f}}\left(1+0,304 \frac{u_{*} k}{v}\right)\right]
\end{gathered}
$$

O termo entre parênteses na equação (50) apresenta como grandeza independente apenas a rugosidade da tubulação. Este termo exerce influência sobre a geração de turbulência.

O diâmetro do tubo não é influenciado pela rugosidade do tubo. A turbulência de um escoamento é função da viscosidade do fluido. Assim, a expressão contida entre parênteses da equação (50) influi diretamente na viscosidade aparente do fluido, por produzir intensificação da turbulência.

Esta expressão pode ser descrita como um fator obtido a partir da razão entre uma viscosidade aparente pela viscosidade molecular do fluido. Conseqüentemente é possível determinar e existência de um número de Reynolds turbulento ou aparente. Este número de Reynolds é descrito por CHIU et al. (1993), sendo conjugado ao fator de atrito.

$$
\frac{v_{a}}{v}=\frac{\operatorname{Re}}{\operatorname{Re}_{a}}=1+0,304 \frac{u_{*} k}{v}
$$


Tabela 2. Cálculo da Função de Viscosidade Turbulenta ou Aparente - Dados: Langelankdsvik et al. (2008)

\begin{tabular}{|c|c|c|c|c|c|c|c|c|c|c|c|c|c|}
\hline $\mathrm{D}(\mathrm{m})$ & ks (m) & $\mathrm{k} / \mathrm{D}$ & $\mathrm{Re}$ & $f$ & $\bar{V}$ & $u^{*}$ & $u^{*} k$ & Rea & & $\bar{a}$ & & $\mathrm{a} /$ & $u^{*} k /$ \\
\hline 0,130 & $5,00 \mathrm{E}-06$ & $3,85 E-05$ & $1,50 \mathrm{E}+05$ & 0,0167 & 17,33 & 0,792 & $3,96 \mathrm{E}-06$ & $1,50 \mathrm{E}+05$ & 1,50E-05 & 1,50E-05 & $-8,14 \mathrm{E}-09$ & 9,99E-01 & $2,64 \mathrm{E}-01$ \\
\hline 0,130 & 5,00E-06 & $3,85 E-05$ & $2,20 \mathrm{E}+05$ & 0,0155 & 25,42 & 1,119 & 5,59E-06 & $2,21 \mathrm{E}+05$ & 1,50E-05 & 1,49E-05 & $-8,29 E-08$ & 9,94E-01 & $3,73 E-01$ \\
\hline 0,130 & 5,00E-06 & 3,85E-05 & $3,00 \mathrm{E}+05$ & 0,0146 & 34,66 & 1,481 & $7,40 \mathrm{E}-06$ & $3,05 \mathrm{E}+05$ & 1,50E-05 & 1,48E-05 & $-2,42 \mathrm{E}-07$ & 9,84E-01 & $4,94 \mathrm{E}-01$ \\
\hline 0,130 & 5,00E-06 & $3,85 \mathrm{E}-05$ & $5,00 \mathrm{E}+05$ & 0,0134 & 57,76 & 2,364 & $1,18 \mathrm{E}-05$ & $4,91 \mathrm{E}+05$ & 1,50E-05 & 1,53E-05 & $2,89 \mathrm{E}-07$ & $1,02 \mathrm{E}+00$ & $7,88 \mathrm{E}-01$ \\
\hline 0,130 & 5,00E-06 & $3,85 E-05$ & $6,00 \mathrm{E}+05$ & 0,0132 & 69,32 & 2,816 & 1,41E-05 & $5,34 \mathrm{E}+05$ & 1,50E-05 & 1,68E-05 & $1,85 \mathrm{E}-06$ & $1,12 \mathrm{E}+00$ & 9,39E-01 \\
\hline 0,130 & 5,00E-06 & $3,85 \mathrm{E}-05$ & $7,00 \mathrm{E}+05$ & 0,0127 & 80,87 & 3,222 & 1,61E-05 & $6,67 \mathrm{E}+05$ & 1,50E-05 & 1,57E-05 & $7,45 \mathrm{E}-07$ & $1,05 E+00$ & $1,07 \mathrm{E}+00$ \\
\hline 0,130 & 5,00E-06 & $3,85 E-05$ & $8,30 \mathrm{E}+05$ & 0,0122 & 95,89 & 3,745 & 1,87E-05 & $8,43 \mathrm{E}+05$ & 1,50E-05 & 1,48E-05 & $-2,38 \mathrm{E}-07$ & $9,84 \mathrm{E}-01$ & $1,25 \mathrm{E}+00$ \\
\hline 0,130 & $5,00 \mathrm{E}-06$ & $3,85 \mathrm{E}-05$ & $1,00 \mathrm{E}+06$ & 0,0121 & 115,53 & 4,493 & $2,25 \mathrm{E}-05$ & $8,85 \mathrm{E}+05$ & 1,50E-05 & 1,69E-05 & 1,94E-06 & $1,13 \mathrm{E}+00$ & $1,50 \mathrm{E}+00$ \\
\hline 0,130 & 5,00E-06 & $3,85 \mathrm{E}-05$ & $1,40 \mathrm{E}+06$ & 0,0117 & 161,74 & 6,185 & $3,09 \mathrm{E}-05$ & $1,08 \mathrm{E}+06$ & 1,50E-05 & 1,94E-05 & $4,41 \mathrm{E}-06$ & $1,29 E+00$ & $2,06 \mathrm{E}+00$ \\
\hline 0,130 & $5,00 \mathrm{E}-06$ & $3,85 E-05$ & $2,00 \mathrm{E}+06$ & 0,0114 & 231,05 & 8,722 & $4,36 \mathrm{E}-05$ & $1,27 \mathrm{E}+06$ & 1,50E-05 & $2,37 \mathrm{E}-05$ & $8,69 \mathrm{E}-06$ & $1,58 \mathrm{E}+00$ & $2,91 \mathrm{E}+00$ \\
\hline 0,130 & 5,00E-06 & $3,85 \mathrm{E}-05$ & $2,80 \mathrm{E}+06$ & 0,0112 & 323,48 & 12,103 & $6,05 \mathrm{E}-05$ & $1,41 \mathrm{E}+06$ & 1,50E-05 & 2,98E-05 & $1,48 \mathrm{E}-05$ & $1,98 \mathrm{E}+00$ & $4,03 E+00$ \\
\hline 0,130 & 5,00E-06 & $3,85 E-05$ & $3,90 \mathrm{E}+06$ & 0,0111 & 450,55 & 16,783 & 8,39E-05 & $1,49 \mathrm{E}+06$ & 1,50E-05 & 3,92E-05 & $2,42 E-05$ & $2,62 \mathrm{E}+00$ & $5,59 \mathrm{E}+00$ \\
\hline 0,130 & 5,00E-06 & $3,85 \mathrm{E}-05$ & $5,50 \mathrm{E}+06$ & 0,0111 & 635,40 & 23,668 & $1,18 \mathrm{E}-04$ & $1,49 \mathrm{E}+06$ & 1,50E-05 & 5,53E-05 & $4,03 \mathrm{E}-05$ & $3,69 \mathrm{E}+00$ & $7,89 \mathrm{E}+00$ \\
\hline 0,130 & 5,00E-06 & $3,85 E-05$ & $7,50 \mathrm{E}+06$ & 0,0110 & 866,45 & 32,129 & 1,61E-04 & $1,58 \mathrm{E}+06$ & 1,50E-05 & $7,13 \mathrm{E}-05$ & $5,63 \mathrm{E}-05$ & $4,76 \mathrm{E}+00$ & $1,07 \mathrm{E}+01$ \\
\hline 0,130 & 5,00E-06 & $3,85 \mathrm{E}-05$ & $1,05 \mathrm{E}+07$ & 0,0110 & 1213,03 & 44,980 & $2,25 \mathrm{E}-04$ & $1,58 \mathrm{E}+06$ & 1,50E-05 & 9,99E-05 & 8,49E-05 & $6,66 \mathrm{E}+00$ & $1,50 \mathrm{E}+01$ \\
\hline 0,130 & 5,00E-06 & $3,85 E-05$ & $1,48 \mathrm{E}+07$ & 0,0109 & 1709,80 & 63,112 & $3,16 \mathrm{E}-04$ & $1,67 \mathrm{E}+06$ & 1,50E-05 & $1,33 \mathrm{E}-04$ & $1,18 \mathrm{E}-04$ & $8,87 E+00$ & $2,10 \mathrm{E}+01$ \\
\hline 0,130 & 5,00E-06 & $3,85 E-05$ & $2,00 \mathrm{E}+07$ & 0,0109 & 2310,54 & 85,287 & $4,26 \mathrm{E}-04$ & $1,67 \mathrm{E}+06$ & 1,50E-05 & 1,80E-04 & $1,65 \mathrm{E}-04$ & $1,20 \mathrm{E}+01$ & $2,84 \mathrm{E}+01$ \\
\hline
\end{tabular}


O equacionamento apresenta uma constante, anteriormente citada, determinada experimentalmente. Esta constante deve ser ajustada via ensaios de laboratório. O equacionamento, portanto, dever ser generalizado como na equação (52).

$$
\frac{v_{a}}{v}=1+C \frac{u_{*} k}{v}
$$

Onde:

$C=$ Constante adimensional;

$k=$ Rugosidade equivalente hidráulica do tubo;

$u_{*} \quad=\quad$ Velocidade de atrito;

$v=$ Viscosidade molecular;

$v_{a}=$ Viscosidade aparente.

Para o ajuste do coeficiente " $C$ " contido na equação (52), foram utilizados dados fornecidos por LANGELANKDSVIK et al. (2008). Tais dados, conforme já citado em capítulos anteriores, foram ensaiados com instrumentação de grande precisão no laboratório da Universidade de Princeton, Estados Unidos.

A partir do ajuste numérico apresentado no gráfico contido na figura (35) foi determinado o parâmetro $C=0,3721$, com um coeficiente de ajuste $R^{2}=0,9883$. Substituindo o valor de C na equação (52), foi possível chegar às equações (53) e (54). 


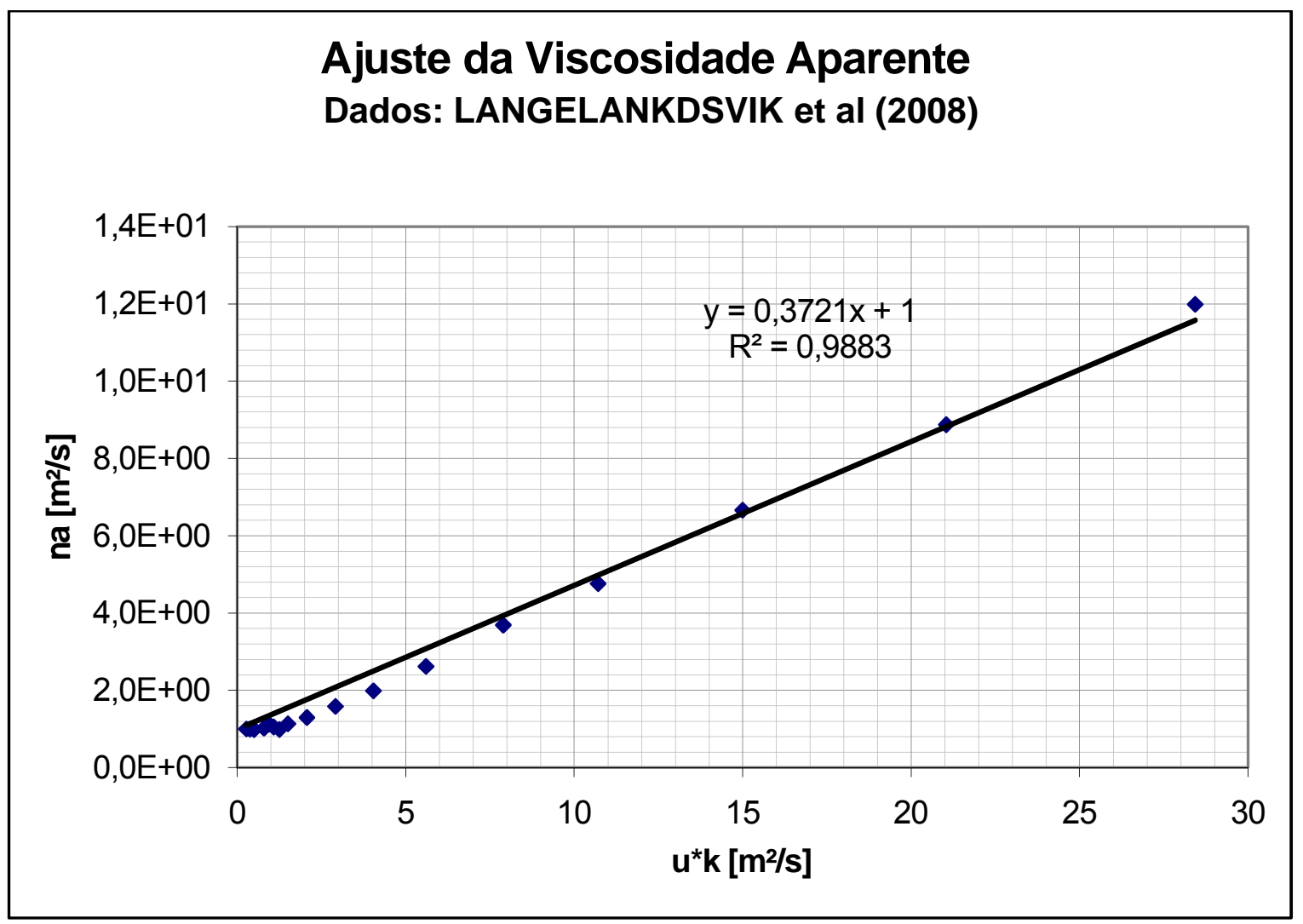

Figura 35. Gráfico de ajuste para obtenção da constante "C".

$$
\begin{gathered}
\frac{v_{a}}{v}=1+0,3721 \frac{u_{*} k}{v} \\
\operatorname{Re}_{a}=\operatorname{Re}\left(1+0,3721 \frac{u_{*} k}{v}\right)^{-1}
\end{gathered}
$$

A expressão entre parênteses na equação (54) pode ser transformada na expressão entre colchetes na equação (55).

$$
\operatorname{Re}_{a}=\operatorname{Re}\left[1+\frac{0,3721}{\sqrt{8}} \operatorname{Re} \sqrt{f}\left(\frac{k}{D}\right)\right]^{-1}
$$

Onde:

$$
\begin{aligned}
& D=\text { Diâmetro do tubo; } \\
& f \quad=\text { Fator de atrito; }
\end{aligned}
$$


$k=$ Rugosidade hidraulicamente equivalente do tubo;

$\operatorname{Re}=$ Número de Reynolds molecular;

$\operatorname{Re}_{a}=$ Número de Reynolds aparente;

$u_{*} \quad=$ Velocidade de atrito;

$v=$ Viscosidade molecular;

$v_{a}=$ Viscosidade aparente.

\subsubsection{Ajuste do parâmetro de Entropia}

Conforme descrito anteriormente, o equacionamento desenvolvido por $\mathrm{CHIU}$ et al. (1993), de base totalmente conceitual, descreve o escoamento dentro de um tubo atendendo suas principais hipóteses. Apesar de apresentar tais vantagens, este equacionamento contém o parâmetro de entropia $(M)$, para o qual não há, até onde esta pesquisa verificou nenhum equacionamento disponível.

Foi possível obter os valores correspondentes do parâmetro de entropia $(M)$ tomando-se como base os dados de fator de atrito e número de Reynolds, para regime turbulento liso, apresentados por McKEON et al. (2008). O cálculo do parâmetro de entropia foi elaborado a partir de método iterativo, utilizando-se a equação (27). Para tal cálculo foi desenvolvido, através da linguagem Visual Basic Application (VBA), inserido na planilha eletrônica Microsoft Excel, o algoritmo de cálculo descritos nas figuras (36) e (37).

Visando o melhor ajuste, foram elaboradas três formas diferentes de relacionamento entre o número de Reynolds e o parâmetro de entropia $(M)$. A primeira forma foi um ajuste direto entre número de Reynolds e o parâmetro de entropia. A segunda foi um ajuste entre o número de Reynolds e o exponencial do 
parâmetro de entropia. A terceira forma foi entre o número de Reynolds e o exponencial do parâmetro de entropia multiplicado pelo parâmetro de entropia.

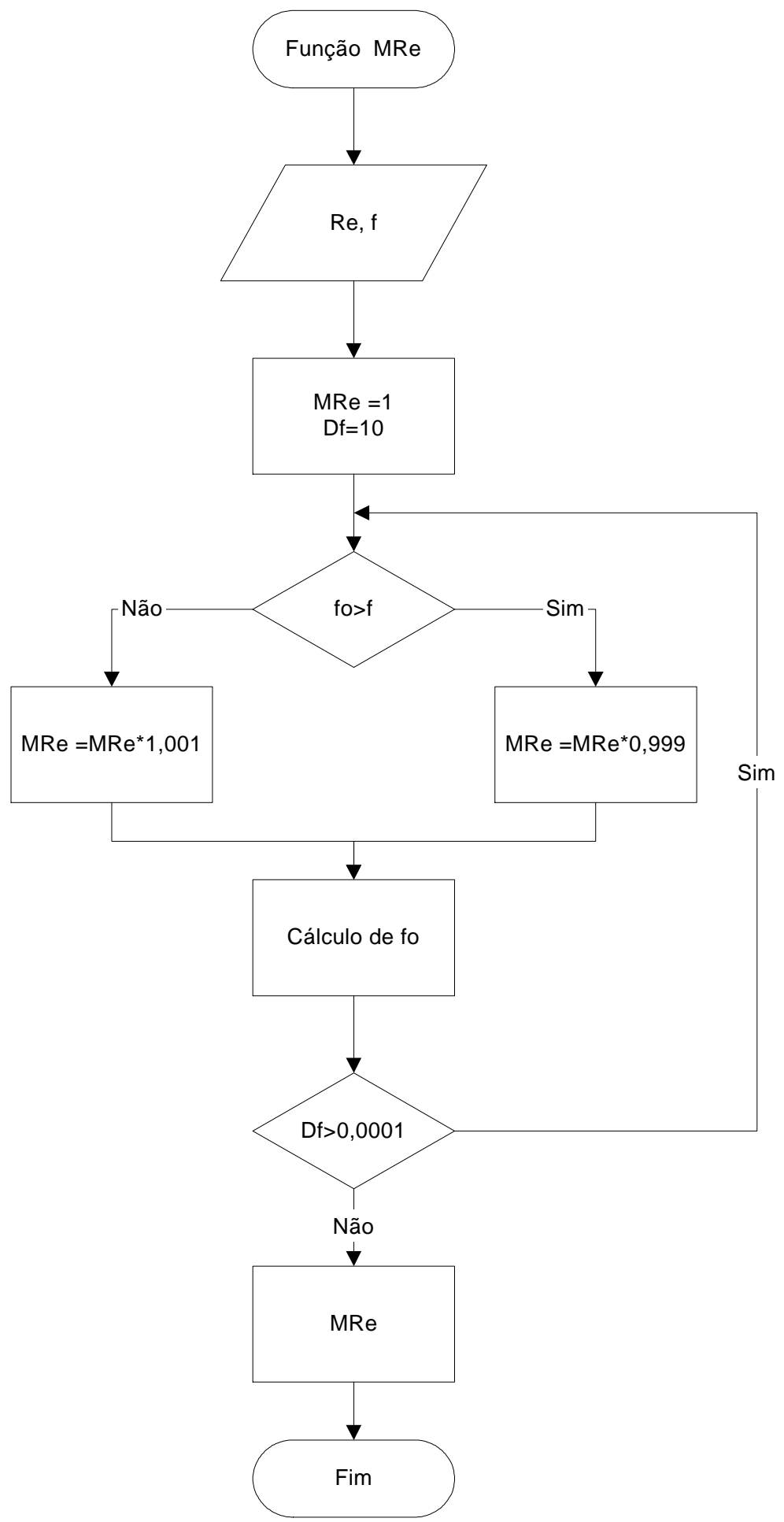

Figura 36. Fluxograma de cálculo do parâmetro de entropia (M). 
Function MRe(f, Re)

$\mathrm{MRe}=1$

$\mathrm{Df}=10$

Do While Df > 0.0001

If fo $>f$ Then

$\mathrm{MRe}=\mathrm{MRe}{ }^{*} 0.999$

Else

$\mathrm{MRe}=\mathrm{MRe}{ }^{*} 1.001$

End If

fo $=(32 / \mathrm{Re}){ }^{*}\left((\operatorname{Exp}(\mathrm{MRe})-1)^{\wedge} 2\right) /\left(\mathrm{MRe}{ }^{*} \operatorname{Exp}(\mathrm{MRe})-\operatorname{Exp}(\mathrm{MRe})+1\right)$

$D f=A b s(f o-f) / f$

Loop

End Function

Figura 37. Algoritmo de cálculo do parâmetro de entropia (M) escrito em Visual Basic Application (VBA). 
Tabela 3. Cálculo do Parâmetro de Entropia (M)

\begin{tabular}{ccccc}
\hline $\mathrm{f}$ & $\mathrm{Re}$ & $\mathrm{M}$ & $\mathrm{e}^{\wedge} \mathrm{M}$ & $\mathrm{Me} \mathrm{e}^{\wedge}$ \\
\hline $4,285 \mathrm{E}-02$ & $3,080 \mathrm{E}+03$ & 1,69 & $5,429 \mathrm{E}+00$ & $9,183 \mathrm{E}+00$ \\
\hline $4,260 \mathrm{E}-02$ & $3,264 \mathrm{E}+03$ & 1,79 & $5,995 \mathrm{E}+00$ & $1,074 \mathrm{E}+01$ \\
\hline $3,995 \mathrm{E}-02$ & $3,980 \mathrm{E}+03$ & 2,04 & $7,675 \mathrm{E}+00$ & $1,564 \mathrm{E}+01$ \\
\hline $3,797 \mathrm{E}-02$ & $4,835 \mathrm{E}+03$ & 2,29 & $9,888 \mathrm{E}+00$ & $2,266 \mathrm{E}+01$ \\
\hline $3,610 \mathrm{E}-02$ & $5,959 \mathrm{E}+03$ & 2,56 & $1,293 \mathrm{E}+01$ & $3,308 \mathrm{E}+01$ \\
\hline $3,364 \mathrm{E}-02$ & $8,162 \mathrm{E}+03$ & 2,95 & $1,914 \mathrm{E}+01$ & $5,651 \mathrm{E}+01$ \\
\hline $3,088 \mathrm{E}-02$ & $1,090 \mathrm{E}+04$ & 3,27 & $2,619 \mathrm{E}+01$ & $8,553 \mathrm{E}+01$ \\
\hline $2,903 \mathrm{E}-02$ & $1,365 \mathrm{E}+04$ & 3,51 & $3,341 \mathrm{E}+01$ & $1,172 \mathrm{E}+02$ \\
\hline $2,670 \mathrm{E}-02$ & $1,899 \mathrm{E}+04$ & 3,87 & $4,771 \mathrm{E}+01$ & $1,844 \mathrm{E}+02$ \\
\hline $2,386 \mathrm{E}-02$ & $2,943 \mathrm{E}+04$ & 4,32 & $7,512 \mathrm{E}+01$ & $3,244 \mathrm{E}+02$ \\
\hline $2,364 \mathrm{E}-02$ & $3,131 \mathrm{E}+04$ & 4,39 & $8,071 \mathrm{E}+01$ & $3,544 \mathrm{E}+02$ \\
\hline $2,086 \mathrm{E}-02$ & $4,085 \mathrm{E}+04$ & 4,58 & $9,764 \mathrm{E}+01$ & $4,473 \mathrm{E}+02$ \\
\hline $2,216 \mathrm{E}-02$ & $4,144 \mathrm{E}+04$ & 4,68 & $1,079 \mathrm{E}+02$ & $5,052 \mathrm{E}+02$ \\
\hline $2,061 \mathrm{E}-02$ & $5,636 \mathrm{E}+04$ & 4,99 & $1,471 \mathrm{E}+02$ & $7,344 \mathrm{E}+02$ \\
\hline $2,061 \mathrm{E}-02$ & $5,636 \mathrm{E}+04$ & 4,99 & $1,471 \mathrm{E}+02$ & $7,344 \mathrm{E}+02$ \\
\hline $2,061 \mathrm{E}-02$ & $5,636 \mathrm{E}+04$ & 4,99 & $1,471 \mathrm{E}+02$ & $7,344 \mathrm{E}+02$ \\
\hline $2,000 \mathrm{E}-02$ & $5,922 \mathrm{E}+04$ & 5,02 & $1,509 \mathrm{E}+02$ & $7,572 \mathrm{E}+02$ \\
\hline $1,929 \mathrm{E}-02$ & $7,397 \mathrm{E}+04$ & 5,26 & $1,921 \mathrm{E}+02$ & $1,010 \mathrm{E}+03$ \\
\hline $1,805 \mathrm{E}-02$ & $8,476 \mathrm{E}+04$ & 5,35 & $2,101 \mathrm{E}+02$ & $1,124 \mathrm{E}+03$ \\
\hline $1,815 \mathrm{E}-02$ & $9,846 \mathrm{E}+04$ & 5,55 & $2,561 \mathrm{E}+02$ & $1,420 \mathrm{E}+03$ \\
\hline $1,686 \mathrm{E}-02$ & $1,200 \mathrm{E}+05$ & 5,70 & $2,995 \mathrm{E}+02$ & $1,708 \mathrm{E}+03$ \\
\hline $1,666 \mathrm{E}-02$ & $1,456 \mathrm{E}+05$ & 5,93 & $3,759 \mathrm{E}+02$ & $2,229 \mathrm{E}+03$ \\
\hline $1,594 \mathrm{E}-02$ & $1,760 \mathrm{E}+05$ & 6,11 & $4,502 \mathrm{E}+02$ & $2,751 \mathrm{E}+03$ \\
\hline $1,594 \mathrm{E}-02$ & $1,848 \mathrm{E}+05$ & 6,17 & $4,781 \mathrm{E}+02$ & $2,950 \mathrm{E}+03$ \\
\hline $1,529 \mathrm{E}-02$ & $2,296 \mathrm{E}+05$ & 6,39 & $5,930 \mathrm{E}+02$ & $3,787 \mathrm{E}+03$ \\
\hline
\end{tabular}

\begin{tabular}{ccccc}
\hline $\mathrm{f}$ & $\mathrm{Re}$ & $\mathrm{M}$ & $\mathrm{e}^{\wedge} \mathrm{M}$ & $\mathrm{Me} \mathrm{e}^{\wedge} \mathrm{M}$ \\
\hline $1,511 \mathrm{E}-02$ & $2,377 \mathrm{E}+05$ & 6,41 & $6,098 \mathrm{E}+02$ & $3,911 \mathrm{E}+03$ \\
\hline $1,462 \mathrm{E}-02$ & $2,982 \mathrm{E}+05$ & 6,65 & $7,718 \mathrm{E}+02$ & $5,132 \mathrm{E}+03$ \\
\hline $1,461 \mathrm{E}-02$ & $3,085 \mathrm{E}+05$ & 6,69 & $8,036 \mathrm{E}+02$ & $5,375 \mathrm{E}+03$ \\
\hline $1,384 \mathrm{E}-02$ & $4,081 \mathrm{E}+05$ & 6,96 & $1,054 \mathrm{E}+03$ & $7,339 \mathrm{E}+03$ \\
\hline $1,365 \mathrm{E}-02$ & $4,678 \mathrm{E}+05$ & 7,11 & $1,221 \mathrm{E}+03$ & $8,678 \mathrm{E}+03$ \\
\hline $1,324 \mathrm{E}-02$ & $5,378 \mathrm{E}+05$ & 7,24 & $1,390 \mathrm{E}+03$ & $1,006 \mathrm{E}+04$ \\
\hline $1,324 \mathrm{E}-02$ & $5,378 \mathrm{E}+05$ & 7,24 & $1,390 \mathrm{E}+03$ & $1,006 \mathrm{E}+04$ \\
\hline $1,249 \mathrm{E}-02$ & $7,507 \mathrm{E}+05$ & 7,56 & $1,925 \mathrm{E}+03$ & $1,456 \mathrm{E}+04$ \\
\hline $1,244 \mathrm{E}-02$ & $8,242 \mathrm{E}+05$ & 7,67 & $2,139 \mathrm{E}+03$ & $1,640 \mathrm{E}+04$ \\
\hline $1,183 \mathrm{E}-02$ & $1,024 \mathrm{E}+06$ & 7,86 & $2,601 \mathrm{E}+03$ & $2,045 \mathrm{E}+04$ \\
\hline $1,198 \mathrm{E}-02$ & $1,050 \mathrm{E}+06$ & 7,91 & $2,718 \mathrm{E}+03$ & $2,149 \mathrm{E}+04$ \\
\hline $1,131 \mathrm{E}-02$ & $1,342 \mathrm{E}+06$ & 8,13 & $3,383 \mathrm{E}+03$ & $2,749 \mathrm{E}+04$ \\
\hline $1,079 \mathrm{E}-02$ & $1,791 \mathrm{E}+06$ & 8,41 & $4,475 \mathrm{E}+03$ & $3,762 \mathrm{E}+04$ \\
\hline $1,028 \mathrm{E}-02$ & $2,352 \mathrm{E}+06$ & 8,66 & $5,794 \mathrm{E}+03$ & $5,020 \mathrm{E}+04$ \\
\hline $9,890 \mathrm{E}-03$ & $3,109 \mathrm{E}+06$ & 8,94 & $7,632 \mathrm{E}+03$ & $6,823 \mathrm{E}+04$ \\
\hline $9,410 \mathrm{E}-03$ & $4,438 \mathrm{E}+06$ & 9,29 & $1,082 \mathrm{E}+04$ & $1,005 \mathrm{E}+05$ \\
\hline $8,970 \mathrm{E}-03$ & $6,103 \mathrm{E}+06$ & 9,60 & $1,471 \mathrm{E}+04$ & $1,412 \mathrm{E}+05$ \\
\hline $8,620 \mathrm{E}-03$ & $7,757 \mathrm{E}+06$ & 9,82 & $1,844 \mathrm{E}+04$ & $1,811 \mathrm{E}+05$ \\
\hline $8,250 \mathrm{E}-03$ & $1,031 \mathrm{E}+07$ & 10,09 & $2,417 \mathrm{E}+04$ & $2,440 \mathrm{E}+05$ \\
\hline $8,250 \mathrm{E}-03$ & $1,031 \mathrm{E}+07$ & 10,09 & $2,417 \mathrm{E}+04$ & $2,440 \mathrm{E}+05$ \\
\hline $7,980 \mathrm{E}-03$ & $1,368 \mathrm{E}+07$ & 10,37 & $3,198 \mathrm{E}+04$ & $3,317 \mathrm{E}+05$ \\
\hline $7,670 \mathrm{E}-03$ & $1,830 \mathrm{E}+07$ & 10,65 & $4,235 \mathrm{E}+04$ & $4,512 \mathrm{E}+05$ \\
\hline $7,400 \mathrm{E}-03$ & $2,413 \mathrm{E}+07$ & 10,92 & $5,537 \mathrm{E}+04$ & $6,048 \mathrm{E}+05$ \\
\hline $7,200 \mathrm{E}-03$ & $3,015 \mathrm{E}+07$ & 11,14 & $6,879 \mathrm{E}+04$ & $7,662 \mathrm{E}+05$ \\
\hline $7,080 \mathrm{E}-03$ & $3,554 \mathrm{E}+07$ & 11,30 & $8,102 \mathrm{E}+04$ & $9,157 \mathrm{E}+05$ \\
\hline
\end{tabular}




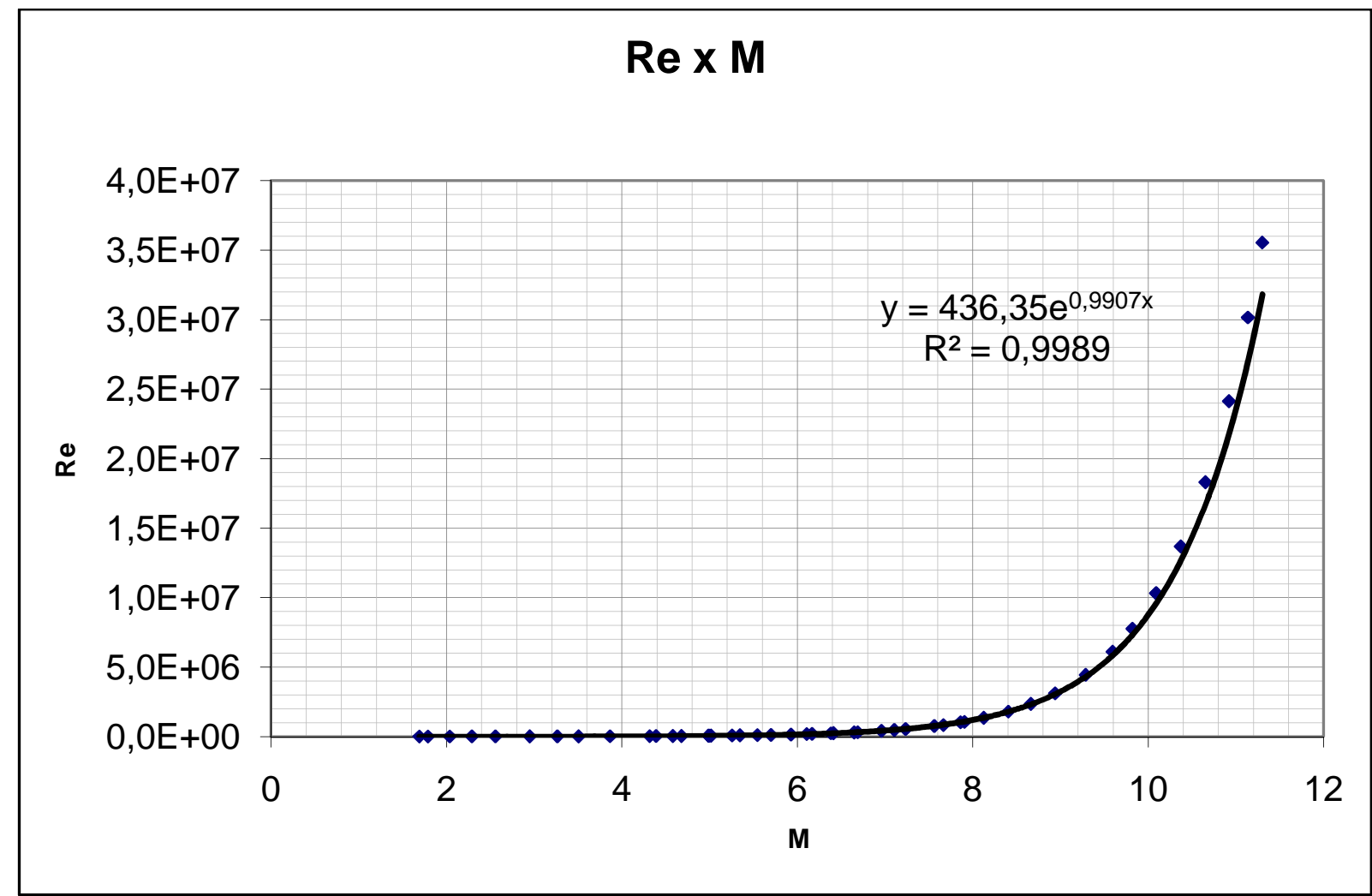

Figura 38. Gráfico de ajuste entre o número de Reynolds e o parâmetro de entropia.

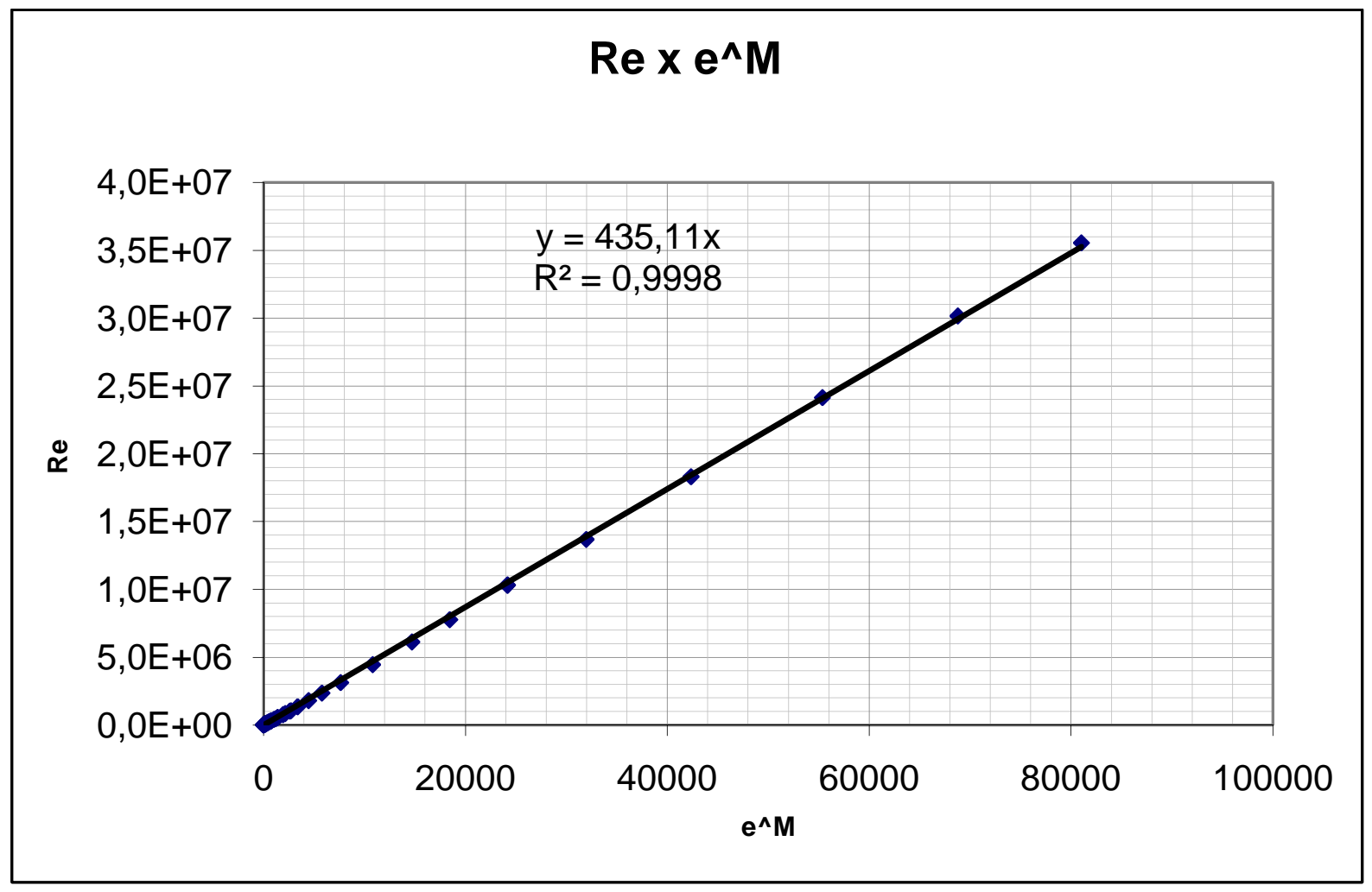

Figura 39. Gráfico de ajuste entre o número de Reynolds e a função exponencial do parâmetro de entropia. 


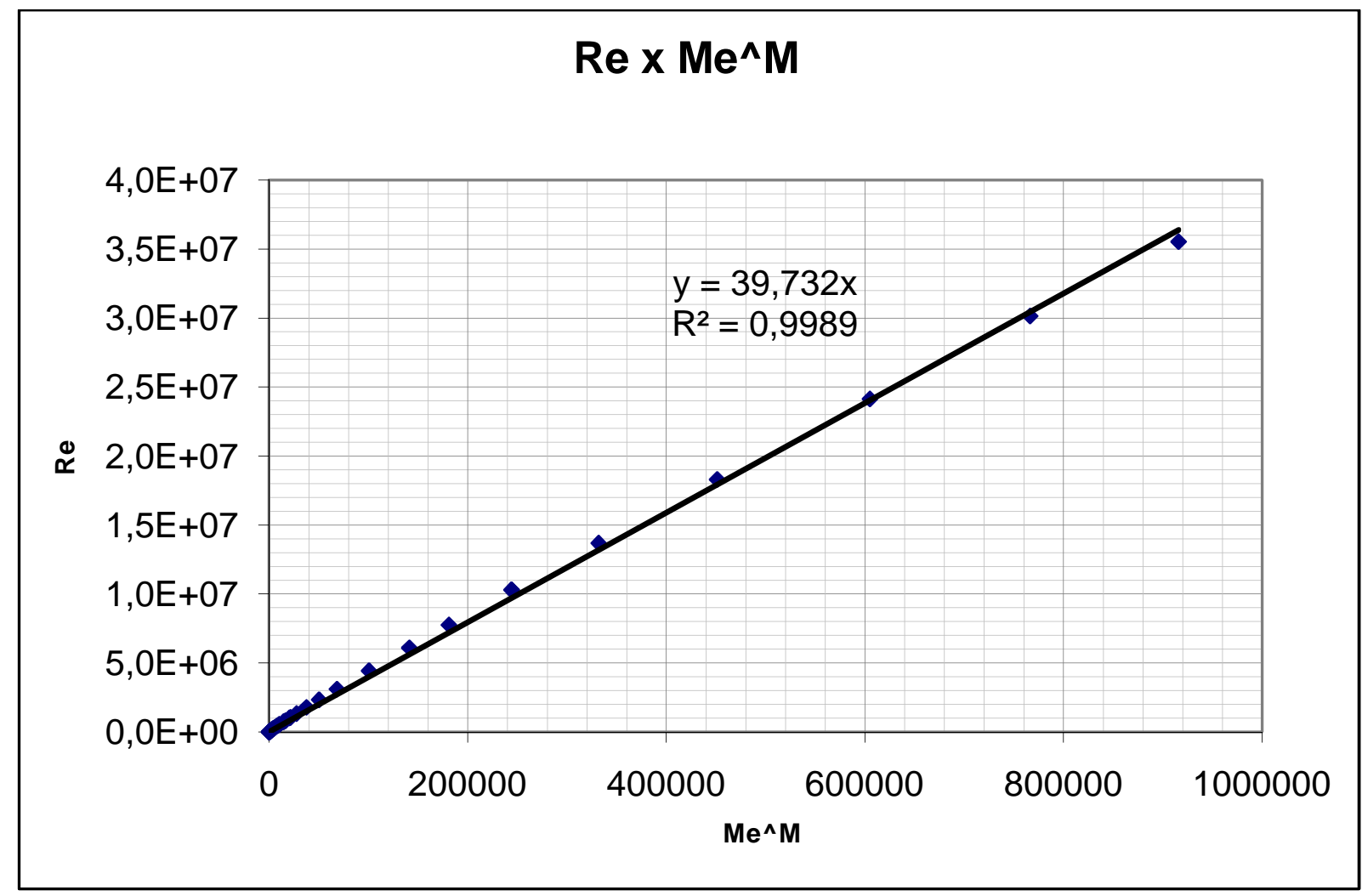

Figura 40. Gráfico de ajuste entre o número de Reynolds e o exponencial do parâmetro de entropia multiplicado pelo parâmetro de entropia.

A partir dos gráficos apresentados nas figuras (38), (39) e (40) foram feitos os ajustes numéricos para determinação de uma fórmula entre o parâmetro de entropia $(M)$ e o número de Reynolds (Re). Dentre os ajustes, o melhor, cujo coeficiente de correlação foi de 0,9998 , foi a relação entre o número de Reynolds e o exponencial do parâmetro de entropia. Têm-se então as equações (56) e (57) que relacionam o número de Reynolds (Re) e o parâmetro de entropia $(M)$.

$$
\begin{aligned}
& \operatorname{Re}_{a}=435,11 e^{M} \\
& M=\ln \left(\frac{\operatorname{Re}_{a}}{435,11}\right)
\end{aligned}
$$

Com a finalidade de simplificar o cálculo do parâmetro de entropia, foi analisada a influência do arredondamento do valor da constante 435,11 para 435 . 
Para esta análise foi elaborada uma tabela com os valores do parâmetro de entropia (M) entre a equação ajustada e a com o coeficiente ajustado arredondado.

Foram considerados valores do número de Reynolds dentro da faixa de valores do regime turbulento. Depois de calculado os parâmetros de entropia $(M)$, citados no parágrafo anterior, estes foram comparados.

Tabela 4. Tabela de comparação entre os valores do parâmetro de entropia (M)

\begin{tabular}{|c|c|c|c|}
\hline \multirow{2}{*}{$\mathrm{Re}$} & \multicolumn{2}{|c|}{ Parâmetro Entropia (M) } & \multirow{2}{*}{$\begin{array}{c}\text { Erro } \\
(\%)\end{array}$} \\
\hline & Original & Arred. & \\
\hline $3,0 \mathrm{E}+03$ & 1,93 & 1,93 & 0,01 \\
\hline $5,0 \mathrm{E}+03$ & 2,44 & 2,44 & 0,01 \\
\hline $7,5 \mathrm{E}+03$ & 2,85 & 2,85 & 0,01 \\
\hline $1,0 \mathrm{E}+04$ & 3,13 & 3,13 & 0,01 \\
\hline $2,5 E+04$ & 4,05 & 4,05 & 0,01 \\
\hline $5,0 \mathrm{E}+04$ & 4,74 & 4,74 & 0,01 \\
\hline $7,5 \mathrm{E}+04$ & 5,15 & 5,15 & 0,00 \\
\hline $1,0 \mathrm{E}+05$ & 5,44 & 5,44 & 0,00 \\
\hline $2,5 \mathrm{E}+05$ & 6,35 & 6,35 & 0,00 \\
\hline $5,0 \mathrm{E}+05$ & 7,05 & 7,05 & 0,00 \\
\hline $7,5 \mathrm{E}+05$ & 7,45 & 7,45 & 0,00 \\
\hline $1,0 \mathrm{E}+06$ & 7,74 & 7,74 & 0,00 \\
\hline $2,5 \mathrm{E}+06$ & 8,66 & 8,66 & 0,00 \\
\hline $5,0 \mathrm{E}+06$ & 9,35 & 9,35 & 0,00 \\
\hline $7,5 \mathrm{E}+06$ & 9,75 & 9,76 & 0,00 \\
\hline $1,0 \mathrm{E}+07$ & 10,04 & 10,04 & 0,00 \\
\hline
\end{tabular}

A tabela (4) indica a viabilidade do arredondamento da constante das equações (56) e (57). O erro associado a este arredondamento é menor que 0,02 \%. Portanto, foi adotado este arredondamento, obtendo se as equações (58) e (59).

$$
\begin{aligned}
& \mathrm{Re}_{a}=435 e^{M} \\
& M=\ln \left(\frac{\operatorname{Re}_{a}}{435}\right)
\end{aligned}
$$

As equações (58) e (59) são o relacionamento entre o parâmetro de entropia $(M)$ e o número de Reynolds aparente $\left(\operatorname{Re}_{a}\right)$. Este relacionamento pode ser 
comparado com o relacionamento proposto por CHIU et al. (1993). A figura (41) faz a comparação entre a figura (21) e as equações (58) e (59).

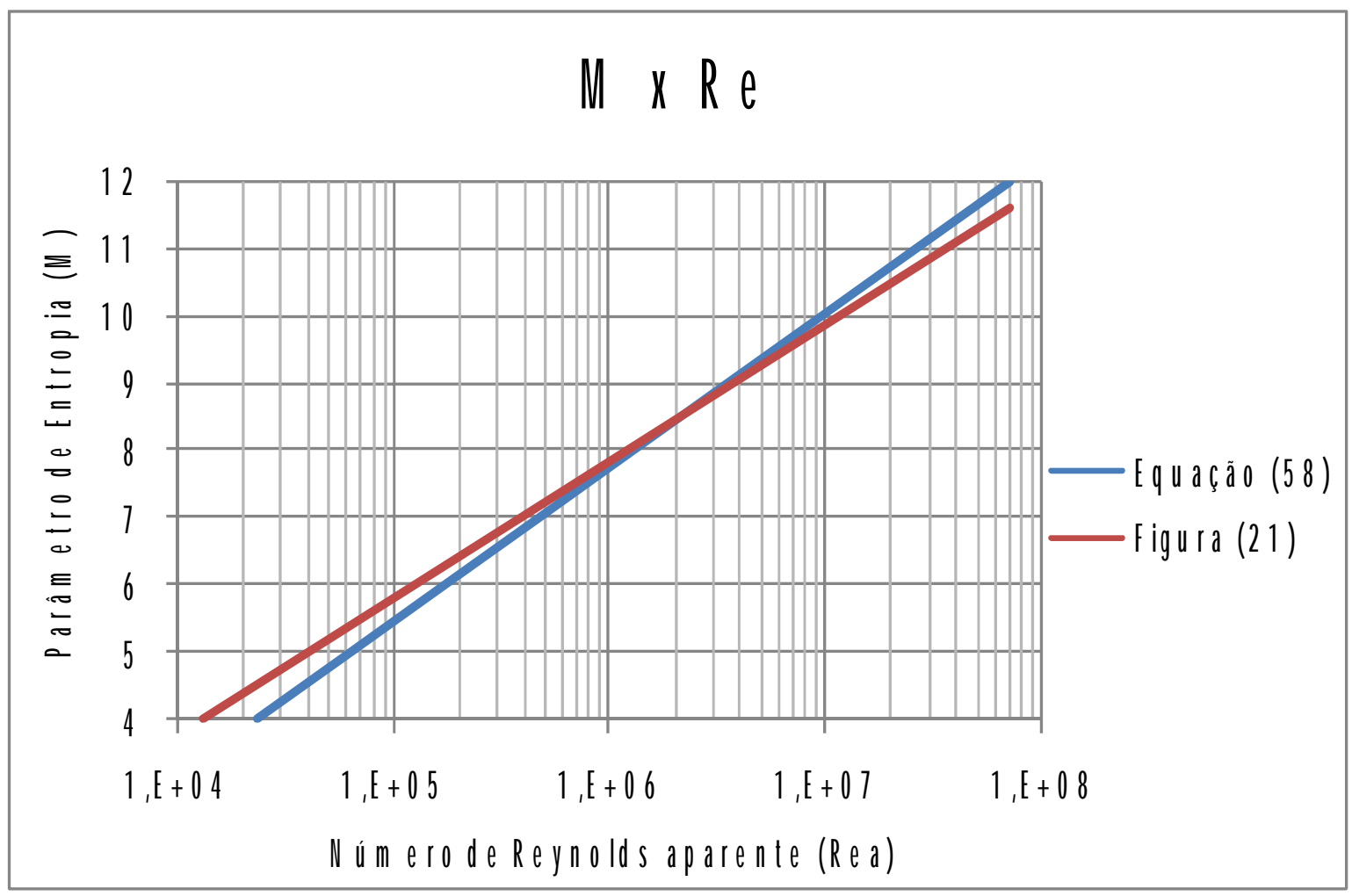

Figura 41. Comparação entre o gráfico da figura (21) e a equação (58).

Substituindo (58) em (27) obteve-se a equação explícita do fator de atrito $(f)$.

Na equação (60) este fator depende unicamente do parâmetro de entropia $(M)$.

$$
f=\frac{32}{435}\left[\frac{\left(e^{M}-1\right)^{2}}{e^{M}\left(M e^{M}-e^{M}+1\right)}\right]
$$

Onde:

$$
\begin{aligned}
& f=\text { Fator de atrito; } \\
& M \quad=\text { Parâmetro de entropia. }
\end{aligned}
$$




\subsubsection{Conjectura de PrandtI}

A conjectura de Prandtl define um adimensional associado ao escoamento turbulento. Esta conjectura afirma que este adimensional é uma constante, conforme descrito na equação (61).

$$
\frac{u_{\max }-\bar{u}}{u_{*}}=C_{p}
$$

Onde:

$$
\begin{aligned}
& C_{p}=\text { Constante de Prandtl; } \\
& \bar{u}=\text { Velocidade média; } \\
& u_{\max }=\text { Velocidade máxima; } \\
& u_{*}=\text { Velocidade de atrito. }
\end{aligned}
$$

É possível reordenar a equação (61), conforme a equação (62), em dois termos, ambos em função da velocidade média do escoamento.

$$
\frac{u_{\max }}{\bar{u}}-1=C_{p} \frac{u_{*}}{\bar{u}}
$$

A equação (24) desenvolvida por CHIU (1993) modela o primeiro termo da equação (62). Esta equação opera apenas em função do parâmetro de entropia, fornecendo o valor da razão entre a velocidade máxima e a velocidade média. Esta equação pode ser reescrita pela equação (63).

$$
\frac{u_{\max }}{\bar{u}}=\frac{M\left(e^{M}-1\right)}{M e^{M}-e^{M}+1}
$$

Substituindo a equação (63) em (62), obtém-se a equação (64). 


$$
\frac{M\left(e^{M}-1\right)}{M e^{M}-e^{M}+1}-1=C_{p} \frac{u^{*}}{\bar{u}}
$$

Substituindo a razão entre a velocidade de atrito e velocidade média pela equação (65), a qual define o fator de atrito, chega-se à equação (66)

$$
\begin{gathered}
\frac{u^{*}}{\bar{u}}=\sqrt{\frac{f}{8}} \\
\frac{M\left(e^{M}-1\right)}{M e^{M}-e^{M}+1}-1=C_{p} \sqrt{\frac{f}{8}}
\end{gathered}
$$

A equação (60) descreve o fator de atrito em função apenas do parâmetro de entropia $(M)$. Substituindo-a na equação (66) obteve-se o equacionamento do adimensional de Prandtl $\left(C_{p}\right)$.

$$
\frac{M\left(e^{M}-1\right)}{M e^{M}-e^{M}+1}-1=\frac{C_{p}}{\sqrt{8}} \sqrt{\frac{32}{435,11}\left[\frac{\left(e^{M}-1\right)^{2}}{e^{M}\left(M e^{M}-e^{M}+1\right)}\right]}
$$

A equação (67) expressa o relacionamento entre o parâmetro de entropia $(M)$ e o adimensional de Prandtl $\left(C_{p}\right)$. A partir da adoção de valores para o parâmetro de entropia $(M)$, os quais estão contidos dentro da faixa de valores do escoamento turbulento, foi possível calcular os valores do adimensional de Prandtl $\left(C_{p}\right)$, que estão indicados na tabela (5). 
Tabela 5. Cálculo do valor do adimensional de Prandtl $\left(C_{p}\right)$.

\begin{tabular}{cccc}
\hline $\mathrm{M}$ & $\mathrm{F} 1(\mathrm{M})$ & $\mathrm{F} 2(\mathrm{M})$ & $\mathrm{C}$ \\
\hline 3,00 & 1,391 & 0,180 & 6,140 \\
\hline 3,25 & 1,365 & 0,172 & 5,990 \\
\hline 3,50 & 1,342 & 0,165 & 5,842 \\
\hline 3,75 & 1,320 & 0,159 & 5,697 \\
\hline 4,00 & 1,301 & 0,153 & 5,555 \\
\hline 4,25 & 1,283 & 0,148 & 5,418 \\
\hline 4,50 & 1,267 & 0,143 & 5,285 \\
\hline 4,75 & 1,253 & 0,139 & 5,157 \\
\hline 5,00 & 1,239 & 0,135 & 5,034 \\
\hline 5,25 & 1,227 & 0,131 & 4,916 \\
\hline 5,50 & 1,216 & 0,127 & 4,803 \\
\hline 5,75 & 1,206 & 0,124 & 4,696 \\
\hline 6,00 & 1,196 & 0,121 & 4,594 \\
\hline 6,25 & 1,188 & 0,118 & 4,496 \\
\hline 6,50 & 1,180 & 0,115 & 4,403 \\
\hline 6,75 & 1,172 & 0,113 & 4,315 \\
\hline 7,00 & 1,165 & 0,111 & 4,230 \\
\hline 7,25 & 1,159 & 0,108 & 4,150 \\
\hline 7,50 & 1,153 & 0,106 & 4,074 \\
\hline 7,75 & 1,148 & 0,104 & 4,001 \\
\hline 8,00 & 1,142 & 0,102 & 3,931 \\
\hline 8,25 & 1,138 & 0,101 & 3,865 \\
\hline 8,50 & 1,133 & 0,099 & 3,802 \\
\hline 8,75 & 1,129 & 0,097 & 3,741 \\
\hline 9,00 & 1,125 & 0,096 & 3,683 \\
\hline 9,25 & 1,121 & 0,094 & 3,628 \\
\hline 9,50 & 1,118 & 0,093 & 3,575 \\
\hline 9,75 & 1,114 & 0,092 & 3,524 \\
\hline 10,00 & 1,111 & 0,090 & 3,475 \\
\hline 10,25 & 1,108 & 0,089 & 3,428 \\
\hline 10,50 & 1,105 & 0,088 & 3,383 \\
\hline & & & \\
\hline
\end{tabular}

A tabela (5) apresenta valores de duas variáveis chamadas de $\mathrm{F} 1(\mathrm{M})$ e F2(M). O termo $\mathrm{F} 1(\mathrm{M})$ representa o valor da razão entre a velocidade máxima e média, menos um. O segundo termo F2(M) representa o valor da razão entre a velocidade de atrito e velocidade máxima.

Na tabela (5) foi possível verificar que o adimensional de Prandtl $\left(C_{p}\right)$, varia em função do parâmetro de entropia. Portanto, considerando que o parâmetro de 
entropia é conjugado com o número de Reynolds para o regime turbulento liso, este adimensional varia em função do número de Reynolds.

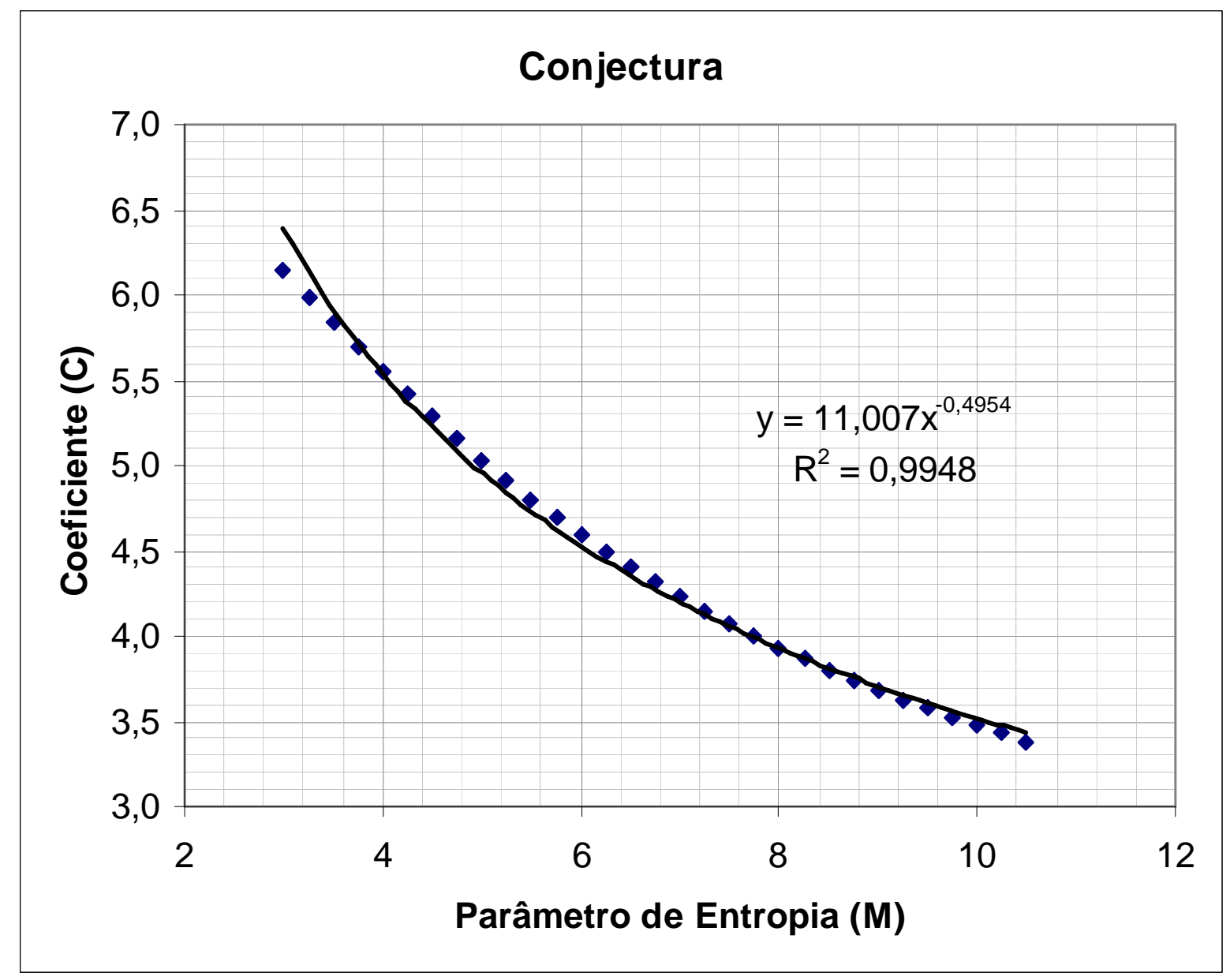

Figura 42. Gráfico do adimensional de Prandtl $\left(C_{p}\right)$ em função do parâmetro de entropia $(\mathrm{M})$.

Os valores deste adimensional foram lançados no gráfico contido na figura (42) em função do parâmetro de entropia. Neste gráfico foi feito um ajuste dos dados, o qual é apresentado na equação (68).

$$
C_{p}=11,007 M^{-0,4954}
$$

Utilizando a equação (66), é possível fazer um rearranjo, transformando-a em um equacionamento que fornece o fator de atrito. 


$$
f=\left[\frac{M\left(e^{M}-1\right)}{M e^{M}-e^{M}+1}-1\right]^{2} \frac{8}{C_{p}{ }^{2}}
$$

Substituindo (67) em (68).

$$
\begin{gathered}
f=\left[\frac{M\left(e^{M}-1\right)}{M e^{M}-e^{M}+1}-1\right]^{2} \frac{8 M^{0,4954 \times 2}}{(11,007)^{2}} \\
f=\left[\frac{M\left(e^{M}-1\right)}{M e^{M}-e^{M}+1}-1\right]^{2} \frac{M^{0,9908}}{15,144}
\end{gathered}
$$

A equação (71) pôde ser desenvolvida a partir do ajuste do coeficiente de Prandtl. A fim de verificar a coerência do desenvolvimento elaborado neste item, esta equação foi comparada com as equações (60) e com a figura (20). Ambos fazem o relacionamento entre o parâmetro de entropia $(M)$ e o fator de atrito $(f)$. Na tabela (6) foi calculado tal relacionamento a partir de tais métodos.

Tabela 6. Tabela de calculo do fator de atrito $(f)$.

\begin{tabular}{|c|c|c|c|}
\hline \multirow{2}{*}{$M$} & \multicolumn{3}{|c|}{ Fator de atrito (f) } \\
\cline { 2 - 4 } & Eq. (60) & Eq. (71) & Fig. (20) \\
\hline 4 & 0,024 & 0,023 & 0,027 \\
\hline 5 & 0,019 & 0,018 & 0,020 \\
\hline 6 & 0,015 & 0,015 & 0,016 \\
\hline 7 & 0,012 & 0,012 & 0,013 \\
\hline 8 & 0,011 & 0,011 & 0,011 \\
\hline 9 & 0,009 & 0,009 & 0,010 \\
\hline 10 & 0,008 & 0,008 & 0,009 \\
\hline 11 & 0,007 & 0,007 & 0,008 \\
\hline 12 & 0,006 & 0,007 & 0,008 \\
\hline
\end{tabular}




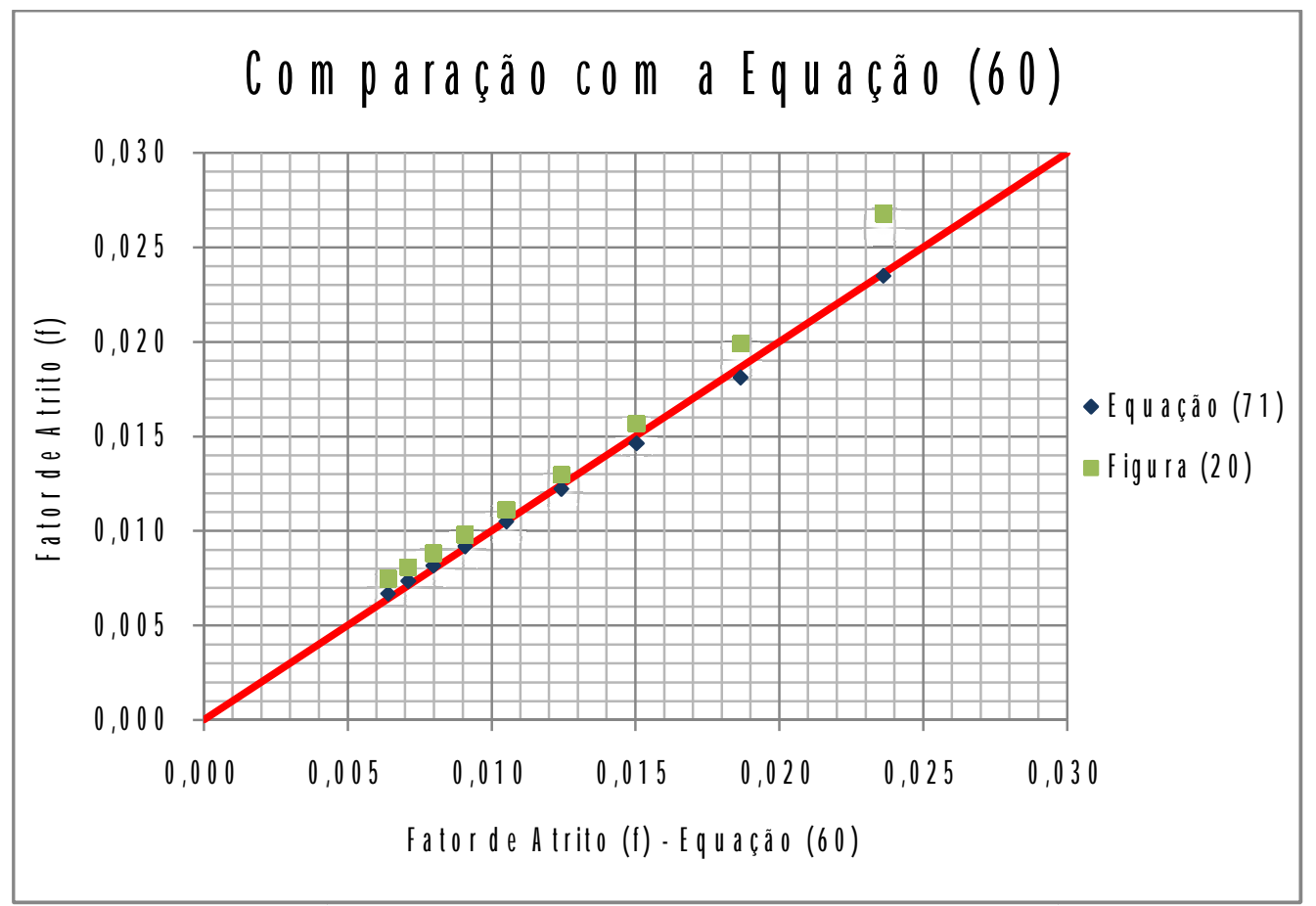

Figura 43. Gráfico de comparação entre a equação (71) e figura (20) com a equação (60).

O gráfico (43) é uma comparação entre as equações propostas nesta tese e o gráfico proposto por CHIU et al. (1993) para o relacionamento entre o parâmetro de entropia $(M)$ e o fator de atrito $(f)$. Neste gráfico é possível verificar que as equações propostas têm comportamento semelhante. Já o relacionamento da figura (20) apresenta relacionamento semelhante, porém nos valores mais altos do fator de atrito $(f)$ exibe uma dispersão com relação aos demais métodos.

A coerência dos doados obtidos através da equação (71) pode ser comprovado pelo gráfico da figura (43), portanto atestando a coerência do desenvolvimento elaborado neste item. O objetivo deste desenvolvimento foi demonstrar o comportamento do adimensional de Prandtl, que não é constante como por ele preconizado.

\subsubsection{Algoritmo de cálculo.}

Os modelos desenvolvidos nos itens 4.6.1 a 4.6.2, quando conjugados, representam o equacionamento do fator de atrito válido para qualquer regime de 
escoamento incompressível. Porém, seu uso só é possibilitado mediante um processo de cálculo iterativo.

Este item teve como objetivo modelar os quatro problemas de cálculo descrito por SOUZA et al. (1991). Foram utilizados os conceitos desenvolvidos nos capítulos anteriores para modelar soluções diretas para estes problemas.

Foram propostas modificações para as faixas de valores referentes ao regime laminar e a transição em relação aos algoritmos de SOUZA et al. (1991). Observando-se os dados fornecidos por McKEON et al. (2008), verifica-se que o regime laminar abrange a faixa de valores de número de Reynolds de 0 a aproximadamente 3.000. Já a faixa de valores do número de Reynolds dentro do regime turbulento, inicia-se aproximadamente em 3.000. FOX e McDONALD (2008) suprimem de seu algoritmo de cálculo interativo a faixa de valores referentes à transição entre regimes.

Com base em tal observação, a transição de valores entre regimes foi suprimida do algoritmo. O valor limite para determinação do regime a ser calculado será o número de Reynolds igual a 3.000. Abaixo deste valor o escoamento será calculado como regime laminar, acima, como turbulento.

A fórmula de cálculo para o regime laminar não será alterada em relação aos modelos propostos por SOUZA et al. (1991). Isto se deve ao fato que, apesar da fórmula de CHIU et al. (1993) ser válida para ambos os regimes, apenas aumentaria os passos de cálculo.

A solução para o regime turbulento iniciou-se a partir da observação dos dados necessários para solução dos modelos apresentados nos capítulos anteriores. Os dados básicos de entrada destes modelos são o número de Reynolds molecular $(\mathrm{Re})$ e o produto entre o número de Reynolds molecular e a raiz do fator 
de atrito $(\operatorname{Re} \sqrt{f})$, também conhecido como número de Rouse. A solução de todos os problemas de cálculo passa por descobrir a relação entre estas variáveis.

Depois de levantados os dados de entrada, buscou-se uma relação entre os mesmos. Para tanto foi utilizado o equacionamento conceitual do fator de atrito desenvolvido por CHIU et al. (1993), equação (27).

Esta equação fornece uma relação entre o fator de atrito $(f)$, número de Reynolds $(\mathrm{Re})$ e o parâmetro de entropia. Através de modificação algébrica, descrita nas equações (72), (73) e (74), foi possível substituir o número de Reynolds (Re) pelo número de Rouse $(\operatorname{Re} \sqrt{f})$.

$$
\begin{aligned}
& \sqrt{f} \sqrt{f}=\frac{32}{\operatorname{Re}}\left[\frac{\left(e^{M}-1\right)^{2}}{M e^{M}-e^{M}+1}\right] \\
& \sqrt{f}=\frac{32}{\operatorname{Re} \sqrt{f}}\left[\frac{\left(e^{M}-1\right)^{2}}{M e^{M}-e^{M}+1}\right] \\
& f=\left\{\frac{32}{\operatorname{Re} \sqrt{f}}\left[\frac{\left(e^{M}-1\right)^{2}}{M e^{M}-e^{M}+1}\right]\right\}^{2}
\end{aligned}
$$

A equação (74) fornece uma relação explícita entre o fator de atrito, parâmetro de entropia e o número de Rouse $(\operatorname{Re} \sqrt{f})$. O uso desta equação pode fornecer dados para o ajuste de uma função entre o parâmetro de entropia e aquele produto. A relação entre o parâmetro de entropia e o número de Reynolds está apresentada no capítulo 4.6.2.

O parâmetro de entropia $(M)$ seria um parâmetro meio para transformação de uma variável em outra. Tanto a relação entre o número de Reynolds $(\operatorname{Re})$ e o 
parâmetro de entropia $(M)$ e a entre o número de Rouse $(\operatorname{Re} \sqrt{f})$ e este são ajustes tomando-se como base os mesmos dados, fornecidos por McKEON et al. (2008); podendo-se concluir que é possível suprir a passagem de cálculo pelo parâmetro de entropia $(M)$, fazendo-se um ajuste direto entre as estas variáveis desejadas.

O ajuste direto entre o número de Reynolds $(\mathrm{Re})$ e o número de Rouse $(\operatorname{Re} \sqrt{f})$ utiliza em ambos os termos dados brutos, sem passar por ajustes matemáticos em relação aos dados fornecidos por McKEON et al. (2008), em ambos os termos. Este fato fornece uma menor distorção dos dados provocados por ajustes numéricos.

A relação entre o número de Reynolds $(\mathrm{Re})$ e o produto do número de Reynolds e a raiz do fator de atrito $(\operatorname{Re} \sqrt{f})$ é válida e conceitualmente correta. Admitindo isto, é possível extrapolar que esta relação vale para qualquer configuração da relação entre o número de Reynolds $(\operatorname{Re})$ e o fator de atrito $(f)$ para o regime turbulento liso.

Tomando-se como base os quatro relacionamentos de entrada descritos por SOUZA et al. (1991), foi possível transformá-los nas duas variáveis que são objetivos deste capítulo. Para esta transformação foram feitos os relacionamentos de todas elas com o número de Reynolds. 
Tabela 7. Relacionamentos a partir do número de Reynolds (Re) e o fator de atrito (f)

\begin{tabular}{|c|c|c|c|c|c|c|}
\hline \multirow{2}{*}{$\mathrm{Re}$} & \multirow{2}{*}{$f$} & \multicolumn{5}{|c|}{ Relacionamentos } \\
\hline & & $\operatorname{Re}\left(f^{\wedge} 0,5\right)$ & $(\operatorname{Re} / f)^{\wedge} 0,5$ & $\operatorname{Re}\left(f^{\wedge} 1 / 5\right)$ & $1 / f^{\wedge} 0,5$ & $\log (\mathrm{Re})$ \\
\hline $1,120 \mathrm{E}+01$ & $5,537 \mathrm{E}+00$ & 26,35 & 1,42 & $1,577 \mathrm{E}+01$ & 0,42 & 1,05 \\
\hline $2,022 E+01$ & $3,492 \mathrm{E}+00$ & 37,78 & 2,41 & $2,597 \mathrm{E}+01$ & 0,54 & 1,31 \\
\hline $2,928 \mathrm{E}+01$ & $2,329 \mathrm{E}+00$ & 44,68 & 3,55 & $3,467 \mathrm{E}+01$ & 0,66 & 1,47 \\
\hline $4,319 \mathrm{E}+01$ & $1,523 \mathrm{E}+00$ & 53,30 & 5,33 & $4,698 \mathrm{E}+01$ & 0,81 & 1,64 \\
\hline $5,773 \mathrm{E}+01$ & $1,173 \mathrm{E}+00$ & 62,52 & 7,02 & $5,960 \mathrm{E}+01$ & 0,92 & 1,76 \\
\hline $6,458 \mathrm{E}+01$ & $9,863 \mathrm{E}-01$ & 64,14 & 8,09 & $6,440 \mathrm{E}+01$ & 1,01 & 1,81 \\
\hline $8,605 \mathrm{E}+01$ & $7,826 \mathrm{E}-01$ & 76,12 & 10,49 & $8,193 \mathrm{E}+01$ & 1,13 & 1,93 \\
\hline $1,133 \mathrm{E}+02$ & 5,709E-01 & 85,61 & 14,09 & $1,013 \mathrm{E}+02$ & 1,32 & 2,05 \\
\hline $1,353 \mathrm{E}+02$ & $4,815 \mathrm{E}-01$ & 93,88 & 16,76 & $1,169 \mathrm{E}+02$ & 1,44 & 2,13 \\
\hline $1,575 \mathrm{E}+02$ & $4,182 \mathrm{E}-01$ & 101,85 & 19,41 & $1,323 \mathrm{E}+02$ & 1,55 & 2,20 \\
\hline $1,794 \mathrm{E}+02$ & $3,655 \mathrm{E}-01$ & 108,46 & 22,15 & $1,467 \mathrm{E}+02$ & 1,65 & 2,25 \\
\hline $2,064 \mathrm{E}+02$ & $3,237 \mathrm{E}-01$ & 117,43 & 25,25 & $1,647 \mathrm{E}+02$ & 1,76 & 2,31 \\
\hline $2,280 \mathrm{E}+02$ & $2,884 \mathrm{E}-01$ & 122,44 & 28,12 & $1,778 \mathrm{E}+02$ & 1,86 & 2,36 \\
\hline $2,709 E+02$ & $2,433 \mathrm{E}-01$ & 133,62 & 33,37 & $2,042 \mathrm{E}+02$ & 2,03 & 2,43 \\
\hline $3,152 \mathrm{E}+02$ & $2,077 \mathrm{E}-01$ & 143,65 & 38,96 & $2,302 \mathrm{E}+02$ & 2,19 & 2,50 \\
\hline $3,589 \mathrm{E}+02$ & $1,834 \mathrm{E}-01$ & 153,70 & 44,24 & $2,557 \mathrm{E}+02$ & 2,34 & 2,55 \\
\hline $4,029 \mathrm{E}+02$ & $1,656 \mathrm{E}-01$ & 163,96 & 49,33 & $2,812 \mathrm{E}+02$ & 2,46 & 2,61 \\
\hline $4,502 \mathrm{E}+02$ & $1,475 \mathrm{E}-01$ & 172,90 & 55,25 & $3,070 \mathrm{E}+02$ & 2,60 & 2,65 \\
\hline $5,225 \mathrm{E}+02$ & $1,245 \mathrm{E}-01$ & 184,36 & 64,78 & $3,444 E+02$ & 2,83 & 2,72 \\
\hline $5,831 \mathrm{E}+02$ & $1,126 \mathrm{E}-01$ & 195,66 & 71,96 & $3,767 \mathrm{E}+02$ & 2,98 & 2,77 \\
\hline $6,718 \mathrm{E}+02$ & $9,917 \mathrm{E}-02$ & 211,56 & 82,31 & $4,232 \mathrm{E}+02$ & 3,18 & 2,83 \\
\hline $7,898 \mathrm{E}+02$ & $8,501 \mathrm{E}-02$ & 230,28 & 96,39 & $4,824 \mathrm{E}+02$ & 3,43 & 2,90 \\
\hline $8,910 \mathrm{E}+02$ & $\frac{0,722 \mathrm{E}-02}{7,7}$ & $\frac{10,10}{247,60}$ & 107,42 & $5,339 \mathrm{E}+02$ & 3,400 & 2,95 \\
\hline $1,013 \mathrm{E}+03$ & $6,707 \mathrm{E}-02$ & 262,35 & 122,90 & $5,901 \mathrm{E}+02$ & 3,86 & 3,01 \\
\hline $1,197 \mathrm{E}+03$ & $5,880 \mathrm{E}-02$ & 290,26 & 142,68 & $6,792 \mathrm{E}+02$ & 4,12 & 3,08 \\
\hline $1,300 \mathrm{E}+03$ & $5,328 \mathrm{E}-02$ & 300,07 & 156,20 & $7,232 \mathrm{E}+02$ & 4,33 & 3,11 \\
\hline $1,390 \mathrm{E}+03$ & $4,815 \mathrm{E}-02$ & 305,01 & 169,91 & $7,578 \mathrm{E}+02$ & 4,56 & 3,14 \\
\hline $1,669 \mathrm{E}+03$ & $4,304 \mathrm{E}-02$ & 346,25 & 196,92 & $8,897 \mathrm{E}+02$ & 4,82 & 3,22 \\
\hline $1,994 \mathrm{E}+03$ & 3,739E-02 & 385,57 & 230,93 & $1,033 \mathrm{E}+03$ & 5,17 & 3,30 \\
\hline $2,227 \mathrm{E}+03$ & $3,405 \mathrm{E}-02$ & 410,94 & 255,74 & $1,133 \mathrm{E}+03$ & 5,42 & 3,35 \\
\hline $2,554 \mathrm{E}+03$ & $3,091 \mathrm{E}-02$ & 449,02 & 287,45 & $1,274 \mathrm{E}+03$ & 5,69 & 3,41 \\
\hline $2,868 \mathrm{E}+03$ & $2,804 \mathrm{E}-02$ & 480,25 & 319,82 & $1,403 \mathrm{E}+03$ & 5,97 & 3,46 \\
\hline $2,903 E+03$ & $3,182 \mathrm{E}-02$ & 517,84 & 302,05 & $1,457 \mathrm{E}+03$ & 5,61 & 3,46 \\
\hline $2,926 \mathrm{E}+03$ & $3,846 \mathrm{E}-02$ & 573,82 & 275,82 & $1,525 \mathrm{E}+03$ & 5,10 & 3,47 \\
\hline $2,955 \mathrm{E}+03$ & $3,363 \mathrm{E}-02$ & 541,90 & 296,43 & $1,499 \mathrm{E}+03$ & 5,45 & 3,47 \\
\hline $2,991 \mathrm{E}+03$ & $4,124 \mathrm{E}-02$ & 607,40 & 269,31 & $1,581 \mathrm{E}+03$ & 4,92 & 3,48 \\
\hline $2,997 \mathrm{E}+03$ & $3,500 \mathrm{E}-02$ & 560,69 & 292,62 & $1,533 \mathrm{E}+03$ & 5,35 & 3,48 \\
\hline $3,047 \mathrm{E}+03$ & $3,875 \mathrm{E}-02$ & 599,80 & 280,41 & $1,590 \mathrm{E}+03$ & 5,08 & 3,48 \\
\hline $3,080 \mathrm{E}+03$ & $4,285 \mathrm{E}-02$ & 637,57 & 268,10 & $1,640 \mathrm{E}+03$ & 4,83 & 3,49 \\
\hline $3,264 \mathrm{E}+03$ & $4,260 \mathrm{E}-02$ & 673,68 & 276,80 & $1,736 \mathrm{E}+03$ & 4,85 & 3,51 \\
\hline $3,980 \mathrm{E}+03$ & 3,995E-02 & 795,50 & 315,63 & $2,090 \mathrm{E}+03$ & 5,00 & 3,60 \\
\hline $4,835 \mathrm{E}+03$ & $3,797 \mathrm{E}-02$ & 942,14 & 356,84 & $2,514 \mathrm{E}+03$ & 5,13 & 3,68 \\
\hline $5,959 \mathrm{E}+03$ & $3,610 \mathrm{E}-02$ & 1132,21 & 406,29 & $3,067 \mathrm{E}+03$ & 5,26 & 3,78 \\
\hline $8,162 \mathrm{E}+03$ & $3,364 \mathrm{E}-02$ & 1497,01 & 492,57 & $4,142 \mathrm{E}+03$ & 5,45 & 3,91 \\
\hline
\end{tabular}

\begin{tabular}{|c|c|c|c|c|c|c|}
\hline \multirow[b]{2}{*}{$\mathrm{Re}$} & \multirow[b]{2}{*}{$f$} & \multicolumn{5}{|c|}{ Relacionamentos } \\
\hline & & $\operatorname{Re}\left(f^{\wedge} 0,5\right)$ & $(\operatorname{Re} / f)^{\wedge} 0,5$ & $\operatorname{Re}\left(f^{\wedge} 1 / 5\right)$ & $1 / f^{\wedge} 0,5$ & $\log (\mathrm{Re})$ \\
\hline $1,090 \mathrm{E}+04$ & $3,088 \mathrm{E}-02$ & 1915,42 & 594,12 & $5,437 \mathrm{E}+03$ & 5,69 & 4,04 \\
\hline $1,365 \mathrm{E}+04$ & $2,903 \mathrm{E}-02$ & 2325,71 & 685,71 & $6,725 \mathrm{E}+03$ & 5,87 & 4,14 \\
\hline $1,899 \mathrm{E}+04$ & $2,670 \mathrm{E}-02$ & 3102,99 & 843,35 & $9,201 \mathrm{E}+03$ & 6,12 & 4,28 \\
\hline $2,943 E+04$ & $2,386 \mathrm{E}-02$ & 4545,96 & 1110,61 & $1,394 \mathrm{E}+04$ & 6,47 & 4,47 \\
\hline $3,131 \mathrm{E}+04$ & $2,364 \mathrm{E}-02$ & 4814,01 & 1150,85 & $1,481 \mathrm{E}+04$ & 6,50 & 4,50 \\
\hline $4,085 E+04$ & $2,086 \mathrm{E}-02$ & 5899,96 & 1399,39 & $1,884 \mathrm{E}+04$ & 6,92 & 4,61 \\
\hline $4,144 \mathrm{E}+04$ & $2,216 \mathrm{E}-02$ & 6168,86 & 1367,49 & $1,934 \mathrm{E}+04$ & 6,72 & 4,62 \\
\hline $5,636 \mathrm{E}+04$ & $2,061 \mathrm{E}-02$ & 8091,14 & 1653,66 & $2,593 E+04$ & 6,97 & 4,75 \\
\hline $5,636 \mathrm{E}+04$ & $2,061 \mathrm{E}-02$ & 8091,14 & 1653,66 & $2,593 E+04$ & 6,97 & 4,75 \\
\hline $5,636 \mathrm{E}+04$ & $2,061 \mathrm{E}-02$ & 8091,14 & 1653,66 & $2,593 \mathrm{E}+04$ & 6,97 & 4,75 \\
\hline $5,922 E+04$ & $2,000 \mathrm{E}-02$ & 8374,97 & 1720,76 & $2,708 \mathrm{E}+04$ & 7,07 & 4,77 \\
\hline $7,397 \mathrm{E}+04$ & $1,929 \mathrm{E}-02$ & 10273,58 & 1958,22 & $3,358 \mathrm{E}+04$ & 7,20 & 4,87 \\
\hline $8,476 \mathrm{E}+04$ & $1,805 \mathrm{E}-02$ & 11387,53 & 2166,99 & $3,797 \mathrm{E}+04$ & 7,44 & 4,93 \\
\hline $9,846 \mathrm{E}+04$ & $1,815 \mathrm{E}-02$ & 13264,72 & 2329,12 & $4,416 \mathrm{E}+04$ & 7,42 & 4,99 \\
\hline $1,200 \mathrm{E}+05$ & $1,686 \mathrm{E}-02$ & 15581,53 & 2667,85 & $5,303 \mathrm{E}+04$ & 7,70 & 5,08 \\
\hline $1,456 \mathrm{E}+05$ & $1,666 \mathrm{E}-02$ & 18793,12 & 2956,26 & $6,419 \mathrm{E}+04$ & 7,75 & 5,16 \\
\hline $1,760 \mathrm{E}+05$ & $1,594 \mathrm{E}-02$ & 22220,65 & 3322,86 & $7,691 \mathrm{E}+04$ & 7,92 & 5,25 \\
\hline $1,848 \mathrm{E}+05$ & $1,594 \mathrm{E}-02$ & 23331,69 & 3404,92 & $8,076 \mathrm{E}+04$ & 7,92 & 5,27 \\
\hline $2,296 \mathrm{E}+05$ & $1,529 \mathrm{E}-02$ & 28390,67 & 3875,09 & $9,951 \mathrm{E}+04$ & 8,09 & 5,36 \\
\hline$\frac{2,2,377 \mathrm{E}+05}{2}$ & $\frac{1,50 \mathrm{~L}-0 \mathrm{c}}{1,511 \mathrm{E}-02}$ & $\frac{2000,01}{29218,74}$ & $\begin{array}{l}3066,27 \\
396,27\end{array}$ & $1,028 \mathrm{E}+05$ & 8,14 & 5,38 \\
\hline $2,982 \mathrm{E}+05$ & $1,462 \mathrm{E}-02$ & 36056,31 & 4516,27 & $1,281 \mathrm{E}+05$ & 8,27 & 5,47 \\
\hline $3,085 \mathrm{E}+05$ & $\frac{1,461 \mathrm{~L}}{1,461 \mathrm{E}-02}$ & 37288,96 & 4595,18 & $1,325 \mathrm{E}+05$ & 8,27 & 5,49 \\
\hline $4,081 \mathrm{E}+05$ & $1,384 \mathrm{E}-02$ & 48010,32 & 5430,19 & $1,734 \mathrm{E}+05$ & 8,50 & 5,61 \\
\hline $4,678 \mathrm{E}+05$ & $1,365 \mathrm{E}-02$ & 54654,58 & 5854,15 & $1,982 \mathrm{E}+05$ & 8,56 & 5,67 \\
\hline $5,378 \mathrm{E}+05$ & $1,324 \mathrm{E}-02$ & 61882,06 & 6373,33 & $2,265 \mathrm{E}+05$ & 8,69 & 5,73 \\
\hline $5,378 E+05$ & $1,324 \mathrm{E}-02$ & 61882,06 & 6373,33 & $2,265 \mathrm{E}+05$ & 8,69 & 5,73 \\
\hline $7,507 \mathrm{E}+05$ & $1,249 \mathrm{E}-02$ & 83897,23 & 7752,68 & $3,124 \mathrm{E}+05$ & 8,95 & 5,88 \\
\hline $8,242 \mathrm{E}+05$ & $1,244 \mathrm{E}-02$ & 91926,94 & 8139,66 & $3,428 \mathrm{E}+05$ & 8,97 & 5,92 \\
\hline $1,024 \mathrm{E}+06$ & $1,183 \mathrm{E}-02$ & 111376,18 & 9303,74 & $4,216 \mathrm{E}+05$ & 9,19 & 6,01 \\
\hline $1,050 \mathrm{E}+06$ & $1,198 \mathrm{E}-02$ & 114925,85 & 9361,95 & $4,334 \mathrm{E}+05$ & 9,14 & 6,02 \\
\hline $1,342 \mathrm{E}+06$ & $1,131 \mathrm{E}-02$ & 142719,67 & 10892,94 & $5,476 \mathrm{E}+05$ & 9,40 & 6,13 \\
\hline $1,791 \mathrm{E}+06$ & $1,079 \mathrm{E}-02$ & 186039,99 & 12883,60 & $7,239 \mathrm{E}+05$ & 9,403 & 6,25 \\
\hline $2,352 \mathrm{E}+06$ & $1,028 \mathrm{E}-02$ & 238470,07 & 15125,93 & $9,415 \mathrm{E}+05$ & 9,86 & 6,37 \\
\hline $3,109 \mathrm{E}+06$ & $9,890 \mathrm{E}-03$ & 309185,32 & 17730,14 & $1,235 \mathrm{E}+06$ & 10,06 & 6,49 \\
\hline $4,438 \mathrm{E}+06$ & $9,410 \mathrm{E}-03$ & 430508,88 & 21716,95 & $1,745 \mathrm{E}+06$ & 10,31 & 6,65 \\
\hline $6,103 E+06$ & $8,970 \mathrm{E}-03$ & 578015,64 & 26084,08 & $2,377 \mathrm{E}+06$ & 10,56 & 6,79 \\
\hline $7,757 \mathrm{E}+06$ & $8,620 \mathrm{E}-03$ & 720190,56 & 29998,07 & $2,998 \mathrm{E}+06$ & 10,77 & 6,89 \\
\hline $1,031 \mathrm{E}+07$ & $8,250 \mathrm{E}-03$ & 936452,25 & 35351,05 & $3,950 \mathrm{E}+06$ & 11,01 & 7,01 \\
\hline $1,031 \mathrm{E}+07$ & $8,250 \mathrm{E}-03$ & 936452,25 & 35351,05 & $3,950 \mathrm{E}+06$ & 11,01 & 7,01 \\
\hline $1,368 \mathrm{E}+07$ & $7,980 \mathrm{E}-03$ & 1222045,97 & 41403,93 & $5,206 \mathrm{E}+06$ & 11,19 & 7,14 \\
\hline $1,830 \mathrm{E}+07$ & $7,670 \mathrm{E}-03$ & 1602687,21 & 48845,87 & $6,909 \mathrm{E}+06$ & 11,42 & 7,26 \\
\hline $2,413 E+07$ & $7,400 \mathrm{E}-03$ & 2075741,09 & 57103,51 & $9,045 \mathrm{E}+06$ & 11,62 & 7,38 \\
\hline $3,015 \mathrm{E}+07$ & $7,200 \mathrm{E}-03$ & 2558312,33 & 64710,90 & $1,124 \mathrm{E}+07$ & 11,79 & 7,48 \\
\hline $3.554 \mathrm{E}+07$ & $7.080 \mathrm{E}-03$ & 299043283 & 7085036 & $1.320 \mathrm{E}+07$ & 11,88 & 7,55 \\
\hline
\end{tabular}




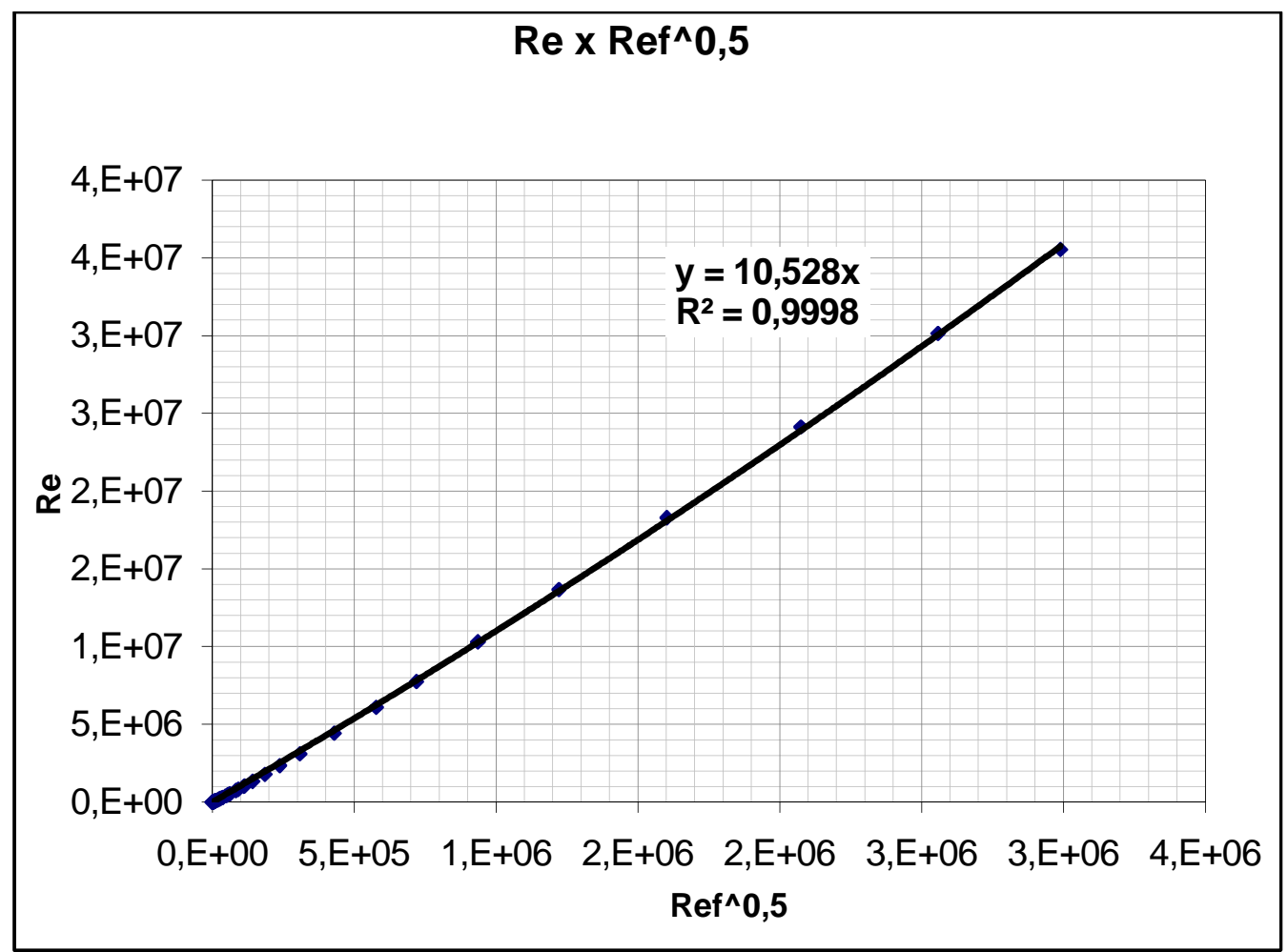

Figura 44. Relacionamento entre o produto do número de Reynolds e a raiz do fator de atrito $(\operatorname{Re} \sqrt{f}$ ) e o número de Reynolds (Re).

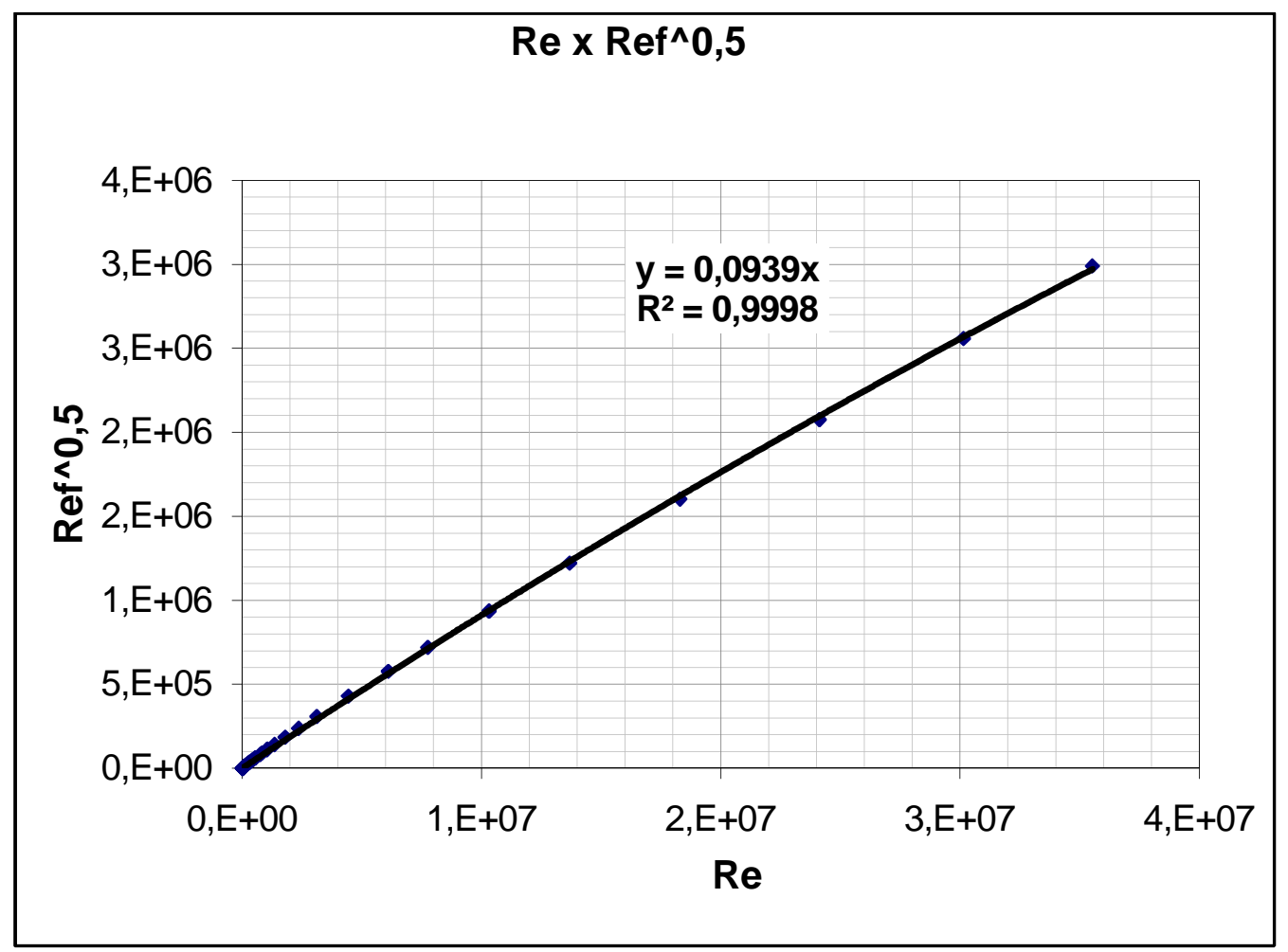

Figura 45. Relacionamento entre o número de Reynolds $(R e)$ e o produto do número de Reynolds e a raiz do fator de atrito $(\operatorname{Re} \sqrt{f})$. 


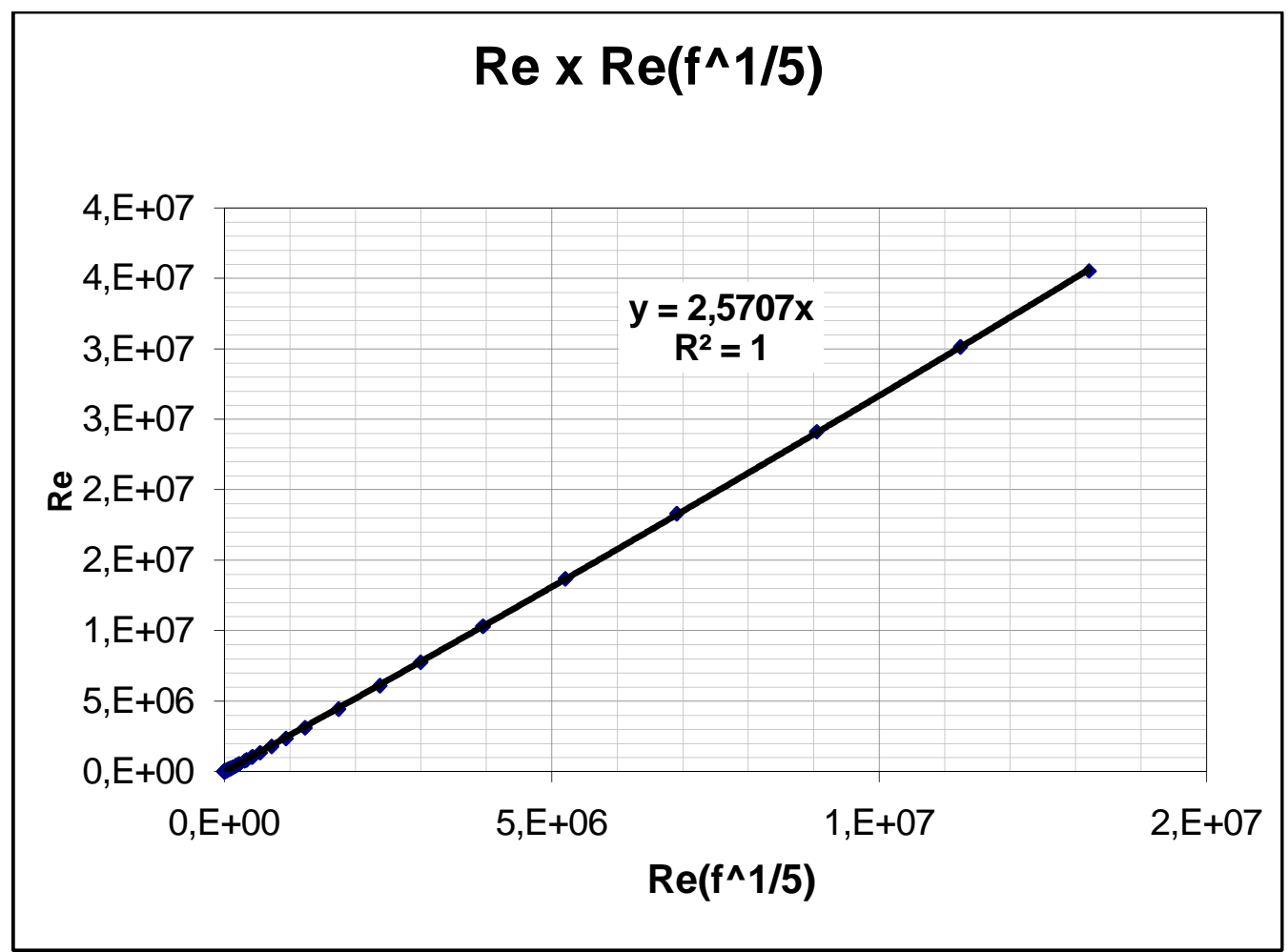

Figura 46. Relacionamento entre a divisão do número de Reynolds e a raiz quinta do fator de atrito ( $\operatorname{Re} / \sqrt[5]{f}$ ) e o número de Reynolds (Re).

\section{$\operatorname{Re} x(\operatorname{Re} / f)^{\wedge} 0,5$}

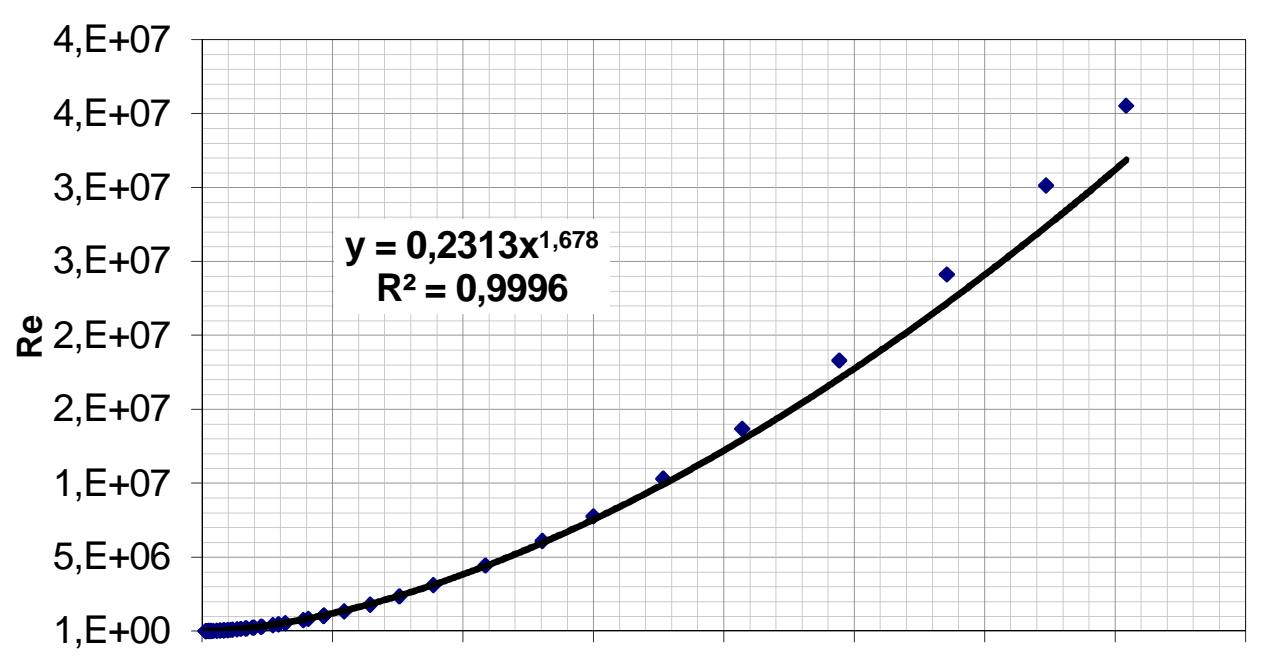

0,E+00 1,E+04 2,E+04 3,E+04 4,E+04 5,E+04 6,E+04 7,E+04 8,E+04

$(\mathrm{Re} / \mathrm{f})^{\wedge} \mathbf{0 , 5}$

Figura 47. Relacionamento entre a raiz quadrada da razão do número de Reynolds e o fator de atrito $(\sqrt{\operatorname{Re} / f})$ pelo número de Reynolds $(\mathrm{Re})$. 


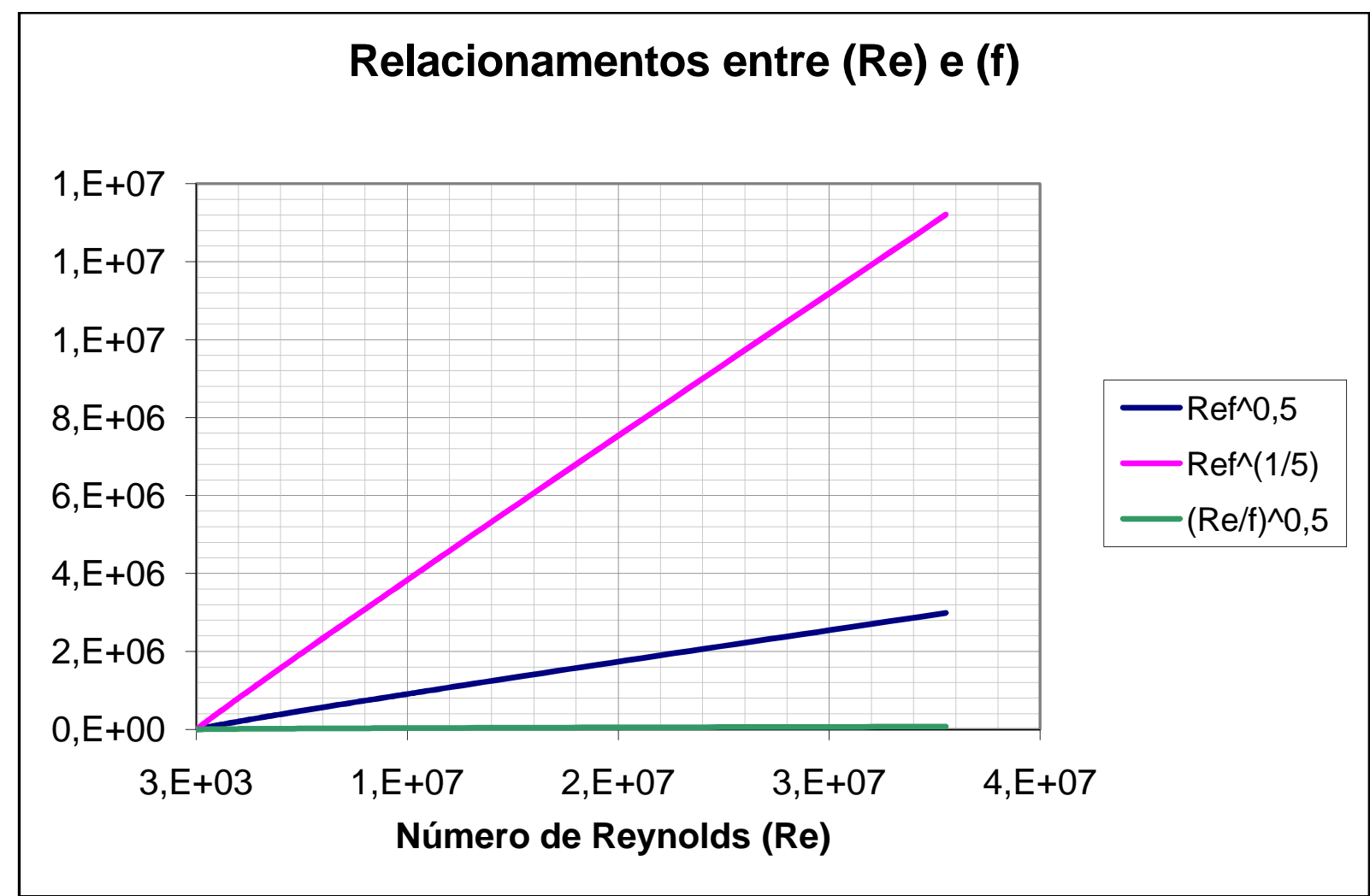

Figura 48. Gráfico resumo dos relacionamentos entre o número de Reynolds $(\operatorname{Re})$ e as combinações entre o número de Reynolds $(\operatorname{Re})$ e o fator de atrito $(f)$.

Os dados calculados na tabela (7) serviram de base para os ajustes entre os relacionamentos do número de Reynolds $(\mathrm{Re})$ e o fator de atrito com o número de Reynolds. Os ajustes dos gráficos (44), (45), (46), (47) e (48) são a base para a solução dos quatro modelos de cálculo.

A partir destes ajustes, para cada situação de cálculo proposta por SOUZA et al. (1991), foi montada uma seqüência de cálculo. Esta seqüência teve como objetivo obter os valores de entrada para os modelos propostos nos capítulos 4.6 .1 e 4.6.2.

Nos algoritmos 3 e 4 o diâmetro é a incógnita, porém no cálculo do número de Reynolds aparente é um dado de entrada. Foi necessário, através de álgebra, suprimir o valor do diâmetro de tal formulação. 
Esta supressão foi feita multiplicando-se e dividindo-se pelo número de Reynolds molecular.

$$
\operatorname{Re}_{a}=\operatorname{Re}\left[1+\frac{0,3721}{\sqrt{8}}(\operatorname{Re} \sqrt{f})\left(\frac{k}{D}\right)\left(\frac{\operatorname{Re}}{\operatorname{Re}}\right)\right]^{-1}
$$

A partir da equação (75), é possível utilizar a razão entre números de Reynolds para substituir o valor do diâmetro da tubulação. Deve ser substituído um dos valores do número de Reynolds desta relação pela fórmula do número de Reynolds. Porém, o algoritmo 3 tem como dado de entrada a vazão e o algoritmo 4, a velocidade.

Considerando os dados de entrada de cada algoritmo, foi necessário criar uma nova equação para cada algoritmo. Para o algoritmo 3, o valor do Número de Reynolds no denominador foi substituído pela fórmula do número de Reynolds em função da vazão.

$$
\begin{gathered}
\operatorname{Re}_{a}=\operatorname{Re}\left[1+\frac{0,3721}{\sqrt{8}}(\operatorname{Re} \sqrt{f})\left(\frac{k}{D}\right)\left(\operatorname{Re} \frac{\pi v D}{4 Q}\right)\right]^{-1} \\
\operatorname{Re}_{a}=\operatorname{Re}\left(1+\frac{0,3721}{\sqrt{8}} \operatorname{Re} \sqrt{f} \frac{\operatorname{Re} \pi v k}{4 Q}\right)^{-1}
\end{gathered}
$$

Todos os dados de entrada da equação (77) são dados de entrada do algoritmo 3 e calculados no mesmo. Portanto foi possível suprimir o valor do diâmetro do cálculo do algoritmo 3 , utilizando apenas os dados disponíveis no modelo.

O algoritmo 4 tem como um de seus dados de entrada a velocidade. Para supressão do valor do diâmetro, foi utilizado o equacionamento do número de 
Reynolds em função da velocidade. Este equacionamento substituiu o número de Reynolds do numerador.

$$
\begin{gathered}
\operatorname{Re}_{a}=\operatorname{Re}\left[1+\frac{0,3721}{\sqrt{8}}(\operatorname{Re} \sqrt{f})\left(\frac{k}{D}\right)\left(\frac{1}{\operatorname{Re}} \frac{V D}{v}\right)\right]^{-1} \\
\operatorname{Re}_{a}=\operatorname{Re}\left(1+\frac{0,3721}{\sqrt{8}} \operatorname{Re} \sqrt{f} \frac{V k}{v \operatorname{Re}}\right)^{-1}
\end{gathered}
$$

Assim como o ocorrido na equação (77) para o algoritmo 3, foi obtida na equação (79) uma equação onde seus dados de entrada são os dados de entrada do algoritmo 3 e calculados no mesmo.

Para facilitar a compreensão, os modelos para as quatro situações de cálculo serão apresentados em forma de fluxograma. 


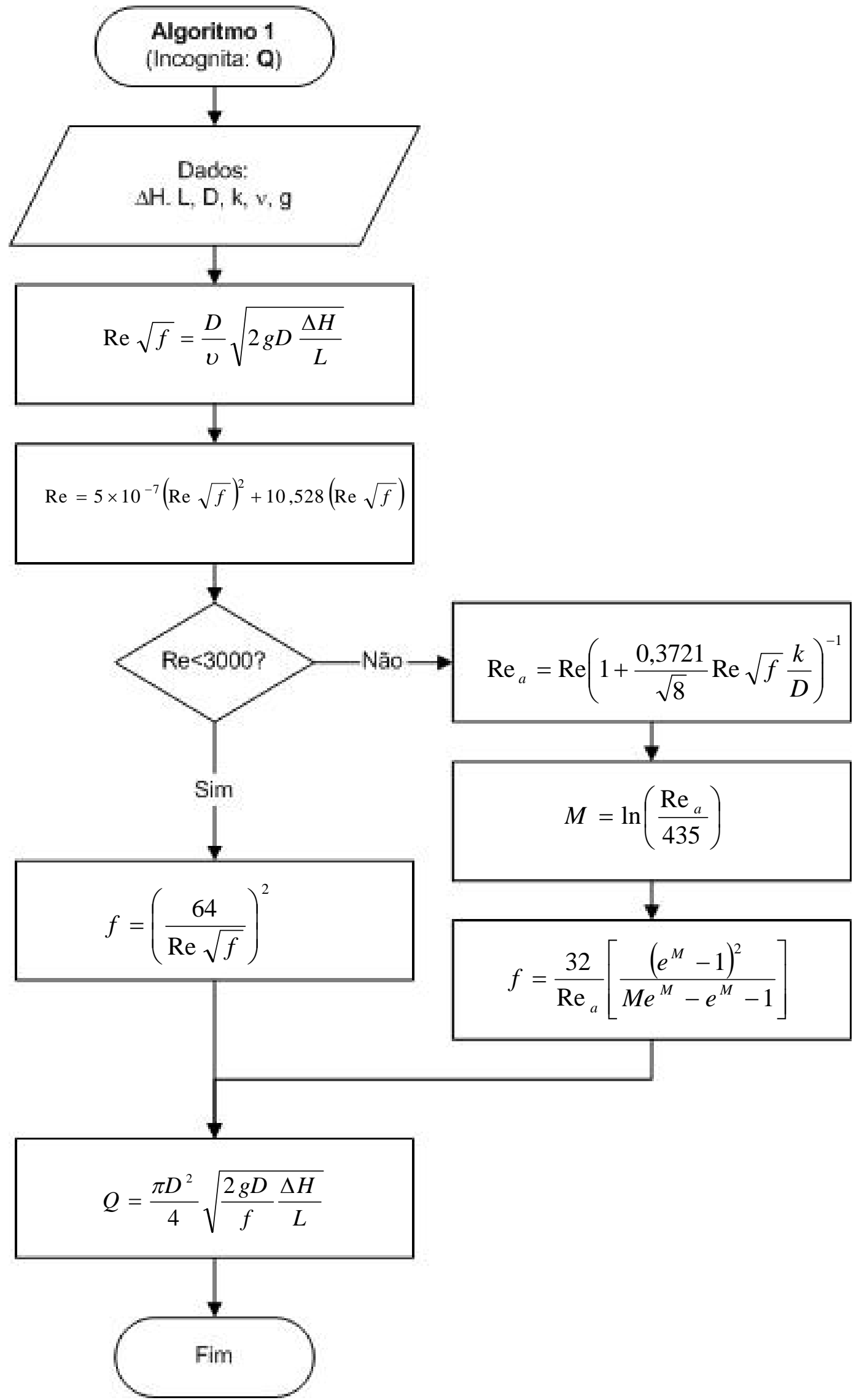

Figura 49. Algoritmo de cálculo 1. 


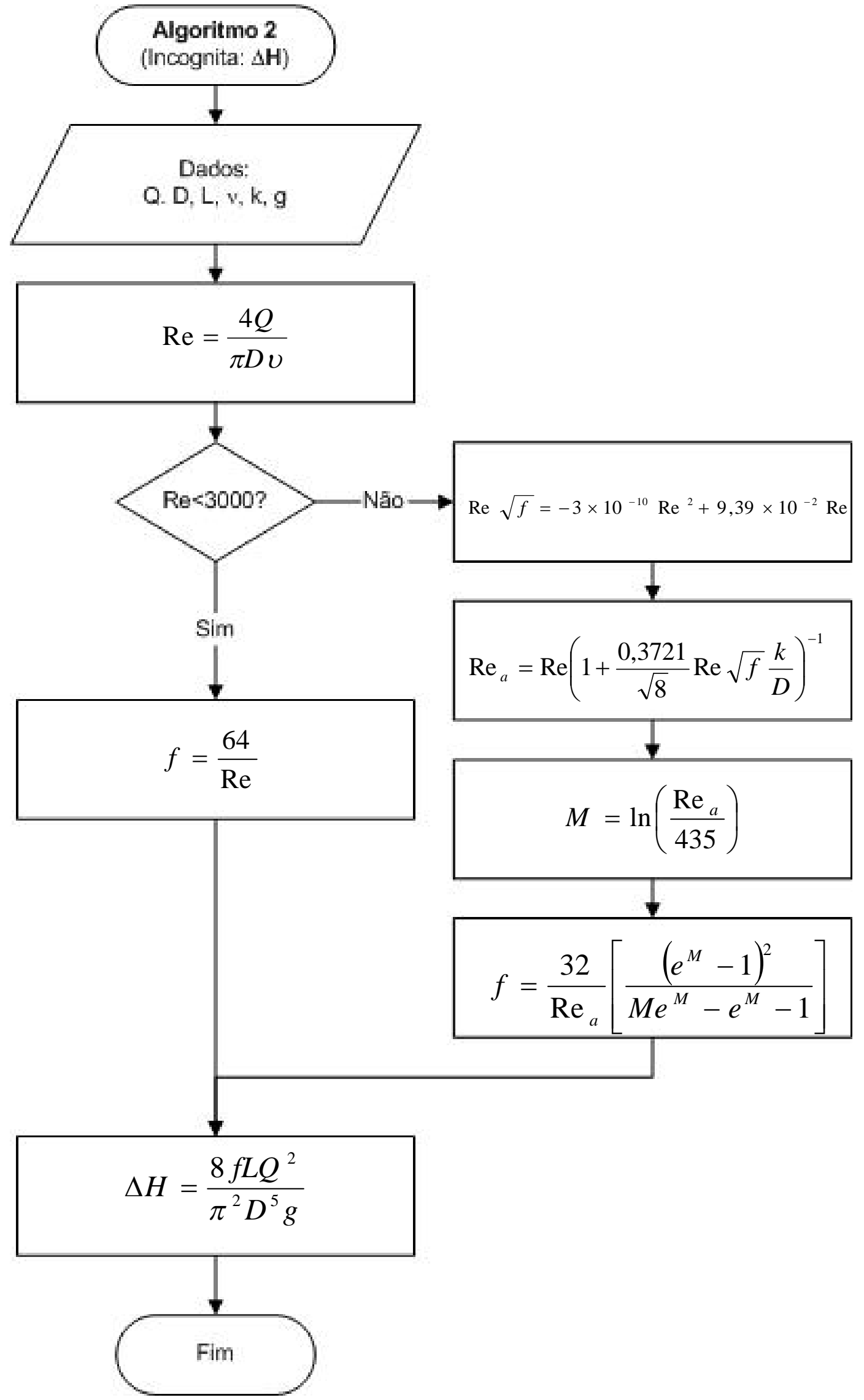

Figura 50. Algoritmo de cálculo 2. 


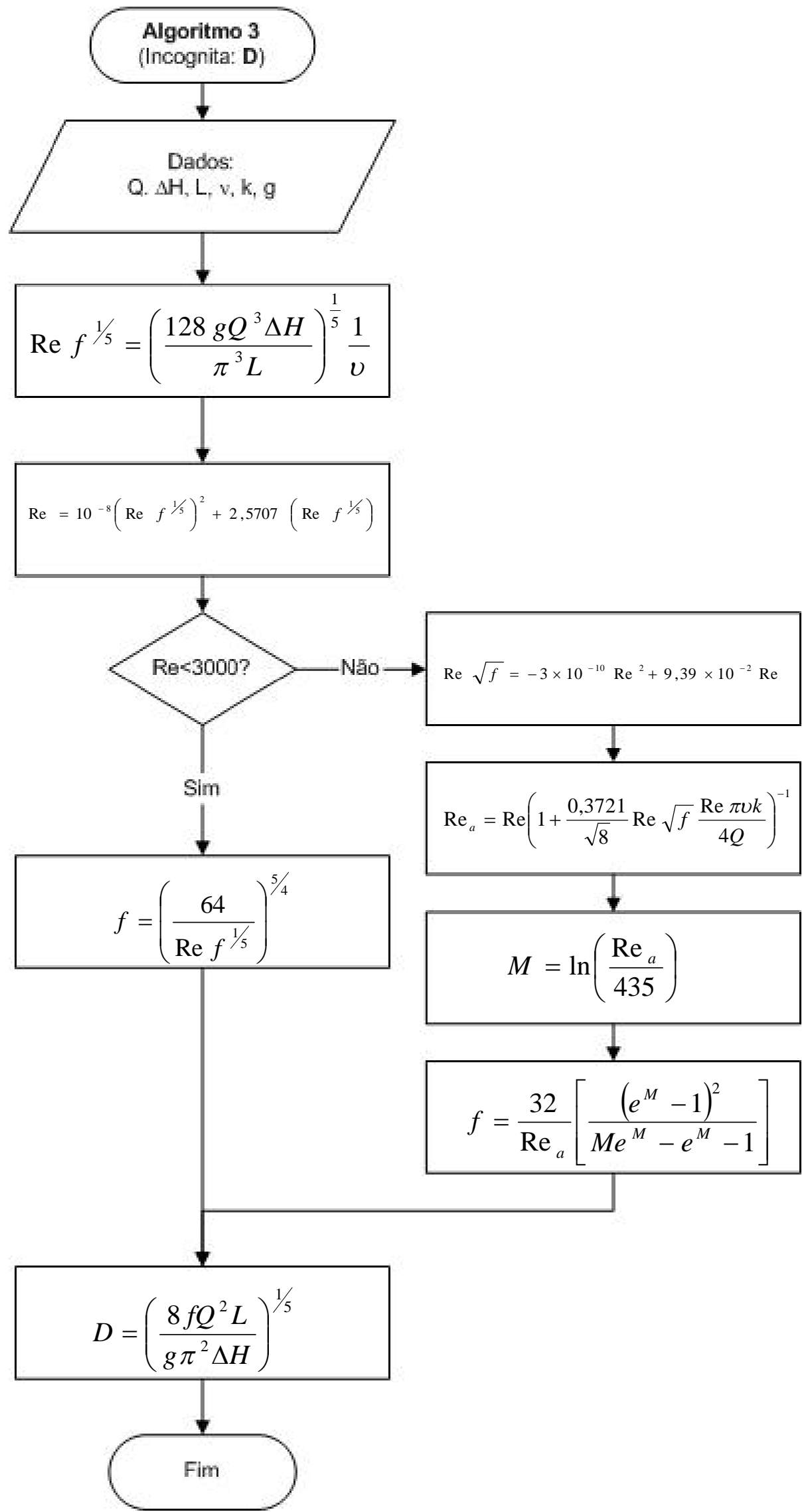

Figura 51. Algoritmo de cálculo 3. 


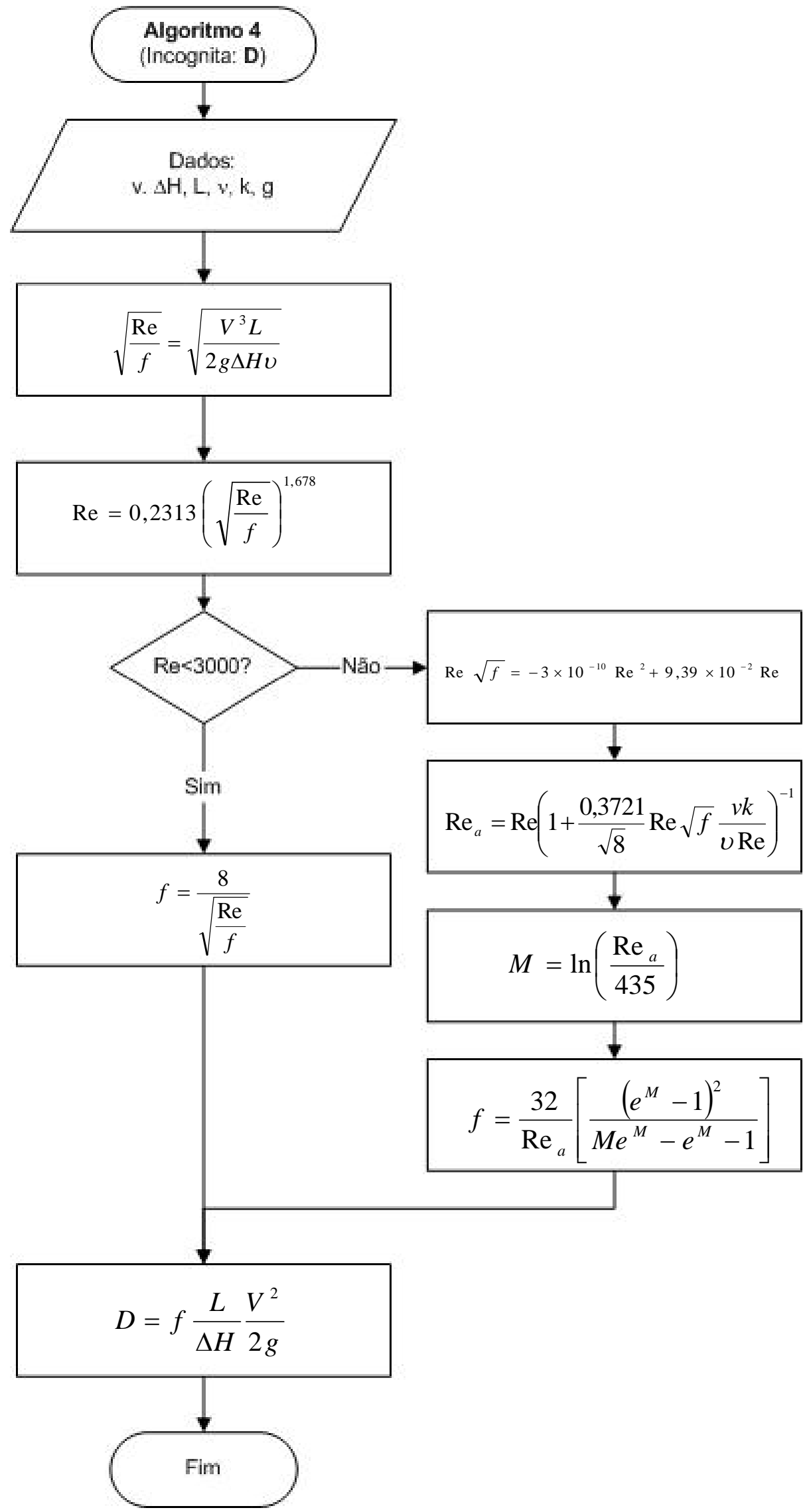

Figura 52. Algoritmo de cálculo 4. 


\subsection{Análise de Consistência}

A análise de consistência teve como objetivo criticar as formulações resultantes deste trabalho. As formulações serão avaliadas por dois métodos distintos. O primeiro é uma análise dimensional, tendo o objetivo de verificar se as dimensões obtidas no resultado são compatíveis com as do valor esperado. Já a segunda visa verificar se as hipóteses de cálculo são compatíveis com as que descrevem o fenômeno físico para os quais foram obtidas.

O item 4.6.1 apresentou como resultado do desenvolvimento ali descrito na fórmula (54). O resultado deste equacionamento é adimensional, pois representa a taxa de variação entre a viscosidade turbulenta e molecular. Das variáveis encontradas neste equacionamento, apenas os valores da rugosidade da parede do tubo (k) e o diâmetro do tubo (D) não são adimensionais. Ambos são variáveis com unidade métrica e estão dispostas de forma que suas unidades se anulam, portanto o resultado da equação (54) é também adimensional.

Nas situações onde o número de Reynolds aparente $\left(\operatorname{Re}_{a}\right)$ torna-se igual ao número de Reynolds molecular ( $\mathrm{Re}$ ), o resultado da equação (54) tem que ser igual a 1. Tal resultado apenas pode ocorrer em duas situações: na ausência de escoamento e na ausência de rugosidade da tubulação.

Para comprovar tais resultados foi feito o limite da equação (54) para os parâmetros relativos ao escoamento $(\operatorname{Re} \sqrt{f})$ e à rugosidade da parede da tubulação (k). As equações (79) e (80) apresentam os limites da equação (54).

$$
\lim _{\operatorname{Re} \sqrt{f} \rightarrow 0}\left(1+\frac{0,3721}{\sqrt{8}} \operatorname{Re} \sqrt{f} \frac{k}{D}\right)=1
$$




$$
\lim _{k \rightarrow 0}\left(1+\frac{0,3721}{\sqrt{8}} \operatorname{Re} \sqrt{f} \frac{k}{D}\right)=1
$$

Os resultados das análises dimensionais e de limites atestaram a consistência da equação (54). A análise dimensional mostrou que o resultado deste equacionamento é compatível com sua utilização. Já a análise dos limites atestou não haver erro teórico em sua concepção.

A segunda formulação a ser avaliada é a resultante do desenvolvimento descrito no item 4.6.2, a equação (60). A análise de limites desta equação foi feita apenas para o limite superior. Tendo em vista que este equacionamento tem como fundo teórico o equacionamento desenvolvido por CHIU (1987), equação (27), a análise do limite inferior foi feita em cima deste equacionamento.

A análise dimensional não é necessária, tanto na equação (27) como na equação (60), pois estes equacionamentos utilizam apenas grandezas adimensionais. A análise de limites foi feita tomando-se o limite máximo e mínimo do parâmetro de entropia $(M)$. Apenas será feito o limite do termo da equação onde o parâmetro de entropia está inserido.

Impondo-se o parâmetro de entropia $(M)$ tendendo ao infinito na equação (60):

$$
\begin{gathered}
f=\frac{32}{435}\left\{\lim _{M \rightarrow \infty}\left[\frac{\left(e^{M}-1\right)^{2}}{e^{M}\left(M e^{M}-e^{M}+1\right)}\right]\right\} \\
\lim _{M \rightarrow \infty}\left[\frac{\left(e^{M}-1\right)^{2}}{e^{M}\left(M e^{M}-e^{M}+1\right)}\right] \Rightarrow \lim _{M \rightarrow \infty}\left[\frac{e^{2 M}\left(1-\frac{1}{e^{M}}\right)^{2}}{e^{2 M}\left(M-1+\frac{1}{e^{M}}\right)}\right]=\frac{1}{\infty}=0
\end{gathered}
$$


O limite da equação (27) para o parâmetro de entropia $(M)$ tendendo ao infinito é zero. Esta afirmação está correta, pois, o fator de atrito é inversamente proporcional ao número de Reynolds (Re) e, conseqüentemente ao parâmetro de entropia $(M)$. Quando o número de Reynolds $(M)$ tende ao infinito, o fator de atrito ( $f$ ) tende a zero.

Ao impor o parâmetro de entropia $(M)$ tendendo a zero, tem-se:

$$
f=\frac{32}{\operatorname{Re}}\left[\lim _{M \rightarrow 0} \frac{\left(e^{M}-1\right)^{2}}{M e^{M}-e^{M}+1}\right] \Rightarrow \frac{32}{\operatorname{Re}}\left(\frac{0}{0}\right)
$$

O resultado do limite da equação (84) não existe em nenhum conjunto numérico válido. Com objetivo de resolver esta indeterminação foi aplicada a regra de L'Hospital. Esta regra consiste em fazer a derivada separada do numerador e do divisor da equação (84), após então, analisa-se novamente o limite.

$$
f=\frac{32}{\operatorname{Re}}\left[\lim _{M \rightarrow 0} \frac{2\left(e^{M}-1\right) e^{M}}{(M-1+1) e^{M}}\right] \Rightarrow \frac{32}{\operatorname{Re}}\left(\frac{0}{0}\right)
$$

Novamente, na equação (85), o limite do termo de entropia da equação (27) apresentou uma indeterminação. Foi aplicada novamente a regra de L'Hospital.

$$
f=\frac{32}{\operatorname{Re}}\left[\lim _{M \rightarrow 0} \frac{2 e^{M}}{1}\right] \Rightarrow \frac{32}{\operatorname{Re}}(2) \Rightarrow \frac{64}{\operatorname{Re}}
$$

Após a aplicação da regra de L'Hospital pela segunda vez, o limite da equação (86) chegou a uma determinação. Esta determinação encaixa-se perfeitamente com o resultado clássico para determinação do fator de atrito no regime laminar. 
As análises dimensionais e de limites atestam que a equação (27), apresentada por CHIU et al. (1993) é consistente. Esta formulação foi a base conceitual para a equação (60).

A terceira equação que teve sua consistência analisada foi a equação (24), também desenvolvida por CHIU et al. (1993). Esta equação é, juntamente com a analisada anteriormente, base para o desenvolvimento do item 4.6.3.

Assim como na análise anterior, a equação (24) é formada unicamente por grandezas adimensionais, portanto dispensando tal análise. Novamente a análise volta-se ao limite inferior e superior do parâmetro de entropia $(M)$.

Impondo-se o valor do parâmetro de entropia $(M)$ tendendo ao infinito:

$$
\lim _{M \rightarrow \infty}\left(\frac{\bar{u}}{u_{\max }}\right)=\lim _{M \rightarrow \infty}\left(\frac{M e^{M}-e^{M}+1}{M e^{M}-M}\right) \Rightarrow \lim _{M \rightarrow \infty}\left[\frac{M e^{M}\left(1-\frac{1}{M}+\frac{1}{M e^{M}}\right)}{M e^{M}\left(1-\frac{1}{M e^{M}}\right)}\right]=1
$$

Aplicando-se o limite tendendo ao infinito na equação (24) resultou em 1 para a razão entre a velocidade média e a máxima. Este resultado significa que o perfil de velocidades tende a uma distribuição uniforme com $\bar{u}=u_{\max }$.

Ao impor-se zero como o limite inferior do parâmetro de entropia $(M)$, tem-se:

$$
\lim _{M \rightarrow 0}\left(\frac{\bar{u}}{u_{\max }}\right)=\lim _{M \rightarrow 0}\left(\frac{M e^{M}-e^{M}+1}{M e^{M}-M}\right)=\frac{0}{0}
$$

Semelhante ao que aconteceu na análise tendendo a zero da equação (27), o limite tendeu a uma indeterminação. Novamente foi utilizada a regra de L'Hospital para solucionar esta indeterminação. 


$$
\lim _{M \rightarrow 0}\left(\frac{\bar{u}}{u_{\max }}\right)=\lim _{M \rightarrow 0}\left(\frac{M e^{M}+e^{M}-e^{M}}{M e^{M}-e^{M}-1}\right)=\frac{0}{0}
$$

Novamente o resultado tendeu à indeterminação. Pela segunda vez foi aplicada a regra de L'Hospital à equação (89).

$$
\lim _{M \rightarrow 0}\left(\frac{\bar{u}}{u_{\max }}\right)=\lim _{M \rightarrow 0}\left(\frac{M e^{M}+e^{M}}{M e^{M}+e^{M}+e^{M}}\right)=\frac{1}{2}
$$

Reorganizando-se os termos da equação (90), tem-se:

$$
u_{\max }=2 \bar{u}
$$

O limite inferior do parâmetro de entropia aplicado à equação (24) resultou na equação (91). Esta equação relata que, para o regime laminar, a velocidade máxima é o dobro da média. Este resultado é apresentado por FOX e McDONALD (2008) para descrever o perfil de escoamento laminar.

Esta análise verificou que todas as equações envolvidas neste tópico são consistentes. Este trabalho pôde então seguir para a validação preliminar, item pelo qual será avaliado o uso do equacionamento proposto, comparado com os modelos existentes.

\subsection{Verificação Preliminar}

A validação preliminar dos modelos apresentados foi divida em três partes. A primeira teve como objetivo analisar os resultados do modelo, para regime turbulento liso, desenvolvido no capítulo 4.6.2. Na segunda parte foram analisados os resultados obtidos quando combinados os modelos dos capítulos 4.6.1 e 4.6.2. A última parte da validação preliminar objetivou analisar os dados obtidos a partir dos 
modelos desenvolvidos no capítulo 4.6.4, os quais também tiveram como base associações entre os modelos desenvolvidos nos capítulos 4.6.1 e 4.6.2.

A análise do modelo 4.6.2 foi feita para os regimes laminar e turbulento. Para esta análise foi utilizada a equação (60), tendo como sua base o parâmetro de entropia. Como parâmetro de comparação, foi utilizada a equação para o regime laminar (64/Re). Para regime turbulento liso, as equações de Nikuradse, zerando-se o dado da rugosidade na equação de Colebrook, equação (4). E o equacionamento proposto por McKEON et al. (2008), equação (32), também para o regime turbulento liso.

Para o cálculo do fator de atrito para o regime laminar, foi adotado zero para todos os valores do parâmetro de entropia $(M)$. Esta consideração é necessária, pois a equação (60) vale apenas para o regime turbulento. Foi adotado como limite entre regimes laminar e turbulento, conforme adotado no capítulo 4.6.4, o valor do número de Reynolds (Re) igual a 3.000 .

A tabela (8) apresenta os resultados da primeira análise desta validação. Em seguida, como forma de comparação, os resultados de todas as equações foram lançados no gráfico da figura (53). 
Tabela 8. Comparação entre modelos matemáticos para o fator de atrito - Escoamento Liso

\begin{tabular}{ccccccccc}
\hline \multirow{2}{*}{$\mathrm{Re}$} & \multicolumn{2}{c}{ Entropia } & \multicolumn{2}{c}{ Laminar } & \multicolumn{2}{c}{ Nikuradse } & \multicolumn{2}{c}{ McKeon } \\
\cline { 2 - 10 } & $\mathrm{M}$ & $\mathrm{fe}$ & $\mathrm{f}$ & $\mathrm{f} / \mathrm{fe}$ & $\mathrm{f}$ & $\mathrm{f} / \mathrm{fe}$ & $\mathrm{f}$ & $\mathrm{f} / \mathrm{fe}$ \\
\hline $5,0 \mathrm{E}+02$ & 0,00 & 0,1280 & 0,1280 & 0,0000 & - & - & - & - \\
\hline $1,0 \mathrm{E}+03$ & 0,00 & 0,0640 & 0,0640 & 0,0000 & - & - & - & - \\
\hline $1,5 \mathrm{E}+03$ & 0,00 & 0,0427 & 0,0427 & 0,0000 & - & - & - & - \\
\hline $2,0 \mathrm{E}+03$ & 0,00 & 0,0320 & 0,0320 & 0,0000 & - & - & - & - \\
\hline $2,5 \mathrm{E}+03$ & 0,00 & 0,0256 & 0,0256 & 0,0000 & - & - & - & - \\
\hline $3,0 \mathrm{E}+03$ & 0,00 & 0,0213 & 0,0213 & 0,0000 & - & - & - & - \\
\hline $3,5 \mathrm{E}+03$ & 2,08 & 0,0466 & - & - & 0,0399 & 0,1441 & 0,0391 & 0,161 \\
\hline $4,0 \mathrm{E}+03$ & 2,22 & 0,0440 & - & - & 0,0399 & 0,0931 & 0,0391 & 0,111 \\
\hline $8,0 \mathrm{E}+03$ & 2,91 & 0,0334 & - & - & 0,0328 & 0,0196 & 0,0324 & 0,032 \\
\hline $1,6 \mathrm{E}+04$ & 3,60 & 0,0264 & - & - & 0,0274 & 0,0347 & 0,0272 & 0,028 \\
\hline $3,2 \mathrm{E}+04$ & 4,30 & 0,0216 & - & - & 0,0231 & 0,0706 & 0,0231 & 0,069 \\
\hline $6,4 \mathrm{E}+04$ & 4,99 & 0,0181 & - & - & 0,0198 & 0,0905 & 0,0199 & 0,094 \\
\hline $1,3 \mathrm{E}+05$ & 5,68 & 0,0156 & - & - & 0,0171 & 0,0973 & 0,0172 & 0,106 \\
\hline $2,6 \mathrm{E}+05$ & 6,38 & 0,0136 & - & - & 0,0149 & 0,0941 & 0,0151 & 0,107 \\
\hline $5,1 \mathrm{E}+05$ & 7,07 & 0,0121 & - & - & 0,0131 & 0,0836 & 0,0133 & 0,100 \\
\hline $1,0 \mathrm{E}+06$ & 7,76 & 0,0109 & - & - & 0,0116 & 0,0677 & 0,0118 & 0,087 \\
\hline $2,0 \mathrm{E}+06$ & 8,46 & 0,0099 & - & - & 0,0103 & 0,0483 & 0,0105 & 0,070 \\
\hline $4,1 \mathrm{E}+06$ & 9,15 & 0,0090 & - & - & 0,0093 & 0,0265 & 0,0095 & 0,050 \\
\hline $8,2 \mathrm{E}+06$ & 9,84 & 0,0083 & - & - & 0,0083 & 0,0033 & 0,0086 & 0,029 \\
\hline $1,6 \mathrm{E}+07$ & 10,54 & 0,0077 & - & - & 0,0076 & 0,0207 & 0,0078 & 0,006 \\
\hline $3,3 \mathrm{E}+07$ & 11,23 & 0,0072 & - & - & 0,0069 & 0,0449 & 0,0071 & 0,017 \\
\hline $6,6 \mathrm{E}+07$ & 11,92 & 0,0067 & - & - & 0,0063 & 0,0690 & 0,0065 & 0,040 \\
\hline $1,3 \mathrm{E}+08$ & 12,62 & 0,0063 & - & - & 0,0057 & 0,0928 & 0,0059 & 0,063 \\
\hline $2,6 \mathrm{E}+08$ & 13,31 & 0,0060 & - & - & 0,0053 & 0,1160 & 0,0055 & 0,085 \\
\hline $5,2 \mathrm{E}+08$ & 14,00 & 0,0057 & - & - & 0,0049 & 0,1387 & 0,0050 & 0,108 \\
\hline & & & & & & & & \\
\hline
\end{tabular}

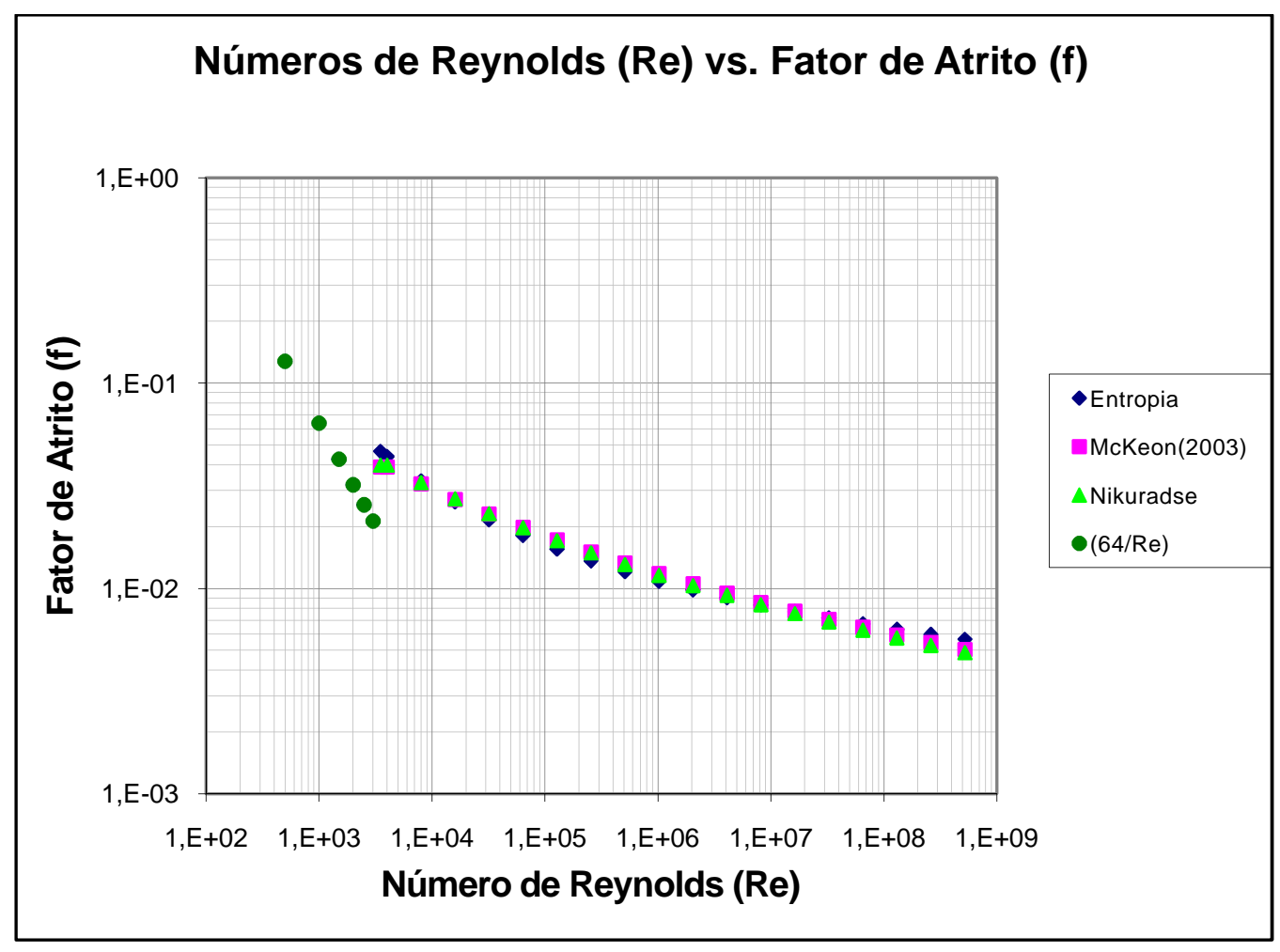

Figura 53. Comparação entre cálculos de fatores de atrito. 
A comparação entre os modelos de cálculo do fator de atrito foi praticamente coincidente. Esta proximidade pode ser observada tanto na tabela (8), quanto no gráfico (51), onde os pontos se sobrepõem. Este fato deve-se a ambos os modelos terem base teórica.

O gráfico da figura (53) apresenta a comparação entre os modelos de equacionamento do fator de atrito para regime turbulento de Nikuradse, McKeon e Entropia. O modelo apresentado no capítulo 4.6.2 (Entropia) apresentou um comportamento muito similar aos demais modelos.

Superada a análise do equacionamento proposto no item 4.6.2, a qual referese ao equacionamento do fator de atrito $(f)$, tanto para o regime laminar, quanto para o turbulento liso, foi realizada a análise para os regimes turbulento misto e turbulento rugoso. Esta análise teve como base a associação das equações propostas nos itens 4.6 .1 e 4.6.2.

Para realizar a análise dos resultados, a associação das equações (55) e (60) foi confrontada com a equação de Colebrook (4). Foram testados para diversas condições de rugosidade relativa hidraulicamente equivalente da parede da tubulação $(k / d)$, variando entre 0 e 0,01 . Os resultados encontram-se na tabela (9). 
Tabela 9. Comparação entre Métodos - Escoamentos turbulento misto e turbulento rugoso.

\begin{tabular}{|c|c|c|c|c|c|c|c|c|c|c|c|c|c|c|c|c|c|c|}
\hline \multirow{3}{*}{$\operatorname{Re}$} & \multicolumn{18}{|c|}{ Rugosidade Relativa } \\
\hline & \multicolumn{3}{|c|}{ Liso } & \multicolumn{3}{|c|}{0,0001} & \multicolumn{3}{|c|}{0,0004} & \multicolumn{3}{|c|}{0,001} & \multicolumn{3}{|c|}{0,004} & \multicolumn{3}{|c|}{0,01} \\
\hline & Entropia & Colebrook & $f$ & Entropia & Colebrook & $f$ & Entropia & Colebrook & $f$ & Entropia & Colebrook & $f$ & Entropia & Colebrook & $f$ & Entropia & Colebrook & $f$ \\
\hline $4,00 \mathrm{E}+03$ & 0,0440 & 0,0399 & 9,3E-02 & 0,0442 & 0,0400 & $9,5 \mathrm{E}-02$ & 0,0448 & 0,0403 & $1,0 \mathrm{E}-01$ & 0,0461 & 0,0409 & $1,1 \mathrm{E}-01$ & 0,0525 & 0,0438 & 1,7E-01 & 0,0658 & 0,0491 & $2,5 \mathrm{E}-01$ \\
\hline $8,00 \mathrm{E}+03$ & 0,0335 & 0,0328 & $2,0 \mathrm{E}-02$ & 0,0337 & 0,0329 & $2,3 E-02$ & 0,0344 & 0,0334 & $3,0 \mathrm{E}-02$ & 0,0358 & 0,0341 & 4,6E-02 & 0,0428 & 0,0378 & 1,2E-01 & 0,0568 & 0,0442 & $2,2 \mathrm{E}-01$ \\
\hline $1,60 \mathrm{E}+04$ & 0,0264 & 0,0274 & $3,4 \mathrm{E}-02$ & 0,0267 & 0,0276 & $3,1 \mathrm{E}-02$ & 0,0276 & 0,0281 & $2,0 \mathrm{E}-02$ & 0,0292 & 0,0292 & $2,3 E-04$ & 0,0370 & 0,0339 & $8,4 \mathrm{E}-02$ & 0,0519 & 0,0413 & $2,0 \mathrm{E}-01$ \\
\hline $3,20 \mathrm{E}+04$ & 0,0216 & 0,0231 & 7,0E-02 & 0,0220 & 0,0234 & 6,6E-02 & 0,0230 & 0,0242 & 5,2E-02 & 0,0250 & 0,0257 & 2,7E-02 & 0,0337 & 0,0315 & 6,7E-02 & 0,0493 & 0,0397 & $1,9 \mathrm{E}-01$ \\
\hline $6,40 \mathrm{E}+04$ & 0,0181 & 0,0198 & 9,0E-02 & 0,0186 & 0,0202 & $8,4 \mathrm{E}-02$ & 0,0200 & 0,0213 & $6,8 \mathrm{E}-02$ & 0,0223 & 0,0233 & 4,1E-02 & 0,0319 & 0,0300 & 5,8E-02 & 0,0479 & 0,0388 & 1,9E-01 \\
\hline $1,28 \mathrm{E}+05$ & 0,0156 & 0,0171 & 9,7E-02 & 0,0162 & 0,0177 & $9,0 \mathrm{E}-02$ & 0,0179 & 0,0193 & 7,3E-02 & 0,0207 & 0,0217 & 4,6E-02 & 0,0309 & 0,0293 & $5,4 \mathrm{E}-02$ & 0,0472 & 0,0383 & 1,9E-01 \\
\hline $2,56 \mathrm{E}+05$ & 0,0136 & 0,0149 & $9,4 \mathrm{E}-02$ & 0,0145 & 0,0158 & 8,7E-02 & 0,0167 & 0,0179 & 7,2E-02 & 0,0198 & 0,0207 & 4,7E-02 & 0,0304 & 0,0288 & 5,2E-02 & 0,0469 & 0,0381 & $1,9 \mathrm{E}-01$ \\
\hline $5,12 \mathrm{E}+05$ & 0,0121 & 0,0131 & $8,3 \mathrm{E}-02$ & 0,0133 & 0,0144 & $7,8 \mathrm{E}-02$ & 0,0159 & 0,0170 & $6,8 \mathrm{E}-02$ & 0,0193 & 0,0202 & $4,6 \mathrm{E}-02$ & 0,0302 & 0,0286 & $5,1 \mathrm{E}-02$ & 0,0467 & 0,0380 & $1,9 \mathrm{E}-01$ \\
\hline $1,02 \mathrm{E}+06$ & 0,0109 & 0,0116 & $6,8 \mathrm{E}-02$ & 0,0126 & 0,0134 & $6,8 \mathrm{E}-02$ & 0,0155 & 0,0165 & $6,5 \mathrm{E}-02$ & 0,0190 & 0,0199 & 4,6E-02 & 0,0300 & 0,0285 & $5,1 \mathrm{E}-02$ & 0,0466 & 0,0379 & 1,9E-01 \\
\hline $2,05 \mathrm{E}+06$ & 0,0099 & 0,0103 & $4,8 \mathrm{E}-02$ & 0,0121 & 0,0128 & $5,9 \mathrm{E}-02$ & 0,0152 & 0,0162 & $6,3 \mathrm{E}-02$ & 0,0189 & 0,0198 & $4,5 \mathrm{E}-02$ & 0,0300 & 0,0285 & $5,1 \mathrm{E}-02$ & 0,0465 & 0,0379 & $1,9 \mathrm{E}-01$ \\
\hline $4,10 \mathrm{E}+06$ & 0,0090 & 0,0093 & $2,6 \mathrm{E}-02$ & 0,0118 & 0,0124 & 5,2E-02 & 0,0151 & 0,0160 & $6,1 \mathrm{E}-02$ & 0,0188 & 0,0197 & 4,5E-02 & 0,0299 & 0,0284 & $5,1 \mathrm{E}-02$ & 0,0465 & 0,0379 & 1,9E-01 \\
\hline $8,19 E+06$ & 0,0083 & 0,0083 & 3,2E-03 & 0,0116 & 0,0122 & 4,8E-02 & 0,0151 & 0,0160 & $6,1 \mathrm{E}-02$ & 0,0188 & 0,0197 & 4,5E-02 & 0,0299 & 0,0284 & $5,1 \mathrm{E}-02$ & 0,0465 & 0,0379 & $1,9 \mathrm{E}-01$ \\
\hline $1,64 \mathrm{E}+07$ & 0,0077 & 0,0076 & $2,1 \mathrm{E}-02$ & 0,0116 & 0,0121 & $4,5 \mathrm{E}-02$ & 0,0150 & 0,0159 & $6,0 \mathrm{E}-02$ & 0,0188 & 0,0196 & 4,5E-02 & 0,0299 & 0,0284 & $5,1 \mathrm{E}-02$ & 0,0465 & 0,0379 & $1,9 \mathrm{E}-01$ \\
\hline $3,28 \mathrm{E}+07$ & 0,0072 & 0,0069 & $4,5 \mathrm{E}-02$ & 0,0115 & 0,0120 & $4,4 \mathrm{E}-02$ & 0,0150 & 0,0159 & $6,0 \mathrm{E}-02$ & 0,0188 & 0,0196 & $4,5 \mathrm{E}-02$ & 0,0299 & 0,0284 & $5,0 \mathrm{E}-02$ & 0,0465 & 0,0379 & $1,9 \mathrm{E}-01$ \\
\hline $6,55 \mathrm{E}+07$ & 0,0067 & 0,0063 & 6,9E-02 & 0,0115 & 0,0120 & 4,3E-02 & 0,0150 & 0,0159 & 6,0E-02 & 0,0188 & 0,0196 & 4,5E-02 & 0,0299 & 0,0284 & $5,1 \mathrm{E}-02$ & 0,0465 & 0,0379 & $1,9 \mathrm{E}-01$ \\
\hline $1,31 \mathrm{E}+08$ & 0,0063 & 0,0057 & 9,3E-02 & 0,0115 & 0,0120 & 4,3E-02 & 0,0150 & 0,0159 & $6,0 \mathrm{E}-02$ & 0,0188 & 0,0196 & $4,5 \mathrm{E}-02$ & 0,0299 & 0,0284 & $5,1 \mathrm{E}-02$ & 0,0465 & 0,0379 & $1,9 \mathrm{E}-01$ \\
\hline $2,62 \mathrm{E}+08$ & 0,0060 & 0,0053 & 1,2E-01 & 0,0115 & 0,0120 & 4,3E-02 & 0,0150 & 0,0159 & $6,0 \mathrm{E}-02$ & 0,0188 & 0,0196 & 4,5E-02 & 0,0299 & 0,0284 & 5,0E-02 & 0,0465 & 0,0379 & $1,9 \mathrm{E}-01$ \\
\hline $5,24 \mathrm{E}+08$ & 0,0057 & 0,0049 & 1,4E-01 & 0,0115 & 0,0120 & $4,3 E-02$ & 0,0150 & 0,0159 & $6,0 \mathrm{E}-02$ & 0,0188 & 0,0196 & 4,5E-02 & 0,0299 & 0,0284 & $5,0 \mathrm{E}-02$ & 0,0465 & 0,0379 & $1,9 \mathrm{E}-01$ \\
\hline
\end{tabular}




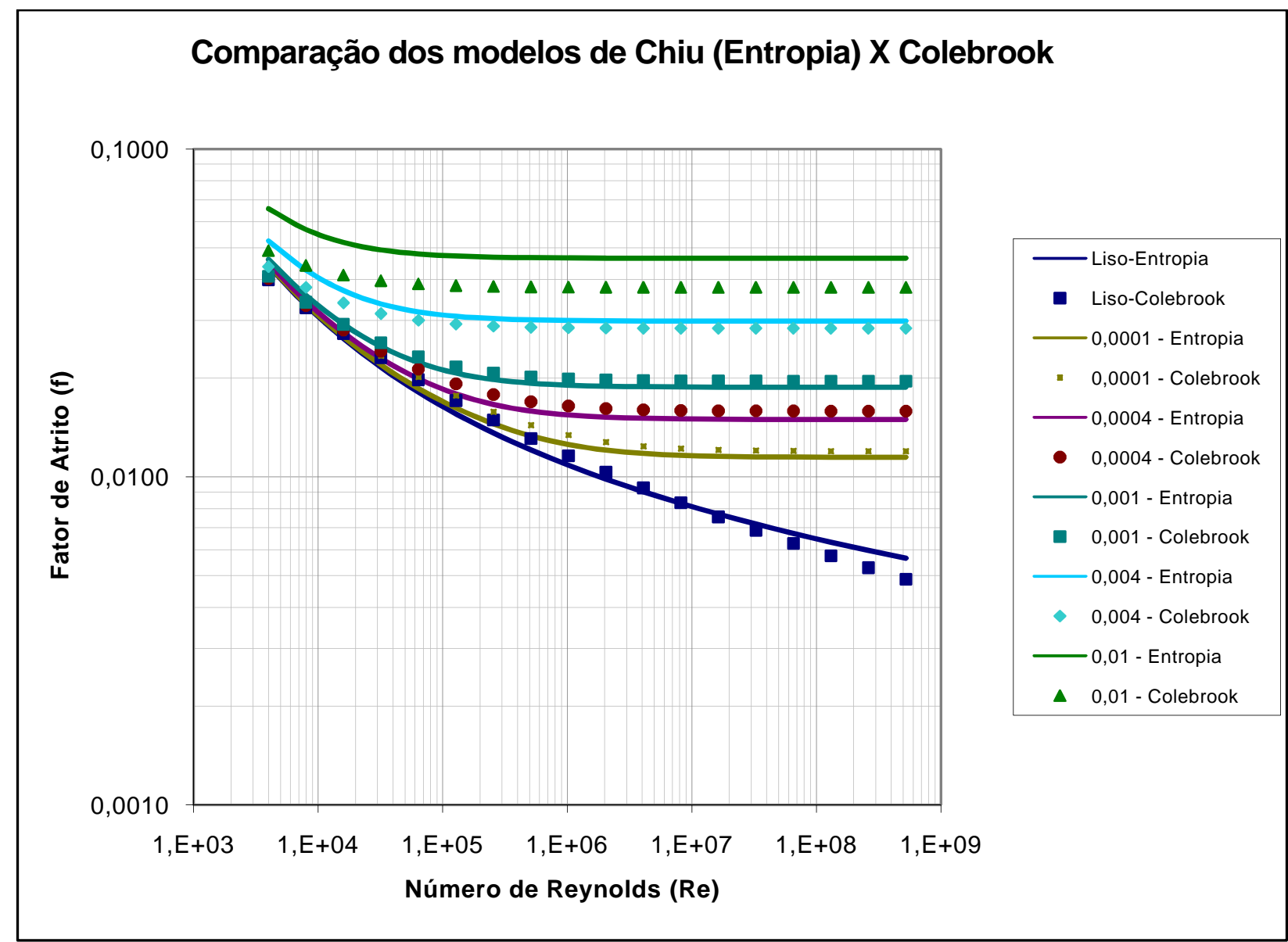

Figura 54. Harpa de comparação entre métodos de determinação do fator de atrito (f) para os regimes turbulento misto e turbulento rugoso.

$\mathrm{Na}$ figura (54) foram impressos em um gráfico, em escala logarítmica, os dados calculados na tabela (9). Os dados referentes ao modelo baseado no parâmetro de entropia, referente a associação das propostas dos capítulos 4.6 .1 e 4.6.2, foram desenhados em linhas contínuas. Já os dados referentes ao modelo de Colebrook, foram representados através de pontos no gráfico. Tal decisão foi tomada para facilitar a comparação, pois devido ao grande número de pontos, uma comparação entre os modelos ficara prejudicada.

Depois de analisado o gráfico (52) foi verificado que os modelos da entropia e de Colebrook tem comportamento muito próximos dentro da faixa de rugosidades relativas entre 0 e 0,004 . Acima desta faixa de valores, conforme mostrado no 
gráfico (52) há um distanciamento entre os dados dos modelos. Esse distanciamento pode ser interpretado.

Ambos os modelos contém ajustes numéricos, porém existem duas diferenças importantes entre ambos. A primeira refere-se ao embasamento teórico dos modelos. A segunda refere-se à qualidade dos dados utilizados para os ajustes numéricos.

O modelo de Colebrook foi concebido a partir do modelo de Nikuradse para escoamentos turbulentos liso. Este modelo tem um problema conceitual, pois não consegue descrever o perfil de velocidades nas proximidades das paredes do tubo.

Os dados obtidos nas experiências de Colebrook, Nikuradse e outros autores clássicos refletem uma preocupação com a precisão das medidas, tanto quanto os dados obtidos em trabalhos recentes. O que pode atribuir uma qualidade melhor aos dados atuais é apenas a evolução tecnológica das instrumentações. Como a instrumentação sempre estará evoluindo, dados ainda melhores serão obtidos no futuro.

Levando-se em conta os dois parágrafos anteriores e as divergências entre os resultados dos modelos acima descritos, é possível estabelecer qual modelo é mais vantajoso, do ponto de vista da precisão. A associação dos modelos apresentados nos capítulos 4.6.1 e 4.6.2 é a mais favorável.

A terceira e última avaliação teve como objetivo comparar os dados obtidos com os quatro modelos apresentados no capítulo 4.6.4. A formulação de tais modelos teve como base os modelos apresentados nos capítulos 4.6.1 e 4.6.2, os quais foram avaliados anteriormente por este capítulo.

Os resultados destes modelos foram comparados com os dados fornecidos por LANGELANDSVIK et al. (2008). Apesar de estes dados fazerem parte do ajuste 
numérico de tais modelos, foram utilizados como parâmetro de comparação, pois são dados considerados paradigmas por este trabalho. A partir desta comparação foram propostos os ajustes necessários para os modelos dos itens 4.6.4.

As tabelas (10) a (13) apresentam os cálculos de validação realizados para cada modelo. Os gráficos das figuras (55) e (56) foram elaborados para facilitar a visualização das tabelas referentes aos algoritmos 1 e 2 respectivamente. Já os algoritmos 3 e 4, por terem como incógnita o diâmetro e o diâmetro ensaiado por LANGELANDSVIK et al. (2008) foi unicamente $D=0,130 \mathrm{~m}$, inviabilizou a construção de gráficos para comparação de tais algoritmos. 
Tabela 10. Tabela de validação do algoritmo 1. Comparação entre vazão de ensaio e calculada.

\begin{tabular}{|c|c|c|c|c|c|c|c|c|c|c|c|c|c|c|}
\hline \multicolumn{8}{|c|}{ Dados Langelandsvik et al (2008) } & \multicolumn{6}{|c|}{ Algoritmo 1} & \multirow{2}{*}{ Erro $(\%)$} \\
\hline $\mathrm{D}(\mathrm{m})$ & $\bar{k}(\mathrm{~m})$ & & $\mathrm{Re}$ & $f$ & $\bar{U}$ & $\bar{Q}$ & $\mathrm{H} / \mathrm{L}$ & $\operatorname{Ref}^{\wedge} 0,5$ & $\operatorname{Re}$ & $\overline{\text { Ret }}$ & $\bar{M}$ & $f$ & $\bar{Q}$ & \\
\hline 0,130 & $5,00 \mathrm{E}-06$ & 1,50E-05 & $1,50 E+05$ & 0,0167 & 17,33 & 0,23 & 1,97 & $1,94 \mathrm{E}+04$ & $2,04 \mathrm{E}+05$ & $1,86 \mathrm{E}+05$ & 6,06 & 0,0145 & 0,25 & 7,4 \\
\hline 0,130 & $5,00 \mathrm{E}-06$ & $1,50 \mathrm{E}-05$ & $2,20 \mathrm{E}+05$ & 0,0155 & 25,42 & 0,34 & 3,93 & $2,74 \mathrm{E}+04$ & $2,89 \mathrm{E}+05$ & $2,54 \mathrm{E}+05$ & 6,37 & 0,0136 & 0,36 & 6,6 \\
\hline 0,130 & $5,00 \mathrm{E}-06$ & $1,50 \mathrm{E}-05$ & $3,00 E+05$ & 0,0146 & 34,66 & 0,46 & 6,88 & $3,62 E+04$ & $3,82 E+05$ & $3,23 E+05$ & 6,61 & 0,0131 & 0,48 & 5,7 \\
\hline 0,130 & $5,00 \mathrm{E}-06$ & $1,50 \mathrm{E}-05$ & $5,00 E+05$ & 0,0134 & 57,76 & 0,76 & 17,55 & $5,79 \mathrm{E}+04$ & $6,11 E+05$ & $4,72 E+05$ & 6,99 & 0,0123 & 0,80 & 4,6 \\
\hline 0,130 & $5,00 \mathrm{E}-06$ & $1,50 \mathrm{E}-05$ & $6,00 E+05$ & 0,0132 & 69,32 & 0,92 & 24,90 & $6,89 \mathrm{E}+04$ & $7,28 \mathrm{E}+05$ & $5,40 E+05$ & 7,12 & 0,0120 & 0,96 & 4,9 \\
\hline 0,130 & $5,00 \mathrm{E}-06$ & $1,50 \mathrm{E}-05$ & $7,00 E+05$ & 0,0127 & 80,87 & 1,07 & 32,60 & $7,89 \mathrm{E}+04$ & $8,34 \mathrm{E}+05$ & $5,96 \mathrm{E}+05$ & 7,22 & 0,0118 & 1,11 & 3,7 \\
\hline 0,130 & $5,00 \mathrm{E}-06$ & $1,50 \mathrm{E}-05$ & $8,30 E+05$ & 0,0122 & 95,89 & 1,27 & 44,03 & $9,17 E+04$ & $9,69 \mathrm{E}+05$ & $6,62 E+05$ & 7,33 & 0,0116 & 1,30 & 2,5 \\
\hline 0,130 & $5,00 \mathrm{E}-06$ & $1,50 \mathrm{E}-05$ & $1,00 E+06$ & 0,0121 & 115,53 & 1,53 & 63,39 & $1,10 E+05$ & $1,16 \mathrm{E}+06$ & $7,48 \mathrm{E}+05$ & 7,45 & 0,0114 & 1,58 & 3,1 \\
\hline 0,130 & $5,00 \mathrm{E}-06$ & $1,50 \mathrm{E}-05$ & $1,40 E+06$ & 0,0117 & 161,74 & 2,14 & 120,14 & $1,51 E+05$ & $1,61 E+06$ & $9,09 E+05$ & 7,64 & 0,0111 & 2,20 & 2,9 \\
\hline 0,130 & $5,00 \mathrm{E}-06$ & $1,50 \mathrm{E}-05$ & $2,00 E+06$ & 0,0114 & 231,05 & 3,06 & 238,90 & $2,14 \mathrm{E}+05$ & $2,27 \mathrm{E}+06$ & $1,09 \mathrm{E}+06$ & 7,83 & 0,0108 & 3,15 & 2,9 \\
\hline 0,130 & $5,00 \mathrm{E}-06$ & $1,50 \mathrm{E}-05$ & $2,80 E+06$ & 0,0112 & 323,48 & 4,28 & 460,04 & $2,96 \mathrm{E}+05$ & $3,16 \mathrm{E}+06$ & $1,26 \mathrm{E}+06$ & 7,97 & 0,0105 & 4,42 & 3,1 \\
\hline 0,130 & $5,00 \mathrm{E}-06$ & $1,50 \mathrm{E}-05$ & $3,90 E+06$ & 0,0111 & 450,55 & 5,97 & 884,53 & $4,11 E+05$ & $4,41 E+06$ & $1,43 E+06$ & 8,10 & 0,0104 & 6,18 & 3,5 \\
\hline 0,130 & $5,00 \mathrm{E}-06$ & $1,50 \mathrm{E}-05$ & $5,50 E+06$ & 0,0111 & 635,40 & 8,41 & 1759,16 & $5,79 \mathrm{E}+05$ & $6,27 E+06$ & $1,59 \mathrm{E}+06$ & 8,21 & 0,0102 & 8,78 & 4,3 \\
\hline 0,130 & $5,00 \mathrm{E}-06$ & 1,50E-05 & $7,50 \mathrm{E}+06$ & 0,0110 & 866,45 & 11,47 & 3241,70 & $7,87 E+05$ & $8,59 \mathrm{E}+06$ & $1,72 E+06$ & 8,28 & 0,0101 & 11,98 & 4,4 \\
\hline 0,130 & $5,00 \mathrm{E}-06$ & $1,50 \mathrm{E}-05$ & $1,05 E+07$ & 0,0110 & 1213,03 & 16,06 & 6353,74 & $1,10 E+06$ & $1,22 \mathrm{E}+07$ & $1,85 E+06$ & 8,36 & 0,0100 & 16,85 & 4,9 \\
\hline 0,130 & $5,00 \mathrm{E}-06$ & $1,50 \mathrm{E}-05$ & $1,48 \mathrm{E}+07$ & 0,0109 & 1709,80 & 22,64 & 12508,58 & $1,55 \mathrm{E}+06$ & $1,75 \mathrm{E}+07$ & $1,98 \mathrm{E}+06$ & 8,42 & 0,0099 & 23,75 & 4,9 \\
\hline 0,130 & $5,00 \mathrm{E}-06$ & $1,50 \mathrm{E}-05$ & $2,00 E+07$ & 0,0109 & 2310,54 & 30,59 & 22842,54 & $2,09 \mathrm{E}+06$ & $2,42 E+07$ & $2,09 \mathrm{E}+06$ & 8,48 & 0,0098 & 32,21 & 5,3 \\
\hline
\end{tabular}


Tabela 11. Tabela de validação do algoritmo 2. Comparação entre perda de carga de ensaio e calculada.

\begin{tabular}{|c|c|c|c|c|c|c|c|c|c|c|c|c|c|c|}
\hline \multicolumn{8}{|c|}{ Dados Langelandsvik et al (2008) } & \multicolumn{6}{|c|}{ Algoritmo 2} & \multirow{2}{*}{ Erro $(\%)$} \\
\hline$D(m)$ & $\bar{k}(\mathrm{~m})$ & & $\operatorname{Re}$ & $f$ & U & $\bar{Q}$ & $H / L$ & $\operatorname{Re}$ & $\operatorname{Ref}^{\wedge} 0,5$ & $\overline{\text { Ret }}$ & $\overline{\mathrm{M}}$ & f & $\mathrm{H} / \mathrm{L}$ & \\
\hline 0,130 & $5,00 \mathrm{E}-06$ & $1,50 \mathrm{E}-05$ & $1,50 E+05$ & 0,0167 & 17,33 & 0,23 & 1,97 & $1,50 \mathrm{E}+05$ & $1,41 E+04$ & $1,40 \mathrm{E}+05$ & 5,77 & 0,0153 & 1,80 & $-8,4$ \\
\hline 0,130 & $5,00 \mathrm{E}-06$ & $1,50 \mathrm{E}-05$ & $2,20 \mathrm{E}+05$ & 0,0155 & 25,42 & 0,34 & 3,93 & $2,20 \mathrm{E}+05$ & $2,06 \mathrm{E}+04$ & $1,99 \mathrm{E}+05$ & 6,13 & 0,0143 & 3,62 & $-7,9$ \\
\hline 0,130 & $5,00 \mathrm{E}-06$ & $1,50 \mathrm{E}-05$ & $3,00 \mathrm{E}+05$ & 0,0146 & 34,66 & 0,46 & 6,88 & $3,00 \mathrm{E}+05$ & $2,81 E+04$ & $2,63 \mathrm{E}+05$ & 6,40 & 0,0136 & 6,40 & $-7,1$ \\
\hline 0,130 & $5,00 \mathrm{E}-06$ & $1,50 \mathrm{E}-05$ & $5,00 E+05$ & 0,0134 & 57,76 & 0,76 & 17,55 & $5,00 E+05$ & $4,69 \mathrm{E}+04$ & $4,04 E+05$ & 6,83 & 0,0126 & 16,47 & $-6,1$ \\
\hline 0,130 & $5,00 \mathrm{E}-06$ & $1,50 \mathrm{E}-05$ & $6,00 E+05$ & 0,0132 & 69,32 & 0,92 & 24,90 & $6,00 E+05$ & $5,62 \mathrm{E}+04$ & $4,67 E+05$ & 6,98 & 0,0123 & 23,16 & $-7,0$ \\
\hline 0,130 & $5,00 \mathrm{E}-06$ & $1,50 \mathrm{E}-05$ & $7,00 E+05$ & 0,0127 & 80,87 & 1,07 & 32,60 & $7,00 \mathrm{E}+05$ & $6,56 \mathrm{E}+04$ & $5,25 \mathrm{E}+05$ & 7,10 & 0,0120 & 30,91 & $-5,2$ \\
\hline 0,130 & $5,00 \mathrm{E}-06$ & $1,50 \mathrm{E}-05$ & $8,30 E+05$ & 0,0122 & 95,89 & 1,27 & 44,03 & $8,30 E+05$ & $7,77 \mathrm{E}+04$ & $5,95 E+05$ & 7,22 & 0,0118 & 42,60 & $-3,3$ \\
\hline 0,130 & $5,00 \mathrm{E}-06$ & $1,50 \mathrm{E}-05$ & $1,00 \mathrm{E}+06$ & 0,0121 & 115,53 & 1,53 & 63,39 & $1,00 E+06$ & $9,36 \mathrm{E}+04$ & $6,78 \mathrm{E}+05$ & 7,35 & 0,0116 & 60,58 & $-4,4$ \\
\hline 0,130 & $5,00 \mathrm{E}-06$ & $1,50 \mathrm{E}-05$ & $1,40 E+06$ & 0,0117 & 161,74 & 2,14 & 120,14 & $1,40 \mathrm{E}+06$ & $1,31 E+05$ & $8,42 E+05$ & 7,57 & 0,0112 & 114,86 & $-4,4$ \\
\hline 0,130 & $5,00 \mathrm{E}-06$ & $1,50 \mathrm{E}-05$ & $2,00 E+06$ & 0,0114 & 231,05 & 3,06 & 238,90 & $2,00 E+06$ & $1,87 \mathrm{E}+05$ & $1,03 \mathrm{E}+06$ & 7,77 & 0,0109 & 227,53 & $-4,8$ \\
\hline 0,130 & $5,00 \mathrm{E}-06$ & $1,50 \mathrm{E}-05$ & $2,80 E+06$ & 0,0112 & 323,48 & 4,28 & 460,04 & $2,80 E+06$ & $2,61 E+05$ & $1,21 E+06$ & 7,93 & 0,0106 & 435,70 & $-5,3$ \\
\hline 0,130 & $5,00 \mathrm{E}-06$ & $1,50 \mathrm{E}-05$ & $3,90 E+06$ & 0,0111 & 450,55 & 5,97 & 884,53 & $3,90 \mathrm{E}+06$ & $3,62 E+05$ & $1,38 \mathrm{E}+06$ & 8,06 & 0,0104 & 829,56 & $-6,2$ \\
\hline 0,130 & $5,00 \mathrm{E}-06$ & $1,50 \mathrm{E}-05$ & $5,50 E+06$ & 0,0111 & 635,40 & 8,41 & 1759,16 & $5,50 E+06$ & $5,07 \mathrm{E}+05$ & $1,54 \mathrm{E}+06$ & 8,17 & 0,0102 & 1624,18 & $-7,7$ \\
\hline 0,130 & $5,00 \mathrm{E}-06$ & $1,50 \mathrm{E}-05$ & $7,50 \mathrm{E}+06$ & 0,0110 & 866,45 & 11,47 & 3241,70 & $7,50 E+06$ & $6,87 E+05$ & $1,67 E+06$ & 8,25 & 0,0101 & 2985,88 & $-7,9$ \\
\hline 0,130 & $5,00 \mathrm{E}-06$ & $1,50 \mathrm{E}-05$ & $1,05 E+07$ & 0,0110 & 1213,03 & 16,06 & 6353,74 & $1,05 \mathrm{E}+07$ & $9,53 \mathrm{E}+05$ & $1,80 E+06$ & 8,33 & 0,0100 & 5793,43 & $-8,8$ \\
\hline 0,130 & $5,00 \mathrm{E}-06$ & $1,50 \mathrm{E}-05$ & $1,48 \mathrm{E}+07$ & 0,0109 & 1709,80 & 22,64 & 12508,58 & $1,48 \mathrm{E}+07$ & $1,32 \mathrm{E}+06$ & $1,92 E+06$ & 8,39 & 0,0099 & 11411,45 & $-8,8$ \\
\hline 0,130 & $5,00 \mathrm{E}-06$ & $1,50 \mathrm{E}-05$ & $2,00 E+07$ & 0,0109 & 2310,54 & 30,59 & 22842,54 & $2,00 E+07$ & $1,76 \mathrm{E}+06$ & $2,02 E+06$ & 8,44 & 0,0099 & 20699,10 & $-9,4$ \\
\hline
\end{tabular}


Tabela 12. Tabela de validação do algoritmo 3. Comparação entre diâmetro de ensaio e calculado.

\begin{tabular}{|c|c|c|c|c|c|c|c|c|c|c|c|c|c|c|c|}
\hline \multicolumn{8}{|c|}{ Dados Langelandsvik et al (2008) } & \multicolumn{7}{|c|}{ Algoritmo 3} & \multirow{2}{*}{ Erro $(\%)$} \\
\hline $\mathrm{D}(\mathrm{m})$ & $k(m)$ & & $\operatorname{Re}$ & $f$ & U & $\bar{Q}$ & $\mathrm{H} / \mathrm{L}$ & $\operatorname{Ref}^{\wedge}(1 / 5)$ & $\operatorname{Re}$ & $\operatorname{Ref}^{f} 0,5$ & Ret & $\bar{M}$ & $f$ & $\bar{D}$ & \\
\hline 0,130 & $5,00 \mathrm{E}-06$ & $1,50 \mathrm{E}-05$ & $1,50 \mathrm{E}+05$ & 0,0167 & 17,33 & 0,23 & 1,97 & $6,62 E+04$ & $1,70 \mathrm{E}+05$ & $1,60 \mathrm{E}+04$ & $1,56 \mathrm{E}+05$ & 5,88 & 0,0150 & 0,127 & $-2,16$ \\
\hline 0,130 & $5,00 \mathrm{E}-06$ & $1,50 \mathrm{E}-05$ & $2,20 E+05$ & 0,0155 & 25,42 & 0,34 & 3,93 & $9,56 \mathrm{E}+04$ & $2,46 \mathrm{E}+05$ & $2,31 E+04$ & $2,17 \mathrm{E}+05$ & 6,21 & 0,0140 & 0,127 & $-1,96$ \\
\hline 0,130 & $5,00 \mathrm{E}-06$ & $1,50 \mathrm{E}-05$ & $3,00 \mathrm{E}+05$ & 0,0146 & 34,66 & 0,46 & 6,88 & $1,29 \mathrm{E}+05$ & $3,31 E+05$ & $3,11 E+04$ & $2,82 E+05$ & 6,47 & 0,0134 & 0,128 & $-1,72$ \\
\hline 0,130 & $5,00 \mathrm{E}-06$ & $1,50 \mathrm{E}-05$ & $5,00 E+05$ & 0,0134 & 57,76 & 0,76 & 17,55 & $2,11 \mathrm{E}+05$ & $5,43 E+05$ & $5,09 \mathrm{E}+04$ & $4,24 E+05$ & 6,88 & 0,0125 & 0,128 & $-1,42$ \\
\hline 0,130 & $5,00 \mathrm{E}-06$ & $1,50 \mathrm{E}-05$ & $6,00 E+05$ & 0,0132 & 69,32 & 0,92 & 24,90 & $2,53 \mathrm{E}+05$ & $6,50 E+05$ & $6,09 \mathrm{E}+04$ & $4,87 E+05$ & 7,02 & 0,0122 & 0,128 & $-1,58$ \\
\hline 0,130 & $5,00 \mathrm{E}-06$ & $1,50 \mathrm{E}-05$ & $7,00 E+05$ & 0,0127 & 80,87 & 1,07 & 32,60 & $2,92 E+05$ & $7,52 E+05$ & $7,05 E+04$ & $5,44 \mathrm{E}+05$ & 7,13 & 0,0120 & 0,128 & $-1,17$ \\
\hline 0,130 & $5,00 \mathrm{E}-06$ & $1,50 \mathrm{E}-05$ & $8,30 \mathrm{E}+05$ & 0,0122 & 95,89 & 1,27 & 44,03 & $3,44 \mathrm{E}+05$ & $8,85 \mathrm{E}+05$ & $8,29 E+04$ & $6,11 E+05$ & 7,25 & 0,0118 & 0,129 & $-0,74$ \\
\hline 0,130 & $5,00 \mathrm{E}-06$ & $1,50 \mathrm{E}-05$ & $1,00 E+06$ & 0,0121 & 115,53 & 1,53 & 63,39 & $4,14 \mathrm{E}+05$ & $1,06 E+06$ & $9,97 E+04$ & $6,93 \mathrm{E}+05$ & 7,37 & 0,0115 & 0,129 & $-0,97$ \\
\hline 0,130 & $5,00 \mathrm{E}-06$ & $1,50 \mathrm{E}-05$ & $1,40 E+06$ & 0,0117 & 161,74 & 2,14 & 120,14 & $5,75 \mathrm{E}+05$ & $1,48 \mathrm{E}+06$ & $1,38 \mathrm{E}+05$ & $8,50 E+05$ & 7,58 & 0,0112 & 0,129 & $-0,93$ \\
\hline 0,130 & $5,00 \mathrm{E}-06$ & $1,50 \mathrm{E}-05$ & $2,00 E+06$ & 0,0114 & 231,05 & 3,06 & 238,90 & $8,17 \mathrm{E}+05$ & $2,11 E+06$ & $1,97 \mathrm{E}+05$ & $1,03 E+06$ & 7,77 & 0,0109 & 0,129 & $-0,97$ \\
\hline 0,130 & $5,00 \mathrm{E}-06$ & $1,50 \mathrm{E}-05$ & $2,80 E+06$ & 0,0112 & 323,48 & 4,28 & 460,04 & $1,14 \mathrm{E}+06$ & $2,94 \mathrm{E}+06$ & $2,74 E+05$ & $1,20 \mathrm{E}+06$ & 7,92 & 0,0106 & 0,128 & $-1,06$ \\
\hline 0,130 & $5,00 \mathrm{E}-06$ & $1,50 \mathrm{E}-05$ & $3,90 \mathrm{E}+06$ & 0,0111 & 450,55 & 5,97 & 884,53 & $1,59 \mathrm{E}+06$ & $4,10 \mathrm{E}+06$ & $3,80 \mathrm{E}+05$ & $1,36 \mathrm{E}+06$ & 8,04 & 0,0104 & 0,128 & $-1,23$ \\
\hline 0,130 & $5,00 \mathrm{E}-06$ & $1,50 \mathrm{E}-05$ & $5,50 \mathrm{E}+06$ & 0,0111 & 635,40 & 8,41 & 1759,16 & $2,24 E+06$ & $5,80 \mathrm{E}+06$ & $5,34 \mathrm{E}+05$ & $1,50 E+06$ & 8,15 & 0,0103 & 0,128 & $-1,52$ \\
\hline 0,130 & $5,00 \mathrm{E}-06$ & $1,50 \mathrm{E}-05$ & $7,50 \mathrm{E}+06$ & 0,0110 & 866,45 & 11,47 & 3241,70 & $3,04 \mathrm{E}+06$ & $7,92 \mathrm{E}+06$ & $7,25 \mathrm{E}+05$ & $1,62 E+06$ & 8,22 & 0,0102 & 0,128 & $-1,55$ \\
\hline 0,130 & $5,00 \mathrm{E}-06$ & $1,50 \mathrm{E}-05$ & $1,05 E+07$ & 0,0110 & 1213,03 & 16,06 & 6353,74 & $4,26 E+06$ & $1,11 \mathrm{E}+07$ & $1,01 E+06$ & $1,74 \mathrm{E}+06$ & 8,29 & 0,0101 & 0,128 & $-1,73$ \\
\hline 0,130 & $5,00 \mathrm{E}-06$ & $1,50 \mathrm{E}-05$ & $1,48 \mathrm{E}+07$ & 0,0109 & 1709,80 & 22,64 & 12508,58 & $5,99 \mathrm{E}+06$ & $1,58 \mathrm{E}+07$ & $1,41 \mathrm{E}+06$ & $1,84 \mathrm{E}+06$ & 8,35 & 0,0100 & 0,128 & $-1,70$ \\
\hline 0,130 & $5,00 \mathrm{E}-06$ & $1,50 \mathrm{E}-05$ & $2,00 E+07$ & 0,0109 & 2310,54 & 30,59 & 22842,54 & $8,10 E+06$ & $2,15 E+07$ & $1,88 \mathrm{E}+06$ & $1,91 E+06$ & 8,39 & 0,0099 & 0,127 & $-1,81$ \\
\hline
\end{tabular}


Tabela 13. Tabela de validação do algoritmo 4. Comparação entre diâmetro de ensaio e calculado.

\begin{tabular}{|c|c|c|c|c|c|c|c|c|c|c|c|c|c|c|c|}
\hline \multicolumn{8}{|c|}{ Dados Langelandsvik et al (2008) } & \multicolumn{7}{|c|}{ Algoritmo 4} & \multirow{2}{*}{ Erro (\%) } \\
\hline $\mathrm{D}(\mathrm{m})$ & $\mathrm{k}(\mathrm{m})$ & & $\overline{\operatorname{Re}}$ & $f$ & $\bar{U}$ & $\overline{\mathrm{Q}}$ & $\mathrm{H} / \mathrm{L}$ & $(\operatorname{Re} / f)^{\wedge} 0,5$ & $\overline{\operatorname{Re}}$ & $\overline{\operatorname{Ref}^{\wedge} 0,5}$ & Ret & $\overline{\mathrm{M}}$ & $f$ & $\bar{D}$ & \\
\hline 0,130 & $5,00 \mathrm{E}-06$ & 1,50E-05 & $1,50 \mathrm{E}+05$ & 0,0167 & 17,33 & 0,23 & 1,97 & $3,00 \mathrm{E}+03$ & $1,58 \mathrm{E}+05$ & $1,48 \mathrm{E}+04$ & 1,47E+05 & 5,82 & 0,0151 & 0,127 & $-1,94$ \\
\hline 0,130 & 5,00E-06 & 1,50E-05 & $2,20 \mathrm{E}+05$ & 0,0155 & 25,42 & 0,34 & 3,93 & $3,77 E+03$ & $2,32 \mathrm{E}+05$ & $2,17 \mathrm{E}+04$ & $2,10 \mathrm{E}+05$ & 6,18 & 0,0141 & 0,127 & $-1,82$ \\
\hline 0,130 & 5,00E-06 & 1,50E-05 & $3,00 \mathrm{E}+05$ & 0,0146 & 34,66 & 0,46 & 6,88 & $4,53 E+03$ & $3,16 \mathrm{E}+05$ & $2,96 \mathrm{E}+04$ & $2,77 \mathrm{E}+05$ & 6,45 & 0,0134 & 0,128 & $-1,65$ \\
\hline 0,130 & 5,00E-06 & 1,50E-05 & $5,00 \mathrm{E}+05$ & 0,0134 & 57,76 & 0,76 & 17,55 & $6,11 \mathrm{E}+03$ & $5,21 \mathrm{E}+05$ & $4,89 \mathrm{E}+04$ & $4,21 \mathrm{E}+05$ & 6,88 & 0,0125 & 0,128 & $-1,40$ \\
\hline 0,130 & $5,00 \mathrm{E}-06$ & 1,50E-05 & $6,00 \mathrm{E}+05$ & 0,0132 & 69,32 & 0,92 & 24,90 & $6,74 \mathrm{E}+03$ & $6,15 \mathrm{E}+05$ & $5,76 \mathrm{E}+04$ & 4,79E+05 & 7,00 & 0,0122 & 0,128 & $-1,52$ \\
\hline 0,130 & 5,00E-06 & 1,50E-05 & $7,00 \mathrm{E}+05$ & 0,0127 & 80,87 & 1,07 & 32,60 & $7,42 \mathrm{E}+03$ & $7,23 \mathrm{E}+05$ & $6,77 \mathrm{E}+04$ & $5,43 E+05$ & 7,13 & 0,0120 & 0,128 & $-1,16$ \\
\hline 0,130 & $5,00 \mathrm{E}-06$ & 1,50E-05 & $8,30 E+05$ & 0,0122 & 95,89 & 1,27 & 44,03 & $8,25 E+03$ & $8,63 E+05$ & $8,08 E+04$ & $6,19 \mathrm{E}+05$ & 7,26 & 0,0117 & 0,129 & $-0,78$ \\
\hline 0,130 & 5,00E-06 & 1,50E-05 & $1,00 E+06$ & 0,0121 & 115,53 & 1,53 & 63,39 & $9,09 E+03$ & $1,02 \mathrm{E}+06$ & $9,51 \mathrm{E}+04$ & $6,89 \mathrm{E}+05$ & 7,37 & 0,0115 & 0,129 & $-0,95$ \\
\hline 0,130 & 5,00E-06 & 1,50E-05 & $1,40 \mathrm{E}+06$ & 0,0117 & 161,74 & 2,14 & 120,14 & $1,09 E+04$ & 1,39E+06 & $1,30 \mathrm{E}+05$ & $8,33 E+05$ & 7,56 & 0,0112 & 0,129 & $-0,86$ \\
\hline 0,130 & 5,00E-06 & 1,50E-05 & $2,00 E+06$ & 0,0114 & 231,05 & 3,06 & 238,90 & $1,32 E+04$ & 1,91E+06 & $1,78 \mathrm{E}+05$ & $9,82 \mathrm{E}+05$ & 7,72 & 0,0109 & 0,129 & $-0,84$ \\
\hline 0,130 & 5,00E-06 & 1,50E-05 & $2,80 E+06$ & 0,0112 & 323,48 & 4,28 & 460,04 & $1,58 E+04$ & $2,57 \mathrm{E}+06$ & $2,39 \mathrm{E}+05$ & 1,11E+06 & 7,84 & 0,0107 & 0,129 & $-0,84$ \\
\hline 0,130 & 5,00E-06 & 1,50E-05 & $3,90 E+06$ & 0,0111 & 450,55 & 5,97 & 884,53 & $1,87 E+04$ & $3,42 E+06$ & $3,18 \mathrm{E}+05$ & 1,21E+06 & 7,93 & 0,0106 & 0,129 & $-0,90$ \\
\hline 0,130 & $5,00 \mathrm{E}-06$ & 1,50E-05 & $5,50 \mathrm{E}+06$ & 0,0111 & 635,40 & 8,41 & 1759,16 & $2,23 E+04$ & $4,56 \mathrm{E}+06$ & $4,22 \mathrm{E}+05$ & $1,28 \mathrm{E}+06$ & 7,98 & 0,0105 & 0,128 & $-1,06$ \\
\hline 0,130 & $5,00 \mathrm{E}-06$ & 1,50E-05 & $7,50 \mathrm{E}+06$ & 0,0110 & 866,45 & 11,47 & 3241,70 & $2,61 E+04$ & $5,97 \mathrm{E}+06$ & $5,49 \mathrm{E}+05$ & $1,33 \mathrm{E}+06$ & 8,02 & 0,0105 & 0,129 & $-0,99$ \\
\hline 0,130 & 5,00E-06 & 1,50E-05 & $1,05 \mathrm{E}+07$ & 0,0110 & 1213,03 & 16,06 & 6353,74 & $3,09 E+04$ & $7,91 \mathrm{E}+06$ & $7,24 \mathrm{E}+05$ & $1,35 \mathrm{E}+06$ & 8,04 & 0,0104 & 0,128 & $-1,04$ \\
\hline 0,130 & 5,00E-06 & 1,50E-05 & $1,48 \mathrm{E}+07$ & 0,0109 & 1709,80 & 22,64 & 12508,58 & $3,68 E+04$ & $1,06 \mathrm{E}+07$ & $9,64 \mathrm{E}+05$ & $1,36 \mathrm{E}+06$ & 8,05 & 0,0104 & 0,129 & $-0,89$ \\
\hline 0,130 & 5,00E-06 & 1,50E-05 & $2,00 E+07$ & 0,0109 & 2310,54 & 30,59 & 22842,54 & $4,28 E+04$ & 1,37E+07 & $1,23 E+06$ & $1,36 \mathrm{E}+06$ & 8,04 & 0,0104 & 0,129 & $-0,87$ \\
\hline
\end{tabular}




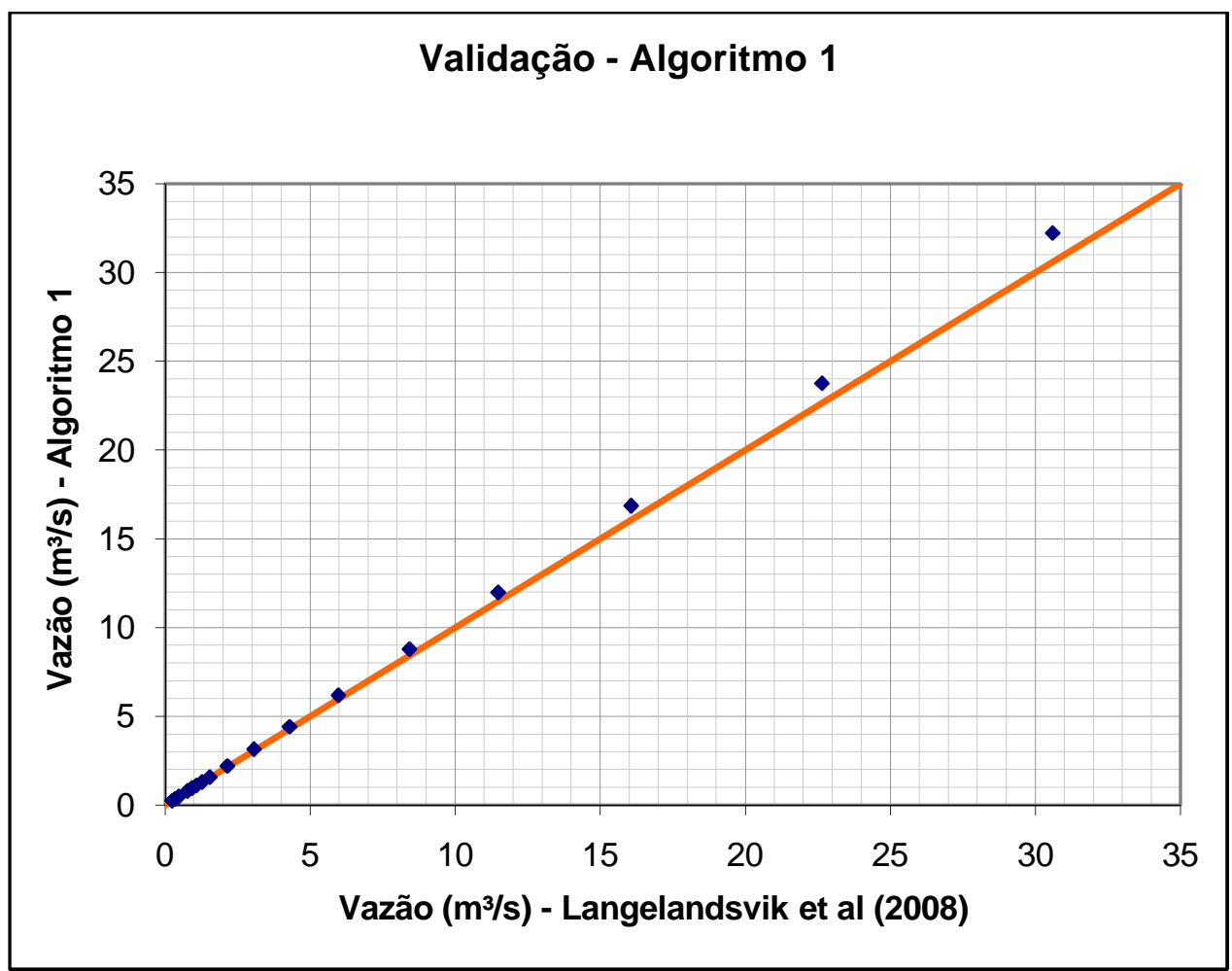

Figura 55. Gráfico de comparação entre dados de ensaios e dados calculados através do algoritmo 1.

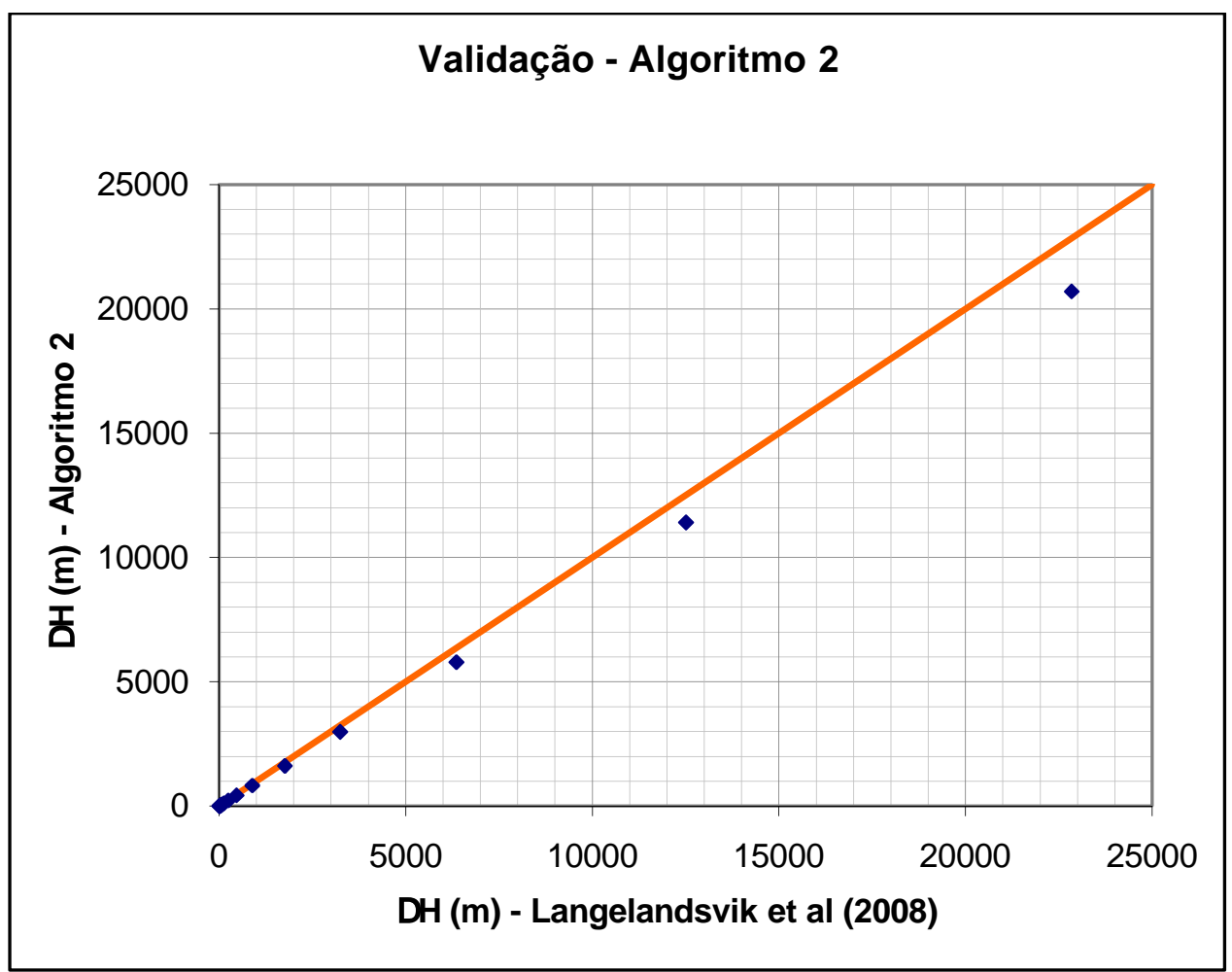

Figura 56. Gráfico de comparação entre dados de ensaios e dados calculados através do algoritmo 2. 
Os resultados obtidos através dos quatro algoritmo corroboraram a verificação da validade e a adequação das mesmas.

\subsection{Reformulação do Modelo}

Tanto a análise de consistência, quanto a validação preliminar do modelo evidenciaram a eficácia e eficiência dos modelos apresentados no capítulo 4.6. Não sendo necessário reformular os modelos propostos, tendo em vista que atendem os objetivos preconizados. 


\section{EXEMPO DE APLICAÇÃO DO MODELO}

Este singelo exemplo de aplicação que será analisado a seguir não tem a pretensão de ser uma validação do modelo ou uma demonstração cabal de sua validade, trata-se apenas de uma aplicação clássica de qualquer formulação sobre o fator de atrito. Esta aplicação tem seu valor como uma demonstração didática de aplicação do modelo proposto.

Um dos aspectos da aplicação apresentada a seguir é o uso de 3 dos 4 algoritmos de cálculo propostos. Tal aspecto, apesar de não ter valor acadêmico, tem valor didático para divulgação da utilização prática do modelo proposto no dia-adia.

A escolha do estudo a ser utilizado para validação foi pautada em alguns parâmetros. O primeiro foi à disponibilidade, ou seja, a facilidade com que o autor teve de conseguir os dados. A complexidade do estudo, dentre os disponíveis, foi o segundo parâmetro. A última foi a relevância relativa ao porte do projeto.

\subsection{Apresentação do projeto}

Foi escolhido um estudo de viabilidade datado de 2006. Este estudo foi conduzido pelo autor, tendo este Anotação de Responsabilidade Técnica (ART) e atestado de elaboração.

Este estudo de viabilidade visava a construção de uma adutora de aproximadamente $12 \mathrm{~km}$ de comprimento. Esta adutora teria objetivo de levar água da Adutora do Rio Claro à cidade de Biritiba Mirim-SP. Esta rede, em decorrência de sua carga, poderia abastecer este município sem a necessidade de uso de nenhum sistema de elevação de pressão (booster). 
Esta pressão provém do desnível existente em um sifão invertido, da qual esta rede seria derivação. Este sifão invertido liga dois aquedutos, fazendo a travessia de um vale existente entre estes. Tem um desnível próximo a 100 metros até o ponto mais baixo, onde seria o ponto de derivação, com a descida em um ângulo aproximado de $45^{\circ}$.

A definição do traçado da rede foi feita com auxílio de orto-fotos e fotos de satélite. Esta definição teve como princípio utilizar as estradas existentes, não passando em nenhuma área privada ou protegida.

Depois de definido o caminhamento, foi feito o levantamento "in loco" do estudo. Este estudo, tendo em vista ser um estudo de viabilidade, foi levantado através do uso de um GPS. O erro de aproximadamente 5 metros do GPS foi considerado, tolerável. Foram levantados 56 pontos, contendo coordenadas UTM e cota.

Utilizando os pontos coordenados foi elaborado o perfil e o caminhamento da adutora. As figuras (57) e (58) apresentam o caminhamento e o perfil da adutora, respectivamente.

Foi considerada uma vazão de fim de plano de $40 \mathrm{l} / \mathrm{s}$ para a cidade. Esta vazão visa atender todas as comunidades urbanas do município em questão.

Estes dados subsidiaram a elaboração de uma modelação matemática de tal adutora. Esta modelação visou determinar o diâmetro da tubulação e, conseqüentemente, o custo aproximado do projeto executivo e da obra. 


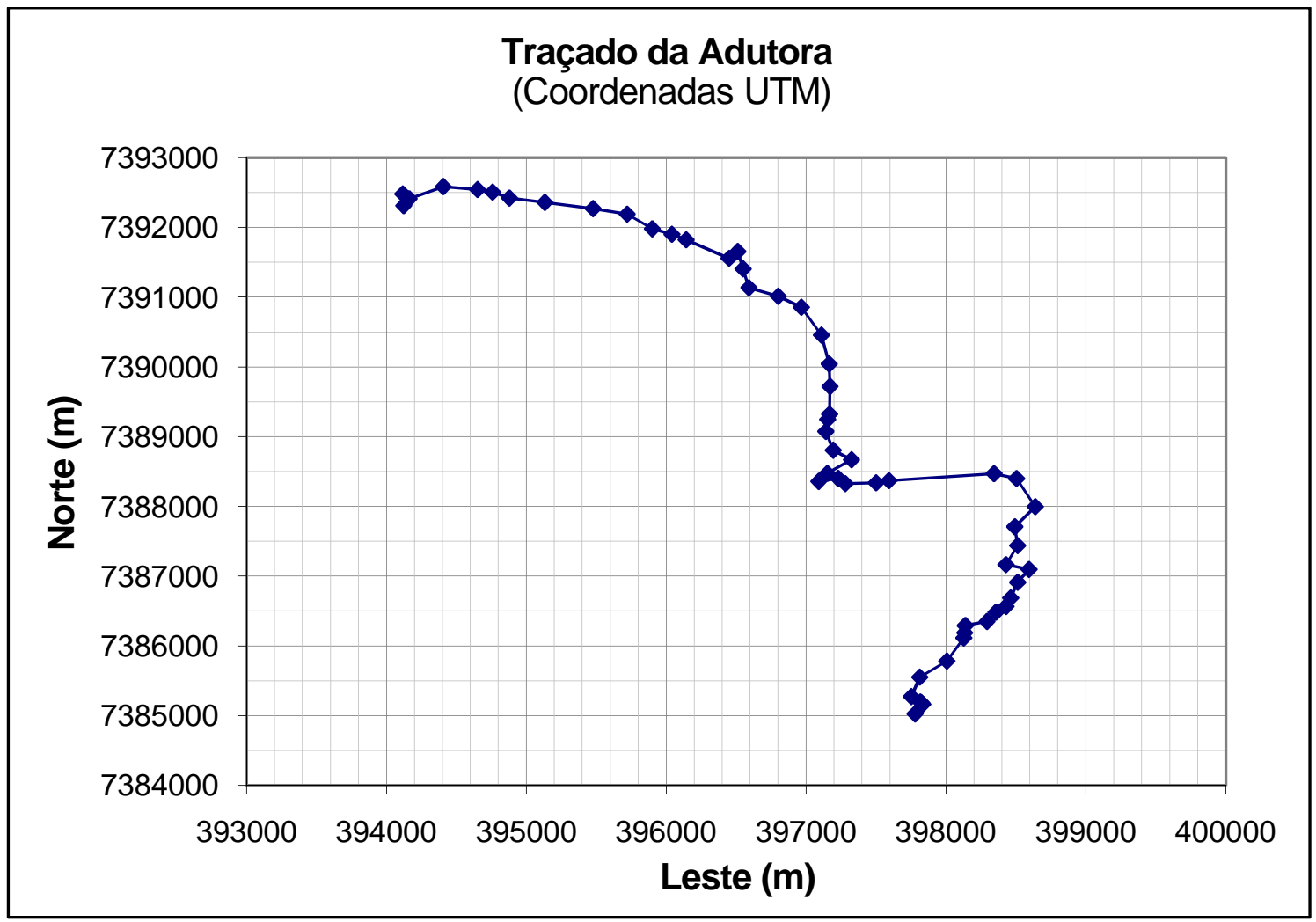

Figura 57. Caminhamento da adutora.

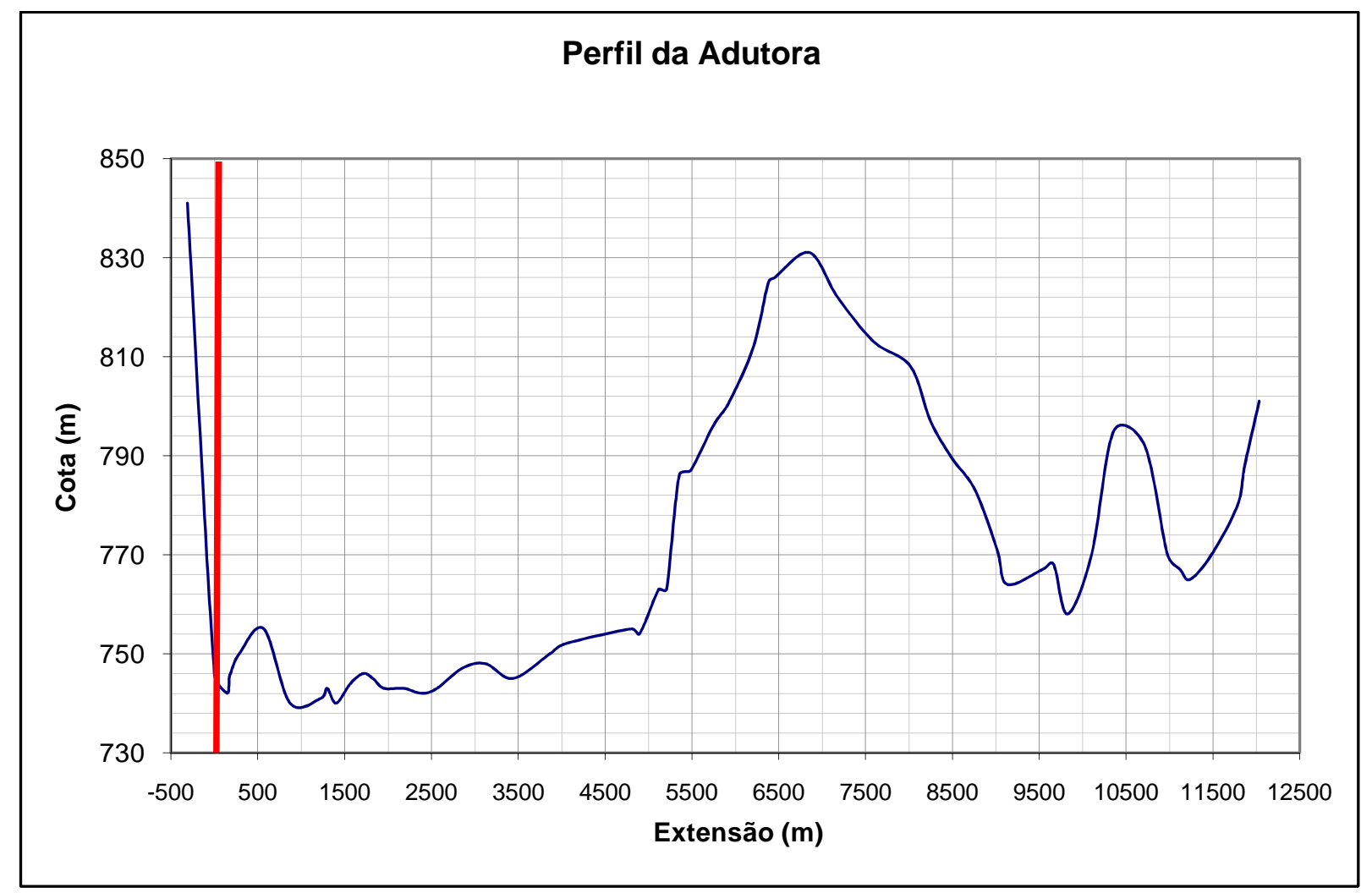

Figura 58. Perfil da adutora. O traço vermelho indica a interligação entre a adutora existente e a projetada. 
Neste estudo houve um problema a ser superado. Foi necessário elaborar uma solução técnica para que a água vencesse uma montanha existente no meio do traçado. A diferença entre a cota superior do sifão e a cota desta montanha era de 10 metros. Considerando apenas a perda de carga distribuída ao longo da linha, a linha de carga total da tubulação deveria passar 5 metros acima da cota do topo desta montanha (831). A cota de chegada do reservatório mais alto da cidade é de 801, foi adotada uma carga piezométrica para chegada do escoamento neste ponto de 20 metros. A partir da chegada esta adutora seria interligada a redes existentes.

Este estudo foi dividido em duas partes. A primeira visou determinar o diâmetro de uma tubulação para que a linha de carga total seja 5 metros superior à cota da montanha. A segunda parte visou determinar o diâmetro da tubulação a partir da cota mais alta da montanha para que a água pudesse chegar ao reservatório.

A perda de carga distribuída do escoamento deveria ser menor que 0,73 $\mathrm{m} / \mathrm{km}$ no primeiro trecho. Esta, no segundo trecho, deveria ser menor que 2,70 $\mathrm{m} / \mathrm{km}$.

O estudo adotou como material a ser utilizado nesta tubulação o PEAD (polietileno de alta densidade). Este material fornece uma tubulação praticamente lisa, podendo a rugosidade relativa da tubulação a ser considerada aproximadamente zero.

Com base nestes dados foi modelado através do sistema computacional EPAnet, desenvolvido pela Agência de Proteção Ambiental dos Estado Unidos (Environmental Protection Agency). Com o auxílio deste sistema foram modelados os dois trechos de tubulação, obtendo-se os diâmetros necessários para utilização desta adutora, sem que se fosse necessário nenhum tipo de bombeamento. 
Foram obtidos dois diâmetros diferentes para esta tubulação. O primeiro trecho resultou em $350 \mathrm{~mm}$. No segundo trecho o diâmetro adotado foi de $250 \mathrm{~mm}$.

A carga piezométrica no ponto crítico foi de 7,19 metros, cujo ponto é o de cota mais elevada, 831 metros. Já no ponto de interligação final da rede, a uma cota de 801 metros, a carga piezométrica foi de 26,10 metros.

\subsection{Utilização do modelo matemático}

O modelo teve como objetivo dimensionar o diâmetro da adutora anteriormente citada. Além disto, foram calculadas as cargas disponíveis utilizando os diâmetros comerciais logo superiores aos calculados. Numa terceira etapa foi calculada a vazão máxima que a poderá passar pela rede, considerando os valores limites de carga impostos anteriormente.

Assim como no estudo de viabilidade citado anteriormente, dividiu-se o estudo da rede em dois trechos. O primeiro vai da captação até o ponto crítico, a 6853 metros de distância e cota de 831 metros. O segundo inicia-se no ponto crítico e vai até o final da adutora, na cota 801 , percorrendo 5178 metros.

\subsubsection{Cálculo do diâmetro do trecho 1}

Levando-se em conta as considerações anteriores, os dados são apresentados na tabela (14).

Tabela 14. Dados de entrada para o cálculo do diâmetro do trecho 1.

\begin{tabular}{lcccc}
\hline \multicolumn{1}{c}{ Dados } & & & Valor & Unidade \\
\hline Vazão & $(\mathrm{Q})$ & $=$ & 0,04 & $\mathrm{~m}^{3} / \mathrm{s}$ \\
\hline Extensão & $(\mathrm{L})$ & $=$ & 6853 & $\mathrm{~m}$ \\
\hline Rugosidade equivalente & $(\mathrm{k})$ & $=$ & $1, \mathrm{E}-04$ & $\mathrm{~m}$ \\
\hline Perda de carga & $(\mathrm{H})$ & $=$ & 5,0 & $\mathrm{~m}$ \\
\hline Viscosidade (água 20ํ) & $(\mathrm{l})$ & $=$ & $1, \mathrm{E}-06$ & $\mathrm{~m}^{2} / \mathrm{s}$ \\
\hline Aceleração gravitacional & $(\mathrm{g})$ & $=$ & 9,81 & $\mathrm{~m} / \mathrm{s}^{2}$ \\
\hline
\end{tabular}


Para o cálculo do diâmetro do trecho foi utilizado o algoritmo 3. A tabela (15) apresenta os cálculos realizados. O diâmetro será calculado em metros (m).

Tabela 15. Cálculo do diâmetro para o trecho 1 da adutora

\begin{tabular}{ccccccc}
\hline $\operatorname{Ref}^{\wedge}(1 / 5)$ & $\operatorname{Re}$ & $\operatorname{Re}^{\wedge} 0,5$ & $\operatorname{Re}(a)$ & $M$ & $f$ & $D$ \\
\hline $7,17 \mathrm{E}+04$ & $1,84 \mathrm{E}+05$ & $1,73 \mathrm{E}+04$ & $1,01 \mathrm{E}+05$ & 5,45 & 0,0164 & 0,312 \\
\hline
\end{tabular}

O resultado do cálculo do diâmetro apresentado na tabela (15) foi $312 \mathrm{~mm}$. Porém este diâmetro não existe comercialmente. Isto posto, foi adotado o diâmetro imediatamente acima, $350 \mathrm{~mm}$.

\subsubsection{Cálculo da carga no ponto crítico do trecho 1}

Devido à alteração do valor do diâmetro, pela adoção de um diâmetro comercial, faz-se necessário recalcular a carga no ponto crítico. Na tabela (16) são apresentados os dados de entrada.

Tabela 16. Dados de entrada para o cálculo da perda de carga no trecho 1.

\begin{tabular}{lccccc}
\hline \multicolumn{1}{c}{ Dados } & & & Valor & Unidade \\
\hline Vazão & & $(\mathrm{Q})$ & $=$ & 0,04 & $\mathrm{~m} 3 / \mathrm{s}$ \\
\hline Extensão & & $(\mathrm{L})$ & $=$ & 6853,57 & $\mathrm{~m}$ \\
\hline Rugosidade & equivalente & $(\mathrm{k})$ & $=$ & $1, \mathrm{E}-04$ & $\mathrm{~m}$ \\
\hline Viscosidade & (água $\left.20^{\circ} \mathrm{C}\right)$ & $(\mathrm{n})$ & $=$ & $1, \mathrm{E}-06$ & $\mathrm{~m} / \mathrm{s}$ \\
\hline Aceleração & gravitacional & $(\mathrm{g})$ & $=$ & 9,81 & $\mathrm{~m} / \mathrm{s}^{2}$ \\
\hline Diâmetro & & $(\mathrm{D})$ & $=$ & 0,350 & $\mathrm{~m}$ \\
\hline
\end{tabular}

Para o cálculo da perda de carga do trecho foi utilizado o algoritmo 2. A tabela (17) apresenta os cálculos realizados. A perda de carga será calculada em metros (m).

Tabela 17. Cálculo da perda de carga para o trecho 1 da adutora

\begin{tabular}{cccccc}
\hline $\operatorname{Re}$ & $\operatorname{Ref}^{\wedge} 0,5$ & $\operatorname{Re}(\mathrm{a})$ & $\mathrm{M}$ & $\mathrm{f}$ & $\mathrm{p} /$ \\
\hline 145513 & 13657 & 96153 & 5,40 & 0,0166 & 7,14 \\
\hline
\end{tabular}




\subsubsection{Cálculo do diâmetro do trecho 2}

O cálculo do diâmetro para o segundo trecho leva em conta a carga calculada no final do trecho 1. Considerando esta carga, e a carga mínima especificada anteriormente no final da adutora, a perda de carga máxima deverá ser de 17,14 metros. Os dados de entrada são apresentados na tabela (18).

Tabela 18. Dados de entrada para o cálculo do diâmetro do trecho 2.

\begin{tabular}{|c|c|c|c|c|c|}
\hline \multicolumn{4}{|c|}{ Dados } & \multirow{2}{*}{$\frac{\text { Valor }}{0,04}$} & \multirow{2}{*}{$\frac{\text { Unidade }}{\mathrm{m}^{3} / \mathrm{s}}$} \\
\hline Vazão & & $(Q)$ & $=$ & & \\
\hline Extensão & & (L) & $=$ & 5178 & $\mathrm{~m}$ \\
\hline Rugosidade & equivalente & (k) & $=$ & 1,E-04 & $\mathrm{m}$ \\
\hline Perda de & carga & $(\mathrm{H})$ & $=$ & 17,14 & $\mathrm{~m}$ \\
\hline Viscosidade & (água $20^{\circ} \mathrm{C}$ ) & ( ) & $=$ & $1, E-06$ & $\mathrm{~m}^{2} / \mathrm{s}$ \\
\hline Aceleração & gravitacional & (g) & $=$ & 9,81 & $\mathrm{~m} / \mathrm{s}^{2}$ \\
\hline
\end{tabular}

Para o cálculo do diâmetro do trecho foi utilizado o algoritmo 3. A tabela (19) apresenta os cálculos realizados. O diâmetro será calculado em metros (m).

Tabela 19. Cálculo do diâmetro para o trecho 2 da adutora.

\begin{tabular}{ccccccc}
\hline $\operatorname{Ref}^{f}(1 / 5)$ & $\operatorname{Re}$ & $\operatorname{Ref}^{f} 0,5$ & $\operatorname{Re}(\mathrm{a})$ & $M$ & $f$ & $D$ \\
\hline $9,70 \mathrm{E}+04$ & $2,49 \mathrm{E}+05$ & $2,34 \mathrm{E}+04$ & $9,95 \mathrm{E}+04$ & 5,43 & 0,0164 & 0,231 \\
\hline
\end{tabular}

O resultado do cálculo do diâmetro apresentado na tabela (19) foi $231 \mathrm{~mm}$. Porém este diâmetro não existe comercialmente. Isto posto, foi adotado o diâmetro imediatamente acima, $250 \mathrm{~mm}$.

\subsubsection{Cálculo da carga do trecho 2}

Devido à alteração do valor do diâmetro, adotado como $250 \mathrm{~mm}$, faz-se necessário recalcular a carga no ponto crítico. Na tabela (20) são apresentados os dados de entrada. 
Tabela 20. Dados de entrada para o cálculo da perda de carga no trecho 2.

\begin{tabular}{lcccc}
\hline \multicolumn{1}{c}{ Dados } & & & Valor & Unidade \\
\hline Vazão & $(\mathrm{Q})$ & $=$ & 0,04 & $\mathrm{~m}^{3} / \mathrm{s}$ \\
\hline Extensão & $(\mathrm{L})$ & $=$ & 5178,8 & $\mathrm{~m}$ \\
\hline Rugosidade equivalente & $(\mathrm{k})$ & $=$ & $1, \mathrm{E}-04$ & $\mathrm{~m}$ \\
\hline Viscosidade (água 20ํ) & $(\mathrm{n})$ & $=$ & $1, \mathrm{E}-06$ & $\mathrm{~m}^{2} / \mathrm{s}$ \\
\hline Aceleração gravitacional & $(\mathrm{g})$ & $=$ & 9,81 & $\mathrm{~m} / \mathrm{s}^{2}$ \\
\hline Diâmetro & $(\mathrm{D})$ & $=$ & 0,250 & $\mathrm{~m}$ \\
\hline
\end{tabular}

Para o cálculo da perda de carga do trecho foi utilizado o algoritmo 2. A tabela (21) apresenta os cálculos realizados. A perda de carga será calculada em metros (m).

Tabela 21. Cálculo da perda de carga para o trecho 2 da adutora

\begin{tabular}{cccccc}
\hline $\mathrm{Re}$ & $\operatorname{Ref}^{\wedge} 0,5$ & $\operatorname{Re}(\mathrm{a})$ & $\mathrm{M}$ & $\mathrm{f}$ & $\mathrm{p} /$ \\
\hline 203718 & 19117 & 101556 & 5,45 & 0,0164 & 25,67 \\
\hline
\end{tabular}

\subsubsection{Cálculo da vazão}

Depois de dimensionados ambos os trechos da adutora, é necessário calcular a vazão máxima. Esta vazão foi calculada sob as condições de cargas limites apresentadas no item 5.1. A tabela (22) apresenta os dados de entrada para ambos os trechos da adutora.

Tabela 22. Dados de entrada para o cálculo da perda da vazão.

\begin{tabular}{lccccc}
\hline \multicolumn{1}{c}{ Dados } & & \multicolumn{3}{c}{ Valor } & Unidade \\
\cline { 5 - 6 } & & & Techo 1 & Techo 2 & \\
\hline Perda de carga & $(\mathrm{H})$ & $=$ & 5,00 & 17,14 & $\mathrm{~m} / \mathrm{s}$ \\
\hline Extensão & $(\mathrm{L})$ & $=$ & 6853 & 5178 & $\mathrm{~m}$ \\
\hline Rugosidade equivalente & $(\mathrm{k})$ & $=$ & $1, \mathrm{E}-04$ & $1, \mathrm{E}-04$ & $\mathrm{~m}$ \\
\hline Viscosidade (água 20ㅇ) & $(\mathrm{n})$ & $=$ & $1, \mathrm{E}-06$ & $1, \mathrm{E}-06$ & $\mathrm{~m}^{2} / \mathrm{s}$ \\
\hline Aceleração gravitacional & $(\mathrm{g})$ & $=$ & $1, \mathrm{E}+01$ & $1, \mathrm{E}+01$ & $\mathrm{~m} / \mathrm{s}^{2}$ \\
\hline Diâmetro & $(\mathrm{D})$ & $=$ & 0,350 & 0,250 & $\mathrm{~m}$ \\
\hline
\end{tabular}

Para o cálculo da vazão nos dois trechos foi utilizado o algoritmo 1. A tabela (23) apresenta os cálculos realizados. A vazão será calculada em metros $\left(\mathrm{m}^{3} / \mathrm{s}\right)$. 
Tabela 23. Cálculo da perda da vazão em ambos os trechos da adutora.

\begin{tabular}{ccccccc}
\hline Trecho & $\operatorname{Ref}^{\mathrm{N}} 0,5$ & $\mathrm{Re}$ & $\operatorname{Re}(\mathrm{a})$ & $\mathrm{M}$ & $\mathrm{f}$ & $\mathrm{Q}$ \\
\hline 1 & $2,48 \mathrm{E}+04$ & $2,61 \mathrm{E}+05$ & $1,35 \mathrm{E}+05$ & 5,74 & 0,0154 & 0,055 \\
\hline 2 & $2,98 \mathrm{E}+04$ & $3,14 \mathrm{E}+05$ & $1,22 \mathrm{E}+05$ & 5,64 & 0,0157 & 0,047 \\
\hline
\end{tabular}

As vazões dos trechos 1 e 2 não são iguais, porém a vazão de projeto da linha adutora é uma vazão que fica entre estas. Para o cálculo da vazão da adutora foram somadas as duas perdas de cargas dos trechos, $\Delta H=20,0$ metros.

Foi colocada em evidência a vazão utilizando a equação da perda de carga do algoritmo 2, figura (50). A partir da equação (91) a vazão pode ser obtida.

$$
\Delta H=\left(\frac{8 f_{1} L_{1}}{\pi^{2} D_{1}^{5} g}+\frac{8 f_{2} L_{2}}{\pi^{2} D_{2}^{5} g}\right) Q^{2}
$$

Para determinação da vazão, portanto, o problema é a obtenção do fator de atrito $(f)$ para cada trecho da adutora. Independente do método utilizado esta obtenção é feita a partir de um processo iterativo, pois o diâmetro varia ao longo da tubulação com vazão constante.

Tabela 24. Cálculo iterativo da vazão máxima da adutora

\begin{tabular}{|c|c|c|c|c|c|c|c|c|c|c|c|c|c|}
\hline \multirow{2}{*}{ Iterac. } & \multirow{2}{*}{ Vazão } & \multicolumn{2}{|c|}{ № Reynolds } & \multicolumn{2}{|c|}{$\operatorname{Ref}^{\wedge} 0,5$} & \multicolumn{2}{|c|}{$\operatorname{Re}(\mathrm{a})$} & \multicolumn{2}{|c|}{ Entropia } & \multirow{2}{*}{$\begin{array}{c}\text { Fator } \\
\mathrm{f1}\end{array}$} & \multirow{2}{*}{$\begin{array}{c}\text { de Atrito } \\
\text { f2 }\end{array}$} & \multirow{2}{*}{$\begin{array}{l}\Delta H \\
(\mathrm{~m})\end{array}$} & \multirow{2}{*}{$\begin{array}{l}\text { Erro } \\
(\%)\end{array}$} \\
\hline & & Re1 & Re2 & 1 & 2 & 1 & 2 & M1 & M2 & & & & \\
\hline 1 & 0,0470 & $1,71 \mathrm{E}+05$ & $2,39 \mathrm{E}+05$ & $1,60 \mathrm{E}+04$ & $2,25 \mathrm{E}+04$ & $1,07 \mathrm{E}+05$ & $1,10 \mathrm{E}+05$ & 5,50 & 5,53 & 0,0162 & 0,0161 & 19,44 & 2,82 \\
\hline 2 & 0,0472 & $1,72 \mathrm{E}+05$ & $2,41 E+05$ & $1,61 E+04$ & $2,26 \mathrm{E}+04$ & $1,07 \mathrm{E}+05$ & $1,10 \mathrm{E}+05$ & 5,51 & 5,53 & 0,0162 & 0,0161 & 19,62 & 1,90 \\
\hline 3 & 0,0475 & $1,73 \mathrm{E}+05$ & $2,42 E+05$ & $1,62 E+04$ & $2,27 E+04$ & $1,07 \mathrm{E}+05$ & $1,10 \mathrm{E}+05$ & 5,51 & 5,53 & 0,0162 & 0,0161 & 19,81 & 0,96 \\
\hline 4 & 0,0477 & $1,74 \mathrm{E}+05$ & $2,43 \mathrm{E}+05$ & $1,63 \mathrm{E}+04$ & $2,28 \mathrm{E}+04$ & $1,08 \mathrm{E}+05$ & $1,10 \mathrm{E}+05$ & 5,51 & 5,54 & 0,0162 & 0,0161 & 20,00 & 0,02 \\
\hline
\end{tabular}

A tabela (24) demonstrou o processo iterativo de obtenção do valor da vazão máxima. Os dados de entrada no algoritmo 2 são apresentados na tabela (22). A vazão máxima que pode escoar pela adutora é de $0,0477 \mathrm{~m}^{3} / \mathrm{s}$. 


\subsection{Validação do modelo}

No capítulo 5.2 foram utilizadas as 3 situações de cálculo aplicáveis das 4 desenvolvidas no capítulo 4.6.4.

Os resultados obtidos a partir do programa computacional EPAnet e a partir dos algoritmos apresentados no capítulo 4.6.4, faz-se necessário uma comparação. A tabela (24) apresenta a comparação entre os cálculos realizados em ambos modelos.

Tabela 25. Comparação de resultados entre modelos de cálculo para dimensionamento de adutora.

\begin{tabular}{cllccccc}
\hline \multirow{2}{*}{ Techos } & \multicolumn{2}{c}{ Dados } & & \multirow{2}{*}{ Unidade } & \multicolumn{2}{c}{ Valor } & \multirow{2}{*}{ Erro (\%) } \\
\cline { 5 - 8 } & & & & EPAnet & Entropia & \\
\hline \multirow{2}{*}{$\mathbf{1}$} & Perda de carga & $(\mathrm{H})$ & $\mathrm{m}$ & 7,19 & 7,14 & 0,70 \\
\cline { 2 - 8 } & Diâmetro & $(\mathrm{D})$ & $\mathrm{m}$ & 0,350 & 0,350 & - \\
\hline \multirow{2}{*}{$\mathbf{2}$} & Perda de carga & $(\mathrm{H})$ & $\mathrm{m}$ & 26,10 & 25,67 & 1,68 \\
\cline { 2 - 8 } & Diâmetro & $(\mathrm{D})$ & $\mathrm{m}$ & 0,250 & 0,250 & - \\
\hline
\end{tabular}

Ambos os modelos apresentaram na tabela (24) dados similares. Para o cálculo do erro, tendo em vista o modelo apresentado neste trabalho ser conceitualmente correto, este foi considerado como paradigma. Tendo em vista que o diâmetro, apesar de ser calculado, optou-se em ambos os casos pela adoção de um diâmetro comercial, estes não foram comparados.

Os modelos apresentados no capítulo 4.6 demonstraram sua eficácia e eficiência. A eficácia deve-se a resultados similares aos modelos existentes, podendo os algoritmos de cálculo ser considerados até mais precisos, conforme argumentos apresentados nos capítulos 4.7 e 4.8. A eficiência deve-se a não ser um modelo iterativo e apresentar redução do número de passagens de cálculo em relação aos modelos apresentados por SOUZA et al. (1991). 


\section{DISCUSSÃO}

Os bons resultados obtidos com os modelos elaborados no capítulo 4 são função dos métodos utilizados para o desenvolvimento dos mesmos. Foram utilizados dois métodos para o desenvolvimento de tais modelos: análise conceitual e ajuste numérico.

A análise conceitual teve como objetivo a obtenção de modelos que tivessem hipóteses físicas mais próximas possível da realidade. Um modelo conceitualmente correto pode ser utilizado em diversas situações, mesmo que se trate de extrapolação.

A partir da análise conceitual foram estudados o mecanismo da turbulência, a validade da conjectura de Prandtl e as interações matemáticas que possibilitaram o desenvolvimento dos algoritmos de cálculo propostos.

Além da análise conceitual, foi utilizado como base para o desenvolvimento um modelo conceitualmente consagrado. Apesar disto, o modelo proposto por CHIU et al. (1993) não é amplamente utilizado. Isto se deveu à existência do parâmetro de entropia, o qual era um parâmetro que, até então, sua relação com o número de Reynolds não havia sido equacionada matematicamente.

O estudo do mecanismo da turbulência partiu do equacionamento de Colebrook para o escoamento turbulento misto. Verificou-se que Colebrook estava correto ao desenvolver o mecanismo da turbulência. A limitação de Colebrook foi associar tal mecanismo ao equacionamento proposto por Nikuradse. A posposta de Nikuradse tem falhas conceituais, já citadas em capítulos anteriores.

,A análise da conjectura de Prandtl foi feita baseada conceitualmente no modelo matemático proposto por CHIU et al. (1993). Foram associados os 
equacionamentos do fator de atrito e do perfil de velocidades desenvolvidos por CHIU et al. (1993), o ajuste elaborado no capítulo 4.6.2 e a conjectura de Prandtl. Os resultados desta associação, no capítulo 4.6.3, indicaram que o coeficiente resultante não é constante, conforme preconizado por Prandtl. Indicando que os modelos baseados nesta conjectura estão conceitualmente incorretos.

Tais análises conceituais culminaram na junção dos modelos baseados no parâmetro de entropia e no equacionamento de Colebrook. A partir desta junção é possível afirmar que existe uma relação unívoca entre o fator de atrito $(f)$ e o número de Reynolds ( $\mathrm{Re}$ ). Portanto, a influência da parede do tubo é um aumento da turbulência do escoamento (e da viscosidade aparente), reduzindo, conseqüentemente o número de Reynolds deste.

A modelagem conceitual foi feito com o objetivo de desenvolver os algoritmos de cálculo apresentados no capítulo 4.6.4. Esta análise, baseada novamente no equacionamento proposto por CHIU et al. (1993), indicou que qualquer relacionamento entre o binômio fator de atrito $(f)$ e o número de Reynolds $(\operatorname{Re})$, desde que não tenha nenhum outro fator associado, é verdadeira. Com isto, foi possível associar tais adimensionais com objetivo de simplificar a resolução das quatro situações de cálculo propostas por SOUZA et al. (1991).

Os ajustes numéricos também tiveram papel fundamental para o sucesso do desenvolvimento dos modelos apresentados nos capítulos anteriores. Com auxílio da Universidade de Princeton, foram escolhidos resultados de ensaios que representassem com boa qualidade as medições de escoamento em condutos forçados.

Foram escolhidos dois trabalhos publicados por pesquisadores da Universidade de Princeton. O primeiro foi McKEON et al. (2008), o qual apresentou 
dados de ensaios, para escoamento para todas as faixas do número de Reynolds em tubos liso, realizados nos laboratórios das Universidades de Princeton e Oregon. O segundo Langelankdsvik et al. (2008), que apresentou dados de ensaios realizados no laboratório da Universidade de Princeton de escoamentos turbulentos em um tubo comercial (diâmetro e confecção padronizados).

Fato notório de tais ensaios é que, em nenhum deles, foi utilizada água como fluido. Isto vem corroborar com a validade deste modelo, o qual vale para qualquer tipo de fluido, desde que respeitada a hipótese de incompressibilidade do escoamento e que se trate de fluido newtoniano.

Utilizando estes dados, foram feitos os ajustes para o modelo de turbulência, determinação da relação entre o número de Reynolds para escoamento turbulento liso $(\operatorname{Re})$ e o parâmetro de entropia $(M)$ e os necessários para os algoritmos de cálculo. Todos os ajustes apresentaram índices de determinação superiores a 0,98, podendo ser considerados bons ajustes numéricos.

Por fim, visando comprovar a eficácia dos modelos, estes foram submetidos a análises de consistências e validação preliminar. A análise de consistência dos modelos visou verificar a validade das hipóteses adotadas, através da análise dos limites dos equacionamentos, e a análise dimensional do resultado. A obtenção dos limites dos equacionamentos não indicou nenhum erro conceitual para os equacionamentos propostos. Já a análise dimensional indicou que todos os equacionamentos apresentam resultados dimensionalmente coerentes.

O objetivo da análise preliminar foi comparar os resultados dos modelos com dados consagrados pela literatura. As análises demonstraram novamente a eficácia da utilização dos modelos propostos. 
A validação ampla visou comparar aos modelos propostos com uma modelagem matemática de um caso real já existente. Foi utilizado um modelo de adutora de água potável modelado matematicamente com 0 programa computacional EPAnet. 


\section{CONCLUSÕES}

Esta tese atendeu aos objetivos propostos no capítulo 2. Os resultados dos modelos comprovaram sua aplicabilidade. Sua eficácia e eficiência foram comprovadas.

Foi proposto um método de cálculo de base conceitual utilizando-se o modelo concebido por CHIU (1987), modelo baseado na entropia máxima. No capítulo 4.7 foi constatado que este modelo atende aos requisitos da Física atribuídos ao escoamento em condutos forçados: princípio da aderência, velocidade máxima no eixo do tubo, gradiente de velocidades nulo no eixo do tubo e gradiente finito na parede do tubo.

O modelo baseado na entropia máxima atende plenamente ao princípio da aderência. Esse princípio descreve que as partículas do fluido que estão em contato com a superfície sólida, no caso da parede do tubo, têm velocidade zero em relação à essa superfície.

Este modelo descreve que o gradiente de velocidades é finito na parede do tubo. No perfil de velocidades o escoamento parte da velocidade relativa zero junto à parede do tubo, aumentando a velocidade à medida em que vai se aproximando do centro deste.

Ao chegar ao centro do tubo, o modelo descreve a velocidade máxima do escoamento. Neste ponto também descreve o gradiente de velocidades valendo zero. Tais considerações estão perfeitamente de acordo com o fenômeno físico que ocorre em condutos forçados.

A estrutura da equação (27), apresentada por CHIU (1987), garante que uma relação unívoca entre o fator de atrito $(f)$ e o parâmetro de entropia $(M)$. Isto 
ocorre pelo fato do parâmetro de entropia $(M)$ ter também uma relação unívoca com o número de Reynolds aparente $\left(\operatorname{Re}_{a}\right)$. O número de Reynolds aparente $\left(\operatorname{Re}_{a}\right)$, portanto, tem uma relação unívoca com o fator de atrito do escoamento $(f)$.

Tal fato torna o modelo conceitual proposto por CHIU (1993) um modelo amplo e irrestrito. Este modelo é válido para qualquer regime de escoamento, seja ele laminar ou turbulento (liso, misto ou rugoso).

A contribuição original deste trabalho é a comprovação da existência de uma relação unívoca entre o fator de atrito $(f)$ e o número de Reynolds aparente $\left(\operatorname{Re}_{a}\right)$. A figura (59) apresenta tal relacionamento em forma de gráfico.

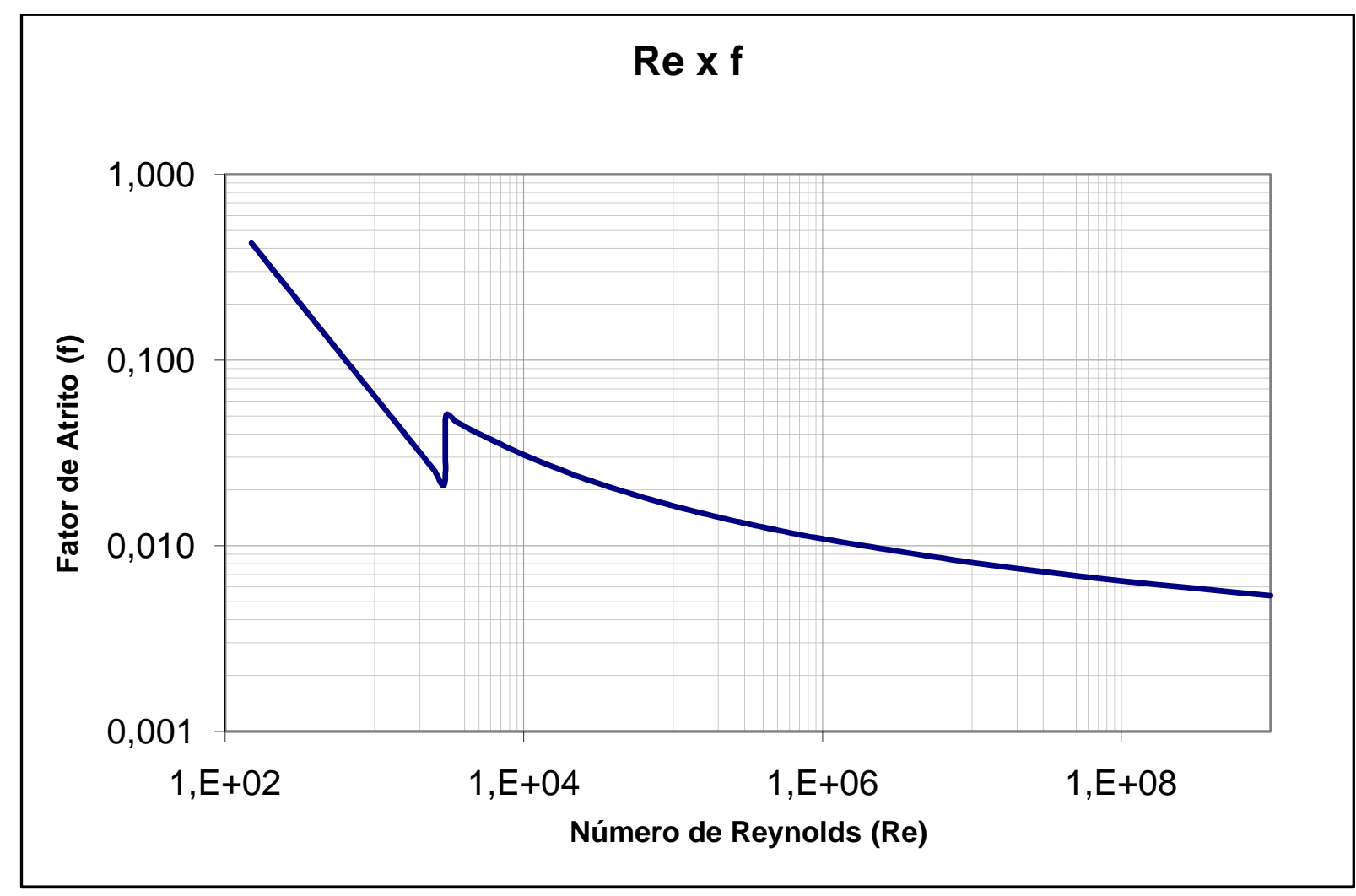

Figura 59. Gráfico do fator de atrito em função do número de Reynolds.

No capítulo 4.7 foi comprovado, através da análise das equações (24) e (27) que o relacionamento unívoco é coincidente no regime laminar, na transição e no regime turbulento liso. Também foi comprovado que o fator de atrito $(f)$ tende a 
zero quando o número de Reynolds aparente $\left(\operatorname{Re}_{a}\right)$ tende ao infinito, e conseqüentemente o parâmetro de entropia $(M)$, tende ao infinito.

Nos regimes turbulentos misto e rugoso o número de Reynolds aparente $\left(\operatorname{Re}_{a}\right.$ ) não coincide com o número de Reynolds molecular (Re). Isto deve-se ao fato de que o primeiro leva em consideração o efeito da turbulência gerada pela rugosidade da parede da tubulação.

Segundo este modelo o acréscimo da turbulência induzido pela ação da rugosidade da parede do tubo gera uma viscosidade aparente $\left(v_{a}\right)$. Esta viscosidade tem valor igual ou superior à viscosidade molecular $(v)$. Estas só se diferenciam no caso de um escoamento turbulento misto ou turbulento rugoso.

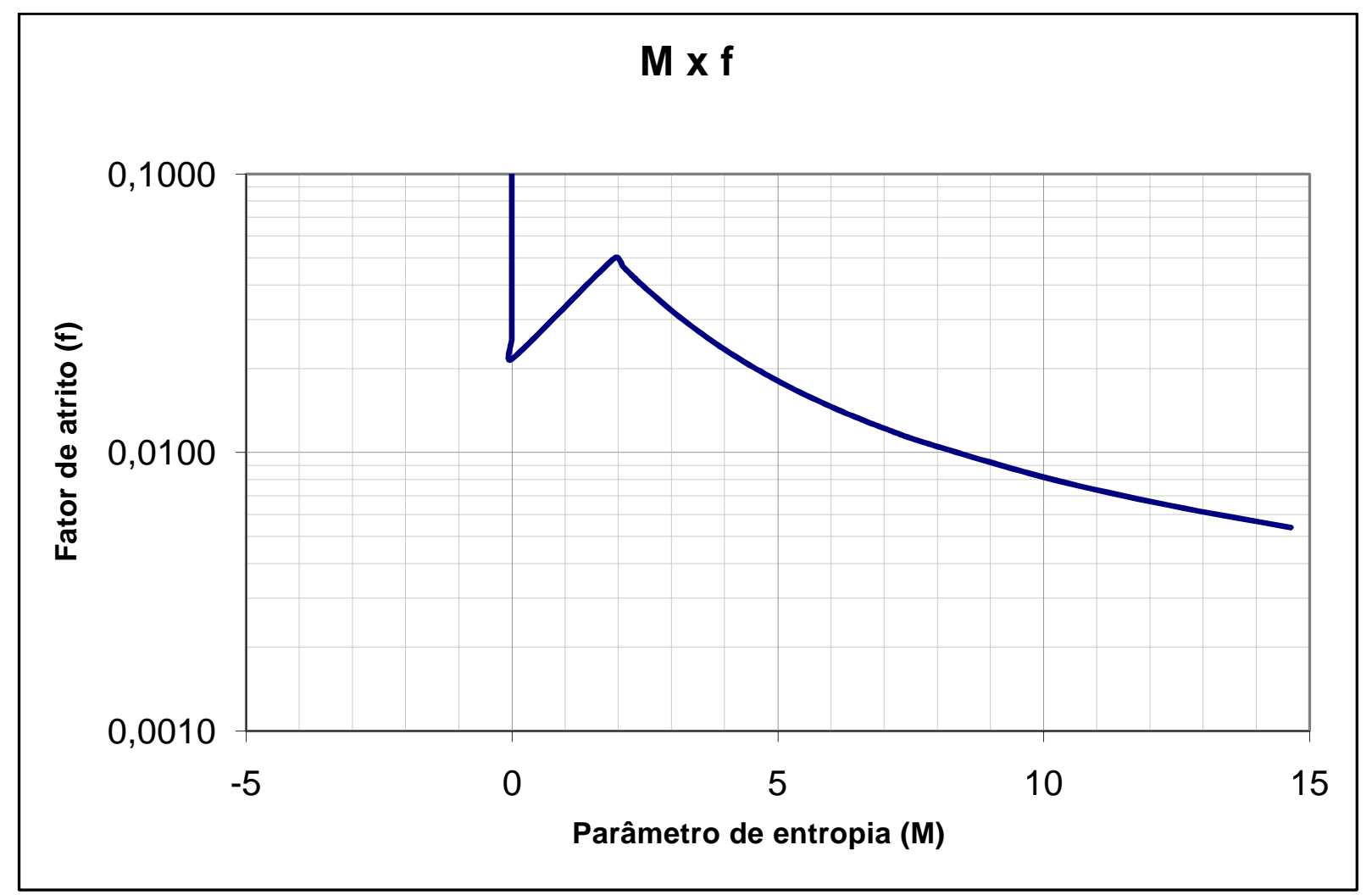

Figura 60. Gráfico do fator de atrito em função parâmetro de entropia. 
O uso da viscosidade aparente $\left(v_{a}\right)$ é o que diferencia o número de Reynolds aparente $\left(\operatorname{Re}_{a}\right)$ do número de Reynolds molecular (Re). Os demais parâmetros utilizados são os mesmo em ambos os casos.

A relação unívoca entre o parâmetro de entropia $(M)$ e o número de Reynolds aparente $\left(\operatorname{Re}_{a}\right)$ para escoamento turbulento foi determinada no capítulo 4.6.2. Essa relação viabiliza o uso do modelo desenvolvido por CHIU et al. (1993) para escoamento forçado.

As equações (58) e (59) representa o relacionamento entre o parâmetro de entropia $(M)$ e o número de Reynolds aparente $\left(\operatorname{Re}_{a}\right)$ para escoamento turbulento. O gráfico (58) descreve tal relacionamento para todos os regimes de escoamento.

O desenvolvimento deste relacionamento viabiliza a verificação da veracidade da Conjectura de Prandtl. Foi utilizado o equacionamento desenvolvido por CHIU et al. (1993) nesta verificação. Conclui-se que o coeficiente determinado nesta conjectura não é constante, invalidando a tese preconizada por Prandtl.

Para a utilização em aplicações práticas do modelo apresentado foram propostos quatro algoritmos de cálculo. Cada algoritmo foi proposto para ser aplicado a um problema diferente de escoamento: cálculo da vazão, ou da perda de carga, ou do diâmetro do tubo (em função da vazão), ou ainda do diâmetro do tubo (em função da velocidade).

Os testes de consistência foram realizados no capítulo 4.7. Tais teste comprovaram, através de análises dimensionais e de limites, a consistência dos modelos propostos.

A verificação preliminar, capítulo 4.8 , teve como objetivo comparar os resultados dos modelo com dados recentes de laboratório e modelos matemáticos 
consagrados. Os resultados obtidos apresentaram grande proximidade com os dados de laboratórios, os quais são mais precisos.

No capítulo 5 foi verificado o uso dos algoritmos de cálculo. Foi utilizado um caso real estudado com auxílio de um sistema computacional existente de grande aceitação (EPAnet). Além de apresentarem resultados semelhantes ao modelo computacional, os algoritmos de cálculo representam a simplificação dos procedimentos para a realização de tais cálculos.

Finalmente, pode-se concluir que os modelos apresentados neste trabalho não só são recomendados para utilização, mas também são recomendados para serem utilizados como bases em futuros desenvolvimentos. Tal afirmação deve-se ao fato de terem bases teóricas comprovadamente consistentes. Para os ajustes numéricos realizados foram utilizados dados de boa qualidade experimental, obtidos com tecnologia contemporânea. 


\section{RECOMENDAÇÕES PARA FUTUROS TRABALHOS}

De acordo com as conclusões apontadas neste trabalho, é recomendado pelo autor para futuros trabalhos que abordarem temas relacionados com esta tese:

- O desenvolvimento de um modelo matemático puramente conceitual relacionando o número de Reynolds $(\operatorname{Re})$ e o parâmetro de entropia $(M)$;

- A elaboração de estudos experimentais para obtenção de grande quantidade de dados para tubos comerciais de diferentes materiais. Estudos os quais devem utilizar instrumentações não intrusivas. Estes serviriam para melhorar o ajuste do equacionamento da turbulência;

- Fazer uso do modelo baseado na entropia para modelagens de fenômenos ainda não bem modelados;

- Estudar a diferença entre o modelo proposto e Colebrook para rugosidades hidráulicas relativas altas. Tal diferença é evidenciada através da figura (54);

- Verificar a existência de uma ponte entre os resultados de Chiu de entropia máxima via teoria da informação com resultados clássicos da Termodinâmica Estatística. 


\section{REFERÊNCIAS}

1. ARAÚJO, J. C.; CHAUDHRY, F. H.. Experimental evaluation of 2-D entropy model for open-channel flow. American Society of Civil Engineers - Journal of Hydraulic Engineering. Reston, vol. 124 (10), p. 1064-1067, 1998.

2. BARBÉ, D. E.; CRUISE, J. F. e SINGH, V. P.. Solution of three-constraint entropy-based velocity distribution. American Society of Civil Engineers Journal of Hydraulic Engineering. Reston, vol. 117 (10), p. 1389-1396, 1991.

3. BERNOULLI, J.. Hydraulica. Lausanne e Genova: Marc-Michel Bousquet et Cie., 1732.

4. BERNOULLI, D.. Hidrodinamica. St. Petersburg: Johann Reinhokd Dulsecker, 1738.

5. CARVALHO, I. L.. Aplicação dos conceitos de probabilidade e entropia máxima no estudo de escoamentos forçados em transições de seções. Tese apresentada à Escola Politécnica da Universidade de São Paulo (EPUSP) para a obtenção do título de Doutor em Engenharia. São Paulo, 2001.

6. CHIU, C. L.. Entropy and probability concepts in Hydraulics. American Society of Civil Engineers - Journal of Hydraulic Engineering. Reston, vol. 113 (5), p. 583-600, 1987.

7. Entropy and 2D velocity distribution in open channel. American Society of Civil Engineers - Journal of Hydraulic Engineering. Reston, vol. 114 (7), p. 738-756, 1988. 
8. Velocity distribution in open channel flow. American Society of Civil Engineers - Journal of Hydraulic Engineering. Reston, vol. 115 (5), p. 576$594,1989$.

9. . ; GWO, F. K. e JYH, M. L. Application of probability and entropy concepts in pipe-flow study. American Society of Civil Engineers - Journal of Hydraulic Engineering. Reston, vol. 119 (6), p. 742-756, 1993.

10. e SAID, C. A. A. Maximum mean velocities and entropy in open channel flow. American Society of Civil Engineers - Journal of Hydraulic Engineering. Reston, vol. 121 (1), p. 26-35, 1995.

11. COLEBROOK, C. F.; WHITE, C. M.. Experiments with fluid friction in roughened pipes. Imperial College, London, 1937.

12. ELSGOLTZ, L.. Ecuaciones Diferenciales y Cálculo Variacional. Moscou: Editorial MIR, 1977.

13. FOX, R. W.; McDONALD, A. T.. Introduction Fluid Mechanics. New York: John Wiley \& Sons, $3^{\mathrm{a} e d ., 1985 .}$

14.FOX, R. W.; McDONALD, A. T., PRITCHARD, P. J.. Introduction Fluid Mechanics. New York: John Wiley \& Sons, 6ªed.,2004.

15. IMPACTA TECNOLOGIA. Access 2000 (Módulo) - Apostila. 20008.

16. KARPELSON, A. E.. Computation of mean velocity distribution in a turbulent flow. Acessado em 24 de abril de 2008. Sitio < http://arxiv.org/abs/physics?papernum=9904030>.

17.LANGELANDSVIK, L. I.; KUNKEL, G. J.; SMITS, Al. J.. Flow in a commercial steel pipe. Journal of Fluid Mech. Cambridge: Cambridge University Press, v 595, p. 323-339, 2008. 
18. LI, J. et al. A simple variational criterion for turbulent flow in pipe. Chemical Engineering Science. Amsterdam: Elsevier Science Ltda., vol. 51, p. 1151-1154, 1999.

19. LIMA, L. F. M.. Termo de atrito em escoamento transitório para condutos forçados. Tese apresentada à Escola Politécnica da Universidade de São Paulo (EPUSP) para a obtenção do título de Doutor em Engenharia. São Paulo, 2006.

20.McKEON, B. J., SWANSON, C. J.; ZARGOLA, M. V.; DORNNELLY, R. J.; SMITS, Alexander J.. Friction factor for smooth pipe flow. Journal of Fluid Mech. Cambridge: Cambridge University Press, v 511, p. 41-44, 2004.

21. McKEON, B. J. et al. A new friction factor relationship for fully developed pipe flow. Journal of Fluid Mech. Cambridge: Cambridge University Press, v 538, p. 429-443, 2005.

22. MINEI, N.. Um método expedito para a medição de vazão em rios e canais abertos. Tese apresentada à Escola Politécnica da Universidade de São Paulo (EPUSP) para a obtenção do título de Doutor em Engenharia. São Paulo, 1999.

23.MOODY, L. F.. Friction factors for pipe flow. Transactions of the A.S.M.E. Princeton: Princeton University, vol. 66, p. 671-684, 1944

24. MORAES, A. G.. Desenvolvimento e validação de um modelo conceitual de aeração em vertedores. Dissertação apresentada à Escola Politécnica da Universidade de São Paulo (EPUSP) para a obtenção do título de Mestre em Engenharia. São Paulo, 2007.

25. OTTONI NETTO, T. B.. Nova concepção sobre o escoamento uniforme de fluídos através de encanamentos circulares. Monografia apresentada para o 
concurso de professor catedrático da cadeira "Hidráulica Teórica e Aplicada" da Escola Nacional de Engenharia da Universidade do Brasil. Rio de Janeiro, 1950.

26. PORTO, R. M.. Hidráulica Básica. São Carlos: EESC-USP, ed. 3, 2004. 519p.

27.PRANDTL, L; TIETJENS, O. G.. Applied Hydro- and Aeromechanics. New York and London: McGraw-Hill Book Company, inc., 1934

28. PRANDTL, L; TIETJENS, O. G.. Fundamentals of Hydro- \& Aeromechanics. New York: McGraw-Hill Book Company, inc., 1957.

29. ROUSE, H. Fluid mechanics for hydraulic engineer. New York: McGraw-Hill, 1946.

30.STREeTER, V. L.; WYLIE, E. Benjamin. Mecânica dos Fluidos. Michigan: McGraw-Hill Book Company, inc., 1982.

31.SWAMEE, P. K.; JAIN, Akalank K.. Explicit equations for pipe-flow problems. American Society of Civil Engineers - Journal of Hydraulic Engineering. Reston, vol. 102 (5), p. 657-664, 1976.

32. SWAMEE, N. e SWAMEE, P. K.. Full-range pipe-flow equations. American Society of Civil Engineers - Journal of Hydraulic Engineering. Reston, vol. 45 (6), p. 841-843, 2007.

33.SOUZA, P. A.; MARTINS, J. R. S.; FADIGA JUNIOR, F. M.. Métodos computacionais aplicados à engenharia hidráulica. São Paulo: CTH, 1991.

34. SIMON, A. L.. Practical Hydraulics. New York: John Wiley \& Sons, Inc., 1976.

35.WALSKI, T. M.; CHASE, Donald, V.; SAVIC, Dragan A.. Water Distribution Modeling. Waterbury: Heastad Press, 2001. 